\title{
Childhood diarrhoea and its prevention in Nicaragua
}

Citation for published version (APA):

Gorter, A. C. (1998). Childhood diarrhoea and its prevention in Nicaragua. [Doctoral Thesis, Maastricht University]. Universiteit Maastricht. https://doi.org/10.26481/dis.19981217ag

Document status and date:

Published: 01/01/1998

DOI:

10.26481/dis.19981217ag

Document Version:

Publisher's PDF, also known as Version of record

\section{Please check the document version of this publication:}

- A submitted manuscript is the version of the article upon submission and before peer-review. There can be important differences between the submitted version and the official published version of record.

People interested in the research are advised to contact the author for the final version of the publication, or visit the DOI to the publisher's website.

- The final author version and the galley proof are versions of the publication after peer review.

- The final published version features the final layout of the paper including the volume, issue and page numbers.

Link to publication

\footnotetext{
General rights rights.

- You may freely distribute the URL identifying the publication in the public portal. please follow below link for the End User Agreement:

www.umlib.nl/taverne-license

Take down policy

If you believe that this document breaches copyright please contact us at:

repository@maastrichtuniversity.nl

providing details and we will investigate your claim.
}

Copyright and moral rights for the publications made accessible in the public portal are retained by the authors and/or other copyright owners and it is a condition of accessing publications that users recognise and abide by the legal requirements associated with these

- Users may download and print one copy of any publication from the public portal for the purpose of private study or research.

- You may not further distribute the material or use it for any profit-making activity or commercial gain

If the publication is distributed under the terms of Article $25 \mathrm{fa}$ of the Dutch Copyright Act, indicated by the "Taverne" license above, 
Childhood diarrhoea and its prevention in Nicaragua 
CIP-DATA KONINKLIKE BIBLIOTHEEK DEN HAAG

Gorter, Anna Cornelia

Childhood diarrhoea and its prevention in Nicaragua

ISBN $90.5681-041-3$

Vormgeving en drukwerk:

Unigraphic, Universiteit Maastricht 


\section{Childhood diarrhoea and its prevention in Nicaragua}

\section{PROEFSCHRIFT}

ter verkrijging van de graad van doctor

aan de Universiteit Maastricht,

op gezag van de Rector Magnificus,

Prof. Dr. A.C. Nieuwenhuijzen Kruseman, volgens het besluit van het College van Decanen, in het openbaar te verdedigen

op donderdag 17 december 1998 om 14.00 uur

door

Anna Cornelia Gorter 


\section{Promotor:}

Prof. Dr. PG. Knipschild

\section{Beoordelingsicommissie:}

Prof. Dr. H.EJ.M. Crebolder (voorzitter)

Prof. Dr. G. Kok

Prof. Dr. C.E. Blanco

Prof. Dr. C.A. Bruggeman

Prof. Dr. I. Wolffers (Vrije Universiteil Amsterdam) 


\section{Contents}

2. Infant morbidity and mortality diarthoeal diseases

3. Well water study, part 1:

Summary

A literature review of the health impact of water supplies, sanitation

and hygiene on the incidence of diarrhoeal disease

1.1 The Relationship between Health and Water 27

1.2 The Importance of Water-borne Transmission $\quad 27$

1.2.1 Other transmission routes 27

$1,2.2$ Survival of the pathogen in water 28

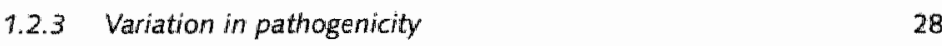

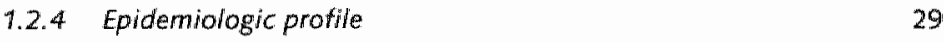

1.2.5 Degree of water contamination 29

1.3 Evidence for the Health Impact of Water Quality, Quantity, Sanitation and Hygiene Improvements

1.3.1 Methodological issues in health impact evaluations of water supply, sanitation and hygiene interventions

1.3.2 Reviews of the health impact of water supply, sanitation and hygiene improvements

1.3.3 The health impact of combined water supply and excreta disposal improvements

1.3.4 The health impad of combined water quantity and/or water quality improvements. 33

1.3.5 Studies evaluating the impact of water quality alone 33

1.3.6 Studies evaluating the impact of moderate water quality improvements $\quad 35$

1.3.7 Studies evaluating the impact of increased water quartity 37

1.3 .8 Studies evaluating the impact of sanitation 37

1.3.9. Studies evaluating the impact of hygiene 38

References

4. The diarrhoeal disease risk factor studies of water supplies, sanitation and hygiene in Villa Carlos Fonseca

4.1 Determinants of drinking water quality in rural Nicaragua 47

4.2 Determinants of domestic water use in rural Nicaragua 
4.3 Water supply, sanitation and diarmoed disease in Nicaragua:

Results from a case-control study

4.4 Hygiene behaviour in rural Nicaragua in relation to diarmoea

4.5 Childhood diarhoea in rural Nicaragua: beliefs and traditional health practices

5. Well water study, part 2:

Summary

A literature review to identify which interventions are most likely to reduce faecal contamination of wells, waterholes and surface water

2.1. The Mechanism of Faecal Contamination of Water Sources

2.2. Determinants of the Level of Faecal Contamination

2.2. 7. Water source

2.2.2. Season

122

2.2.3. Other factors

123

2.3. Interventions to Reduce or Prevent Faecall Contamination of Water Source

2.3.\%. Interventions to Reduce Surface Water Contamination

2.3.2. Interventions to Reduce Well and Waterhole Contamination 124

2.3.3. 'Software' Interventions to Reduce Faecal Contamination 128

References

6. A randomized trial of the impact of rope pumps an water quality

7. Discussion

Summary

Samenvatting

Resumen

Summary of reforences in alphabetic order

Curriculum vitae

\section{Appendix:}

1. The Nicaraguan rope pump

2. Why do child mortality rates fall? An analysis of the Nicaraguan experience

\section{Dankwoord}


Chapter 1

Introduction, description of the study site

Villa Carlos Fonseca 


\section{Chapter 1}

\section{Introduction, description of the study site Villa Carlos Fonseca}

\section{Introduction}

Diarrhoeal diseases in developing countries are still amongst the leading causes of child. hood morbidiry and mortality, although their importance has been declining steadily during the last decades as a resultant of improved living conditions, better treatment protocols and a changing pattern of disease morbidity and mortality 1,2 . When the same living conditions of poverty, inadequate water supplies, poor sanitation and hygiene, and limited education were present in the United States and Western Europe more than half a century ago, the problems with diarrhoeal diseases were similar. With economic development these conditions improved and problems with diarrhoeal diseases greatly diminished 2.3 .

Nicaragua is developing in many aspects, but diarrhoeal disease is still an important cause of childhood death. In the early $1980^{\circ}$ shen our research started it was the leading cause ( $40 \%$ ) of infant mortality, with about 30 deaths per 1,000 life births during the first year of life. At that time no diarrhoeal research had taken place in Nicaragua and what was known was inferred from studies in other countries.

In this thesis I describe our studies and their results. The research started in 1986, with a small team, and the intention of performing only one investigation. Over time more researchers became involved and follow-up studies were designed. It became an integral programme of diarrhoeal disease research and central to the thilization of the results in health promotion programmes. The programme was performed in collaboration with the Nicaraguan Water Institute, the Nicaraguan Ministry of Health, the Technical University of Managua, the Public Health Institute of Managua, the Nicaraguan Foundation DESEAR, the Central American Institute of Health ICAS, the London School of Hygiene and Tropical Medicine and the Liverpool School of Tropical Medicine. It was financed by the WHO, the Leverhulme Trust, UNICEF and the British Embassy in Nicaragua.

Chapter 1 introduces the investigations of diarrhoea, water supplies, sanitation, hygiene and health beliefs, and also the study site Villa Carlos Fonseca, a rural health area, where I worked as a medical officer from 1983 to 1986 and kept on living during the research. Chapter 2 contains an introduction on inlant morbidity and mortality in developing countries as well as on diarrhoeal disease. Chapter 3 is an updated version of an earlier literature review of the health impact of improved water supplies/sanitation and hygiene on the incidence of diarrhoeal disease. 
Chapter 4 presents the water supplies/sanitation/hygiene and health bellefs studies that we performed in Villa Carlos Fonseca. When we started our research the use of case-control studies to investigate risk factors for acute illnesses such as diarrhoeal diseases was strongly advocated by the Diarrhoeal Diseases Control Programme of the World Health Organisation (WHO). The WHO stimulated this development by the publication of guidelines of how to conduct such a studys and by financing them, including our investigation: As part of the study we investigated the microbiological quality of water of traditional sources ${ }^{b}$ and the quantity of water used by the householdsc.

The results supported the notion that not the quality of water, but the availability of water was an important risk factor for diarthoea. They suggest that the transmission of diarthoea in Nicaragua is predominantly water-washed rather than water-borme. Maternal schooling reduced the risk to acquire diarrhoea, possibly an indicator of better hygiene practices. This was supported by the correlation found between per capita domestic water consumption and maternal schooling. A follow-up study was then performed to investigate the relation between mother's education, the different hygiene practices and diarrhoeal diseasesd.

\section{The Villa Carlos Fonseca Studies:}

Investigation of the microbiological water quality of traditional water sources and of the quantity of water used by the households

Case control study of the relation of water supply and sanitation with diarrhoeal disease

Prospective follow-up study of the relationship between hygiene behaviour and diarrhoeal disease

Ethnographic study of traditional health beliefs and practices on diarthoeal disease

Morbidity-mortality survey of a random sample of the population, with special attention to diarphoeal disease and traditional health beliefs and practices.

Literature review of the health impact of water supplies, sanitation and hygiene on the incidence of diarrhoeal disease and to identify which iriterventions are most likely to reduce faecal contamination of wells, waterholes and surface water

A randomized trial of the impact of rope-pumps on water quality

Update of the 1992 literature review

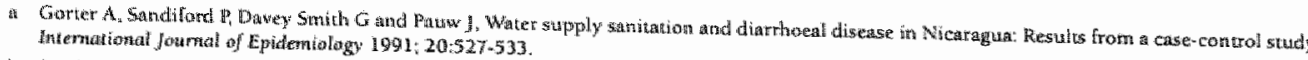

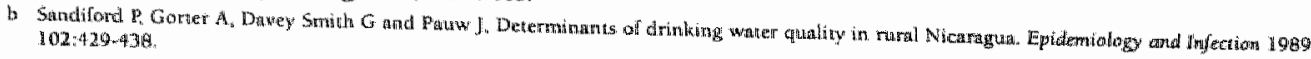

1. Sund 1990: 93:383-389

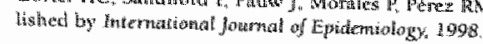


Although in 1989 the mortality due to diarrhoeal diseases was declining the disease was still the leading cause of infant mortality in Nicaragua. One of the possible reasons, in addition to the continuing high incidence of diarrhoea, was the late arrival of children with severe dehydration at the health servicest. To investigate why prevention measures such as the implementation of water supplies, sanitation and hygiene education have had limited results and why some mothers were reluctant to use oral rehydration fluids and/or bring their children to the nearby health service facilities, an ethnographic study of traditional health beliefs and practices was undertaken. A year later we performed a survey of morbidity/mortality and health service utilization. An important part of this study was directed towards quantifying the results of the ethnographic study and determining the importance of local beliefs on the management of cases of diarrhoea.

Chapter 5 is an updated version of an earlier literature review to identily which interventions are most likely to reduce faecal contamination of wells, waterholes and surface water. To improve access to water a programme started to develop an appropriate water lifting device for hand-dug wells; the type of water source most frequently used in Villa Carlos Fonseca and other rural areas of Nicaragua. The programme developed a rustic version of the rope-pump into an appropriate technology, highly efficient, cheap and easy to maintain (appendix ). The National Water Institute of Nicaragua nowadays considers this improved rope-pump as the most appropriate pump for the hand-dug and tube wells of the rural areas and the pump has been introduced in other developing countries of Latin America, Africa and Asia. Given the success of this technology we felt it opportune to investigate the effect of rope-pumps on the microbiological quality of water and on the quantity of water used by the households and a study was undertaken to evaluate these effectss, of which the results are described in Chapter 6.

Chapter 7 discusses the relevance of the Villa Carlos. Fonseca studies. The appendix contains the article on rope-pumps and an article we wrote about the decline of childhood mortality in Nicaraguah.

\section{Description of the study site Villa Carlos Fonseca}

Nicaragua is the largest country in Central America. Since 1900 the population has grown explosively from 500,000 in 1906 , to $1,000,000$ in 1950 , to 4,360,000 inhabitants in 19957 . The fertility rate has decreased slowly from 6.9 births per woman in 1970 to 4.1 in 19953.8 .

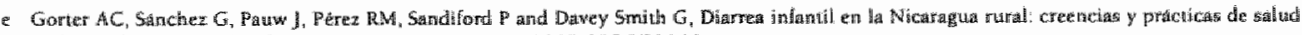

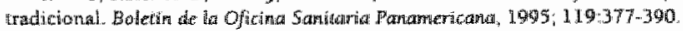

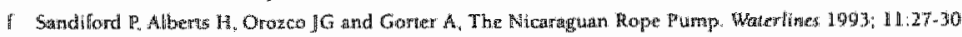

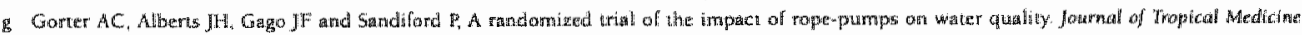
and Hygtene 1995; $982247-255$.

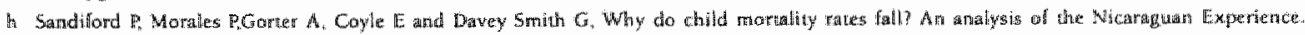
American Joumal of Pulblic Healuh 199.1; B1:30-37. 
Nicaragua has a low-income economy and ranks 30 th on the list of poorest countries of the world. It is the poorest country of Central America; yet it has a surprisingly low infant mortality rate ( 46 per $\, 000$ live births); low prevalence of malnutrition under-5years (12\%); a high enrolment in primary and secondary school; and a relatively low adult illiteracy $(26 \%)$. After several decades of political turmoil, revolution and war it has now a relatively stable democracy.

The country consists of three distinct geographical regions: the Pacific lowlands, the north-central mountains, and the Caribbean lowlands. Villa Carlos Fonseca, where our research takes place, is situated in the Pacific coastal region, a broad and hot lowland plain, broken by about 40 volcanoes. It is a rural municipality within the department of Managua at a distance of $30 \mathrm{~km}$ from Managua, the capital of Nicaragua. Within its area of 500 square kilometres there are approximately 32,000 inhabitants distributed amongst 38 communities (see map). There is one health centre, a small laboratory, and 6 smaller health posts, all poorly equipped and without running water. As referred to earlier, for over 3 years I worked as a Medical Officer in this health area. The daily routine concerned the medical consulting-hour; the organization of the many disease control prom grammes such as those of tuberculosis, malaria and sexually transmitted diseases; the training of personnel and traditional midwives and the organization of vaccination campaigns. Each doctor participated in the night or weekend shifts of a small hospital near our health area, which also served the population of our health area.

The conditions observed most frequently during the consulting-hour consisted of diarrhoeal disease with or without dehydration, respiratory infections, worms and skin diseases in children. Women generally consulted the doctor for prenatal control or family planning, although mental problems were seen frequently as well. Men rarely consulted a doctor and if so, it concerned almost always a serious condition. During the years I worked in this health area, the medical staff consisted of only 2 or 3 doctors. Nowadays the area counts 8 to 10 doctors, mostly trained in Nicaragua, although one has been trained in Russia.

The 38 rural communities are connected through one asphalt main road and many small tracks generally in bad condition. Illiteracy is $29 \%$ which is high compared to the capital Managua $(9 \%)$, but low when compared with the national figure of $43 \%$ of illiteracy
for the rural site.

The last national population census in Nicaragua took place in 1995. Data were published recently? The report presents data from the rural area of the department Managua, of which villa Carlos Fonseca is a part. Living conditions are still poor for that area with 10\% of farnilies living in nothing more than hut, although this number was much higher in a census of $1963(40 \%)$. On average house has 1.9 rooms and 5 persons living in it with an average of 3.4 people sleeping in one room. Of the houses $63 \%$ has electricity.

In the census people were also asked about their daily activities and $47 \%$ of the population answered to be economically active. Of this group $21 \%$ were looking for work at the 


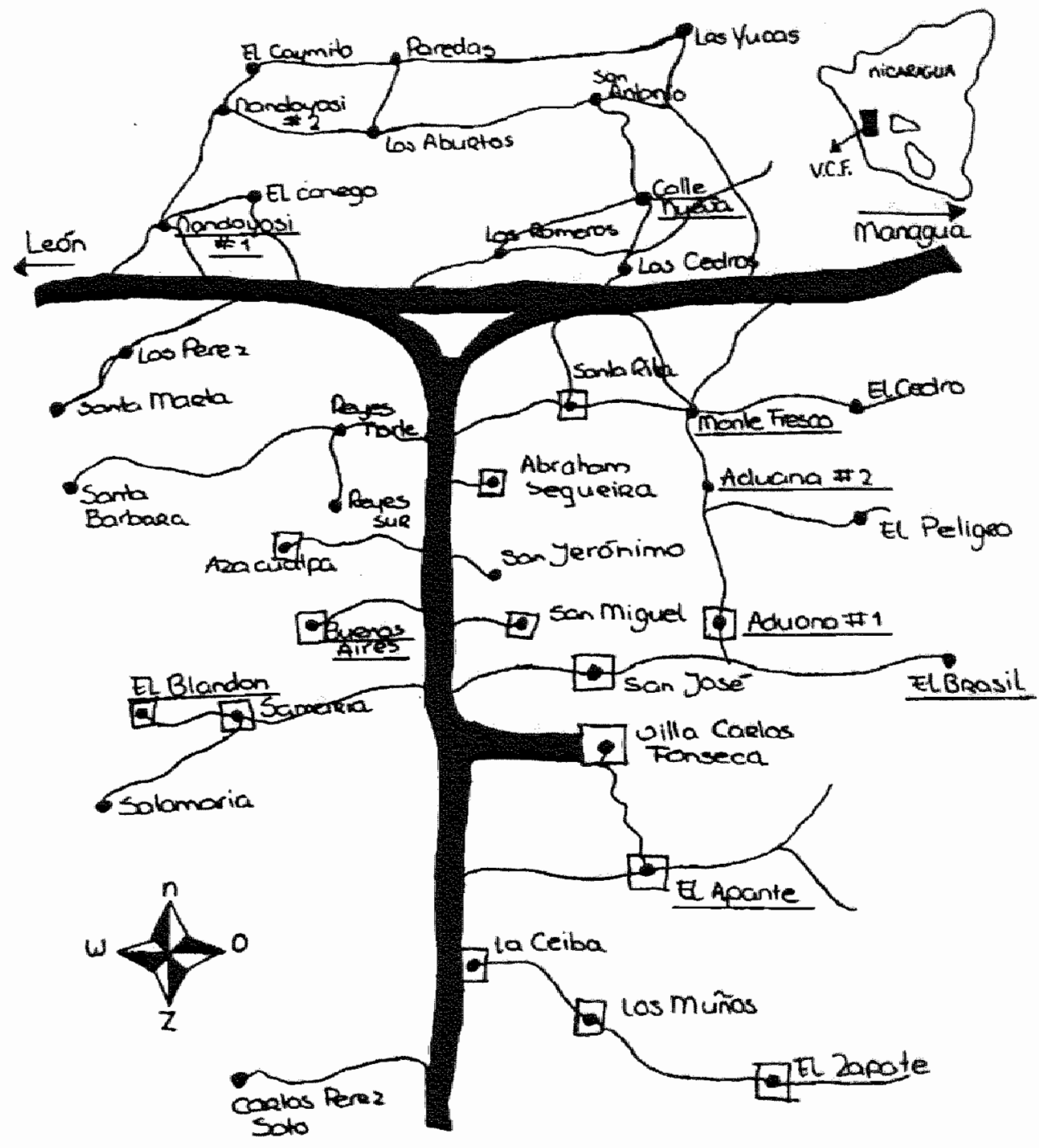

From: wan Klinken $P C_{f}$ Cholerapreventie in Nicaragua. Een onderzoek naar de kenmis, attituden en praktijken ten aanzien van cholera en cholerapreventie. Cholera prevention in Nicaragua (A study of the knowledge, attitudes and practices concerning cholera and cholera prewention). Thesis Health Education, Department of Health Education, University of Maastricht, 1993 
moment of the interview, thus in reality unemployed; $33 \%$ were working in agriculture; $10 \%$ in industry; $4 \%$ did not specify and $32 \%$ were active in the "service" sector of which the majority is working in the informal sector. This sector has become economically the most important one, especially in the city of Managua where $71 \%$ of the economically active people is working in this so called "service" sector.

Villa Carlos Fonseca has been a tropical dry zone for the last decades, characterized by many lost harvests as a result of the increasing deforestation ${ }^{9}$ and the changing weather pattern, related to the Warm Gulf Stream 'El Niño'10. Many agricultural activities are not profitable anymore, especially those of the subsistence farmers who have no irrigation systems and thus are dependent on the annual rains. The most important crop cultivated now is sugarcane, grown with irrigation. There are two small factories which process sugarcane; one produces sugar and the other alcohol. These factories are the only industry of the area.

\section{References}

1 Bern C. Martines J, de Zoysa I and Glass RI, The mugmitude of the global problem of diarrihoeal disease: a ten-year update, Bulletin of the World Health Organization 1992; 70;705-714.

2 Blaser MJ, Smith PD, Rawdin J1, Greenberg HB and Guerrame RL heds), Infections of the gastrointestinal tract, Raven. Press, New York, 1995

3 World Bank, World Dewelopment Repart 1993, Investing in Health, Washington DC: World Bank, 1993.

4 Ministry of Health Nicaragua, Plan Trichal de Salud, 1991-1993, Multiformas, Maragua, Nicaragua, 1991.

5 Eriscoe I, Feachem RG and Rahaman MM, Measuring the impact of water supply and satnitation facilities on diarthoca morbidity: prospects foir case-control methods, WHO/CWS/85.3. World Health Organization, Genewa, Switzerland, 1985.

6. Torres Escobar ID. Determinantes de la morbi montalidad por enfermedad diametica de los menores de cinco anos que acuden a los hespitales infantiles en Managua/Nicaragua, Tesis de grado para optar al titulo en Epidemiologia en el CIES, 1986.

7 Instituto Nacional de Estadisticas y Censos, INEC, Resumen censal, NI censo nucional de poblacion y III de wivienda, 1995, Managua, Nicaragua, 1996.

8 World Bank, World Development Report 1997, The staze im a changing world. Washington DC: World Bank, 1997.

9 Utuing P, Trees, People and Power, Earthscan, 1993.

10 Garcia Camales E, Evaluan graves daños ocasionados por "El Nino". La Prensai, 16 cle Octubre de 1907. 
Chapter 2

Infant morbidity and mortality, diarrhoeal diseases 


\section{Chapter 2}

\section{Infant morbidity and mortality, diarrhoeal diseases}

\section{Infant morbidity and mortality}

Health conditions around the world have improved more in the past forty years than in all previous human history. Infant mortality in developed countries started to decline about two centuries ago, at first slowly. The rate of improvement accelerated in the first half of this century 1,2. Several decades later this phenomenon was also seen in developing countries. For the Latin American countries the decline started around the turn of the century in the relatively highly developed countries of this continent and around 1930 for the less developed countries 3 . For Africa the decline started after World War II4. The decline in developing countries has accelerated over the past thirty years; in the 1960 's infant mortality fell by approximately $2 \%$ a year; in the 1970 's by more than $3 \%$ and in the 1980 's by more than $5 \%$ a year ${ }^{1}$.

Table 1 shows figures for the last 25 years, during which infant mortality (under-1-year) has fallen sharply over a relative short period; almost to a half of the mortality of 19701,5 . Overall mortality of under-5-years in the developing countries has fallen as well; from 152 (per 1,000 life births) in 1975 to 80 in 1996, with nowadays a total of about 1.1 million children dying each year before they reach the age of 51,6,35. For the developed countries the under-5-year mortality declined from 25 to 7 per 1,000 life births.

There are strong parallels between the pattern of mortality decline in the developed countries and the accelerated progress of developing countries over the past 40 years. In both groups the control of communicable diseases, particularly those of childhood, accounts for most of the gains ${ }^{1}$. Part of this reduction has been explained by the declining mortality due to diarrhoeal diseases.

Diarrhoea related mortality has constantly been decreasing since the introduction, early 1978 , of the treatment of dehydration (which plays a substantial role in case fatality) with oral fluid and electrolyte replacement. This oral rehydration therapy, shortly called ORT, became the cornerstone of the child survival programmes of UNICEF and WHO2. During the period 1981- 1986 diarrhoea was estimated as the cause in $36 \%$ of all deaths in underfives 7 . Nowadays diarrhoea is responsible for only about $25 \%$ of deaths among under-5years in developing countries ${ }^{8}$.

Of the estimated billion episodes of diarrhoea which occur each year in under-5-years 3 million cause death ${ }^{6.9}$. In the first year of life around 20 diarrhoeal deaths per 1,000 children occur, meanwhile in the 1- to 4-year age group the rate is much lower with 
5 deaths per 1,000 , although these still account for half of the diarrhoeal deaths in childhood9. After the first 5 years of life mortality rates appear to fall to very low levels and increase later slightly in the elderly2.9.

Table 1. Infant mortality figures World Bank Report 1993 and 1997 )

Economies

Infant mortality rate per 1000 live births 1970

1995

Low income economiles

109

69

Lowermaddle-income

Uppermiddle-income

Continemts

Infant mortality rate per 1,000 live births

\section{Sub-Saharan Africa}

Soutti Asia

India

Middle East \& North Arrica

Lath America \& Caribbean

East Asia \& Pacific

China

Europe and Central Asia

1970

1995

144

138

137

135

82

76

69

63

\section{Central America}

Infant mortality rate per 1,000 liwe births. 1970

Nicaragua

Honduras

Cisatemala

Ell Sahador

Costa kica

The World Bank, jointly with the World Health Organisation (WHO), developed a method to measure the global burden of disease (GBD), combining:

- healthy life years lost because of premature mortality, defined as the difference between actual age at death and life expectancy at that age in a low-mortality population,

- loss of healthy life resulting from disability.

The GBD is measured in units of disability-adjusted life years (DALYs). Worldwide 1,360 millions DALYs were lost in 1990, the equivalent of 42 million deaths of newborn children. There is a huge variation in loss of DALYs across regions, mainly because of differences in premature mortality and much less because of differences in disability. 
In its report of 1993 the World Bank concluded that diarrhoeal diseases are now the second, after respiratory infections, most important cause of disability-adjusted life years lost'. Where diarrhoeal diseases have been the leading cause of childhood mortality for centuries, during the last decades together with the declining overall childhood mortality, a changing pattern is observed towards respiratory infections as being now the most important single cause of death for children in developing countries.

Nicaragua does not make an exception and has experienced even a more impressive decline relatively to its national income, like some other low income countries did such as China and Sri Lankal. Infant mortality in Nicaragua has decreased from 106 per 1,000 live births in 1970 to 44 in 19961,5.35. In 1990, the Ministry of Health reported diarrhoeal disease still as the most important single cause of death and responsible for $40 \%$ of infant mortality and for $33 \%$ of deaths in children of 1 to 4 years old 10 , although a study in the north of the country showed that the prevalence of diarrhoea was lower than that of respiratory infections in under-5-years ${ }^{11}$.

The decline of childhood mortality in Nicaragua and its possible reasons have been investigated by our study team and described in an article in the American Journal of Public Health of 1991 (appendix).

\section{Diarrhoeal diseases}

\section{Definition}

Diarrhoea is a symptom complex characterized by stools of decreased consistency and increased number. Most studies now consider diarrhoea to be present when 3 or 4 or more liquid stools are passed during any 24-hour period. Generally at least 2 days free of diarrhoea are required to determine that an episode is finished. A WHO meeting recommended that the small proportion of diarrhoea episodes which last 2 or more weeks should be defined as persistent diarrhoea ${ }^{2.12}$.

\section{Morbidity and mortality}

Figures based on 7,350 cross-sectional surveys in 70 countries show a global medium of 3.4 episodes per child under 5 years, ranging from 1 to 5 illnesses per year per child in developed countries to 5 to 12 illnesses per year per child in developing countries to as many as 18 in children living in impoverished areas of these countries 7,13 . The incidence is highest in children under 2 years of age, followed by a progressive fall with age 2 . The peak incidence is in children from 6 to 11 months $2,14,15$.

The majority of diarrhoeal episodes resolves within 1 week. A small fraction takes up to 2 weeks and persistent diarrhoea has been found in a range from 3 to $23 \%$ of all episodes, persistent diarrhoea being more frequent when overall diarrhoea incidence is higher ${ }^{2}$. The study in the north of Nicaragua found a range of persistent diarrhoea of 4 to $7 \%$ of: all episodes and a higher case fatality during the wet period when diarrhoea incidence in Nicaragua is highestil. 
The case fatality rate in children under 5 years of age has been reported to be between $0.1 \%$ and $0.7 \%$, and for persistent diarrhoea a rate of $14 \%$ has been published. Case fatality rates vary with age, and are highest among infants under 1 year ${ }^{2.9}$. About $50 \%$ of diarrhoeal deaths are due to acute watery diarrhoea, $35 \%$ to persistent diarrhoea, and $15 \%$ to dysenterys.

\section{Pathogens}

The causes of diarhoea include a wide array of viruses, bacteria, and parasites, many of which have been recognized only in the last decade or two. There are several viruses detected to cause diarrhoea: rotavirus, enteric adenovirus, a growing family of Nonwalk like virus, possibly coronavirus and others 2.15 .

Bacteria which cause diarrhoea are: enterotoxigenic Escherichia coli (ETEC), Campylobacter species, Shigella, Salmonella, Vibrio cholerae, the enteroadherent Escherichia coli (EAEC) designated as: aggregative (EAEC-AA); diffuse-adhering (EAECDA) and localized-adhering (EAEC-LA), furthermore the enterohemorrhagic Escherichia coli $(\mathrm{O} 157 \mathrm{H} 7)$, possibly cytotoxigenic Clostridium difficile, Aeromonas hydrophila, Yersinia enterocolitica, Listeria monocytogenes, and others $2,17.18$.

Parasites known to cause diarrhoea are: Giardia lamblia, Entamoeba hystolytica, Cryptosporidium parvum, Isospora belli, Sarcacystis species, Microsporidia, Cyclospora species, Balantidium coli, Chilomastix mesnili, and intestinal helminthic infections such as Trichuris trichiura, Strongyloides stercoralis, Necator americanus, Ancylostoma duodenale, Capillaria philippinensis and Trichostrongylus species ${ }^{2.19}$.

The frequencies of the enteropathogens causing diarrhoea vary in different countries, especially between those of the developed and developing world. In the developing countries ETEC and rotavirus predominate 2,20 . Norwalk like virus, Campylobacter and Clostridium difficile, and lately also E.Coli $0157: H 7$, have been described as a frequent cause of bloody diarrhoea in the developed world21,22,23. Shigella, Salmonella, Cryptosporidium and Giardia are found throughout the world ${ }^{3}$.

Two types of etiology studies have been performed in the developing countries; hospitalbased studies where the faecal specimens are collected in the health facilities; either outpatient clinics or hospital wards, and community-based studies where the faecal specimens for culture are collected during household visits. Results from these last studies represent the overall occurrence and etiology of diarrhoeal illnesses best, regardless of the severity of the diarrhoea or care-seeking. The hospital-based studies reflect the etiology
of the more severe cases and those which cause a high mortality.

Based on 18 community studies with comprehensive microbiology from 9 developing countries (of the three continents Asia, Africa and Latin-America) ETEC was found to constitute the largest proportion of episodes with a median of $14 \%$. The next most commonly found was Giardia lamblia, although the proportion infected has been highly vari-
able. Campylobacter species have been isolated from a median of $7 \%$, rotaviruses from $5 \%$ 
and Shigella species from $4 \%$, Cryptosporidium parwum was found in $2 \%$ to $7 \%$ of episodes and Entamoeba histolytica in $2 \%$ or less?

In a community-based study performed in the north of Nicaragua in 1990 (before the cholera epidemic) faecal specimens of 188 children under 5 years who had diarthoea at: the moment of the household visit were investigated. Giardia lamblia was found to be the pathogen most frequently seen, followed by Escherichia coli (ETEC and EAEC-LA) and rotavirus, then Entamoeba histolytica and finally one case of Shigella. No Salmonella, or Campylobacter were found"1.

In 52 hospital-based studies with comprehensive microbiology in 29 developing countries (also in the three continents), rotavirus was the pathogen most frequently seen with a median of $20 \%$, although overall the bacterial enteropathogens predominate; ETEC with a median of $12 \%$, Campylobacter species with $7 \%$ and Shigella species with $5 \%$ Aeromonas, Salmonella species and vibrios, especially Vibrio cholerae, may be frequent in some settings. In the latest 9 studies seeking for Cryptosporidium parvum it was found with a median of $5 \%$. Giardia lamblia has been found infrequently and Entamoeba histolytica rarely in the faecal specimens of children with diarrhoea of the hospitalmbased. studies ${ }^{2}$.

Important bacterial causes in the first 2 years of life are ETEC, Shigella and. Campylobacter. The most common parasitic causative agent is Cryptosporidium. Entamoeba histolytica is an uncommon cause of diarrhoea in the first 2 years. Giardia lamblia is commonly isolated in cases, but is usually not the responsible pathogen. Vibrio cholerae $O 1$ can account for as many as 5-10\% of hospital cases in all ages in endemic zones, but is rarely found in children younger than 2 years 24 . Rotavirus is the most common viral agent and is the major cause of severe dehydrating diarrhoea in the first 2 years of life in both developing and developed countries and accounts for $20-40 \%$ of diarrhoea cases requiring hospitalization in many developing countries $2,24,25$. The greater frequency of isolation of this agent in cases of diarrhoea in health facilities studies compared to the community studies reflects the greater severity of the disease ${ }^{2}$.

Pathogens found in the stools of diarthoeal cases of case-control studies are also well represented in controls, indicating an important amount of asymptomatic infections of these pathogens, with Shigella and rotavirus the notable exceptions 26.27 .28 . Giardia was found in $100 \%$ of Egyptian chilldren of 2-4 year old whose stools were examined during 6 months ${ }^{29}$. In fact, studies frequently find two or more enteropathogens simultaneously and it is rarely possible to ascertain which is causing the illness or if they are playing a role each. The high prevalence of asymptomatic infections is probably more an indicator of frequent exposure to a commonly existing pathogen than a long-term carrier state; which seems to be rare ${ }^{2}$.

The etiology of persistent diamhoea (diarrhoea which last 2 or more weeks), which probably accounts for about $35 \%$ of deaths, remains unclear. Multiple bacterial and viral pathogens are often found as well as frequent colonization of the small intestine with co- 
liform (or other) bacteria, which have been shown to cause prolonged diarrhoea in an animal model ${ }^{13.30}$. In several studies Shigella, EAEC-AA, and EAEC-DA"25,31 have been found mone frequendy in persistent than in acute diarrhoea. ETEC, Campylobacter, Aeromonas species, Giardia lamblia and Entamoeba histolytica have similar rates. Meanwhile rotavirus was seen less in persistent than in acute diarrhoea ${ }^{2,27}$. Ongoing infection with the same organism is uncommon. A new enteropathogen is often found in the third week of diarrhoea, suggesting that the prolonged diarrhoea is due to sequential infections with different pathogens2.

\section{Infective dose and host defenses}

All causes of watery diarrhoea have an imbalance in common between the amount of fuid secreted and the ability of the intestinum to reabsorb that fluid. Many cases of diarrhoea may best be considered a pathological exaggeration of what is normally a host protective response to proliferation, attachment, or invasion by enteropathogens ${ }^{2}$.

An important variable in the pathogenesis of diarrhoeal diseases is the infectious dose or the inoculum required to produce symptomatic disease in normal individuals. This infective dose varies, depending on the type of pathogen and host defenses ${ }^{32}$. The infective dose for viruses is in general low; less than 100, meanwhile that of bacteria is high 26,33 . Shigella is alleady infectious at a very small doses "about 10-1,0002,33. Person-to-person transmission seems to be the dominant route for "low-inoculum" agents such as rotavirus, Giardia, Cryprosporidium Entamoeba histolytica and Shigella. They are easily spread from person to person, whereas "high-inoculum" agents such as Vibrio cholerae, Salmonella, and ETEC are usually acquired by ingesting larger numbers of organisms via contaminated food or water ${ }^{2}$.

The infectious dose is lowered when host defenses are not optimal as happens for example when gastric acidity is decreased as is seen in malnutrition and when patients already receive antibiotics ${ }^{2}$.

\section{Seasonality}

Although diarrhoea occurs throughout the whole year, most settings have a peak during the hot and/or rainy months. This seasonality is a composite of the seasonality of pathogens. Most bacterial causes peak during the hot and/or wet months. Meanwhile in tropical areas rotavirus has the same prevalence during the whole year, in more temperate climates it peaks in the cool and/or dry season 2,25,26. A 10-year survey on shigellosis in Teknaf, Bangladesh, showed a round-the-year infection with two peaks: one in the monsoon period and the other in the winter period 34 . In Nicaragua we saw a seasonal variation in our study with the highest incidence of diarthoea during the rainy season. The same results were found in the study in the north of Nicaraguall

\section{Prevention}

Many risk factors which increase morbidity and mortality due to diarrhoeal diseases in developing countries have been identified:

- Increased transmission of pathogens. 
- lack of water of good quality and in sufficient quantity

- lack of sanitation

- poor food hygiene

- poor personal hygiene

- poor domestic hygiene

- poor communal hygiene (neighbours, food vendors, schools, public places)

- Low host resistance

- Limited case management of diarrhoeal disease

The importance of these factors is influenced by the socio-economical, educational, cultural and demographical situation of the different countries and in that way the possibilities of prevention of diarrhoeal morbidity and mortality. Preventing diarrhoeal disease means interruption of the transmission of pathogens. The prevention of death due to diarrhoea may be obtained through the increase of the resistance of the host and the improvement of the case management of diarrhoeal disease:

- Reduction of the transmission of pathogens by improving:

- water supplies and sanitation

- personal and domestic hygiene

- food hygiene

- communal hygiene

- Increase of host resistance

- prevention of low birth weight

- breast feeding

- improved weaning

- supplementary feeding programs

- monitoring child growth

- immunizations (rotavirus, cholera, measles)

- chemoprophylaxis

- Improved case management

- promotion oral rehydration therapy

- improving communication between mother and health personnel by taking in account local culture of health beliefs and practices

- promotion of feeding during diarrhoeal period and recovery

\section{References}

1 World Bank. World Development Report 1993, Inwesting in Heath, Washington DC: World Bank, 2993.

2 Blaser MI. Smith PD, Rawdin Jl, Greenberg HB and Guerrant RL leds), Infections of the Gastirantestinal Traci, Raven Press, New York, 1995.

3 Bahr J and Welthahra, Life expectancy and infant mortahty in Latin America, social science and Medicine 1993, $36 ; 1373$. 1382 .

4. Feachem $2 G$ and Jamison DT (eds, Disease and Mortality in Sub-Satharan Africa, Oxford University Press, Oxford, 1991 .

5 World Bank, World Development Repont 1997, The State in a Changing World, Washington DC: World Bank 1997.

6 World Health Organizavion, The World Health Repont 1996, Fighting Disedse, Fostering Developwtent, Genexa, World Health Organization, 1996 .

7 Tiutty SRA, The impact of imadequate sanitary conditions on health in developing conunties, World Hedth Statistics Quarterly $1990 ; 43: 118-126$ 
8 Weath Organization. The World Health Report 1995, Bridging the Gaps. Geneva, World Health Organization, 1995

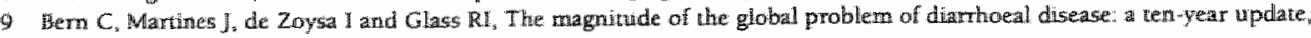
Bulletin of the World Health Organtization 1992: 70:705-714

10. Ministry of Health of Nicaragna, Plon Thienal de Salud; 1991-1993. Maltiformas, Managuat, Nicaragua, 1991 .

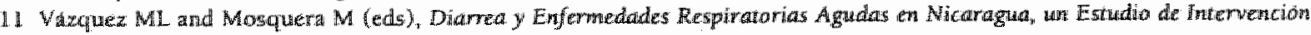
Educatha, 1989-1992, Imprenta UCA, Managua, Nicaingua, 1994.

12 Persistent diarnoea, Bulletin of the Programme for Control of Diantheal Diseases, WHO, 1989; $4: 14$.

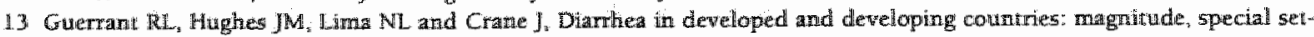
tirigs, and etiologies, Rewiews of infectiows Diseases, $1990 \%$, $12(51) 541-550$.

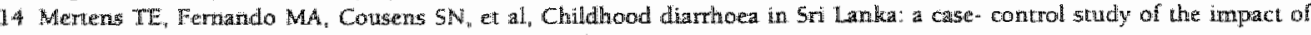
improved water sources, Tropical Medicine and Paredilitology 1990; $41: 98-104$

15 Grorter $A$, Sandiford P, Davey Smith G and Paw J, Water supply samitation and diamhoeal disease in Nicaragua: Results from a caste-control study International Jowrnal of Epidemiology 1991; 20,527-533.

16 Taylor MB, Parker S, Grabow WOK and Cubit WD, An epidemiological investigation of Norwall virus infection in South Africa, Epidemiology and Infection 1996; $116 ; 203-206$

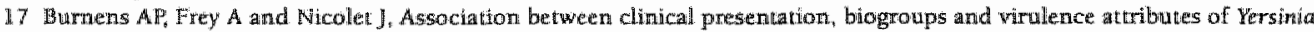
enterocolitica strains in human diarrhoeal disease, Fpidemiology and Infection: 1996, 116:27-34.

18 Salamina 6 , Dalle Donize E, Niccolini A, Poda $G$, Cesaroni D, Bucci M, Fini R, Maldini M, Schuchat $A$, Swaminatham Bs, Bibb Wr Rocourb J, Binkini $N$ and Salmaso $S$, A foodbome outbreak of gastroenteritis involwing Listeria monocytogents, Epidemiology and hafection $1996 ; 117 \div 429+436$.

19 Sorvillo Et, Lieb LE, Kemdt PR and Ash LR, Epidemiology of Cryptosporidiosis among persons with acquited immunodeficiency syndrome in Las Angeles coumty, American Journal of Tropical Medicine and Hygiene 1994; 51:326-331.

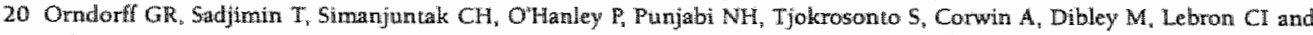
Echeverria Pr Enterotoxigenic Escherichia coli Diarthea in children less than five years of age in Central Java, American Journal of Tropical Medicine and Hygiene $1996 ; 55: 449451$.

21 Armstrong GL, Hollingsworth I and Morris IG. Emerging foodbome pathogens: Escheridhat woli 0157 . HT as a modlel of entry of a new pathogen into the food supply of the developed warld, Epidemiological Rewiews 1996; 18:29.

22 Tilden I. Young W, MCNannara AM, Custer C, Boesel B, Lambert Fair MA, Majtowslid, Vugia D, Werner 5B, Hollingsworth and $J$, Morris $J G_{i}$ A new route of transmission for Escherichia coli: infection from dry temmented salami, American joumal of Public Health 1996: 860:1142-1145

23 MacDonald IAR, Gould IM and Cumow I, Epidemiology of infection due to Escherichia coli olst: a 3-year prospective study, Epidemiology and infection 1996; $116: 279-28$ -

24 Clateson $M$ and Merson MH, Global progress in the control of diartheal diseases, Pediatric Infectious Disease Journal 1990 ; 9. 345-355.

25 Black RE, Brown KH. Becker $S$, et al, Longitudingl studies of infectious diseases and physical growth of children in rural Bangladesh. II. Incidence of diarthea and association with known pathogens, American Journal of Epidemiology 1982 ; $115 \div 315-324$

26 Pinfold JV, Horan NJ and Mara DD, Seasonal effects on the reported incidence of acute tharhoeal disease in Northeast Ithaliand, Intemational Joumal of Epidemiology 1991; 2:777-786.

27 Hack $\mathrm{RE}$, Lopez de Romana $\mathrm{G}$, Brown $\mathrm{KH}$, ex al, lncidence and etiology of infantile diarthea and major routes of transmission in Huascar, Peru, American Joumal of Epidemiology 1989; 129:785-799.

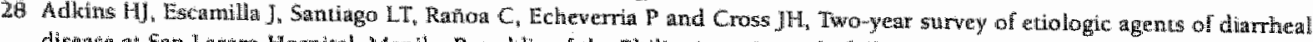

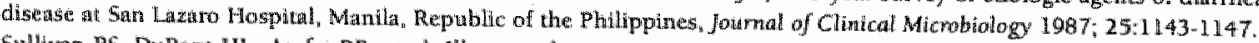

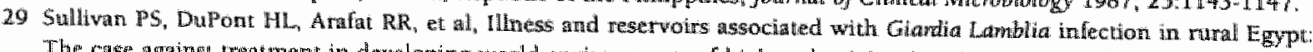
The case against treatmeme da developing world environments of high endemicity American journal of Epidemiology 1988 ;
$127,1272-128 \mathrm{l}$.

30 Shwikh K, Wojtyniak B. Mostafe G and Khan MU, Pattern of dirrhoeal deaths during 1966-1987 in a demographic surveillance area in rarall Bumgladesh. Jowrnal of Diamthow Disease Researth 1990; 8:147-154.

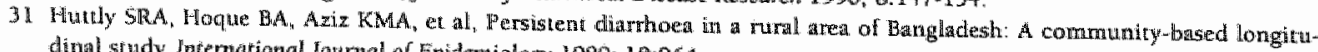
dinal study, Intertational Jowmal of Epidemiology $1989 ; 18: 964$.

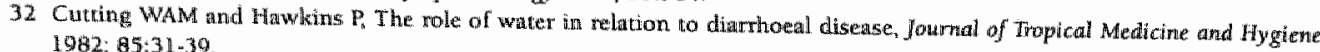
1902: $85: 31-39$

33 Espey $5 A_{1}$ Feachem $R G$ and Hughes JM, Inierventions for the control of diarrhoeal diseases among young children: impro-

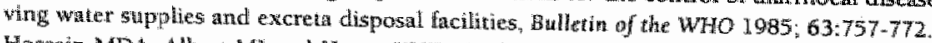

34 Hossain MDA, Abert M] and Hatsan KHZ, Epidemiology of shigellosis in Tekrnal, a constall area of Bangladesh: a 10-year survey, Epideriology and Infection 1990; 105:41-49.

35 Wortd Bank, World Development Indicators 1996, Washington DC: World Bank 1998 
Chapter 3

Well water study, part 1

Anna Gorter, MD

Peter Sandiford, MD

A Consultancy Undertaken for COWATER International INC Liverpool Associates in Tropical Health

1992, updated in 1997 


\section{Summary}

There have been numerous health impact studies of water supply, sanitation and hygiene, although many of these studies have suffered from methodological flaws. There is however, a reasonable consensus that water quality improvements do not generally have as great an impact on health as interventions, which increase the availlability of water or provide human feaces disposal facilities. Those interventions which improve hygienic behaviour at the household level and/or the community level, seem to have the greatest impact.

From the small amount of relevant literature that is available, and taking into account the studies of major water quality improvements, it would appear that a water quality intervention is more likely to have a positive health impact through reducing contamination from very high levels to moderate levels than from moderate levels to low levels. In highly contaminated environments where multiple transmission routes are acting together the health impact of improved water quality may be limited. In developing countries one should not expect more than a 10-20\% reduction in diarrhoeal disease morbidity due to the improvement of the water quality. It should be noted too that such improvements are likely to be more effective where many families share a water source than where the water source is used by just one or two households. For interventions increasing the availability of water one may expect a reduction of $20-30 \%$ or more of the incidence of diarrhoea. Providing human faeces disposal facilities seems to be more effective in urban settings than in rural communities, but depends heavily on the manner in which these facilities are used. Interventions to improve the level of hygiene practices may be highly effective, but depend on the preconditions available such as mother's level of education, facilities for water and for the disposal of faeces, while social and cultural factors may have a reinforcing or restraining influence. Reductions of up to $90 \%$ in incidence of diarrhoea have been reported for the improval of one or more hygiene practices. 


\section{A literature review of the health impact of water supplies, sanitation and hygiene on the incidence of diarrhoeal disease}

\subsection{The Relationship between Health and Water}

Water is not only an essential element for the sustenance of human life but also a cause of much death and disease, particularly in the developing world. Most of morbidity and mortality related to water is due to the role it plays in the transmission of a variety of communicable diseases. Bradley1 developed a classification of water-related illness based on four different transmission routes:

\section{Water-borne transmission.}

This occurs when water is drunk that contains pathogens, which subsequently infect the host. All water-borne diseases with the exception of Guinea worm (dracunculiasis) are faecal-oral. That is, they pass from the faeces of one host to the mouth of another.

\section{Water-washed transmission.}

Here water serves as a positive factor through its use for personal and domestic hygiene. Faecal-oral pathogens are washed away thus preventing person to person transmission. Skin and eye diseases are also preventable with increased availability of water for personal and domestic hygiene purposes.

3. Water-based transmission.

This occurs when certain parasitic worms such as schistosomiasis reside in water and infect their host directly through the skin.

4. Water-related insect vector transmission.

Many insect vectors such as mosquito's breed in water or bite near water (e.g. tsetse flies). By preventing breeding in water or human contact with breeding sites, this form of transmission can be controlled.

\subsection{The Importance of Water-borne Transmission}

Improvements in water quality will obviously have an impact on health in those cases where the transmission route is water-borne. There are several factors, which determine the importance of the water-borne transmission route.

\subsubsection{Other transmission routes}

Firstly, there is the relative importance of other transmission routes. Briscoe ${ }^{2}$ has argued 
that for diseases such as diarrhoea where there are multiple transmission routes, reducing transmission by the dominant route will not necessarily produce a corresponding reduction in the incidence rate of that disease. However, this notion was refuted by Cairncross ${ }^{3}$ who pointed out that Briscoe's case rested upon the assumption that the multiple transmission routes were operating simultaneously which is clearly not the case for any given illness episade. Nevertheless, even if an intervention which prevents $50 \%$ of water-borne transmission, reduces the number of cases from that route by the full $50 \%$, it may have an insignificant overall effect if that route contributes only a small proportion of the total number of cases.

\subsubsection{Survival of the pathogen in water}

Secondly, the importance of the water-borne route also depends upon the ability of the pathogen in question to survive outside of its host. Table $\mathbb{l}$ shows the estimated time for $50 \%$ of a bacterial population to die in a stable well water supply. There is considerable variation in the survival of different pathogens in water, with some such as Vibrio cholerae sensitive to the level of salinity and $\mathrm{pH}^{4}$. Resistance to chlorine affects survival in treated water supplies and indeed, some viruses are known to be able to withstand bactericidal concentrations of chlorine.

Table 1. Survival of various pathogens in a stable well water supply

Pathogen

Survival time hours $\left(T_{50}\right)$

Shigella flexneri

Shigella sonnei

26.8

Shigella dysenteriae

24.8

Enterococcus

22.4

Colfform bacteria

22.0

Salmonella enteritidis

Vibrio cholerae

Salmonella typhi

Solurce: Feachem R ot al, $1987^{5}$

\subsubsection{Variation in pathogenicity}

Differences in pathogenicity also determine the relative importance of the water-borne route for any given aetiology. Pathogenicity of infectious agents is usually measured by the infective dose. This is the number of pathogens which when ingested, gives rise to illness in $50 \%$ of cases. In water, the concentration of pathogens tends to be rather low and therefore it may be difficult to imbibe an infective dose merely by drinking. On the other hand, if contaminated water comes in contact with food, the bacterial pathogens may breed in that medium until an infective dose is reached. The infective dose for viruses is generally less than $100^{6}$. Infective doses of bacteria tend to be higher ${ }^{7}$, but there is considerable variation between the different species. Shigella needs a relatively small 
Briscoe and VanDerslice have pointed out in their article "All coliforms are not created equal" that pathogenicity also depends upon the familiarity of the host with the pathogen. If a certain pathogen is new for the host, illness is much more to be expected than in the case of a pathogen with which the host has become familiar and for which he has created resistances.

An interesting suggestion ${ }^{9}$ has been put forward that reducing waterborne transmission puts evolutionary pressure on organisms tending to reduce their pathogenicity. Alliough Ewald has attempted to provide some empirical support for this hypothesis, which is largely based upon theoretical considerations, his success has been limited by the quality of available historical data. The traditional health impact evaluation would not, of course, measure benelits of this type.

\subsubsection{Epidemiologic profile}

Obviously if the importance of water-borne transmission depends upon pathogen-specific factors, then the impact of water quality improvements will vary according to the relative incidence of these different agents. However, the converse is also true, that is, the distribution of disease will depend upon the various transmission routes that are open to pathogens. Moreover, if Ewald's hypothesis is correct, control of waterborne transmission will tend to reduce the prevalence of the more virulent species as well as reducing virulence within the population of a given species of pathogens".

\subsubsection{Degree of water contamination}

One would expect that the importance of water-borne disease transmission increases with increasing levels of faecal contamination. This is not because a higher level of contamination implies a greater probability of encountering a pathogen, but because it also implies a greater probability of imbibing a pathogenic dose of the agent.

It is important however; to point out that faecal contamination per se does not imply water-borne transmission of disease. Unless the faeces contain a pathogen to which the potential host is susceptible, no infection will be transmitted. There is no doubt that a large amount of faecal matter is consumed by humans without any risk of developing an illness, simply because the faeces contains no pathogens.

Even if infectious agents are present, it is possible that the potential host has already been exposed to them. There are several important implications from this point:

- Firstly, a given level of water supply contamination may have more epidemiologic significance where that water supply serves a large population than where it serves just one or two families. In the latter case, any pathogen in the water may already have been transmitted to family members through other routes.

- Secondly, apparent health impacts due to improved water availability do not necessarily imply reduced water-washed transmission. When an intervention lowers the number of families that is served by a water source, it may actually decrease water-borne uransmission more than water-washed transmission because the frequency of exposure by unfamiliar pathogens and size of the susceptible population is reduced. 
- Thirdly, in-house contamination of stored water may not be as significant as contamination of source water, because family members are already familiar with that specific pathogen ${ }^{8}$.

\subsection{Evidence for the Health Impact of Water Quality, Quantity, Sanitation and Hygiene Improvements}

\subsubsection{Methodological issues in health impact evaluations of water supply, sanitation and hygiene interventions}

The failure to demonstrate a positive health irnpact of several major water supply and sanitation interventions $10,11,12,13,14$ led some scientists to re-examine the methods which were being used. Water supply and sanitation interventions are expensive, politically sensitive and often serve entire communities. These peculiarities make it often impossible to use the epidemiologically rigorous randomised controlled trial design. Most studies that have been performed are therefore observational, and are frequently designed as post hoc evaluations. In a review of 44 published studies of the impact of water supply and sanitation facilities on diarrhoeal disease, Blum and Feachem ${ }^{15}$ identified 8 major methodological flaws. While none of the studies reviewed were entirely free from these flaws, some were much worse than others. The eight major flaws were:
1. Use of inadequate control groups
2. Comparison of one intervention site with one control site
3. Unsatisfactory control of confounding
4. Recall bias in ascertaining disease status
5. Imprecision of disease definition
6. Failure to analyze by age
7. Failure to record facility usage
8. Insufficient consideration of seasonal variation

In addition to these deficiencies in study design, the evaluation of water supply, sanitation and hygiene interventions has been hampered by the enormous cost of carrying out longitudinal studies of the size necessary to address the key issues satisfactorily. Hence, in 1976, an expert panel to the World Bank published a paper discouraging any further studies of this type ${ }^{16}$.

Nevertheless, this paper did lead investigators to look at alternative methods to carry out health impact evaluations of water supply, sanitation and hygiene interventions. Attention focused on the case-control design, mainly because it offered the promise of lower sample sizes and the ability to make retrospective evaluations of successfully functioning water supply, sanitation and hygiene programmes ${ }^{17,18}$,

Since then, various risk factor studies with the case-control design have been carried out in a wide variety of settings. Case-control studies applied in the developed countries for the investigation of the relation between cases of water contamination and the occur- 
rence of diarrhoea have been producing quite clear results $19,20,21,22$. However for the developing countries $23,24,25,26,27,28,29,30,31,32,33,34$ it has to be said that results are not much more consistent than those of the earlier designs. Although it is now possible to define disease status more precisely, the advantages of the case control study in terms of sample size and statistical power are probably not as great as was initially expected. Many of the problems previously identified remain unresolved such as the difficulty in documenting exposure and the selection of an appropriate control group.

Moreover, there are two problems which observational studies will always find difficult to deal with. One is that water supplies, sanitation and 'good' hygiene practices are not allocated randomly within the study population, but tend to correlate strongly with other health-related social and economic factors. Some of these factors are very difficult to measure and hence control for during the analysis stage. A second problem is that these studies are based on an assumption that individuals behave passively with regard to the putative risk factors ${ }^{35}$. In reality though, it is possible, for example, that a household with a contaminated water supply will be more likely to boil a child's drinking water than a household with an uncontaminated water supply. Unless such practices are measured and taken into account, traditional analyses will yield misleading results ${ }^{36}$.

\subsubsection{Reviews of the health impact of water supply, sanitation and hygiene improvements}

We know of three reviews of the many health impact evaluations of environmental sanitation that have been performed over the last fifty years $6,37,38$. Each of these reviews has classified the studies according to whether the interventions improved water quality, water availability, excreta disposal, hygiene or combinations of the four. The most recent one updates the findings of the other two and is therefore the one, which will be discussed most thoroughly. Since this review many more studies have been published in which the impact of water supply, sanitation and hygiene is assessed, either alone or in combination with other improvements.

Although the 1991 Esrey et al review38 considers the potential health impact of water supply, sanitation and hygiene on trachoma, schistosomiasis, hookwom, dracunculiasis, ascariasis and diarrhoea, it are only the latter 3 diseases which improved water quality for drinking might be expected to prevent. The others are therefore not considered here. Table 2 , reproduced from Esrey et al, 38 shows the median reduction in morbidity and mortality for each disease taking all of the studies combined. It appears from this table that dracunculiasis and schistosomiasis are particularly amenable to water and santation interventions. It also seems that mortality is more reduced than morbidity but this may also be due to the difficulties in measuring the latter. 
Table 2. Expected reduction in morbidity and mortality from improved water and sanitation for selected diseases

\begin{tabular}{|c|c|c|c|c|c|c|}
\hline \multirow[b]{2}{*}{ Ascariasis } & \multirow{2}{*}{$\frac{n}{11}$} & \multicolumn{2}{|c|}{$\begin{array}{l}\text { All studies } \\
\text { Medlian reduction }(\%)\end{array}$} & \multirow{2}{*}{ n } & \multicolumn{2}{|c|}{$\begin{array}{l}\text { Rigorous studies } \\
\text { Median reduction }(\%)\end{array}$} \\
\hline & & 28 & $(0-83)$ & & 29 & $(15-83)$ \\
\hline \multicolumn{7}{|l|}{ Diarnoea } \\
\hline Morbidity & 49 & 22 & $(0-100)$ & 19 & 26 & $(0-68)$ \\
\hline Mortality & 3 & 65 & $(43-79)$ & - & - & \\
\hline Dracunculiasis & 7 & 76 & $(37-98)$ & 2 & 78 & $(75-81)$ \\
\hline Hookworm & 9 & 4 & $(0-100)$ & 1 & 4 & \\
\hline Schistosomiasis & 4 & 73 & $(59.87)$ & 3 & 77 & $(59-87)$ \\
\hline Trachoma & 13 & 50 & $(0-91)$ & 7 & 27 & $(0-79)$ \\
\hline Child mortality & 9 & 60 & $(0-82)$ & 6 & 55 & $(20-82)$ \\
\hline
\end{tabular}

Source: Esrey et at, $9991^{38}$

\subsubsection{The health impact of combined water supply and excreta disposal improve- ments}

In four well-conducted studies of the review, the prevalence of ascariasis was reduced among those with water supplies and latrines, the greatest reductions being observed in those settings where household water supplies were provided rather than community standpipes. There was a greater reduction in the intensity of infection (as measured by egg counts) than in the prevalence.

For diarrhoea, studies of combined water supply and sanitation improvements show a $20 \%$ median reduction in morbidity with the better studies having a $30 \%$ median reduction (table 3 ). In the only study that examines the impact on mortality, an $82 \%$ reduction was observed in those with toilets and water compared with those without such facilities, particularly if the child was not breast-fed.

Table 3. Expected reduction in diarchoeal disease morbidity from improvements in one or mone components of water and sanitation.

\begin{tabular}{|c|c|c|c|c|}
\hline & $n$ & $\begin{array}{l}\text { All studies } \\
\text { reduction }(\%)\end{array}$ & $n$ & $\begin{array}{l}\text { Rigorous studies } \\
\text { reduction }(\%)\end{array}$ \\
\hline Water \& sanitation & $7 a / 11 b$ & 20 & $2^{a} / 3^{b}$ & 30 \\
\hline Sanitation & $11 / 30$ & 22 & $5 / 18$ & 36 \\
\hline Water quality \& quantity & $22 / 43$ & 16 & $2 / 14$ & 17 \\
\hline Water quality & $7 / 16$ & 17 & $4 / 7$ & 15 \\
\hline Water quantity & $7 / 15$ & 27 & $5 / 10$ & 20 \\
\hline Hygiene & $6 / 6$ & 33 & $6 / 6$ & 33 \\
\hline
\end{tabular}

\footnotetext{
The number of studies for which morbidity reduction calculation could be made.

b the total number of studies that redated the type of fadlity to diarthoeal morbidity, nutrition and mortaity.
} 
A recent follow-up cross-sectional survey of a water supply, sanitation and hygiene edincation intervention in Bangladesh 39.40 , of which the results were not included in the review, reported about $50 \%$ less diarthoea prevalence in the intervention areas compared to the prevalence of the control areas. See table 4.

Esrey combined data collected in the late 1980's from 8 countries on 3 continents and amalyzed them to test whether incremental health effects regarding diarhoea resulted from incremental improvements in water and sanitation. Optimal (i.e, on the premises) and intermediate (improved public water) water supplies were compared with unimproved water conditions. Optimal (fush toilets or water-seal latrines) and intermediate (latrines) sanitation levels were compared with unimproved samitation. Results were published in 1996.1. Incremental improvements in sanitation were associated with less diarrhoea with each of the three levels of water supplies and the effect was greater among urban dwellers than among rural dwellers. Benefits from improved water were less pronounced than those for sanitation. They occurred only when sanitation was improved and only when optimal water ('on the premises') was present and not with the intermediate water supplies (not 'on the premises').

VanDerslice had a comparable result in a study in the Philippines $\$ 2$. Improving drinking water quality had no effect in neighbourhoods with very poor environmental sanitation. The positive impact of improved water quality was greatest for families living under good sanitary conditions. See table 4.

\subsubsection{The health impact of combined water quantity and/or water quality improvements}

In many of the studies published, it is difficult to determine whether the water supply improved quantity, quality or both and hence the review grouped them together. Two studies found that water supplies alone, reduced ascariasis prevalence by $30 \%$ and $37 \%$ respectively. However, for diarrhoea morbidity only modest reductions (16-17\%) were abserved (table 3). In the nine rigorous studies which looked at mortality, a positive impact was observed only in certain age groups. The studies reporting positive impacts tended to be the ones where the water supply was piped into the homes as opposed to protected wells, tubewells and standpipes. A recent study from Chima (table 4), found that deep well tap water in the house or yard (average total coliform count $0.23 / 100 \mathrm{cc}$ ) was associated with a lower incidence of diarrhoea (38\%), hepatitis (73\%) and cholera $(88 \%)$ but not Shigella, compared with those using surface water at 10 to 40 meters from the home (average total coliform count $77 / 100 \mathrm{cc}$ ).

\subsubsection{Studies evaluating the impact of water quality alone}

Of the 16 studies that are mentioned in the review, which examined the health impacts of pure versus contaminated water supplies, 10 reported positive effects and the median reduction in diarrhoea morbidity was $17 \%$. Among the 7 more rigorous studies, the median reduction was $15 \%$. 
Table 4. Recent studies examining the health impact of water quality on diarrhoea

\begin{tabular}{|c|c|c|c|c|}
\hline Country & Type of improvement & Comparison & Observed impact & Ref. \\
\hline \multirow[t]{2}{*}{ Bangladesh } & $\begin{array}{l}\text { Sanitation \& water } \\
\text { quantity \& quadity }\end{array}$ & $\begin{array}{l}\text { Hand pumps, latrines, } \\
\text { hygiene education vs } \\
\text { control areas }\end{array}$ & $\begin{array}{l}\text { About } 50 \% \text { reduction in } \\
\text { prevalence of diarrhoea }\end{array}$ & 40 \\
\hline & Quality only & $\begin{array}{l}\text { Exclusive wet season } \\
\text { use of hand pump } \\
\text { water }\end{array}$ & Not significant & 39 \\
\hline $\begin{array}{l}\text { Multi-country } \\
\text { study }\end{array}$ & $\begin{array}{l}\text { Water quality \& } \\
\text { quantity \& sanitation }\end{array}$ & $\begin{array}{l}\text { Incremental } \\
\text { improvements }\end{array}$ & $\begin{array}{l}\text { Water only effect with } \\
\text { good sanitation and optimal } \\
\text { water. Sanitation results in } \\
\text { less diarrhoea. }\end{array}$ & 41 \\
\hline China & $\begin{array}{l}\text { Water quality } \\
\& \text { quantity }\end{array}$ & $\begin{array}{l}\text { Deep well tap water } \\
\text { in yard vs surface water }\end{array}$ & $\begin{array}{l}\text { Reduction of } 38 \% \text { in } \\
\text { diarrhoea incidence }\end{array}$ & 43 \\
\hline Philippines & $\begin{array}{l}\text { Water quality } \\
\text { sainitation }\end{array}$ & $\begin{array}{l}\text { Latrine/toilet ws nothing } \\
\text { Level of } F C \text { contamination }\end{array}$ & $\begin{array}{l}\text { Only effect of water under } \\
\text { good santtary conditions. } \\
\text { Sanitation results in } 40 \% \\
\text { reduction }\end{array}$ & 42 \\
\hline Ghana & Water quality & $\begin{array}{l}\text { Borehole and wells vs } \\
\text { holes dug in stream beds }\end{array}$ & $\begin{array}{l}\text { Nil on mortality } \\
\text { insignificant association } \\
\text { with diarrhoea in dry seasom }\end{array}$ & 52 \\
\hline Egypt & Water quality & $\begin{array}{l}\text { Tap water versus well } \\
\text { water for drinking }\end{array}$ & Nill & 47 \\
\hline \multirow[t]{2}{*}{ Malaysia } & Water quality & $\begin{array}{l}\text { Absence vs presence of } \\
F C \text { in water source }\end{array}$ & $\begin{array}{l}\text { Insignificant } 23 \% \text { reduction } \\
\text { in diarthoea. }\end{array}$ & 28 \\
\hline & & $\begin{array}{l}\text { Absence vs presence of } \\
F C \text { in drinking water }\end{array}$ & $\begin{array}{l}\text { Insignificant } 31 \% \text { reduction } \\
\text { in diarrhoea. }\end{array}$ & 28 \\
\hline Nicaragua & Water quality & $\begin{array}{l}\text { Piped water ws protected } \\
\text { wells vs unprotected wells }\end{array}$ & Nil & 33 \\
\hline Nigeria & Water quality & $\begin{array}{l}\text { Borehole vs traditional } \\
\text { source }\end{array}$ & Nil & $48-51$ \\
\hline Sri Lanka & Water quality & Faecal coliform counts & $\begin{array}{l}29 \% \text { reduction in diarrhoea } \\
\text { per ten-fold drop in FC } \\
\text { contamination }\end{array}$ & 26 \\
\hline \multirow[t]{2}{*}{ Indonesta } & $\begin{array}{l}\text { Water quality \& } \\
\text { sanitation }\end{array}$ & $\begin{array}{l}\text { Cross-sectional study of } \\
11 \text { million people, safe } \\
\text { vs unsafe water }\end{array}$ & $\begin{array}{l}50 \% \text { reduction in diarrhoea } \\
\text { in case there is an improve- } \\
\text { ment of } 100 \%\end{array}$ & 45 \\
\hline & Watter quality alone & Idem & $\begin{array}{l}43 \% \text { reduction in diarrhoea } \\
\text { in case there is an improve- } \\
\text { ment of } 100 \%\end{array}$ & \\
\hline Saudi Arabia & Water quality & $\begin{array}{l}\text { Chlorination stored } \\
\text { drinking water, FC counts }\end{array}$ & $\begin{array}{l}48 \% \text { reduction in diarrhoea } \\
\text { incidence }\end{array}$ & 44 \\
\hline
\end{tabular}


There are several studies, published since the review, in which it has been possible to separate out the effect of water quality (table 4). In one of them, carried out in Sri Lanka, ${ }^{26}$ there was a $29 \%$ reduction in diarrhoea associated with a ten-fold drop in faecal contamination. A study in Saudi Arabiat4 found a $48 \%$ reduction in diarrhoea due to the use of chlorinated water. A cross-sectional study in a population of 11 million in Indonesia45 used an altemative approach to measure the effect of water and sanitation (a production function) and found highly significant results for the effect of water quality and to a lesser extent for sanitation. In this case safe water included treated surface water, household treatment systems or untreated but uncontaminated water such as piped systems, shallow wells, deep wells, spring captations and rainwater. Rivers, streams and ponds were considered as unsafe water. However the authors did not control for distance to the water source.

Recently a controlled field trial has been performed under the Masai and results were published in the Lancet. In this study the effect of solar disinfection of drinking water from a contaminated source on the incidence of duarrhoea was measured 46 . The "solar" group received a plastic water bottle and was instructed to fill it and place it on the roof in full sunlight and the control group was instructed to place the bottle with drinking water indoors in the shade. The children of the "solar" group experienced a reduction of $34 \%$ in diarrhoea incidence compared to the control group.

In con trast, other recent studies in Egypt, ${ }^{47}$ Nicaragua, ${ }^{33}$ Nigeria ${ }^{48,49,50,51}$, Ghana ${ }^{52}$ Malaysia ${ }^{28}$ were unable to detect any effect of water quality although in the case of the latter, the small sample size may have prevented detection of a significant effect.

\subsubsection{Studies evaluating the impact of moderate water quality improvements}

The vast majority of evaluated water supply interventions, which specifically address the issue of water quality, has taken water supplies with faecal coliform (FC) counts of, or close to zero, as their reference point, as have the review articles. The median health impact of even such significant reductions in levels of contamination is small compared with those reported for sanitation and water quantity improvements. Clearly one would expect the impact of moderate reductions to be even lower.

Nine studies were identified which enable an empirical assessment of this issue. In seven of the nine studies a dose response between the diarrhoeal incidence and the level of contamination could be found. One of these studies from the Philippines ${ }^{33}$ found little difference between the illness rates of children drinking good quality source water $(<1 \mathrm{E}$. coli per $100 \mathrm{ml}$ ) and those drinking moderately contaminated water $(2-100 \mathrm{E}$. coli per $100 \mathrm{ml}$ ). But children drinking water with over $1,000 \mathrm{E}$. coll per $100 \mathrm{ml}$ had significantly higher rates of diarrhoeal disease than those drinking less contaminated water.

Trivedi $e t$ al in India ${ }^{54}$ studied the effect of 4 different levels of chlorination of highly polluted open shallow wells. Seventy four percent of these wells had 'MPN counts' over

a Moderate reduction as used hete means from thousands down to around one hundred faecal coliforms per $100 \mathrm{cc}$ of water 
1,800 per $100 \mathrm{ml}$ (table 5). The results demonstrate a clear dose response between the level of contamination and the incidence rate of diarrhoea. One must realize that chlorination of water also means that hand washing will be more effective since the chlorinated water presumably not only removes faecal material but kills or debilitates pathogens.

Table 5. Intluence of residual chlorine on water quality and on incidence rates of diarhoeal diseases

\begin{tabular}{|c|c|c|c|c|c|c|}
\hline & & Control & 1 & $\|$ & $\|$ & N \\
\hline \multicolumn{2}{|c|}{ Residual chlorine } & 0 & 0.5 & 0.4 & 0.3 & 0.2 \\
\hline $\begin{array}{l}\text { Average } \\
\text { MPN }\end{array}$ & Before & 820 & 953 & 1089 & 1100 & 880 \\
\hline count ${ }^{*}$ & After & 727 & 17 & 41 & 49 & 82 \\
\hline $\begin{array}{l}\text { Diarrhoea } \\
\text { incidence }\end{array}$ & Before & 19.0 & 20.0 & 22.2 & 20.3 & 10.7 \\
\hline rate & After & 29.5 & 1.1 & 1.7 & 2.1 & 3.0 \\
\hline
\end{tabular}

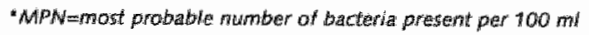

Source: Trivedi et al, 197154

In a study in Indonesiass water sources were classified as either 'safe' (uncontaminated piped water, protected springs and treated water), 'less safe' (springs, deep well pumps, shallow well pumps, dug wells and rainwater) and 'unsafe' (rivers, strearns, and ponds). In a cross-sectional survey of diarrhoea in 8,600 households, $3.8 \%$ of children in the 'safe' group had diarrhoea compared with $4.0 \%$ in the 'less safe' and $6.3 \%$ in the 'unsafe'.

The authors' case-control study in Nicaragua ${ }^{33}$ compared diarrhoea rates in users of piped water sources with users of protected wells and users of unprotected wells. Piped water sources generally had low levels of contamination ( $<1.00$ FCs per $100 \mathrm{ml}$ ), while protected wells had high levels of contamination (over 1,000 FCs per $100 \mathrm{ml}$ ). Unprotected wells (which were mostly small waterholes dug beside rivers and streams) had relatively low mean FC counts during dry periods (179 per $100 \mathrm{ml}$ ) but very high levels after rain had fallen $(15,000$ per $100 \mathrm{ml})$. No difference was detected in diarrhoea incidence between the different water sources.

In a study in Zaire ${ }^{56}$ a trend of increasing diarrhoea incidence with decreasing quality of water provided was found. Incidence was highest in children whose families drew their drinking water from streams or rivers, lower in children whose family was using an unimproved spring, and only half in children from families fetching water from improved springs or hand pump wells. However, the authors did not control for distance to the water source.

VanDerslice presented results of a study in the Philippines ${ }^{57}$ in which diarrhoea became less frequent with increasing quality of drinking water. The protective effect was greater among infants who were not breast-fed. And of course, vice versa, the protective effects 
of breast-feeding were greatest when drinking water was more contaminated.

In the UK during an outbreak of waterborne cryptosporidiosis associated with a public water supply, those drinking larger volumes were more likely to become ill20. Another UK study ${ }^{22}$ had the same results; the more water was drunk from a groundwater supply contaminated with cryptosporidiasis, the higher the risk of cryptosporidiasis. A doseresponse relationship was also seen in a study from CDC Atlanta; people who drank more unboiled well water became more ill with cryptosporidiosis ${ }^{58}$.

\subsubsection{Studies evaluating the impact of increased water quantity}

Of the 15 studies mentioned in the review, which examined the effect of increased amounts of water specifically and independently of water quality, 14 reported positive effects. The median reduction for 7 studies for which this could be calculated, was $27 \%$. Of the 10 rigorous studies a median reduction of $20 \%$ was found. Health benefits were greater for children whose families used more water than for those whose farnilies used less. The quantity of water appears to be more important than the quality of water.

Since then very few studies have been performed which measured the amount of water used or the distance of the house to the water supply (a proxy for quantity of water used) and related the outcomes to the incidence of diarrhoea. The above mentioned multicountry study of Esrey ${ }^{41}$ found that only 'optimal' water supplies (ie, on the premises) had an impact on diarrhoea and not the 'intermediate' supplies (improved public water) compared to the unimproved traditional water conditions. The difference between the 'optimal' and the 'intermediate' water supply concerns the distance to the water source rather than the water quality. When water supplies are 'on the premises' access to water is high, and the quantity of water used will increase. The public water supplies will be at a certain distance from the house as are the unimproved traditional sources and although the quality of water will be much better, this is clearly not enough to create an impact on diarrhoea incidence.

In the authors' baseline studies of traditional water sources in Nicaragua we found a relationship between water consumption and the distance from the house to the water sources9. In the case-control study $^{33}$ we found an association between the water availability and diarrhoea. Children from homes with water supplies over 500 meters from the house had $34 \%$ more diarrhoea than children from houses with a water supply 'on the premises'.

\subsubsection{Studies evaluating the impact of sanitation}

Esrey's review identified 30 studies on the impact of sanitation on diarrhoea. A reduction of $22 \%$ was calculated. For the 18 rigorous studies this was $36 \%$ in the five, for which this could be calculated. The other studies reported on nutritional status and mortality. Sanitation was more effective in reducing mortality among nonbreast-fed infants and children of illiterate mothers than among breast-fed infants and literate mothers. Some studies reported that the method of disposal of human faeces determined the magnitude of the impact. 
In many parts of the developing world children under the age of 5 years do not use Latrines27,60. Children's faeces are often viewed as harmless even though these may be highly contaminated 61 . In Bangladesh Zeithin found that mothers did not realize that faeces cause disease. Half of the mothers had seen their crawling baby touch or eat faeces in the two weeks before62. Even when there are latrines these are frequently not used by children 63,64,65. Mullert7 found that faecal pollution of households was more due to the fact that latrines frequently were not used than poor construction or maintenance of latrines.

Since the review of Esrey in 1991 several studies have reported that latrine ownership alone is not associated with a reduction in diarthoea ${ }^{32,33,67}$. However, hygiene behaviour around the disposal of human faeces was observed to be significantly related to the incidence of diarrhoea $27,28,68,69,70,71,72,73$. The authors' study of hygiene practices found that the use of a diaper or underclothes was significantly related to a reduction in diarrhoea incidence, meanwhille the presence of a latrine had no relation ${ }^{74}$. In Nicaragua young children defecate in the yard and do not make use of latrines, simply because they are afraid of the "black" hole. This result also helps to explain Esrey's finding in the review that fush toilets were more effective than pit latrines.

On the other hand, other new studies found a significant relation between diarrhoea and the presence of a latrine $29,45,56,75$. Furthermore the presence of a latrine may alsio interact with the magnitude of the health impact of improved water supplies. In the multi-country study ${ }^{41}$ improved water supplies had only effect in the presience of good sanitation. "Optimal" sanitation, ie, flush toilets or water-seal-latrines, was more effective than intermediate' sanitation (latrines). Providing human faeces disposal facilities was also more effective in urban settings than in rural communities. In the Philippines 42 not only private human faeces disposal, but also the sanitary conditions of the community, was seen to interact with the health effect of improved water supplies. The authors of the study concluded that improving drinking water quality would have no effect in neighbourhoods with a very poor environmental sanitation. For interventions to control diseases effectively not only private sanitation, but also public sanitation needs to be improved. As Cairncross argues: "Interventions are needed in both domains (public and private) in order to reach the goal of interruption of the transmission"76.

\subsubsection{Studies evaluating the impact of hygiene}

Esreys review identified only 6 studies that reported on the impact of hygiene interventions on diarrhoea morbidity. All were rigorous, and the median reduction was $33 \%$. His conclusion is that those interventions which improve human faeces disposal and water quantity, and which are associated with better hygiene practices, produce greater health impacts than improvements in water quality alone. This is particularly so in highly contaminated environments where diarrhoea rates are high. Because the use of more water is not automatic following the installation of water supplies, hygiene education is a necessary part of the intervention.

Since then many hygiene studies have been published, including guidelines and methods of how to investigate hygiene practices $60,77,78,79$. The water and sanitation studies had 
made it clear that only supplying hardware is not sufficient to reduce the incidence of diarrhoea; personal, domestic and community hygiene plays a crucial role in the transmission of diarthoeal pathogens.

Many of the hygiene studies focussed on handwashing $70,80,81,82,83,84,85,86,47,86,39,90$. For those, which related hand washing practices with diarrhoeal incidence, a decrease of $30 \%$ to $90 \%$ was observed. Contaminated hands are highly efficient vehicles for the cransmission of diarrhoeal disease. Of the personal hygiene behaviours, hand washing is the most critical determinant of diarrhoeag1. In studies measuring the occurrence of hand washing, low frequencies of this practice are seen; in Malawi $13 \%$ of adults washed hands after defecation ${ }^{92}$, in Guatemala $11 \% 65$. In Nicaragua we saw that $76 \%$ of mothers washed their hands before preparing food, but only $26 \%$ before eating 7.4 . People wash their hands in different ways at different times of the day for different purposes; hand washing seems not as much to be linked to health as to social norms ${ }^{60}$. Something alike we already described above, where mothers did not perceive babies' faeces to be important in causing diarrhoea. In order to design cultural appropriate interventions of water supply/sanitation and hygiene the incorporation of anthropological research is indispensablebo. Mothers will only feel motivated to change practices if they understand the relation of this practice with diarrhoea, as we noted in a study in Nicaragua93.

Other studies, including the authors' hygiene study ${ }^{74}$, not only investigated hand washing but also other hygiene practices in order to design or evaluate hygiene education campaigns $28,32,40,68,94,95,96,97,98,99,100$. In addition to hand washing and sanitary removal of human faeces, hygiene practices which frequently were found to be related to the occurrence of diarrhoea are food and water hygiene and the cleanliness of kitchen and compound.

Overall levels of hygiene in villages may play an important role as children spend a lot of their time in other households and on the street1101.102,103. Households can share meals or buy water and food from street vendors ${ }^{61,104}$. In several studies crowding, te, the distance between houses, was reported as a risk factor for duarrhoea ${ }^{64}$ as well as the number of persons and children per household ${ }^{33,105}$. Koopman ${ }^{106}$ stresses in his article of school hygiene in Colombia that in schools in addition to toilets there are other factors, such as person-to-person contact, that are responsible for the transmission of diarrhoea. He argues that interventions in schools are probably more effective than family-based ones, simply because schools have a central role in the diarrhoea transmission of a village because they disseminate the transmission. If the source of schoolchildren as introducers of disease into the home can be reduced, it seems reasonable that illness in their preschool siblings, who have the highest secondary attack rates to these introductions, can be reduced. Many studies have been published recently in which the effect of faecal contamination on diarrhoea rates in childcare settings is described and where the major route of transmission person-to-person is ${ }^{88.107}$. 


\section{References}

1. White GE Bradley DJ, white AU, Drawers of water. Domestic water use in East Afria, Uniwersity of Chicago Press, Chicago, 1972.

2 Briscoe 1, Intervenion sudites and the definition of dominam transmission routes, Anerican foumal of Epidemiology 1984 120.449 .455

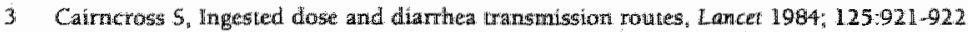

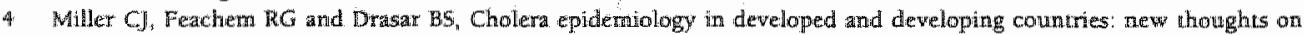
tratusmiston, seasonaliny, and control, Lamcet 1985; Feb 2262-263.

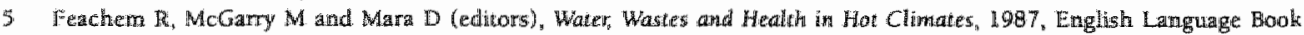
Society and John wiley Sons, Chichester, UK.

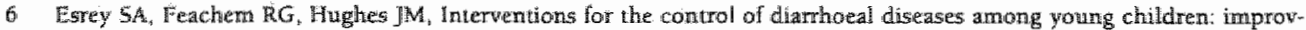
ing water supplies and exereta disposal factlities. Bulletim of the World Health Organization 1985; 63:757-772.

7 Pinfold JV Horan M. Mara DD, Seasonal effects on the reported incidence of acute diarthoeal disease in Northeast Thatiand, Intemational Joumal of Epidewiology $1991 ; 20777-786$.

6 Vamberslice $]$ and Briscoe J. All coliformas are not created equal: A comparison of the effects of water source and in thouse water contarnination on intantile diartheal disease, Wher Resources Reseanch 1993; 29:1983-1995.

9 Ewald PW, Waterborme transmission and the evolutiom of wirulence anong gastrointestimal bacteria, Epidemiology and Infection 1991: 106:83-119

10 Weir BM. An evaluation of thealth and samitation in Egptian villagen. Joumal of the Egyptian Public Health Associationt $1952 ; 27: 55-114$.

11 Kourany $M$, Vasquez MA and Mata LJ, Prevalence of pathogenic enteric bacteria in children in 31 Panamanian communi ties. American Journal of Tropical Medicine and Hygiene 1971; 20:608-615.

12 Levine Rj, Khan MR, D'Sovza $S$ and Nalin DR, Failure of sanitary wells to proteck against chotera and other diarrhoeas in Bargladesh, Lancet 2976; 2:86-89.

13 Feachem $R G$, Burns $\mathbb{E}_{\text {, Cairncross }} S_{5}$ et al, Water, Healih and Developmeme: An Interdisciplinary Evaluation, Trimed Books, London 1978 .

14 Shiffuan MA, Schneider R, Faigenblum JM, al Field studies on water, samitation and health education in relation to heralth status in Central Amertca. Progressiti Water Technology, 1978; $11 \cdot 143-150$.

15 Mlum $D$ and Feachem $\mathbb{R}$, Measuring the impact of water supply and santaton invescments on diarnoeal diseases: probllems of methodology, Intemational Journal of Epidemiology $1983 ; 12,357$ 365.

16 International Bank For Reconstruction and Development. Measurement of the Health Benefirs of Trwestments in Water Supply: Repart of an Expert Pand, Public Utilities Department Report No. PUN 20, Worloi Bank, Washington DC, 1976.

17 Briscone I. Feachern RG and Rahaman MMA. Mecdsuring the Impact of Wacer Supply and Sanitation Facilities: Prospects for Casecontrol Methods. WHOHCWS/85, 3. World Health Organization, Geneva, Swilizerlamd, 1985.

18 Briscae J. Feachem RG and Rahaman MM. Evaluando el Impacto en Salud Agua, Sameamiento y Educacion Samitaria. Centro Interracional de Imwestigaciones para el Desartollo, Ottawa, Canada, 1987.

19 Adak GK, Cowden JM, Nicholas $S$ and Evans HS, The public thealth laboratory service national case-control study of pri-

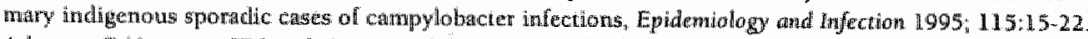

20 Athertom $\mathrm{F}_{0}$ Mewman CPS and Casenore DP, An outbreak of waterborie cryptosporidiosis associated with a public water supply in the UK, Epidemiology and Infertion 1995; 115:123m13 d.

21 Mackenzit, Kistalerctak J and Davis JP, An oubreak of cryptosporidiosis associated with a resort swirnming pool. Eptidemiology and Infectikn 1995; 115:545-553

22 Bridgman $S A$, Robertson RMP, Syed Q, 5 peed N, Andrewa N and Hunter PR, Outbreath of cryptosporidiosis associated with

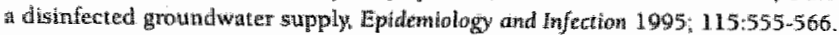

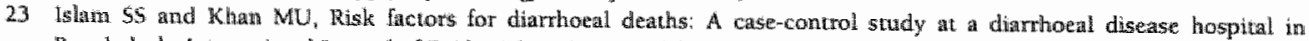

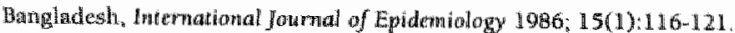

24 Clemens $\mathrm{DD}$ and Stanton BF, An educational intervention for allering water-saritation betwaviors to redace chuldhood diar thea in urban Bangladesh. I. Application of the case-control method for dewelopment of ari interwention, American Jakrial. of Epdatriology $1997 ; 125(2): 284-301$.

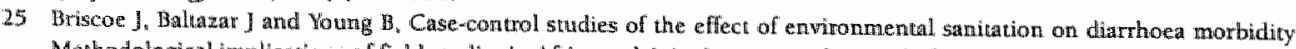
Menhadological implications of field studies in Africa and Asia, Intenational journal of Epidemiology 1988; 17(2):441-447.

26 Mertens TE, Fetuando MA, Cousens SN, at Childhood diarthoea in Sri Lanka a case-control study of the impact of improved water sounces, Tropical Medicine and Parasitology 1990; 41:98.104.

27 Merens $T E_{n}$ Jaffar 5 . Femando $M A_{4}$ Cousens $S N$ and Feachem RG, Excreta disposal behaviour and latrine ownership in retanon to the risk of childhood dianthoea in Sri Lanka, International Journal of Epidemiology 1992; 21:1157-11.648

28 Kunght. SM, Toodaygu W, Caique WC, et al, Risk factors for the transmission of diarthoea in children: A case-control study in tural Malaysia, Intemational Joumal of Epidemiology 1992; 21:812-818.

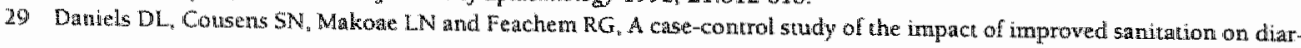


Thoea morbidity in Lesorho, Bulletin of the World Healh Organigariom, $1900,68: 45-463$.

30 Young $\mathrm{B}$ and Briscoe $]$. A case-commol swidy of the effect of enwronmental sanitation on diarthoed morbidity wn Malawi, Joumal of Epidemiology tand Community Health 1948; $42.83-88$.

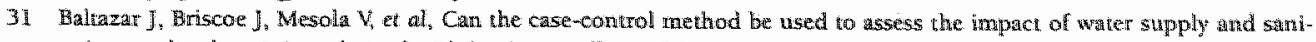
tation on diarthoea? A study in the Philippines. Bulletin of the World Health Organization 1988; $66: 627-695$.

32 Daliazar JC, Tig. IV and Tempongko SB, Hygiene behaviour and hospitalized severe childhood diarthoea: a case-con. trol study, Eulletin of the World Health Otganization 1993; 71:323-328.

33. Gorter AC, Sandiford P. Davey Smith G and Pauw JP, Water supply, sanitation and dinrthoeal disense in Nicaragua: Results From a case-control study, International Joumal of Epidemiology 1991; 20:527.533.

34 Victora $C G$, Smith $\mathbb{P G}$, Vaughan JP, et al, Water supply, sanitation and thousing in melation to the risk of infani morulify from diarthoea, Intenutional Jowrmal of Epidemiology 1988; 17:651-654.

35. Driscoe J. Akin J and Guilkey D. People are not passive acceptors of threats to health: Endogemeity and its consequences. International Jowmal of Epidemiology 1990; 19:147-153.

36 The Cebu Study Team, Underlying and proximate determinants of child health: The Cebu Longitudinal health and nutri. tion study, American Joumal of Epidemiology 1991; 133:105-201.

37 Estey SA and Habich JP, Epidemiologic evidence for health benefits from improved water and sanitation in developing countries, Epidemiologic Reviews 1986: 8:117-128.

36 Esrey SA, Potash JB, Roberts L and Shil C, Effects of improved water supply and sanitation on sascariasis, diarrhoea, diracunculiasis, hookworm infection, schistosomiasis, and trachoma, Bulletin of the World Health Organization 1991; 69:609. 621.

39 Aziz KMA, Hoque BA, Huttly SRA, et al, Water 5upply. Sanitation and Hygiene Education, Report of a Health Itripact 5 tudy in Mizapur, Bargiadesh, Water and Sanitation Report Series of the UNDP-World Bandk Water and Sanitation Program 1990; 1.

40 Hoque BA, Juncker I, Sack RB, Ali M and Aziz KMA. Sustainability of a water, sanitation and lyygiene educatlon project in rural Bangladesh: a 5year follow-up, Bulletin of the World Health Organization 1996; 74:431 437.

41. Esrey SA, Water, waste, and well-being; a multi country study, American Joumal of Epidemiology 1996; $143: 608.623$.

42 Wamberslice ] and Briscoe Jn, Environmental interventions in developing councries: interactions and their implications, American Joumal of Epidemiology 1995; 141:135- 144.

43 Zeng sui W/, Shepard DS, Yun-cheng $Z$, et al, Reduction of enteric infectious disease in rural China by prowiding deep-well tap water, Wullet in of the World Health Organization $1989 ; 67 ; 171-180$.

44 Mahfouz AAR, Abdel-Moneim M Al-Erian RAG and Al-Amari OM, Impact of chlorination of water in domestic stomage tanks on childhood diarthoea: a community trial in the rural areas of Saudi Arabia, Jow rmal of Jropical Medicine and Iy gitene 1995; $98: 126 \% 130$.

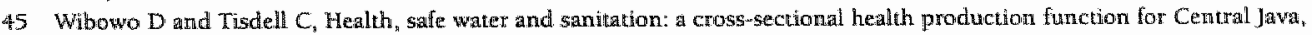
Indonesia, Bulletin of the World Health Organization 1993; 71:237-245

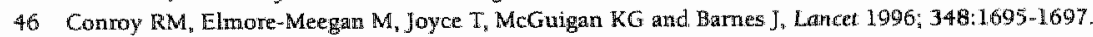

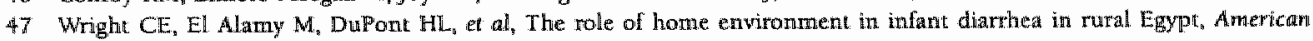
Journal of Epideniology 1991; 134:887-894t.

48 Hutly $5 R A$, Blum. D, Kirkwood BR, et al, The epldemiology of acute diarthoes in a rural community in imo State, Nigerix,

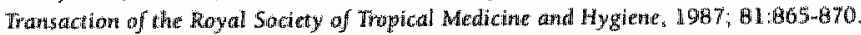

49 The Imo State Evaluation Team, Evaluating water and sanitation projects: lessons from Imo State, Nigeria, Heallh Pollay arud Planning 1989: A:40-49.

so Blum D. Emeh RN, Huttly SRA, eft al, The Imo State (Nigeria) drimking water supply and samitation project. 1 . Deseriptiont of the project, evaluation methods, and impact on interwening variables, frotisactions of the Royal society of Tropical Medicine and Hygiene 1990; $84,309-315$.

51 Hutuly SRA, Blum D, Kirlkwood BR, et al. The Imo State (Nigeria) drimking water supply and sanitation project, 2. Irmpact on dracunculiasis, diarthoea and nutritional status, Transactions of the Royd Society of Tropical Medicine and Hyginte 1.990 ; 84:316-321.

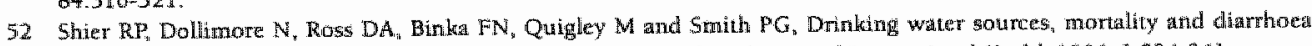
morbidity among young children in Northern Ghana, Tropical Medicine and International Health 1996; 1:334-341.

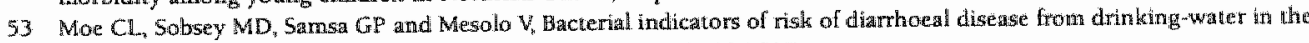
Philippines, Bulletin of the Wotld Health Organization 1991:69:305-317.

54 Trivedi BK, Gandhi HS and Shukla NK, Bacteriological water quality and incidence of water borne diseases in a rural popwhation, Indian foumal of Medical Science 1971; 25:795-801.

55 Sutomo 5 and Tilden $\mathrm{R}$, Water supply and sanitation are good predictors of diarthea Water supply and diarrheall digease in rural areas of Indonesia, Bul Peneliti Kesehat 1987; 15:1-14.

56. Manun'ebo MN, Haggery PA, Kalengaie M, Ashworth A and Kirtwood BR, lnhuence of demographic, sociteconomic and

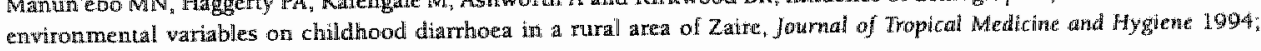
$97: 31-38$

$5 \%$ VanDerslice ]. Popkin B and Briscoe 1. Drinking-water quality, sanitation, and breassi-feeding: their interactive eflects on 
infiant heath, Bulletin of the World Health Organization: 1994; 72:589-601.

58 Dworkin MS, Goldman DP, Wells IG, Kobayashi JM and Herwalid BI, Cryptosporidios is in Washington State: an ontbreak associdted whith well water, Journal for Irffectious Diseases 1996; 1746, 1372-1376.

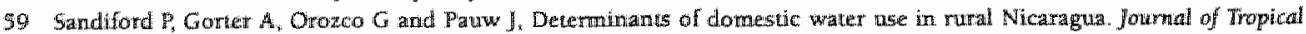
Medicine cind Hygreme 1990; $93 \cdot 383-389$

60 Amedon AM, Recent developments in hygiene behaviour research. an emphassis on methods and meaning, Iropical Adicine and Intemational Heath 1996; 1:171-182.

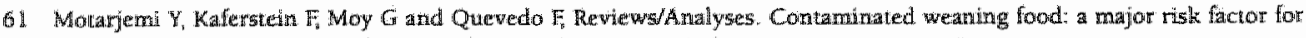

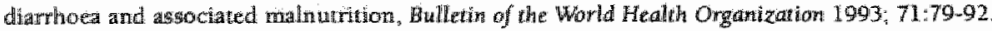

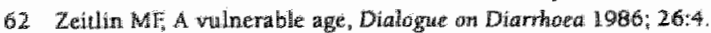

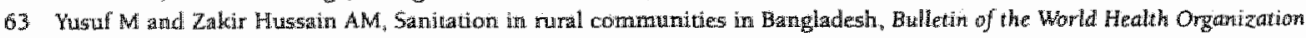
1990; 68:619-624.

64. Lindskog $U_{1}$ Lindskog $P$ and Wall 5 , Water supply, sanikation and health education progranmes in develloping covntries: Problems of Evaluation, Scandinawian Joumal of 5ocial Medicime 1987; 15:123-130

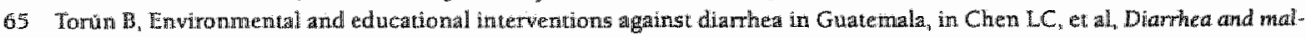
mutrition interactions, mechanisms and interventions. New York: Plenum Press 1982: 235 266.

66 Muller M, Machin Sanchex and Suswillo RR, Evaluation of a sanitation programme using eggs of Ascaris lumbricoides in housetold yard solls as indicators, Journal of Tropical Medicine Hygiene 1989:92:10-16.

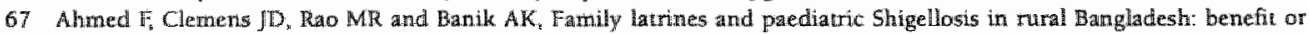
riske? Intemational Joumal of Epidemiolody 1994, 23:856-862.

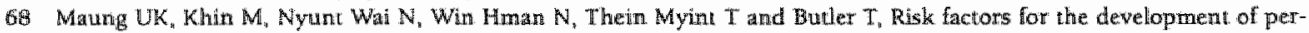

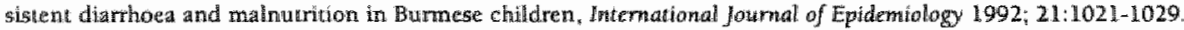

69 Han AM and Moe $K$, Household faecal contamination and diarthoe risk, Joumal of Tropical Medicine and Hygiene 1990 ; $93: 333-336$.

70 Alam and Wai $L$, importance of age in evaluating effects of matemal and domestic hygienc practices on diamboea in rural Bargladeshi children, Journal of Dianhoeal Disease Research 1991; 9(2):104 110 .

71 Jinadu $M K$, Olusi $S \mathrm{O}$, Agun $I 1$ and Fabiyi $A \mathrm{~K}_{\mathrm{v}}$ Childhood diarrhoea in rural Nigeria. 1. Studies on prevelence, mortality and socio-environ mental factors Jound of Didmoeal Disease Rescarch 1991; 9:323-327.

72 mukenya GB and Nwokolo $\mathbb{N}$, Compound hygiene, presence of standpipe and the risk of childhood diarhoca in an turbam settlement of Papua New Gruinea, International Joumal of Epidemiology 1991; 20:534-539.

73 Baltazar JC and Solon PS, Disposal of faeces of children under the two years old and diarthoea incidence: A case-conirol Sindy, Imtermational Jourmal of Epidemiology $1989 ; 18(S 12): 516-519$.

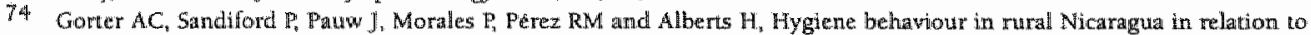
diarrhoea, accepted for publication in the Intemational Joumal of Epidemiology.

75. Hertz E, Hebert J and Landon J, Social and enwironmental factong and life expectancy, infant mortality and maternal moriality rates: results of a cross-national comparison, Social Stience and Medicine 1994; 39:105-114.

76. Cairncross $\mathrm{S}$, Blumenthal, $\mathrm{U}$, Kolsky $\mathrm{P}$, Moraes $\mathrm{L}$ and Tayeh $\mathrm{A}$, The public and domestic domains in the transmission of disease, Tropical Medicine and International Health 1996; $1: 27-34$.

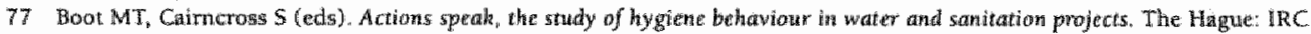
International Water and Santation Centre, London School of Hyghe and Tropical Medicine, 1993.

78 Caincross 5 , Developing evaluation guttelines for studytrig bygiene practices, waterlines 1991; 10:2-5.

79 Cousens $S$, Kanki B, Joure 5, Diallio I and Curtis V, Reactivity and repeatability of hygiene behaviour: structured obsterva-

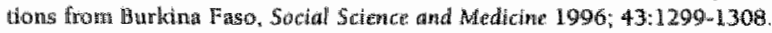

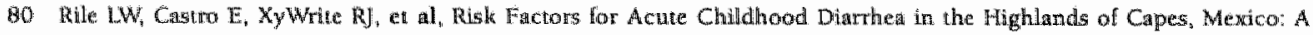
Strategy for Intervention. Bulletin of the Panamerican Health orgamization 1990; 24:210-216

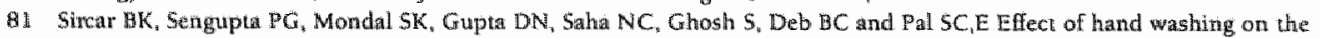

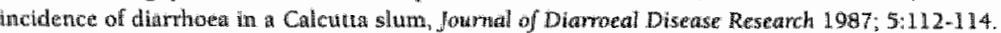

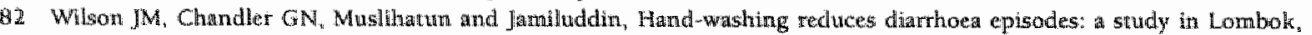

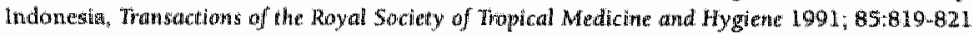

83 Alwa N, Predictors of diarhoea in young Bangladeshi children, joumal of Tropical Pediatrics 1995; 41:278-280.

84 Hoque BA, Malhalatabis D. Alar MA and Islam MS, Post-defecation hand washing in Bangladesh practice and efficiency perspectives, Public Hedih 1995; 109:15-24.

85 Shahid NS, Greenough WB, Samadi AR, Huq Ml and Rahman N, Hand washing with scoap reduces diarthoea and spread of bacterianl pathogerse in a Banghadesh village Jownal of Diarthoeai Disease Research 1996; 14:85-89.

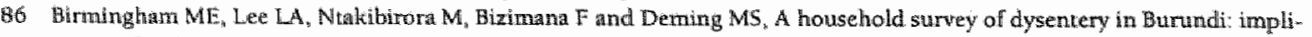
cations for the current pandemic in sub-Saharan Africa, Bulletin of the World Heal horganization 1997; 75:45-53.

97 Omotade OO. Kayode CM, Adeyemo AA and Oladepo O, Obserwations on hand washing practices of mothers and enwronmenal conditions in Ona-Ara Local Govermment Anea of Oyo State, Nigeria, Jahrnal of Diamhocal Disease Rescarch $1995: 3: 22: 4228$ 
Q8 Laborde Dj, Weigle KA, Weber DJ and KotchJB, Effect of fecal contamination on diaratheal ulmess rates in day-care cert.ters, Amterican Joumal of Epidemiology $1993 ; 138: 243-255$

89: Kallenthaler EC and pinfold JV Microbiological methods for assessing hand wastwing practices in hygiene behawiour stud. ies, Joumal of Tropical Medicine and Hygiene 1995; 98:10 - 106.

90 Kaltenthaler EC, Elsworth AM, Schweiger MS, Mara DD and praunthole DA, Faecal contamination on childrens hands and envitronmental surfaces in primary schools in Leeds. Epiderniology and Infection 1995; 1 15:527-534:

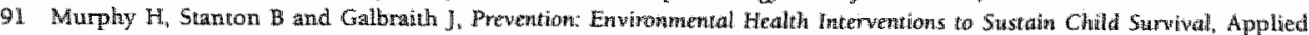
study No.3, Environmental Heath Project, prepared for the Office of Health, and Nutrition, US Agency for Imternational Development (EHP activity $127-\mathrm{CC}$ ), June 1996

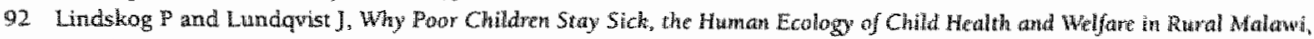
Scandinavian Institute of African Studies, Uppsala 1989; Reseanch Repori No 85.

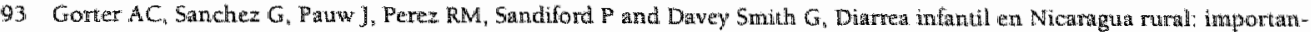
cia de comprender las creencias y practicas medicas tradicionales. Biolein de la Oficina Samitaria Pamamericana, 1995; $119 \cdot 377-390$

94 Kalterthaler EC and Drasar BS, The study of hygiene behaviour in Botswana: a combination of qualitative and quantitiative methods, Tropical Medicine and International Health 1996; 1:690-698.

95 Curtis $V$, Cousens $S$, Mertens $\mathbb{T}$, Traore $E$, Kanki $B$ and Diallo I, Structured observations of hygiene buhaviours in Burkinat Faso: validity, variability, and utility, Bulletin of the World Health Onganization 1993; 71:23,32.

96 Ahmed Nu, Zeilin MF, Reiser AS, Super CM and Gershoff SN, A longitudinal study of the impact of behavioural chinge intervention on cleanliness, diarrhoeal morbidity and growth of children in rural Bangladesh, Social Science and Medicine $1993 ; 37: 159-171$.

97 Dikassa L, Mock N, Magnani R, Rice J, Abdoh A, Mercer D and Dermand W, Matemal behavioural risk factors fior severe childhood diarnhoeal disease in Kinshasa, Zaire, International Joumol of Epideniology 1993; 22:327-333.

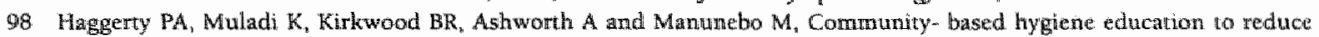

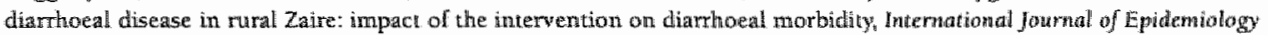
1994; 23:1050-1059.

99 Gilman RT, Marquís GS, Ventura G, Campos M, Spira W and Diaz F Whater cost and awailability: key determinants of family hygiene in a Pernvian Shamtytown, American Joumal of Public Health 1993; 83:1554-1558.

100 ZeEthin MF, Ahmed NU, Beiser AS, Zeitlin JA, Super CM and Guldan GS, Developmential behavioural, and envirommental risk factors for diarrhoea anong rural Bangladeshi children of less than wo years, journol of Dianhoeal Disedise kesearch $1995 ; 13: 99-105$

101 Picketing H, Social and environmental factors associated with dianthoea and growth in young children: child health in urban Africa, Social Science and Medicine $1985 ; 21: 121-127$.

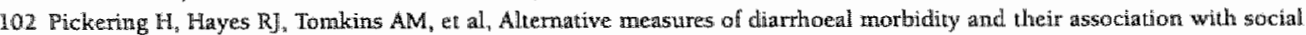
and erwironmental factors in urban children in The Gambia, Transactions of the Royal Soctety of Tropital Medicine and! Hygiene $1987 ; 81: 853-859$.

103 Bruch HA, Ascoli W, Scrimshaw NS and Gordon JE, Studies of diartheal disease in Central America. W. Environmental factors in the origin and transmission of acute diarneal discase in four Guatemalan villages, American Journal of Tropical Mfedicine and Hygiene 1963; 12:567-579.

104 Pinfold JW, Faecal contamination of water and fingertp-rinses a a method for evaluating the effect of Low cost watler supply and sartitation activities on facco-oral disease transmission. Il. A hygiene intervention sudy in rurial north-east Thailand, Epidemiology and Infection 1990; 105:363-389.

105 Rahman M. Rahaman MM, Wojtyniak B and Aziz KMS, Impact of environmental sanitation and crowding on anfant mor tality in mural Bangladesh. The Lancet 1985; July 6.

106 Kooptana J5, Diwrthea and school toilet hygiene in Cali, Colombia, American Journal of Epidemiology 1978; 107:412-at20

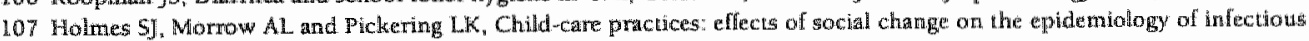
disases and antibiotic resstance, Epidemiologic Reviews $1996 ; 18: 10-28$. 
Chapter 4

The diarrhoeal disease risk factor studies of water supplies, sanitation and hygiene in Villa Carlos Fonseca 


\section{Section 4.1}

\section{Determinants of drinking water quality in rural Nicaragua}

P. Sandiford ${ }^{1}$, A.C. Gorter ${ }^{2}$, G. Davey Smith $^{3}$ and J.P.C. Pauw ${ }^{4}$

Published in Epidemiology and Infection, 1989; 102:429-438 


\section{Summary}

One hundred and fifty-three water samples from rural Nicaragua were examined for the presence of faecal coliforms during both wet and dry periods. A linear model was fitted by analysis of covariance with the logarithm of the faecal coliform count as the dependant variable. As expected, traditional water sources were grossly contaminated at all times whereas piped water sources were much cleaner. Hand-dug protected wells had significantly higher levels of faecal contamination than unprotected riverside wells and springs during the dry season. The possible reasons for this unexpected finding are discussed. A close association between rainfall and faecal contamination was demonstrated but the effect of rainfall depended on the type of water source. An association between water quality and the size of the community served by the source was also detected. The finding that stored water was usually more contaminated than fresh water samples is consistent with the results from other studies. Since it is unusual for water quality to be inversely correlated with accessibility, this study site would be suitable for investigating the relative importance of water-borne versus water-washed transmission mechanisms in childhood diarrhoea. 


\section{Introduction}

It is generally believed that the use of inadequate water supplies relates closely to the high incidence of childhood diarrhoea in most developing countries, in spite of the difficulties that have been encountered in measuring this relationship (Blum \& Feachem, 1983; Esrey \& Habicht, 1986). Diarrhoea, like all faecal-oral diseases, can be transmitted by both water-borne or water-washed mechanisms (Cairncross \& Feachem, 1983). Water-borne transmission occurs when the pathogen is in water that is drunk by a person or animal which may then become infected. Improvements in drinking water quality will reduce water-borne transmission. In water-washed transmission, domestic and personal hygiene plays a key role and therefore disease is prevented by increasing the quantity of water used for hygienic purposes, irrespective of the quality of that water (Cairncross $\&$ Feachem, 1983). It is still not known which of these transmission mechanisms is more important for diarrhoea (Feachem et al. 1978). Although most work suggests that improvements in water quantity are more likely to reduce the incidence of diarrhoea than improvements in microbiological quality (Esrey \& Habicht, 1986; Briscoe, 1978; Esrey et al. 1985; Freij et al. 1978; Schliessman, 1959), at least one study has shown a greater benefit from water quality improvements, especially in younger children (Hebert, 1984).

The relative importance of these two transmission mechanisms has major implications in the design and construction of rural water supplies. Although water supply projects often increase both the quality and quantity of water used, such interventions are usually very expensive. It is now becoming clear that it is beyond the economic ability of most developing nations to provide sophisticated water supplies to entire populations (Schneider $e t$ al. 1978; Walsh \& Warren, 1979). On the other hand, there are several relatively inexpensive interventions which might independently improve either water quality (e.g. simple chlorinators or filtration systems) or increase water consumption (e.g. hand pumps and well digging). This paper presents the results of a study of the microbiological quality of drinking water sources in rural Nicaragua which will be used in the anallysis of a case-control study of the relationship between water quality, water accessibility and childhood diarrhoea.

\section{Materials and methods}

The study site was Villa Carlos Fonseca, a rural municipality on the Pacific coastal lowlands with a population of approximately 20000 spread amongst 35 communities. A population-based survey of the zone was made from a random sample (stratified by community) of $244(6.7 \%)$ of the households on record with the Ministry of Internal Commerce whose consumer census is the most up-to-date population census available. Ministry officials estimate its completeness to be approximately $95 \%$. Each of the houses selected was visited by a trained interviewer who interviewed the female head of household. The water supply for the household was ascertained and inspected. It was thereby possible to classify the different types of water source and to estimate the proportion of the population using each of them. 
Sites for monthly water-sampling were chosen at random for each type of water-supply identified in the population-based survey. Additional water samples were also randomly selected at different times to provide sufficient statistical power to test diverse hypotheses. Water samples were collected in sterile glass bottles and transported to the laboratory in a cold box containing freezer packs. In all cases; analysis by the multiple tube method was commenced within 8 hours of collection. The glassware and media were sterilized the day before in an autoclave at $121^{\circ} \mathrm{C}$ for 15 minutes. Five sets of five tubes were inoculated with $10 \mathrm{ml}, 1 \mathrm{ml}, 0.1 \mathrm{ml}, 0.01 \mathrm{ml}$ and $0.001 \mathrm{ml}$ of each sample. Samples were incubated first in lauryl tryptose broth (Gibco Laboratories no. 28300) for 24 hours at $37^{\circ} \mathrm{C}$ in a warm-air incubator. Positive tubes were confirmed by inoculating a further set of tubes containing E. Coll medium (Difco Laboratories no. 0314-01-0) and incubating these at $44.5^{\circ} \mathrm{C}$ in a water-bath for an additional 24 hours. Most probable number faecal coliform (FC) counts were calculated from the proportion of tubes at each dilution confirmed as positive, that is gas-producing (APHA, 1981).

A linear model was fitted by analysis of covariance with the natural logarithm of the FC counts as the dependent variable. The independent variables considered were; type of water source, recent rainfall, time of sampling (morning or afternoon), presence of a windlass on protected wells, whether the sample was 'fresh' or stored and size of the community from which the sample was taken. The latter was considered large if communities were of greater than 1500 inhabitants. It was thought that this might be an adequate surrogate for population density, especially since the houses in the communities of this size were arranged in street blocks whereas smaller communities consisted of a single main road with occasional side streets. Pairwise comparisons were made using the Tukey-Kramer studentized range test to control for type $\mathbb{I}$ experimentwise error (Einot \& Gabriel, 1975).

\section{Results}

Trained field-workers were successful in interviewing females heads of household at 240 (98\%) of the homes selected. Water supplies were classified into five main types: domiciliary connections, public standpipes, protected wells, unprotected wells and springs, and rivers or streams. The domiciliary connections in one area functioned for less than 4 hours per day, but the rest provided water virtually all day and were quite reliable. All public piped water came from boreholes, there being three different boreholes providing water to standpipes and another two different boreholes suppling the networks of domiciliary connections. The protected wells were hand-dug, generally to a depth of about 4 metres, and were surrounded by a precast concrete headwall. As a rule they were partially lined by stone which was sometimes joined to the headwall by mortar. Water was drawn in a bucket on a rope supported by a crossbar and pulley. Many were roofed and some had a windlass, but none incorporated a drainage apron. They were usually privately owned and sited in the yards of peoples homes. Springs and unprotected wells were shallow holes in the ground usually adjacent to rivers in which water accumulated either by filtering up from below or by seepage from above (or both). They were often carved out 
from sandstone. As the springs and unprotected wells formed an indistinguishable continuum they will both be referred to as unprotected wells. None of the water supplies were treated.

The proportion of houses with each type of water source is shown in Table 1 together with the number of water samples taken from each. The number of samples taken during the wet period is low due to the drought in 1986 which greatly reduced the length of the wet season.

Table 1. Population and water sample distribution by water source

No. of samples taken

\begin{tabular}{lccccc} 
Water source & $\begin{array}{c}\text { Population } \\
\text { served (\%) }\end{array}$ & $\begin{array}{c}\text { No. of } \\
\text { sources tested }\end{array}$ & $\begin{array}{c}\text { Wet } \\
\text { period }\end{array}$ & $\begin{array}{c}\text { Dry } \\
\text { period }\end{array}$ & Total \\
\hline Rivers and streams & 2.5 & 5 & 3 & 16 & 19 \\
Unprotected wells and springs & 26.3 & 13 & 6 & 25 & 31 \\
Protected bucket wells & 52.5 & 15 & 5 & 37 & 42 \\
Protected wells with pumps & 2.0 & 7 & 0 & 11 & 11 \\
Public standpipes & 1.7 & 3 & 3 & 21 & 24 \\
House connections & 15.0 & 7 & 3 & 23 & 26 \\
Total & 100 & 50 & 20 & 133 & 153 \\
\hline
\end{tabular}

The complete model fitted is shown in Table 2, together with the significance level for each variable. Only those interactions found to be statistically significant are shown. In fitting the model, each monthly measurement of a single source is considered as an independent sample as it was noted that there was almost as much water quality variation for

Table 2. Parameters included in the water quality model

Variable name (and type)

Main effects

Type of water source * * (categorical)

Rainfall period * (dummy)

Community size * (dummy)

Storage **: (dummy)

Interactions

Type of water source

by rainfall * *
Range of values

$1=$ rivers/stream

2 =unprotected wells

$3=$ protected bucket wells

$4=$ protected wells with pumps

$5=$ public standpipes

$6=$ house coninections

$\mathrm{D}=\mathrm{dry}$ period (July-December)

$1=$ wet period (mid-May-lune)

$a=5 m a l l i(\leq 1500$ inhabitants)

$1=$ large ( $>1500$ inhabitants)

$a=$ tresh sample

$1=$ sample from storage vessel 
repeated samples from the same site as there was for different samples from different situes.

Geometric mean FC counts of each water source for the wet and dry periods are shown in Table 3. All mean values quoted are least squares means" which adjust the estimates to allow for the unbalanced design. There were not enough samples taken during the wet period to permit pairwise comparisons but the quality of piped water is obviously much better than that of traditional sources. It would be interesting to obtain sufficient samples during this period to test whether protected wells are less contaminated than the unprotected sources. For the dry period, the distribution of $F C$ counts by water source is plotted in Fig. la. Pairwise comparisons were made using the Tukey-Kramer studentized range test (Fig. 1 b).

Table 3. Geometric mean faecal coliform counts by water source for each weather period

\begin{tabular}{lrr} 
Water source* & Wet period & Weather period \\
\hline Rivers and streams & 14700 & 11100 \\
Unprotected well and springs & 15250 & 179 \\
Protected bucked wells & 4300 & 1410 \\
Protected wellsw with pumps & No samples taken & 22 \\
Public standpipes & 19 & 11 \\
House connections & 2 & 0 \\
\hline
\end{tabular}

" Does not include storet: water samples

The nature of the water source/rainfall interaction can be seen in Table 3 . While the quality of water drawn from springs and unprotected wells improves strikingly in the dry period, the quality of other sources did not change greatly. Unprotected wells and springs seem to be more contaminated than protected wells during the wet period, but they are significantly less contaminated during the dry period.

Table 4 shows for each type of water source how the quality depends on the size of the community from which the water was sampled. The quality of piped water sources does not depend on the community size but it appears that the quality of traditional water sources does. In fact for piped water, quality seemed to improve in the larger communities but this difference is unlikely to be signilicant. 
Rivers and streams

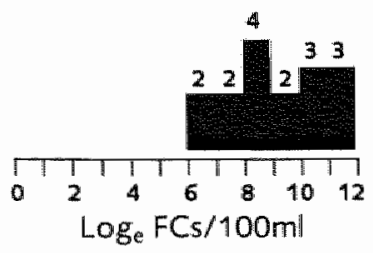

Protected bucket wells

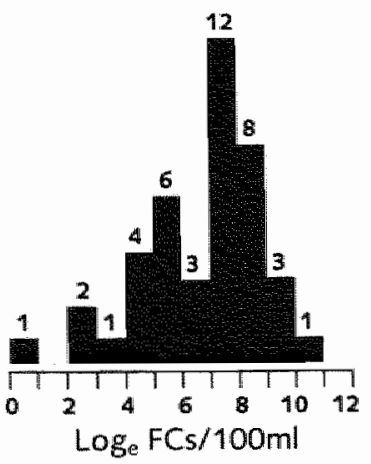

Public standpipes

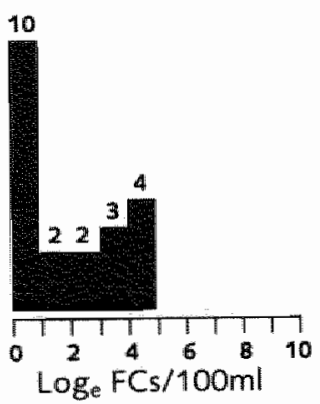

Unprotected wells and springs

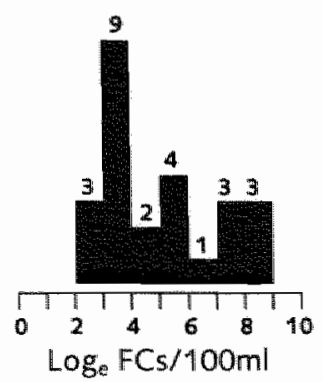

Protected wells with pumps

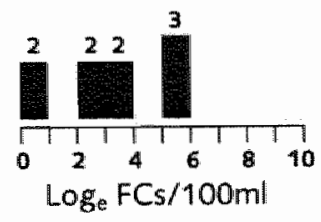

Domicilliary connections

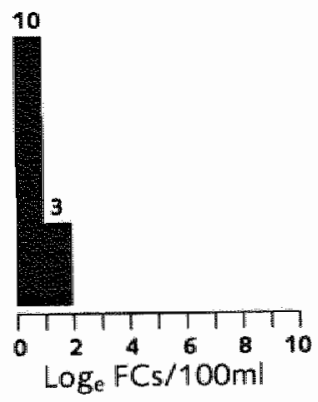

Fig. 1(a). Histograms of geometric mean faecal colform counts by water source for the dny period. 
Table 4. Geometric mean faecal coliform counts by water source and community size

\begin{tabular}{lrrr} 
Water source* & Large & Community size + & Small \\
\hline Rivers and streams & 27800 & 5760 \\
Unprotected wells and springs & 767 & 83 \\
Protected bucked wells & 450 & 977 \\
Protected wells with pumps & 16 & 39 \\
Public standpipes & No samples taken & 7 \\
House connections & 0 & 5 \\
\hline
\end{tabular}

t There were 3 communities considered to be large and 16 commurities dassified as smal.

- Does not include wet period or stored water samples.

As indicated in the Table 2, water stored in homes is significantly more contaminated than water drawn directly from the source. The geometric mean $\mathrm{FC}$ count of stored water from domiciliary connections was 94 compared with 0 for the unstored samples. There were not enough samples to determine how domestic storage affects water drawn from other sources.

Of the 42 samples taken from protected bucket wells, 6 were taken from wells incorporating a windlass. It was hypothesized that the presence of a windlass on a protected well would reduce the contamination since the rope does not drag on the ground. In fact, the

Water source

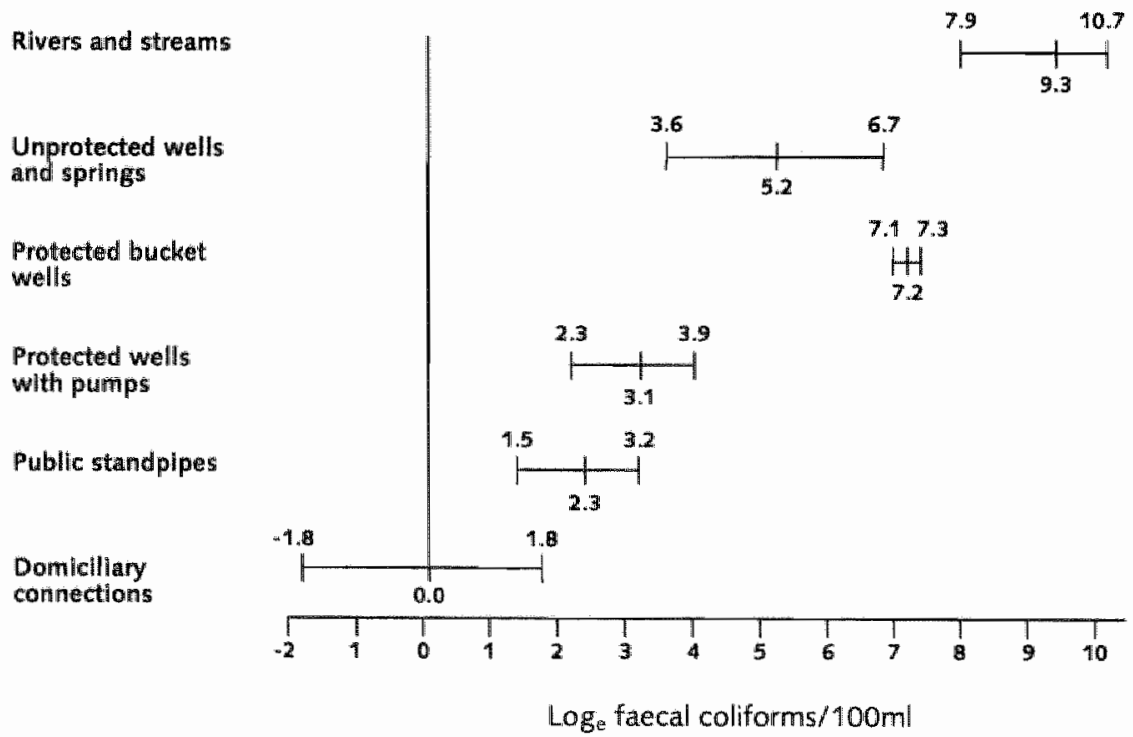

Fig. 1(b) Geonetric mean faecal coliform counts with $95 \%$ confidence limits by water source for the dry period. N.B. Does not include wet period or stored water samples. 
(least squares) geometric mean FC count of those wells with a windlass was $1420 \mathrm{com}$ pared with 1100 for those without $(P=0.77)$, though caution should be excercised in interpreting this result owing to the small number of samples from wells with a windlass.

\section{Discussion}

In many ways this analysis confirms the results obtained from several other studies in that the quality of water was found to depend greatly on the type of water source from which it is drawn, the weather prior to the time of sampling, and whether it was taken directly from the source or from a storage vessel in the home (Freij et al. 1978; Schneider et al. 1978; Shiffman et al. 1978; Young Briscoe, 1987; Muhammed \& Morrison, 1975; Torun, 1982; Barrell \& Rowland, 1979). It does not pretend to take into account all the variables that have been considered in other work (e.g. soil type, well diameter, depth, distance to the nearest latrine, etc.) and there are other variables which might affect the water quality of domestic wells which have not generally been considered in this type of study (e.g. literacy, presence of domestic animals, etc.).

As in other studies, there is a very high level of contamination in the traditional water sources. The unexpected finding was that protected domestic wells were significantly more contaminated than unprotected riverside wells and springs during the dry period. Most studies of rural water quality have found that protected sources are generally less polluted than unprotected sources. Tomkins et al. (1978) and Wright (1982) both found that protected wells were less contaminated than unprotected wells during the dry season. Isely (1978) and Lehmusluoto (1987) also both found protected springs to be less contaminated than unprotected springs though in the latter study the difference was not statistically significant. On the other hand in Nigeria (Blum et al. 1987) found significantly lower faecal streptococci counts in ponds and unprotected springs than in traditional wells during the period of lower contamination, but it was not clear how well protected their 'traditional wells' were.

There are two possible explanations for the observed difference in water quality between the protected and the unprotected sources. One is that the protected wells are exposed to greater faecal contamination in spite of their protection. The other is that a structural difference tends to make the unprotected water sources less polluted during the dry period.

The first hypothesis is supported by the fact that protected wells in this part of Nicaragua are almost all privately owned and located close to houses where children and domestic animals deffecate openly. Also, $72 \%$ of these wells are in homes with latrines although most of them are situated at least 10 metres from the well (Sandiford et al. unpublished results). In contrast, the unprotected wells are usually dug beside rivers and streams 50 100 metres from the nearest houses.

It would seem unlikely that a structural difference could explain why unprotected wells have lower FC counts during dry weather than protected wells. Protected wells all have 
parapets at least one metre high, they usually incorporate crossbar and pulley, and often have a roof, a cover, and/or a windlass, while unprotected wells are much shallower and do not have parapets. One important feature of the unprotected well though, is the small volume of water which it holds (usually only $20-40$ litres). As each generally serves several families, the high demand for water creates a rapid tumover which would readily eliminate externally introduced contaminants. It has been observed that some families empty these wells and allow them to refill each time they collect water (Pauw et al in preparation). The protected wells on the other hand, contain a much greater volume of water which is emptied by their owners only once or twice a year.

Though more research is needed to determine the relative importance of these two explanations the quality of water from protected wells does appear to be more variable than that from unprotected wells (Fig. la) suggesting that certain factors in the domestic environment may give rise to contamination. Not all protected wells had higher counts than unprotected wells.

It is notable that the presence of a windlass appeared to have no effect on the water quality of domestic wells. Those with an electric pump to extract the water were significantly less contaminated than those using a bucket and rope, in spite of being virtually identical in other respects. It is possible that much of the contamination of protected bucket wells originates from water spilt around the parapet seeping back into the well. Pumps which pipe water away from the well clearly avoid this problem. The complete absence of drainage aprons in the Nicaraguan wells studied makes them rather susceptible to this type of pollution (Cairncross \& Feachem, 1983).

The poor quality of springs and unprotected wells during periods of rainfall is probably due to run-off into the wells. Similar problems have been noted with unprotected springs in other studies (Moore, de la Cruz \& Vargas-Mendez, 1965; Barrell \& Rowland, 1979). It would be interesting to investigate the impact of spring protection during the rainy periods. A modest drop in the quality of domestic well water was also noted with the rainlall which is consistent with other studies (Voelker \& Heukelekian, 1960; Barrell \& Rowland, 1979).

Community size was found to be significantly associated with water quality and this was particularly noticeable in the rivers, springs and unprotected wells. An association between water contamination and proximity to towns has previously been reported (Muhammed \& Morrison, 1975: Bradley \& Emutwon, 1968) but only for rivers and streams. It may be that the more families using a source, the greater the potential for contamination. In lact the mean number of houses using unprotected wells and springs in large communities is 4.2 compared with 2.9 in smaller communities (Sandiford $\&$ Gorter, unpublished results). Communty size did not seem to affect the quality of protected well water where an average of 2.2 families are served by each well in both small and large communities. 
This study has shown that water quality in protected wells is not always better than that in unprotected wells, though the reasons are not entirely clear. More research is needed to determine the most cost-effective means of protecting hand-dug wells. If cheap but effective structural modifications to traditional water sources can be found, these may prove to be appropriate interventions for the prevention of water-borne illinesses.

\section{Acknowledgements}

This study was supported by the Diarrhoeal Diseases Control Programme of the World Health Organization and the New Zealand Medical Research Council. The authors would like to thank the staff of the Instituto Nicaraguerse de Acueductos y Alcantarillados for their encouragement and assistance and in particular to $\mathrm{Mr} \mathrm{J}$. Delgadillo and $\mathrm{Mr} S$. Tercero. We would also like to thank Dr S. Cairncross and Dr P. Davis for their helpful comments and suggestions. George Davey Smith is a Wellcome Fellow in Clinical Epidemiology.

\section{References}

APHA (1981). Stondard Methods for the Examination of Water and Wastewater Washington: American Public Health Association, American Water Works Association and Water Pollution Control Federation.

Bartell, R.A.E. \& Rowlank, M.G.M. (1979). The telationship between rainfall and well water pollution in at West African (Gambian) village. Jourmal of Hygiene 83,143 m 150

Blum, D. Feachem, R.G. (1983). Measuring the impact of water supply and sanitation investments on diarrhoeal diseases: Problems of methodology. International Journal of Epidemiology 12,357.365.

Blum, D.,Hutly, S.R.A., Okoro, J.I., Akujobi, C., Kirkwood, B.R. \& Feachem, R.G. (1987). The bacteriological quality of traditional water sources in mortheastern Imo State, Nigeria. Eppidemiology and Infection 99,429-437.

Bradley, D.). \& Emurwon, P. (1968). Predicting the epidemiological effects of changing water sources; : Part I. A quantitative approach. East African Medical Joumal 45, 285 -291.

Briscoe, J. (1978). Role of water supply in improving health in poor countries (with spectial reference to Barngladesh). Americam Jounal of Clinical divitrition $31,2100-2113$.

Caincross, 5. Fe Feachem, R.G. (1983). Envirommental Health Enginecring in the Trapics. An Introductory Text, pp. 4.9. Chichester: Wiley sons.

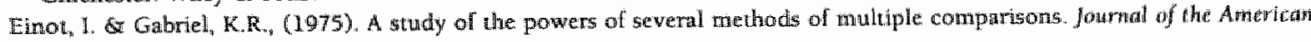
Statistical Association 70, 574 .

Fsrey, 5.A. Feachem, R.G. Hughes J.M. (1985). Interventions for the control of diarhoed diseases among young children improwing water supplies and exccteta disposal facilikies. Bulletim of the World Health Orgatization $63.757-772$.

Estey, SA Habicht, ]. (1986). Epidemiclogic evidence for heallth benefies from improved water and sanitution in developing countries. Epidemiologic Newiews 8, $117-128$.

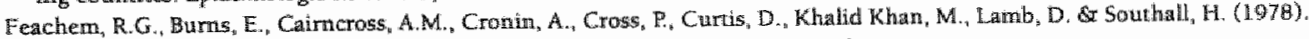
Water, Health and Development: An Interdisciptirary Evaluation. Inondon: Trimed.

Freaj, H., 5terky, $G_{n}$, Wadstrom, I. \& Wall, S. (1978). Child Health and diarthoeal disease iri telation to supply and use of water in African Communities. Prouress in Water Technology $11,49-55$.

Hebert, J R. (1984). Watter quality and water quantity and wasting in South India. Tropicall E Geographite Medicine 36, 375-381.

lsely, R.B. (1978). A communiry orgamization approach to cleam water and waste disposalin Cameroonian williges. Progress in Water Tectonology 11, 109-116.

Lehmusluoto, F. (1987), Sumey on Contamination of Water Sowres and Household Waters as am Integrated Part of Impact Managemeni, pp. 37-39. Uniwersity of Tampere, Finland.

Moore HA, de la Crue $\mathrm{E}$ and Vargas-Mendez $\mathrm{O}$ (1965), Diartheal disease sudies in Costa Rica: IV rhe influence of sanitation. upon the prevalence of intestinal infection and diarneal disease, American Joumal of Epidemiologi, B2:162-184.

Muhammed, S.1. \& Morrison, S.M. (1975). Water quality in Kiambu Distriet, Kenya East Africant Medical Joumal $52,269-276$.

Schliessram, J. (1959). Diarthoeal disease and environment. Bulletin of the World Health Organization 21.381-386. 


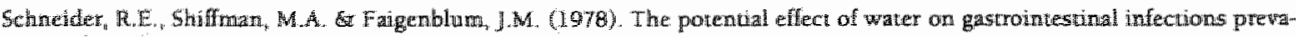

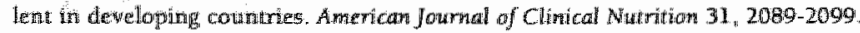

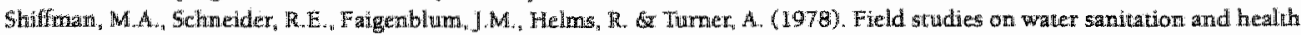
educaton in relation to heallh suaw in Central America. Progress tin Water Technology 11, 143-150,

Tomkins, A.M., Drasar, S.S. Bradley, A.K. Williamson, W.A. (1978). Water supply and nutritonal status in rural Northerm Nigeria, Transactions of the Royal Sociefy of Tropical Medicine and Hygiene 72, 239-243.

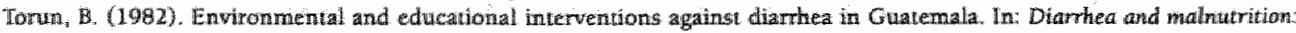
interactions management and inteventions (ed. L.C. Chen and N.S. Scrinshaw), Pp. 235-266. New York: Plemum Press.

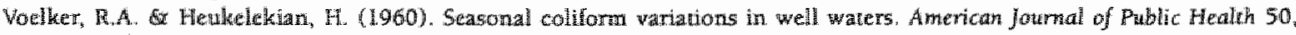
$1873-1881$.

Walsh. I.A. Warren, K, S. (1979), Selective primary health care: An interim strategy for disease control in developing countries. New England foumal of Medicine 301, 967-974.

Wrght, R.C. (1982). A comparison of the levels of faccal indicator bacteria in water and human fateces in a rural area of a tropical developing country (Sierra Leone) Joumal of Hygiene 89, 69-78.

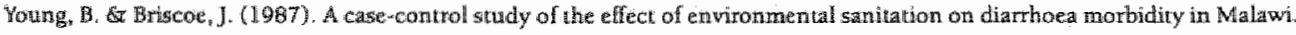
Journal of Epidemilotogy and Community thed th $42,33-88$. 


\section{Section 4.2}

\section{Determinants of domestic water use in rural Nicaragua}

P. Sandiford", A.C. Gorter², J.G. Orozco² and J.P Pauw².

Published in Journal of Tropical Medicine and Hygiene, 1990; 93:383-389

1 Departmeme of International Community Heality, Liverpool School of Tropical Medieine, Liverpmot. LK

2. Programa de lngeneria Ambiental, Uniwersidad Nacionai de Ingeneria, Mansgisa, Nicaragua 


\section{Summary}

In order to investigate the factors affecting domestic water use in rural areas of developing countries, an analysis was performed of water consumption estimates from 1029 different households in Nicaragua collected between May 1986 and December 1988. Eight of the 22 variables hypothesised to be related to per capita domestic water consumption, were included in the final multiple regression model. These were; household size, site of clothes washing, the type of water source, mother's and father's levels of schooling, distance to the water source, wealth, and ownership of cattle. According to this model, a decrease in the distance to the water source from 1000 to 10 metres is associated with an increase in per capita water consumption of $20 \%$. Similarly, families where the mother has 6 years of schooling use $17 \%$ more water than families where the mother has had no formal edlucation. The same difference in the father's schooling is assaciated with $12 \%$ greater per capita water consumption. A better understanding of the factors affecting domestic water use is needed to improve the design of interventions aimed at reducing the transmission of water-washed disease in developing countries. 


\section{Introduction}

It is has now become apparent that the quantity of water used for the purposes of domestic and personal hygiene is an important factor in the control of diarrhoea (and possibly other faecal-oral diseases) (Esrey \& Habicht 1986; Esrey et al.1985; Victora et al.1988; Sandiford 1989). Increasing domestic water use in many settings is believed to be at least as effective in preventing diarrhoea morbidity and mortality in children as improving the microbiological quality of drinking water (Cairncross 1987). In fact, some of the spectacular failures of water supply interventions to improve child health and survival can be attributed to the absence of any significant increase in domestic water consumption by the intended beneficiaries (Kawata 1978; Schliessman 1959).

There is therefore clearly a need to develop water supply and health promotion interventions which raise per capita domestic water consumption and/or increase the prow portion of domestic water used for purposes of domestic and personal hygiene. A review of the published literature revealed a poverty of information on the factors related to domestic water use in rural areas of developing countries.

Given the well-recognised public health importance of childhood diarrhoea in developing countries, such a gap in our knowledge is of some significance. This paper presents an investigation of the variables related to water consumption obtained from a large casecontrol study of diarrhoea performed in rural Nicaragua from May 1986 until December 1988. It is not intended to be a definitive study of all the possible factors which combine to determine behavioural patterns of water use. Rather, it is an exploratory analysis of certain correlates of rural domestic water use, with a view to contributing to the design of health promotion programmes which maximize the quantity of water used for domestic and personal hygiene, with or without structural improvements in rural water supplies.

\section{Material and methods}

The study was carried out in Villa Carlos Fonseca, a rural municipality on the Pacific coastal plains of Nicaragua with a population of approximately 30000 . Children under the age of 5 years who presented with diarrhoea to health facilities in the study zone were matched by age and clinic to children presenting with non-diarrhoeal illnesses (mainly acute lower respiratory tract infections). A total of 1228 episodes of diarrhoea and 1228 control illnesses were recruited to the study. Trained interviewers collected data on a variety of factors from female heads of household at their homes. These included reported daily water consumption, the types of water source, distance from the house to the water source(s), the ownership of cattle and presence of domestic animals, the parents' occupations and levels of education, indicators of socio-economic status, and household size including the proportion of inhabitants under the age of 5.

Water consumption estimates were not collected from houses with piped water as the 
precision of the data was likely to be low. Therefore water consumption figures were available for only 1962 of the 2456 interviews. The selection procedure used for the casecontrol study was such that children could be recruited on more than one occasion so some homes were visited more than once. The 1962 figures for water consumption were thus obtained from a total of 1455 separate interviews, of which 1029 were initial visits and 426 were repeat visits (after an interval of at least 3 months). The repeatability of the mothers' water consumption estimates was assessed by comparing the rates given at the initial visit with those obtained in the repeat interview. Only the first home visits were used in the analysis of the factors relating to domestic water consumption.

Per capita daily domestic water consumption (PCWC) was obtained by dividing total daily water consumption by the number of household inhabitants. The total water consumption was calculated by the computer programme for data entry which multiplied the volume of each water container by the number of times it was filled in a day. The fact that there is little variety in the bucket size used for water collection in Villa Carlos Fonseca made it a simple matter for field workers to estimate the volumes. The result was then tested for association with 22 factors which could potentially influence it, using a linear regression model.

Following the recommendations of MacClure and Willett (1987), the measurement of repeatability for the continuous and ordinal scale variables was evaluated by the intraclass (i.e. within household) correlation coefficient. For indicator variables, repeatability was measured using the kappa score which takes into account the degree of concordance to be expected by chance alone (Fleiss 1981). Negative kappa scores indicate less concordance than that which would be expected by chance. Positive kappa scores suggest better concordance than that expected by chance with kappa scores of 1 representing perfect agreement between the repeated measurements. For dichotomous variables, it is generally accepted that values below 0.40 imply poor repeatability, 0.40 to 0.75 good repeatability, and values ahove 0.75 indicate excellent repeatability (Fleiss 1981). It is important to bear in mind that kappa scores for variables with more than two categories tend to be lower than those for dichotomies. In the statistical analysis, the natural logarithm of daily per capita domestic water consumption $\log (\mathrm{PCWC})$ was used as the dependent wariable in fitting a linear model by analysis of covanance. The transformation was performed in order to make the variance of $\log$ (PCWC) approximately the same for each value of the independent variables and to normalise the distribution of the residuals. The final model was arrived at by stepwise inclusion of the variable which at each stage gave rise to the greatest statistically significant $(P<0.05)$ improvement in the goodness of fit. At the same time, any variable whose exclusion did not significantly reduce the goodness of fit was removed from the model at each stage. Interactions between the hypothesized factors were also assessed for statistical significance. 
Table 1. Repeatability of measurement of the parameters studied.

\section{Variable}

\section{Continuous variables}

Total dally water consumption

Household size

Per capita water consumption

Log (per capita water consumption)

Mother's level of schooling

Father's level of schooling

Distance to the water source

Log (distance to water source)

No. houses sharing water source

No. of under 5-year-olds

Frequency of drawing water*

children

women

men

\section{Indicator variables}

Type of water source

Site of clothes washing

Site of bathing

Presence of a latrine

Literacy of mother

Literacy of father

Mother's occupation $t$

Father's occupation +

Type of flooring in house

Electric power

Domestic animals owned

pig

horse

poultry

cattle

Ownership of land (yes/no)

Drimking water protection
Intracllass Correlation Coefficient

0.57

0.64

0.45

0.44

0.89

0.79

0.65

0.73

0.71

0.51

0.45

0.41

0.44

Kappa score

0.84

0.58

0.59

0.75

0.77

0.67

0.56

0.68

0.74

0.76

0.47

0.57

0.32

0.66

0.60

0.31

- Ordinal varables with three levels corresponding to "usually", 'sometimes: and "newer".

+ These variables each have fiour levels of classifification. All others are dichotomous.

\section{Results}

Table 1 lists the 22 factors hypothesized to be related to PCWC and presents the repeatability estimates for each.

The variables included in the final regression model are shown in Table 2 . Although it was found that PCWC is greater when men contribute to water collection, this variable was not included in the final regression model because it was felt that the involvement 
of men in water collection may be a consequence of high rates of PCWC rather than a cause. None of the interactions tested were found to be statistically significant. In particular, the likelihood of the child suffering from diarrhoea was found to be unrelated to per capita domestic water consumption wether as a main effect or as an interaction term.

Table 2. Variables included in the final regression model of water consumption

\begin{tabular}{lccc} 
Variable & Coefficient & Std error & $t$-Value \\
\hline Household size & -0.0761 & 0.0059 & $12.82^{* * *}$ \\
Site of dothes washing & -0.2461 & 0.0517 & $4.77^{* * *}$ \\
Type of water source & -0.1731 & 0.0472 & $3.66^{* * *}$ \\
Mother's level of schooling (years) & 0.0267 & 0.0083 & $3.22^{* *}$ \\
Father"s level of schooling (years) & 0.0190 & 0.0073 & $2.67^{* *}$ \\
Log (distance to the water source) & -0.0401 & 0.0156 & $2.56^{*}$ \\
Type of flooring in the house & -0.1147 & 0.0503 & $2.28^{*}$ \\
Ownership of cattle & 0.0785 & 0.0386 & $2.04^{*}$ \\
Constant term & 4.0186 & 0.0842 & $47.75^{* * *}$ \\
\hline
\end{tabular}

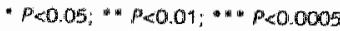

As the dependent variable in the regression model was the natural logarithm of PCWC, the coefficients obtained represent relative rather than absolute differences. The effect of each variable is therefore best expressed in terms of the associated percentage increase or decrease in PCWC. These differences are summarized in Table 3 which shows mean values and the percentage change in PCWC for each level of the variables included in the final model. The effect of water availability (as measured by the distance from the home to the main water supply) on PCWC is portrayed in Figure 1. It was found that a logarithmic transformation of the distance from the home to the water source improved the fit of this variable in the regression model. The crude PCWC rates (and their $95 \%$ confidence limits) were calculated by taking the geometric mean PCWC within log-distance intervals of equal size.

\section{Discussion}

The repeatability of the mother's daily per capita domestic water consumption estimates was not very high, perhaps owing to the fact that PCWC is calculated as the ratio of two other variables (total daily household water consumption and the number of household inhabitants), each of which is subject to measurement error. As no objective measure of PCWC was obtained, it is uncertain to what extent these estimates reflect actual rates of water consumption. Cairncross and Cliff (1987) found that observed domestic water consumption was quite similar to reported water consumption in a study performed in Mozambique, though the estimates were obtained from different samples of the population. No published research has been identified which directly compares observed with reported rates of water consumption. It would be valuable to know how accurately 
women estimate their household water consumption. This would permil comparisons of the relative efficiency of observation versus interview as data collection methods for studies of water use.

Table 3. Levels and changes in PCWC associated with the indicator variables included in the regression model.

\begin{tabular}{|c|c|c|c|}
\hline Variable & $\begin{array}{l}\text { Mean PCWC } \\
\text { (1/person/day) }\end{array}$ & $\begin{array}{l}\text { Crude } \\
\% \text { change }\end{array}$ & $\begin{array}{l}\text { Adjusted } \\
\% \text { change }\end{array}$ \\
\hline \multicolumn{4}{|l|}{ Site of clothes washing } \\
\hline in the home & 32.8 & & \\
\hline at the river & 20.7 & -36.9 & -21.8 \\
\hline \multicolumn{4}{|l|}{ Ownership of cattle } \\
\hline not owmed & 24.0 & & \\
\hline owned & 23.1 & -3.8 & 8.2 \\
\hline \multicolumn{4}{|l|}{ Flooring of house } \\
\hline tile or concrete & 29.7 & & \\
\hline clay & 22.4 & -24.6 & -10.8 \\
\hline \multicolumn{4}{|l|}{ Type of water source } \\
\hline protected well & 27.7 & & \\
\hline river/spring/unprotected well & 18.2 & $-34,3$ & -15.9 \\
\hline \multicolumn{4}{|l|}{ Mother's level of schooling* } \\
\hline nil & 19.9 & & \\
\hline 3 years & 23.1 & 16.1 & 8.3 \\
\hline 6 years & 27.5 & 38.2 & 17.4 \\
\hline 9 years & 37.2 & 86.9 & 27.2 \\
\hline \multicolumn{4}{|l|}{ Father's level of schooling" } \\
\hline nil & 20.5 & & \\
\hline 3 years & 23.4 & 14.1 & 5.9 \\
\hline 6 years & 28.0 & 36.6 & 12.7 \\
\hline 9 years & 23.9 & 16.6 & 18.7 \\
\hline \multicolumn{4}{|l|}{ Household size * } \\
\hline 4 persons & 32.9 & & \\
\hline 8 persons & 23.3 & -29.2 & 26.2 \\
\hline 12 persions & 18.8 & -42.9 & 45.6 \\
\hline 16 persions & 23.7 & .28 .0 & 59.9 \\
\hline
\end{tabular}

" Crude and adjusted percentage change is in relation to the mininum level showin in the tatole.

Of the total variance explained by the regression model (28.7\%), a large proportion (12.3\%) was attributable to just one variable, namely household size. The inverse correlation between PCWC and household size can be explained by the economies of scalle in certain activities requiring water, such as cooking and cleaning the house. Only a minority of water uses (e.g. drinking and bathing) can be expected to increase in direct proportion to the number of people living in the house. Household size has consistently been found to be inversely related to PCWC in previous studies (Darr et al. 1975; Feachem et al. 1978; White et al. 1972; Wong 1987). 


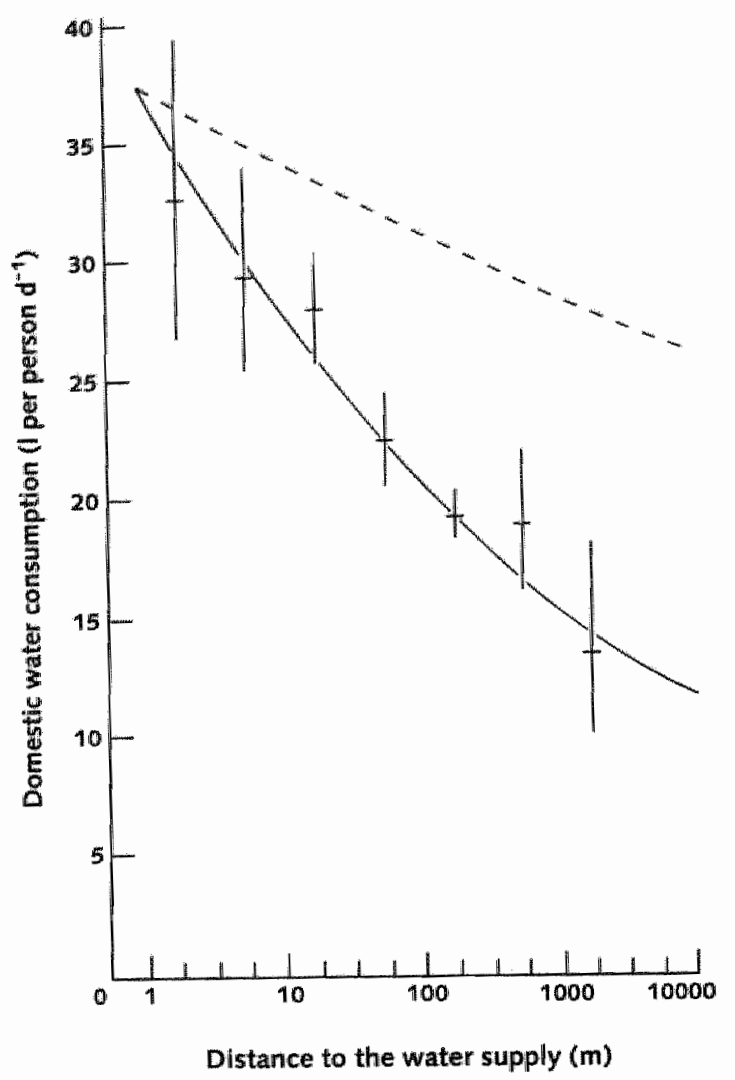

Figure 1. The relationship between water consumption and the distance from the house to the water supply. _- Crude regression line; -....., adjusted regression line. Bars represent mean and upper and lower $95 \% \mathrm{Cl}$

The importance of the site of clothes washing is mostly a consequence of the way PCWC was measured. Water consumption estimates by female heads of household pertain only to water carried home. They do not include water which is used for washing clothes at the source. Furthemore, those families which wash clothes at the river generally bathe there too. Though the site of bathing was also included in early regression models, it became statistically insignificant when the site of clothes washing was introduced. Obviously, the high level of collinearity existing between the site of clothes washing and the site of bathing makes it difficult to separate the independent effects of one from another. The $21.8 \%$ lower PCWC in households washing clothes at the riverside compared with those who perform their laundry at home is thus an indication of water used for bathing as well as for clothes washing.

A statistically significant relationship was identified between water availability and 
PCWC. This is consistent with results from research in Thailand (Frankel \& Shouvanavirakul 1973), but not all investigations have demonstrated such a correlation. In studies performed in Lesotho (Feachem et al. 1978) and in East Africa (White al. 1972), per capita water use did not decrease significantly for unpiped rural areas until the source was at least $1 \mathrm{~km}$ from the home. The constraints of linear regression modelling prevent one from defining the shape of the adjusted distance/PCWC curve, but it is interesting that the crude relationship shows some similarity to the moclel postulated by Cairncross (1987) on the basis of studies in Africa. According to this model, PCWC increases sharply when water is supplied to the home or yard but flattens out for return journey times from 10 to 30 minutes and then decreases gradually for distances greater than $1 \mathrm{~km}$. The crude rates plotted in Figure 1 offer some support for this model. For water sources up to $18 \mathrm{~m}$ from the house, PCWC varies little. From 18 to $180 \mathrm{~m}$ PCWC drops from 27.9 to $19.1 \mathrm{l}$ per person $\mathrm{d}^{-1}$. There is then virtually no change in $\mathrm{PCWC}$ for distances up to $560 \mathrm{~m}$. PCWC falls again from 18.7 to 13.21 per person $\mathrm{d}^{-1}$ between 560 and $1800 \mathrm{~m}$.

It should be recognised, however, that these are crude rates which do not allow for factors such as the change in site of clothes washing which could partly explain the observed falls in PCWC. It is for this reason that the slope of the unadjustec regression line is much steeper than the adjusted regression line. It seems that as distance from the house to the water source increases, people change their patterns of water use; more families bathe and wash clothes at the river rather than carry the water to their homes. Nevertheless, there remains a small but statistically significant, independent effect of water availability on PCWC. This was also found by Frankel and Shouvanavirakul (1973) who noted that when public standpipes were far from villagers' houses (they do not state how far), washing and bathing occurred at the site of water collection but even allowing for this change in the pattern of water use, PCWC was still higher in the villages with closer water sources.

A close relationship was found between water consumption and the type of household flooring (clay versus concrete or tile), a variable found to be a good indicator of wealth in this setting (Sandiford et al. 1989). The correlation between wealth and PCWC persisted even after controlling for water availability, education levels, the ownership of cattle, household size and the site of clothes washing (although the relationship was weak er). Other studies have also observed associations between water consumption and socio-economic indicators (Darr et al. 1975; White et al. 1972; Wong 1987). There are several reasons why poor people might consume less water. On the one hand they may have fewer tools or equipment associated with water use, smaller gardens, or fewer containers and less time to draw water. On the other hand, there may be cultural factors such as differences in hygiene practice between the wealthy and the poor. The relative importance of cultural factors in domestic water use is supported by the associations which have also been noted with parental schooling (Darr et al. 1975; Wong 1987) and race (Darr et al. 1975) and by White and colleagues" finding that PCWC "seems to be more sensitive to gross differences in material wealth from one area or culture to another than within such groups'. 
Parental schooling emerged as a particularly strong determinant of PCWC in this analysis. The mother's and the father's levels of education each independently predicted PCWC. Other studies have either found no relationship with schooling (White et al. 1972) or have not distinguished between male and female levels of education (Darr et al. 1975; Wong 1987). In Nicaragua, the father's level of schooling is probably a reasonable proxy for family income while the mother's level of schooling may indicate more cultural family characteristics such as hygiene practice. More work is needed to identify the precise mechanism by which education affects PCWC.

PCWC was significantly higher in households drawing water from protected wells than from unprotected shallow wells, springs or rivers. One reason may have been the limited capacity and flow of water from unprotected wells and springs. It is customary to 'clean' these wells by emptying them with a small basin before and allowing them to refill before drawing water (Sandiford et al. 1989). This takes about 30 minutes in the dry season and thus adds considerable time to daily water collection. Another possible reason for the lower PCWC associated with these sources is that the riverbeds where they are found are often at the bottom of steep paths. The importance of terrain has been mentioned by White et al. (1972).

No significant variation in water consumption between the dry and wet seasons was detected in this study. This is consistent with results from East Africa (White et al. 1972), but in Thailand, rainwater collection during the wet season reduced the demand from piped water sources. In contrast, rainwater use is not common in this area of Nicaragua.

Families with cattle had higher rates of PCWC than those without, but only after controlling for the other variables in the model. The $8.2 \%$ difference in PCWC is likely to be an underestimate as in some cases cattle were watered from a different source so their consumption was not included as a part of domestic water use.

The multiple regression model developed in this analysis, while a useful first approximation is undoubtedly deficient in several respects. Only a small proportion of the total variance in water consumption estimates was explained by the various factors tested. Although much of the residual variance could be accounted for by measurement error associated with the rather low repeatability of the mother's water consumption estimates, there are also factors which have been found to be significant in other studies which were not tested in this analysis. They include the size of the water container, the number of baths per day, and family incorne.

One should note that PCWC was found to be unrelated to the case/control status of the child suggesting that water consumption may not be an important risk factor for childhood diarrhoea in rural Nicaragua. However, in another analysis it was found that the distance from the house to the water source (i.e. the availability of water) was significantly associated with diarrhoea (Sandiford, 1989). A likely explanation for this is the low repeatability of water consumption estimates (as measured by the intraclass correlation coefficient), compared with the repeatability of water availability measurements. 
This could mean that the distance from the house to the water source is actually a better proxy for the quantity of water used in hygiene-related activities than the per capita domestic water consumption estimate itself, especially since the water used by a family for the practice of hygiene may be only a small proportion of total daily water consumption.

It is clear from this analysis that several factors are important determinants of domestic water consumption. Those most likely to be related to the amount of water used for hygiene practice (and therefore to diarrhoea morbidity) are the mother's and father's level of schooling, the distance from the home to the water source, and the type of water source. Given the strength of the association between water supply and schooling, it may prove more cost-effective, in some settings, to increase domestic water consumption for hygiene (and thereby reduce child diarrhoea morbidity) by educational interventions than by structural improvements in water supplies.

\section{Acknowledgements}

This work was funded by grants from the Diarrhoeal Diseases Control Programme of the World Health Organization and the Medical Research Council of New Zealand. The authors would like to express their gratitude to Julio Delgadillo of the Nicaraguan Institute of Aqueducts and Sewage Systems and Leonel Arguello of the Nicaraguan Ministry of Health for their support in initiating and conducting this research. A special word of thanks is owed to Iris Gutierrez for her assistance in data processing. Finally, we are indebted to all our field workers for the great care they took with their work.

\section{References}

Caimcross 5 . (1987) The benefins of water supply. In Developing Warld Water $I_{\mathrm{e}}$ (ed. J. Pickford), Groswenor, London.

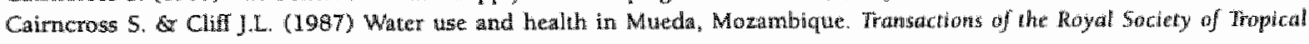
Medicine and Hyglewe 81, 51 .

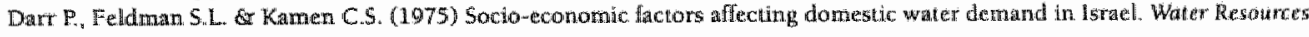
Research 11 , 805 .

Esrey 5.A., Feachem R.G. Hughes J.M. (1985) interventions for the control of diarthoeal diseases among young chiddren: improwing water supplies and excreta disposal facilities. Bullatim of the world healdi Organization $63,757$.

Esrey S.A. \& Habicht ]. (1986) Epidemiologic evidence for health bentefits from improwed water and samitation in deweloping countries Epidemiologic Reviews 8, 117 .

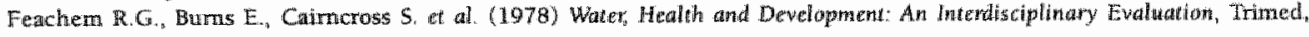
Londion.

Fleises J. (1981) Statistical methods for rates and propartions, 2nd edin., Wiley. New Yorlk.

Frankel R.J. S Shouvanawiakul P (1973) Water consumption in small communities of northeast Thalland, Water Reschurces Research 9,1196

Kawati K. 1978) Water and other environmental interventions - the mimimum inwestrent concept. Amurrican Joumbal of Clinical Wutrition $31,211.4$.

Maclure M. and Willen W.C. (1987) Misinterpretation and trisuse of the kappa statichic. Amierican Journal of Epidemiology 126 , 161 .

Sandiford P (1989) A case-comtrol study of enviramental sanitation and childhood diarhoea morbidity in rural Nicaragua. MMedSci thesis, Department of Commanity Healiti, University of Auckland.

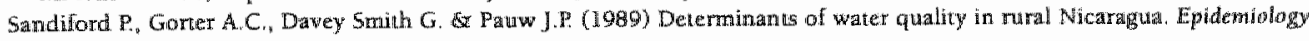


Wha Infection 102,429 .

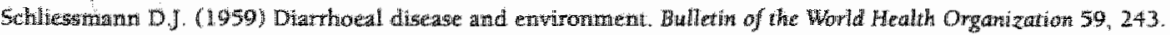

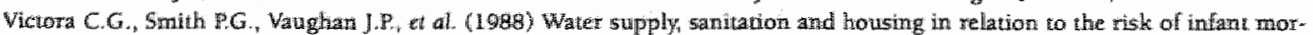
tally from tianthoea, International Journal of Epidemiology 17,651

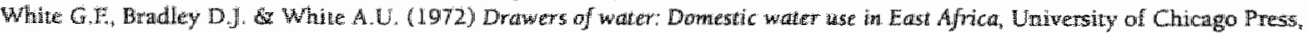
Chicago.

Wong $5 . T$, (1987) Thai rurd fomestic water constumption: A case study of whilage commumity whth no orgarized water supply system. Water International 12,60. 


\section{Section 4.3}

\section{Water supply, sanitation and diarrhoeal disease in Nicaragua: Results from a case-control study}

Anna C. Gorter ${ }^{1}$, Peter Sandiford ${ }^{2}$, George Davey Smith ${ }^{3}$, Johanna P. Pauw ${ }^{1}$

Published in International Journal of Epidemiology, 1991; 20:527-533 


\begin{abstract}
A case-control study of risk factors for child diarrhoeal disease was undertaken in a ruxal area of Nicaragua. Some 1229 children under the age of five were matched with an equal number of children of the same age presenting with other illnesses unrelated to water and sanitation. The main types of water supply were sampled at monthly intervals and tested for the presence of faecal coliforms in order to characterize their microbiological quality. In spite of marked differences in water quality between the different types of water supply, no relationship was found with diarrhoea morbidity. In contrast, there was a statistically significant association between water availability and diarrhoea morbidity. Children from homes with water supplies over 500 metres from the house had incidence rates of diarrhoea $34 \%$ higher than those of children from houses with their own water supply. Owning a latrine was not found to be significantly related to diarrhoea morbidity. A mother's level of schooling was inversely correlated with the frequency of diarrhoea in her children. A significant association was also found between the number of children under the age of five living in the house and the incidence of diarrhoea. These effects remained significant after controlling for confounding variables by conditional logistic regression.
\end{abstract}




\section{Introduction}

It is well known that acute diarrhoeall disease is one of the most important causes of morbidity and mortality in children under five years of age. Mortality rates of over 20 per 1000 children in their first two years of life have been reported in Latin American countries and average morbidity rates are estimated at two episodes per year ${ }^{1}$.

The use of oral rehydration therapy has been promoted to reduce diarrhoea mortality, recognising that other strategies are necessary to reduce diarrhoeal morbidity2. In 1982, the Diarrhoeal Diseases Control Programme of the World Health Organization commenced a systematic study of the strategies that might play a role in the control of diarrhoea. One of the seven strategies considered to be viable was the improvement of water supplies and sanitation ${ }^{3}$.

However, the relationship between improvements in water supply or sanitation and diarrhoeal disease is still not completely understood. Although reviews of more than 50 investigations on the relationship between diarrhoea and environmental sanitation found positive impacts in the majority ${ }^{4,5}$, there was considerable variation in the magnitude of the effects observed. For example, while there was a median reduction of $25 \%$ associated with improvements in water availability, the impact ranged from $0 \%$ to $100 \%$. Similarly, they found that the reduction in morbidity associated with water quality improvements ranged from 0 to $90 \%$ (median $16 \%$ ).

The presence of design faults in many of these studies could explain the lack of consistency in the results. Blum and Feachem ${ }^{5}$ identified eight important methodological flaws. in the designs of 44 published studies and concluded that 'while most of the studies do claim to show an improvement in one or more health indicators, critical review of the papers raises serious doubts as to the validity of their conclusions'.

Since then, efforts have been made to develop rigorous methodologies to measure the health impact of strategies aimed at reducing diarrhoeal morbidity? The outcome of this has been the application of case-control designs whose superior efficiency in comparison with cohort studies, even for investigating common diseases, allows data of higher quality to be collected ${ }^{8}$. This article presents results from one application of the case-control method to the study of the relationship between acute diarrhoeal disease and environmental risk factors.

\section{Methods}

This study was undertaken in Villa Carlos Fonseca, a rural municipality located on the Pacific coast about $30 \mathrm{~km}$ from Managua, the capital of Nicaragua. Within its area of 500 square kilometres there are approximately 30000 inhabitants distributed amongst 35 communities. There is one health centre (with a small laboratory but no beds) and six smaller health posts. 
A random sample of houses registered with the Ministry of Internal Commerce's consumer census was visited in order to determine the prevalence of the different types of water supply and sanitation. A subsample was then selected of sites representative of each type of water source from which monthly samples were taken to measure microbiological water quality by faecal coliform count. The results from a multivariate analysis of the water quality data have been published elsewheres.

Cases and controls were recruited from the health centre and five of the six health posts, matched by age and the health care facility where they were first seen. All children under the age of five presenting with diarrhoea (defined as four or more liquid motions per day, with or without mucus, fever or blood), were recruited as cases, provided that they had not been included in the study as cases or as controls within the previous seven days. Children presenting with other symptoms in addition to diarrhoea were included as cases as long as they fulfilled the criteria. A child could be recruited on more than one occasion as either a case or a control irrespective of the previous diagnosis, provided that it had not been included in the previous seven days. Each case was matched to one control, which was defined as the next child of the same age group presenting to that clinic with one or more of the following conditions:
(a) Acute respiratory tract infection
(c) Otitis
(e) Non-specific fever
(g) Mallaria
(i) Urinary tract complaints
(k) Oral candidiasis
(b) Measles
(d) Mumps
(A) Skin disorders
(h) Conjunctivitis
(j) Chickenpox
(1) Allergy

Specifically excluded from the control group were children diagnosed as having hepatitis, typhoid or parasitosis, or presenting with nausea, stomach pains, breast-milk intolerance or mild diarrhoea. Children with any form of trauma were also excluded from the control group because it is believed that they may be drawn from a different population than those who present with diarrhoea and thus their inclusion would introduce selec-
tion bias

At the health centre and each of the five health posts, a research assistant was employed to fill in the data forms, measure the child's height and weight, and to match controls with cases. Seven age categories were used for the purpose of matching ( $<1$ month, 1-5 months, 6-11 months, 1 year, 2 years, 3 years and 4 years). The doctors and nurses staffing the clinics were responsible for making the diagnosis so they were also taught the selection criteria. Clinic data forms recorded a variety of information about the child, including its date of birth, age, sex, weight, height, type of feeding and diagnosis.
Ownership of a latrine and drinking water supply were also noted to permit cross-checks
with home visit data.

Field workers unaware of the subject's diagnosis were sent to the home of each child in order to verify by direct observation the type of water supply and presence or absence of 
a latrine. They reinterviewed the mother, asking once again the child's age and type of feeding but questions were also added to ascertain the parents' levels of schooling, their employment, and the number of household inhabitants (including the proportion under five years of age). Interviewers noted the distance from the house to the water supply and certain indicators of socioeconomic status such as the floor and roof construction materials, the types of domestic animal owned, and the possession of a radio, television, refrigerator, car, horse or cattle. If the child was normally cared for by someone other than the mother data was collected from that person and if the mother or guardian was not at home a repeat visit was arranged. Where a family had already been visited within the three preceding months, the visit was not repeated unless the family had changed their address.

Least-squares linear models were fitted to identify the determinants of bacteriological water quality ${ }^{9}$ and household water consumption ${ }^{10}$. The ratio of discordant pairs was used as an estimator of the incidence rate ratio for the different levels of each risk factor. The rate ratio was tested for statistical significance using McNemar's test in the first place and then by conditional logistic regression while controlling for confounding variables. The $95 \%$ confidence intervals were estimated by maximum likelihood.

\section{Results}

\section{Water Quality}

The six main types of water supply identified in the population survey were rivers and streams, unprotected wells, protected wells, wells with mechanical pumps, public standpipes and domiciliary connections. Unprotected wells include springs and generally consist of shallow holes dug at the bank of a river or gully. Protected wells are usually at least seven metres deep and are surrounded by a parapet with the water drawn in a bucket on a rope.

The (geometric mean) faecal coliform counts obtained from each type of water source are shown in Figure 1. There was a marked difference in the degree of contamination of piped water compared with water from wells or other traditional sources. It was surprising to discover that during periodls of low rainfall, the water quality of the unprotected wells was better than that of protected wells. Water quality was worse during wet periods, especially in the unprotected wells. The results of the water quality analysis have been presented elsewhere 9 .

\section{Relationships between Water Supply and Diarrhoea Morbidity}

A total of 1229 cases-control pairs were recruited between May 1986 and March 1988. The recruitment of cases by month is shown in Figure 2 . There is seasonal variation such that during the rainy season more cases of diarrhoea were recruited than during the dry season. The majority of cases were less than one year old and $80 \%$ were under two years of age. Home visit data was obtained for 2436 of the 2458 subjects (99.1\%). 
Rivers streams

Unproterted wells

Protected wells

Wells with pumps"

Public standpipes

House connections

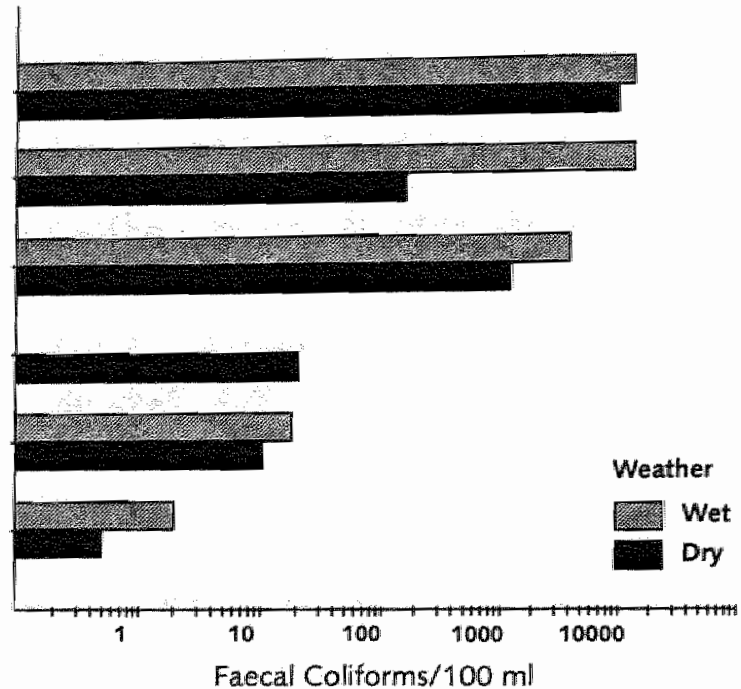

- No sampies were haken from wells whith pumps curing the wet period

Figure 1. Geometric mean faecal coliform counts by type of water source during wet and dry weather (months with $>200$ mm rain defined us wet)

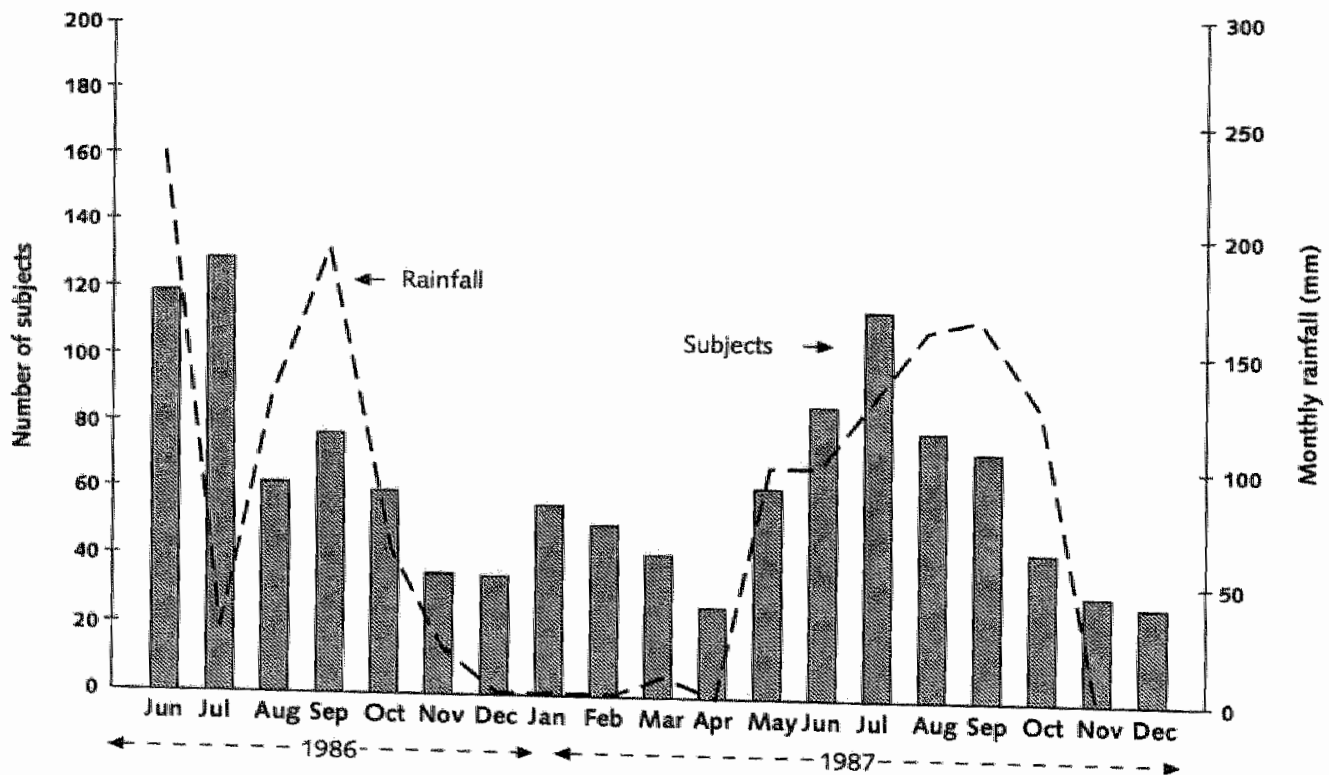

Figure 2. Monthy rainfall and recruitment of subiects. 
Table 1 shows the relative rates of diarrhoea for the risk factors investigated. Of these factors, only water availability, the level of matemal education and the number of under five year old children living in the house were significantly associated with diarrhoea morbidity. There was no indication that the presence of a latrine or the type of water source (a reasonable proxy for bacteriological water quality), were risk factors for diarhoca.

Water availability was significantly associated with diarthoea when included in the logistic regression model as a continuous variable, implying that the frequency of diarrhoea increases exponentially with unit increases in the distance from the house to the water source (Figure 3). Thus, in houses with a water sources 500 metres away, children had

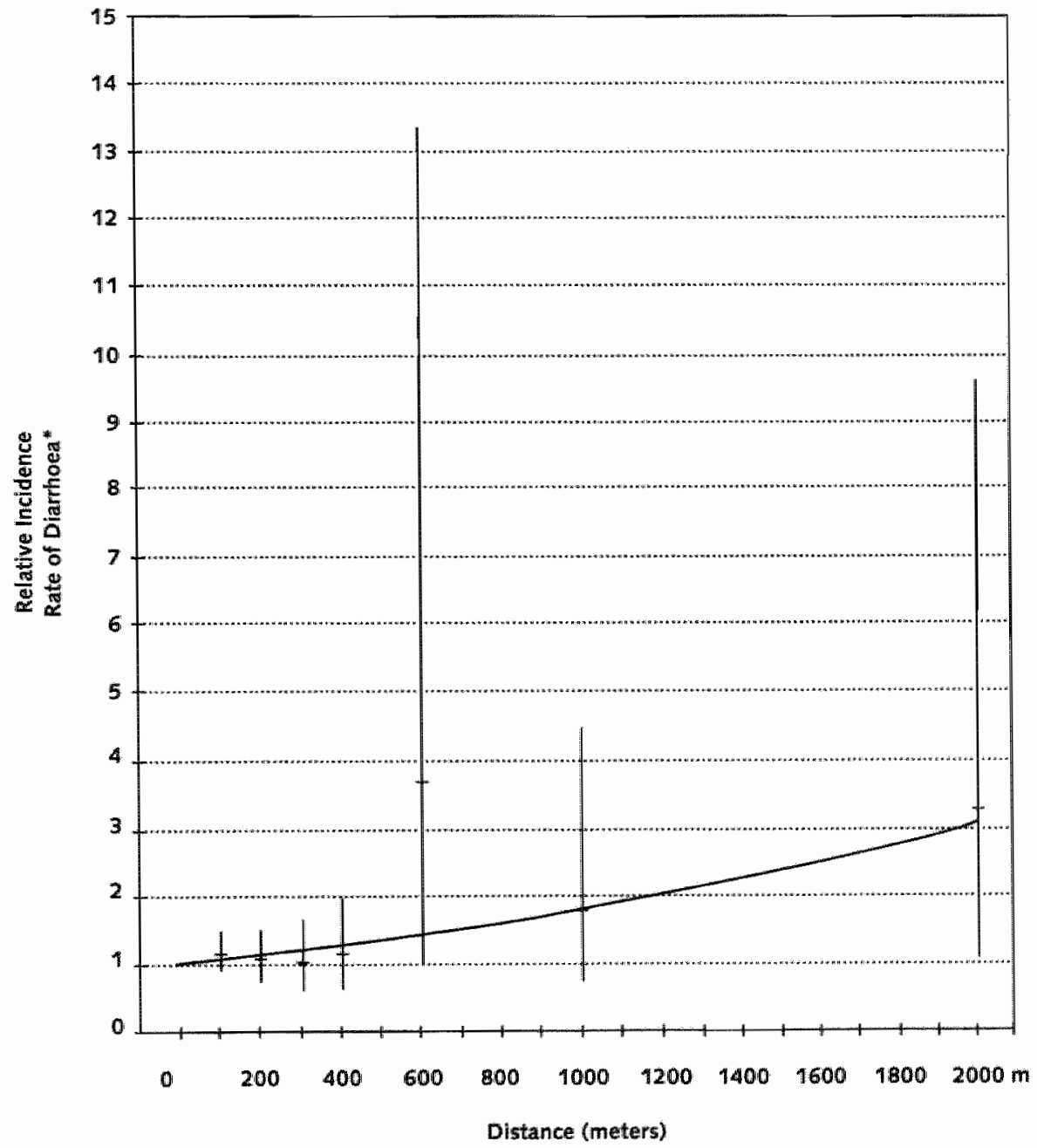

* Compared with homes adfacent to their water supply

Figure 3. Relative rates of diarhoea morbidity by distance from the home to the water source (point estimates, $95 \%$ confidence limits and trend finel 
Table 1. The distribution of diarhoed cases and controls by exposure with crude and adiusted relative rates

\section{Risk factor}

piped water supply

protected well

unprotected well

river / stream

$\chi^{2}(3 \mathrm{df}) *$

\section{Distance to water source}

$<50$ metres

50 - 149 metres

150 - 249 metres

250 - 349 metres

350 - 4.49 metres

450 - 749 metres

$750-1249$ metres

$\geq 1250$ metres

$x^{2}(1 \mathrm{~d}$ trend)

\section{Presence of a lattine}

no latrine

latrine

$x^{2}(1 \mathrm{df})$

\section{Maternal schooling}

$$
\text { primary school }
$$

secondary school

$x^{2}$ (1 dff trend)

\section{Type of water source}

\section{Cases}

2.4

521

407

10

713

249

85

38

28

12

14

13

462

690

351

687

114

No. children under five years

$\begin{array}{lr}1 & 302 \\ 2 \cdot 4 & 810 \\ 25 & 40 \\ 2 \text { ( } 1 \text { dif trend) } & \end{array}$

Controls

201

562

382

9

751

230

85

44

27

4

8

5

459

695

307

720

127

349

778

27

Odds ratios
Crude $\quad$ Adjustedt

1.00

0.86

1.01

1.08

3.16

1.00

0.92

1.11

1.17

4.32

$95 \%$ confidence Intervals
$(0.69-1.24)$

$(0.37 \cdot 3.67)$
$(0.80-1.55)$
1.00

1.00

1.16

1.06

1.00

1. 12

3.61

1.80

3.29

$7.24 *$

$(0.91-1.47)$

$(0.74-1.50)$

$(0.62-1.62)$

1.12

$(0.63-1.98)$

3.79

1.78

$(0.98-13.3)$

2.69

$(0.73-4.44)$

$6.55^{*}$

$(1.13-9.61)$

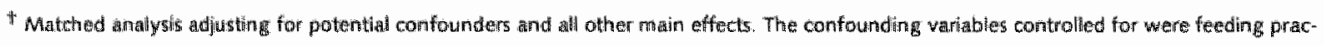

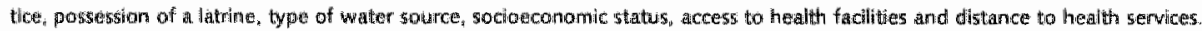

T The $X^{2}$ stentistic ursed is the scoufe test.

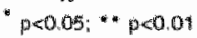


$34 \%(95 \%$ CI 2-56\%) more diamhoea than in houses adjacent to their water supply.

Child diarrhoea morbidity was found to depend on the mother's level of schooling Children of women with primary school education had $18 \%$ less diarthoem than those of women with no formal education. The children of women with secondary school education suffered $26 \%$ less diarrhoea than those who had not attended school. There was no correlation between the incidence of diarthoea and a father's level of education once the other variables had been included in the model.

It was also discovered that the rate of diarrhoea in houses with more than four children under five was $70 \%$ higher than in houses with just one under five year old. In houses with two to four children under five, the rate was $22 \%$ higher.

\section{Discussion}

The results presented support the notion that access to water is an important risk factor for diarrhoea. Most studies have not attempted to obtain separate estimates for the impact of water quality and water availability, (indeed the two are often highly correlated making this difficult to achieve in practice), but there are two review papers which divide health impact evaluations of water supply into those where the improvement was predominantly in water quality and those where the improvement was mainly in water availability. The first of these found that the median percentage reduction in diarrhoea incidence for studies where the improvement was mainly in water avallability was $25 \%$ compared with $16 \%$ for those studies where the improvement was predominantly in water quality4. The second paper which reviewed many of the same studies, showed that the highest proportion of studies reporting a positive impact were those where the intervention resulted in increased water availabilitys. Our findings are consistent with these results as it was found that high rates of diarrhoea occur in the houses with water sources more than 500 metres away. At distances under 500 metres however, the effect of water availability is small.

Since these reviews there have been several case-control studies of diarrhoea and environmental sanitation $11,12,13,14,13$. Two of them 11,12 assessed the joint impact of improved water supply (mainly water quality) and excreta disposal facilities compared with neither or just one of these interventions. These studies did not report statistically significant effects although they were the earlier case-control studies with rather small sample sizes.

Another study's used mortality from diarthoea as the outcome measure and detected a significant association with water avalability. They also observed a lower mortality rate in families using treated water but this was not significant after controlling for con= founding variables. Diarthoea mortality was unrelated to sanitation.

The Lesotho case-control study14 showed an association between diarrhoea morbidity and latrine ownership which was statistically significant in crude analyses but not in the 
logistic regression analysis (although the odds ratio remained 0.76 ). Diarthoea also showed crude associations with water consumption and with the type of water supply (which may be a proxy for water quality) but these were not analysed by logistic regres. slon.

In a case-control study performed in Sri Lanka, diarthoea morbidity was significantly related to the type of water source both before and after adjusting for confounders ${ }^{15}$. The authors believe that this is an effect more of water quality than of water avallability. When disease status was compared with geometric mean faecal coliform counts (adjusting for source and area) there was a small but statistically insignificant difference between cases and controls.

It is difficult to make any general statement about the relative importance of water quality, water availability or sanitation from these studies. Their importance may actually vary from one country to another according to differences in geographical setting, behaviour patterns, transmission routes of the common aetiological organisms, or the nature of the water supplies and excreta disposal facilities. It is also possible that the inconsistencies clerive from biases in one or more of the studies.

Our results suggest that the transmission of diarrhoea in Nicaragua is predominantly water-washed rather than water-borne. Where the prevention of diarrhoea is an important consideration in the design of water supply projects, the main focus should be on improving water availability and not water quality. It implies that the practice of boiling drinking water (advice frequently included in health education materials in Nicaragua) may be of little benefit. Taking into account the cost for the family of boiling water and its other disadvantages 16 , it may be wise to reconsider the inclusion of this advice in health education programmes. On the other hand, it was not possible in this study to assess whether the lack of an association between water quality (at the source) and diarrhoea was in part due to the practice of boiling water in the home. Recent observational studies performed in Villa Carlos Fonseca however, suggest that drinking water for infants is not usually boiled (umpublished results).

The strong association between maternal schooling and child health has been demonstrated previously in Nicaragual7, and elsewhere 19 . Although the precise mechanism by which child health depends on a mother's level of education is unknown, it is plausible that hygiene practice is important 20 . This is supported by the correlation found between per capita domestic water consumption and maternal schoolinglo. It is possible that as well as using more water, educated mothers also dedicate a greater proportion of the
water they collect to hygiene-related activities.

At this stage however, there is only indirect evidence for an association between hygiene practice and matternal schooling. Education is a complex social variable and its relationship with health could have several components. A mother's education is closely associrelationships, and with her health-seeking access to health services, with intrafamilial power 
significant relationship between diarrhoea morbidity and paternal education in this study suggests that the effect of the mother's education is not merely' a reflection of socioeconomic status. However, the influence of education on the behaviour of the mothers with their sick children could explain the observed relationship with diarrhoea. For example, if educated mothers give home-based oral rehydration therapy while uneducated mothers tend to seek professional help, diarrhoea morbidity will appear lower in the group of educated mothers. More research is needed to clarify the importance to child health of maternal literacy and education.

The higher rate of diarrhoea morbidity in houses with more children under the age of five requires little explanation. Secondary transmission of diarrhoea is obviously facilitated by person to person contact between the children in the house. Family planming programmes or improved housing may have some impact on diarrhoea incidence but the effect observed in this study was small except where more than four children under five years old lived in the house.

The results obtained from this study do not allow comment on the efficacy of other methods for preventing diarrhoea recommended by the World Health Organization, such as the promotion of breast feeding, measles immunization or improvements in weaning practice ${ }^{3}$. The study does suggest that improvements in water availability and hygiene education can be effective interventions for the prevention of child diarrhoea.

\section{Acknowledgements}

This study was funded by the Diarrhoeal Diseases Control Programme of the World Health Organization and the New Zealand Medical Research Council.

The authors would like to express their gratitude to Julio Delgadillo, Sergio Tercero and the laboratory staff of the Instituto Nicaraguense de Acueductos y Alcantarillados for their assistance during this investigation. We would also like to thank Leonel Argüello and Milton Valdez of the Ministry of Health for the support in setting up the study. Simon Cousens, Thierry Mertens and Richard Feachem of the London School of Tropical Medicine and Hygiene, and Peter Davis from the University of Auckland gave us very valuable advice at various stages of the project. Finally, a special word of thanks to Iris Gutierrez for her tremendous work in processing the data.

\section{References}

1 Snyder JD. Merson MH. The magnitude of the global problem of acute dianthoeal disease: a revew of active survellance data. Bull WHO 1922; 60,605-613.

2 Feachem RG, Hogan RC. Merson MH. Diarhoeal diseases contral: reviews of potential inferwentions. Bull WHO 1963; 61: $637-640$

3 Feachem RG. Prewenting diurrhoea: what are the policy options? Health Palicy and Planning $1.986 ; 1: 109-117$

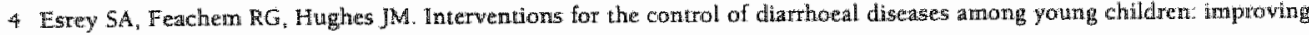




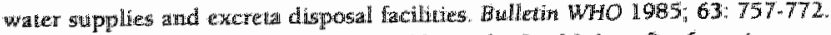

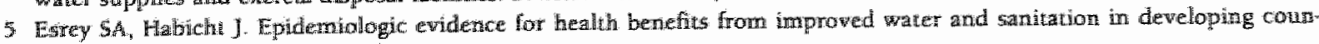
Wries. Epidemologic pevirwat 1986; 8: 117-126.

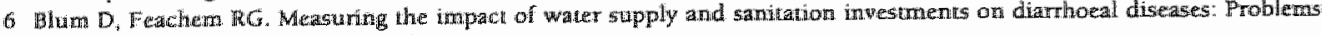
of methodology. Int J Epidtertiol. 1983; $12: 357$

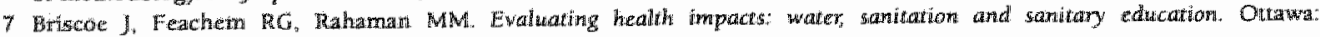
Interwational Development Resterch Centre, 1987 ; wublication no IDRC.248.

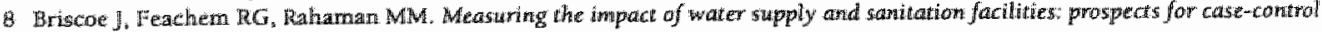
methods. Geneva. World Health Organization, 1985; documemit WHOKCW5/853.

9 Sandiford $P$, Gorter $A C$, Dawey smin $G$, Pau JP. Determinats of drinking water qualing in rumal Nicaragua. Epidemiology arid Infection $1989 ; 102: 429-438$

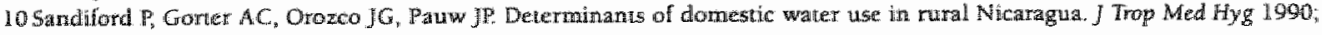
93: $383-9$.

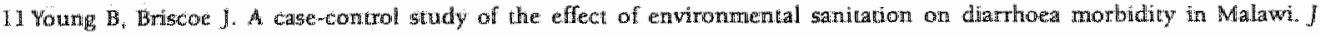
Epiluemiol Commi Health $198 \%, 42: 93-88$.

12 Baltazar J. Briscoe J. Mesola $V$ et al. Can the case-control method be ured to assess the impact of water supply and samitacion on diarthea? A study a the Philippines Bull Who 1988; 66: 627-635.

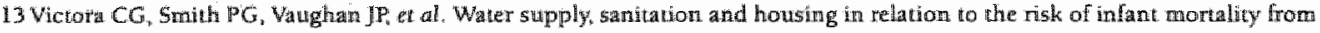
diarthoed. In J Epidemiol 17: 651-654.

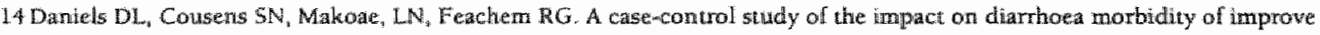
sanutation factilities in lesotho. Bull WHO 1990 , in press.

15 Merteas TE, Fernanito MA Cousens SN, Kirkwood BK, Marshall IF de C, Feachern RG. Childhood diarthoea in Sri Lanka: a case-control study of the impact of improwed waller sources. Trop Med Parasit 1990, $11: 98-104$.

16 Millew DW. Boiling drinking water a critical look. Waterlines 1989 ; 5: 2-5.

17 Fayer Dy. Fincuesta demogrdfica nacional de Nicaragua: Amalisis de las preguntas retrospectiwas. San Jose: Centro Latimorataticamo de Demografia, 1.982.

LB Behm H, Primante DA. Le martalidad en los primeros años de wida en paises de la América Latina. Nicaragua 1966-67. San Jose. Cencto Latinotmericano de Demografia 1977 ; Series A; no 1036.

19 Grosse RN, Auftrey C. Literacy and health status in developing countries. Aun Rew Public Health 1989; 10:281-297.

20 Pacey A. Hygiene and titeracy. Wortimes $1982 ; 1: 26-29$. 
Section 4.4 .

Hygiene behaviour in rural Nicaragua in relation to diarrhoea

Anna C Gorter, ${ }^{1,2,3}$ Peter Sandiford, ${ }^{3}$ Johanna Pauw, ${ }^{1}$ Patricia Morales, ${ }^{1}$ Rosa Maria Pérez ${ }^{1}$ and Henk Alberts."

Accepted for publication in International Joumal of Epidemiology

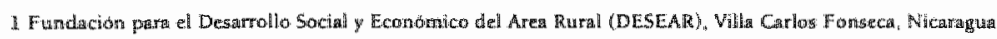

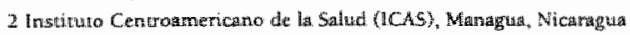

3 Insticune for ficalth Sector Development, 27 Otd Street, London. ECIV 9AH. 


\section{Abstract}

Background. Childhood diarrhoea is a leading cause of morbidity and mortality in Nicaragua. Amongst the risk factors for its transmission are "poor" hygiene practices. We investigated the effect of a large number of hygiene practices on diarrhoeal disease in children aged $<2$ years and validated the technique of direct observation of hygiene behaviour.

Methods. A prospective follow-up study was carried out in a rural zone of Nicaragua. From the database of a previously conducted case-control study on water and sanitation 172 families were recruited, half of which had experienced a higher than expected rate of diarrhoea in their children and the other half a lower rate. Hygiene behaviour was observed over two mornings and diarrhoea incidence was recorded with a calendar, filled out by the mother, and collected every week for 5 months.

Results. Of 46 'good' practices studied, 39 were associated with a lower risk of diarrhoea, five were unrelated and only for two a higher risk was observed. Washing of hands, domestic cleanliness (kitchen, living room, yard) and the use of a diaper/underclothes by the child had the strongest protective effect. Schooling ( $>3$ years of primary school) and better economic position (possession of a radio) had a positive influence on general hygiene behaviour, education having a slightly stronger effect when a radio was present. Individual hygiene behaviour appeared to be highly variable in contrast with the consistent behaviour of the community as a whole. Feasible and appropriate indicators of hygiene behaviour were found to be domestic cleanliness and the use of a diaper or underclothes by the child.

Conclusion. A consistent effect of almost all hygiene practices on diarrhoea was detected, more schooling producing better hygiene behaviour. The high variability of hygiene behaviour at the individual level requires repeated observations (at least two) before and after the hygiene education in case one wants to measure the impact of the campaign on the individual. 


\section{Introduction}

Child hood diarrhoea is a leading cause of morbidity and mortality in developing countries ${ }^{1}$. As such it has stimulated much research that is aimed at understanding its etiology and evaluating preventive and therapeutic strategies. The Diarrhoeal Diseases Control Programme of the World Health Organisation has selected several areas which merit special consideration:2 improvements in water availability and sanitation; improved nutrition, especially the promotion of breast feeding and better weaning practices; good personal and domestic hygiene; immunization against measles and rotavirus; and oral rehydration therapy (ORT).

Over the last decade several epidemiological studies have examined hygiene practices as risk factors for childhood diarrhoea ${ }^{3-13}$. Some of these practices identified as risk factors have subsequently been used as targets for behaviour modification through health education campaigns ${ }^{14-19}$. While hand washing has been the subject of many studies ${ }^{7,0,16,18,20-27}$, other specific behaviours have received less attention 13,28.

Several investigations have used observation data, but little work has been performed to confirm their validity and repeatability ${ }^{28}$. Two studies, one in Burkina Faso ${ }^{29}$ and one in Bangladesh ${ }^{30}$, compared responses from KAP (knowledge, attitudes, practices) questionnaires with observation data and found that results could be very different. Desirable practices were reported but not observed more times than they were observed but not reported. The studies claimed that data from direct observation are more valid than from questionnaires. However, repeated observations of a small sample of households in one of the studies ${ }^{29}$ revealed a high variability of hygiene behaviour. The authors suggested that studies should be undertaken to assess this variability, and validity and repeatability of direct observation versus KAP questionnaires for measuring hygiene practice.

In this paper we present a study of the influence of hygiene practices on the incidence of diarrhoea in children aged $<2$ years, the relationship with maternal education and socioeconomic position and the repeatability of direct observation of these practices. The study was carried out as part of an integrated programme of diarrhoea research in an area of rural Nicaragua. The initial investigation was a case-control study examining risk factors for diarrhoea. It was found that reduced availability of water and low maternal education were related to increased rates of diarrhoea ${ }^{31}$. Other studies examined the determinants of water quality and domestic water use ${ }^{32,33}$. Subsequent work documented lay beliefs regarding the causes, treatment and prevention of diarrhoea, mothers' responses to diarrhoea, their willingness to use ORT ${ }^{34}$ and possible explanations for Nicaragua's decline in infant mortality over the past 20 years ${ }^{35}$. Results from this programme, e.g. the demonstration that poor availability of water was associated with a higher risk of diarrhoea, have informed and encouraged the development of prevention programmes such as production of rope pumps for water and sanitation programmes ${ }^{36-39}$ and other health promotion activities. 


\section{Materials and methods}

The studies were conducted in Villa Carlos Fonseca, a rural municipality on the Pacific coastal plains of Nicaragua, $40 \mathrm{~km}$ from the capital Managua. Within its area of $500^{2}$ killometers there are approximately 32000 inhabitants living in 38 different communities. It is almost an entirely agricultural society.

This investigation of the effect of hygiene practices on diarrhoea incidence is a prospective follow-up study of families who had participated in the initial case-control study that examined the links between diarrhoea and environmental sanitation ${ }^{31}$. A total of 2458 illness episodes were recruited to that study; 1229 bouts of diarrhoea plus a control group of 1229 illnesses not directly related to water supply and sanitation. As it was possible for children to be recruited on more than one occasion, and for different children within one family to be recruited, a total of 1402 families were included in the study and this group became the sampling frame for the prospective follow-up study of hygiene practices.

Of these 1402 different families, 585 mothers of infants had presented a child to the health facilities on two or more occasions with a diarrhoeal episode or with an illness serving as a control. Since cases of diarrhoea had been matched to controls at the outset, there was initially a probability of exactly $50 \%$ that any given episode was one of diarrhoea. This was effectively still the case with the reduced group of 585 families (of 1641 episodes of illness, 824 or $50,24 \%$ were diarrhoea). The cumulative binomial probabiliry was calculated of observing more cases of diarrhoea than of control diseases within a given family. Using these probabilities 397 families were selected as 'high risk' or 'low risk' for diarrhoea and of these 172 also had a child $<2$ years old at the start of the follow-up period. Thus a total of 88 'high risk' and 84 'low risk' mothers were selected.

Before data collection was commenced in January 1989, a pilot study was performed with 41 households selected at randorm from a local population register. Observations lasting 3-4 hours were made by studly assistants. They used a data recording form that was made intentionally open-ended in order to gain some idea of the range of practices likely to be encountered. From the results and experience obtained in this initial study a structured observation recording form was designed and pretested. Information was recorded on food hygiene (including baby's bottle hygiene), personal hygiene around study child, domestic hygiene, water hygiene and safe faeces disposal, as well as details on social, economic and educational status of the families, availability of water, and presence of latrines. A variety of different starting times for the observations were tried in order to find the period when most of the relevant activities were occurring.

Eight female field workers were recruited with at least 2 years of secondary school and who could not be distinguished from the local women. All had experience in child care and had managed household activities. The field workers attended a week long training workshop and were then accompanied and supervised by the study assistants for about three observations, until the latter were satisfied with their work. During the study every 
fourth observation was overseen by one of the assistants. After each observation we reviewed the forms, checking in particular for inconsistencies and omissions, and discussing certain problems.

In each house, two periods of observations were carried out by the same field worker from about $8.30 \mathrm{am}$ to $1 \mathrm{pm}$ which is when most of the relevant domestic activities take place. The second observation was performed after 1 to 2 weeks and the observer had no access to the form of the first observation. Field. workers were assigned randomly to a family and were blind to the diarrhoeal history of them. The purpose of the visit (observation of hygiene practices) was not revealed. Permission was given by the mothers to observe their children.

All observations were performed during the dry season. The incidence of diarrhoea in children aged $<2$ years was measured for 5 months. We started one month after the observations and included the rainy season when diarrhoea incidence in Nicaragua is highes $^{31}$. The mothers were asked to fill out a daily diarrhoea calendar, especially designed for illiterate women. If there was more than one child aged $<2$ years, a diarrhoea calendar was given for each child. A photo of the child was taken and attached to the calendar. This also served as an incentive for the mother to take part in the study. A field worker visited the home each week and collected the completed calendars, reviewing them with the mothers to verify the accuracy of the record.

Coding and data entry was performed. Statistical packages (Epi Info and Lotus) were used for data analysis. Following the recommendations of MacClure and Willett ${ }^{\text {to }}$, the repeatability of the dichotomous variables was measured using the unweighted Kappa score which takes into account the degree of concordance to be expected by chance alone 41 . Negative Kappa scores indicate less concordance than would be expected by chance. Positive Kappa scores between 0 and 1 suggest better concordance than expected by chance, with Kappa scores of 1 representing perfect agreement between the repeated measurements. For dichotomous variables, as are all variables of the hygiene behaviour presented, it is generally accepted that values $<0.40$ imply poor repeatability, 0.40 to 0.75 good repeatability, and values $>0.75$ indicate excellent repeatability ${ }^{41}$. Kappa scores are known to be biased however, when prevalence is either very high or very low $w^{42,43}$ Differences in proportions were tested for statistical significance using the $\chi^{2}$ statistic, and for trend using the Mantel-Haenszel extension to the $x^{2}$ test.

\section{Results}

All 172 families could be observed. The observed children had a mean age of 13 months. The average household consisted of almost eight family members. Mothers had a mean age of 28 years and a mean education of 3 years (range from 0 to 11 ), with $23 \%$ being illiterate. Half of the houses were connected to electricity, $46 \%$ had a radio, $39 \%$ a concrete or tiled floor (as opposed to earthen), and only $7 \%$ a television. 
Diarrhoeal incidence data were collected from all families on whom observations were made, in $85 \%$ of cases for the full 5 months, in a further $6 \%$ between 4 and 5 months, $2 \%$ between 3 and 4 months and in $7 \%$ for $<3$ months. The most important reason for leaving the incidence study prematurely was moving out of the study zone, furthermore two mothers were unwilling to continue filling out the diarrhoea calendar and two children died. Extensive analysis of the incidence data has been presented elsewhere ${ }^{4 .}$.

In 54 of the 172 families, no diarrhoea was reported in the entire study period. These 54 mothers were compared with the 118 where at least one child had experienced one or more episodes of diarrhoea. An episode of diarrhoea was defined as four or more watery motions within a 24-h period. Mean age of children in the 'diarnhoea' group was 12 months; almost the same as that of children in the 'diarrhoea-free' group which was 13 months. Their breastfeeding and weaning profile at onset of study was exactly the same for both groups: $7 \%$ were never breastfed, $53 \%$ were being breastfed at the time the study began, and $40 \%$ had been weaned.

There was no difference in the duration of follow-up between families in the 'diarrhoea' group and those in the 'diarrhoea-free' group. Thus, the analysis of the relationship between diarrhoea with hygiene practice could be carried out using the full sample size of mothers, independently of how long they participated in the incidence study. Nevertheless, to see whether the different follow-up durations would influence the results, an analysis of the whole sample was compared with one excluding the 12 families who participated $<3$ months. Only slight differences were seen. The analyses presented here are with all participating mothers

Table I presents the Kappa score for each hygiene practice and hygiene facility that could be observed twice. Since not all behaviours occurred during the visit, not every practice could be observed both times. Therefore the effective sample size varies for each hygiene practice studied. The Table also shows the percentage of mothers who performed the different 'good' hygiene practices during the first observation and the percentage who did this during the second one. The denominator is thus the number of mothers who could be observed twice on this particular hygiene practice.

Table 2 compares the frequency of 'good' practice between families in whom an episode of diarrhoea was recorded and those in whom no diarthoea occurred. Significant differences were detected for washing hands before preparing food, and having a clean kitchen floor. Several other practices were of borderline statistical significance. Of the 46 'good' practices studied only two went in the opposite direction (neither of which were statistical significant), five were unrelated and for 39 the association was in the expected direction. Of these 46 'good' practices, 18 were consistently performed by more than half of the families which stayed 'diarrhoea-free' and 14 by more than half of them who had presented diarrhoea. In all categories hygiene behaviour was poor with the exception of water hygiene and safe faeces disposal. Hands were only consistently washed before preparing food and on none of the other occasions such as before eating and picking up
the child. 
Table 1. Kappa score and frequency of "good' hygiene behaviour

'Good' hyggiene practices

Families Observations

observed $2 x$ First ${ }^{4} \quad$ Second ${ }^{2}$

\section{Food hygiene}

Hands washed before preparing food

Hands washed when contaminated during cooking

Fruit washed before eating

All food in covered pans or no food left

Utensils covered

Hands of mother washed before eating

Hands of child washed before eating a meal

Hands of child washed before eating a snack

child is assisted when eating

Baby's bottle hygiene

Hands washed before preparing baby's bottle 85

Hands washed before giving bottle or breast feeding 103

Hands of child washed before drinking bottle

Bottle given by adult (against child holds bottle)

Bottle used is clean

Bottle covered

113
87
41
171
171
50
47
53
39

$79 \%$
$33 \%$
$27 \%$
$64 \%$
$8 \%$
$24 \%$
$13 \%$
$23 \%$
$62 \%$

$74 \%$

$0,47 *$

$32 \%$

$22 \%$

$0,66^{*}$

$64 \%$

0,34

$9 \%$

$28 \%$

0,12

$0,66^{*}$

0,38

$11 \%$

$11 \%$

$56 \%$

0,28

0,22

$0,58 *$

\section{0}

93

84

91

\section{Personal hyglene aroumd the child}

Hands washed before picking up child

Child taken care by own mother not by caretaker

\section{$54 \%$ \\ $25 \%$ \\ $26 \%$ \\ $44 \%$ \\ $96 \%$ \\ $67 \%$}

$59 \%$

$0,43 *$

$30 \%$

0,35

$28 \%$

0,09

$40 \%$

0,06

$98 \%$

$66 \%$

$-0,03$

$0,43 *$

Mother/caretaker attends the child all the time

\section{$16 \%$ \\ $81 \%$ \\ $31 \%$ \\ $42 \%$}

\section{Domestic hygiene}

Table was cleaned within half hour after eating, cooking 138

Utensills cleaned within half hour after being used $\quad 142$

Kitchen floor clean at onset of the observation

Living room floor clean at onset of the observation

Barrier against animals in the house

Chase dogs out of the house when they enter

Chase pigs out of the house when they enter

Chase chickens out of the house when they enter

Garbage organized in little heaps or not present

Carbage (if present) $>2$ varas $^{3}$ from house

\section{Water hyglene}

Cover on well is in use

Vessel to draw water is clean

Vessel to store water is cleaned before filled with water

$>2$ water vessels in the house

$>25$ gallon water stored in the different vessels

\section{$62 \%$}

$45 \%$

$29 \%$

$32 \%$

$4 \%$

$11 \%$

$26 \%$

$10 \%$

$33 \%$

$55 \%$

$21 \%$

$91 \%$

$71 \%$

$40 \%$

$50 \%$

$56 \%$
$11 \%$

$82 \%$

$26 \%$

$40 \%$

0,24

0,59 *

$0,70^{*}$

$0,58 *$

$57 \%$

$42 \%$

$29 \%$

$34 \%$

$3 \%$

$13 \%$

$30 \%$

$8 \%$

$32 \%$

$56 \%$

0,31

0,31

$0,43^{*}$

0,29

$0,48^{\circ}$

0,18

$0,45^{*}$

$0,53^{*}$

0,36

0,31

$\begin{array}{ll}20 \% & 0,65^{*} \\ 94 \% & 0,25 \\ 71 \% & 0,53^{*} \\ 45 \% & 0,46^{*} \\ 50 \% & 0,69 * \\ 59 \% & 0,38\end{array}$


Table 1 Continued

'Cood" hygilene practlices

Families Obsemations

observed $2 \times$ First 1 Second?

Kappa

\section{Safe faeces disposal}

No dirty paper in and around latrine

No faeces on slab of latrine

No human faeces in the house

No human faeces on the patio

No animal faeces in the house

No animal faeces on the patio

No faeces $<5$ varas from house

Child uses a diaper or underclothes

Child defacated and bottom was cleaned

Faeces removed from where deposited

Mother washes hands after visiting latrine

\begin{tabular}{rlcc}
108 & $91 \%$ & $91 \%$ & 0,23 \\
108 & $94 \%$ & $98 \%$ & $-0,03$ \\
171 & $97 \%$ & $98 \%$ & $0,43^{*}$ \\
171 & $93 \%$ & $90 \%$ & 0,36 \\
171 & $80 \%$ & $80 \%$ & 0,28 \\
171 & $35 \%$ & $33 \%$ & $0,49 *$ \\
157 & $59 \%$ & $59 \%$ & $0,42^{*}$ \\
170 & $78 \%$ & $77 \%$ & $0,56^{*}$ \\
22 & $86 \%$ & $82 \%$ & 0,15 \\
22 & $91 \%$ & $77 \%$ & 0,18 \\
3 & $33 \%$ & $33 \%$ & \\
& & & \\
& & & \\
172 & $65 \%$ & $66 \%$ & $0,96 *$ \\
168 & $86 \%$ & $84 \%$ & $0,79 *$ \\
123 & $42 \%$ & $42 \%$ & $0,78^{*}$ \\
172 & $63 \%$ & $65 \%$ & $0,95 *$ \\
\hline
\end{tabular}

Water and sanitation facilities

Good water source (tap or protected weli)

Distance to water source $<150$ varas

Well has a cover on wellhead or cover is nearby

Existence of a latrine

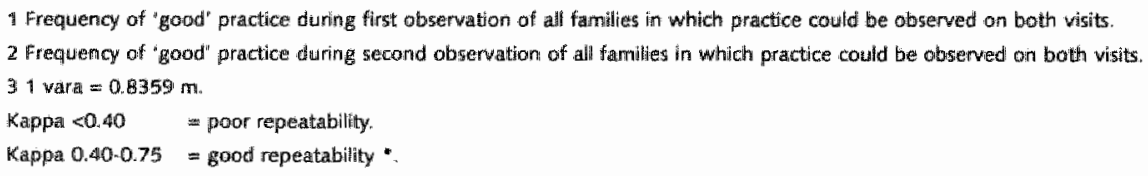

Table 2. The proportion in which 'good' practice was observed on both wisits in 'diarthoea-free' and 'diarhoea' families.

\section{'Goad' hyglene practices}

Families 'Diarthoea-free' Families with

observed $2 x$ famillies $(N=54)$ diarrhoea $(N=118)$

\section{Food hyglene}

Hands washed betore preparing food

Hands wasined when contaminated during cooking

Fruit washed before eating

All food in covered pans or no food left

Utensils covered

Hands of mother washed before eating

Hands of child washed before eating a meal

Hands of chilic washed before eating a snack

Child is assisted when eating

113

\section{Baby's bottle hygiene}

Hands washed before preparing baby's bottle Hands washed before giving bottle or breast feeding Hands of child washed before drinking bottle Bottle given by adult (against child holds bottle) Bottle used is clean Battle covered

$\begin{array}{rr}81 \% & 60 \% \\ 29 \% & 24 \% \\ 23 \% & 7 \% \\ 39 \% & 46 \% \\ 9 \% & 4 \% \\ 13 \% & 14 \% \\ 13 \% & 0 \% \\ 10 \% & 3 \% \\ 55 \% & 46 \%\end{array}$

$36 \%$

$10 \%$

$6 \%$

$34 \%$

$93 \%$

$52 \%$ 
Table 2 Continued

"Good" hygiene practices Famillies 'Dlarrhoea-fire' Families with

observed $2 x$ families $(N=54)$ diarmoea $(N=118)$

Personal hygiene around the child

Hands washed before picking up child

Child taken care by own mother not by caretaker

Clean appropriate place for child to stay

Mother/caretaker attends child all the time

170

163

164

\section{Domestic hygiene}

Table was cleaned within

hall hour after eating. cooking

Utensils cleaned within half hour after being used

Kitchen floor clean at onset of the observation

171

170

Living floor room cleain at oniset of the observation

Barrier against animals in the house

171

95

54

Chase pigs out of the house when they enter

116

Chase chickens out of the house when they enter

171

Garbage organized in little heaps or not present

Garbage (if present) $>2$ varas from houlse
$6 \%$

$76 \%$

$24 \%$

$36 \%$
$4 \%$

$75 \%$

$21 \%$

$28 \%$

\section{Water hygiene}

Cover on well is in use

Vessel to draw water is clean

Vessel to store water is cleaned before filled with water 31

$>2$ watter vessels in the house

$>25$ gallon water stored in the different vessels

All watter vessels for drinking water covered

\section{Safe faeces disposal}

No dity paper in and around latrine

No faeces on slab of latrine

No human faeces in the house

No human faeces on the patio

No animal faeces in the house

Water and sanitation facilities

Good water source (tap or protected well)

Distance to water source $<150$ varas 
Table 3. The proportion of "diarhoea-free" families according to wether "good" practice was observed" twice, oncer or not at all.

\section{'Good' hygiene practices}

Families Twice Once ${ }^{a}$ Not at allia observed $2 x$

\section{Food hygiene}

Hands washed before preparing tood

Hands washed when contaminated during cooking

Frwit washed before eating

Hands of mother washed before eating

Hands of chill washed before eating a meal

Hands of child washed before eating a snack

$\begin{array}{rrrr}113 & 39 \% & 18 \% & 19 \% \\ 87 & 36 \% & 38 \% & 29 \% \\ 41 & 60 \% & 30 \% & 27 \% \\ 50 & 29 \% & 42 \% & 23 \% \\ 47 & 100 \% & 29 \% & 29 \% \\ 53 & 67 \% & 42 \% & 3.4 \%\end{array}$

\section{Baby's bottle hygiene}

Hands washed before preparing baby's bottle

Hands washed before giving bottle or breast feeding

$\begin{array}{rrrr}85 & 39 \% & 25 \% & 16 \% \\ 103 & 53 \% & 26 \% & 31 \% \\ 90 & 50 \% & 31 \% & 22 \% \\ 93 & 23 \% & 33 \% & 29 \% \\ 84 & 28 \% & 20 \% & \\ 91 & 31 \% & 26 \% & 21 \%\end{array}$

Hands of child washed before drinking bottle

Bottle given by adult (against child holds bottle)

Bottle used is clean

Bottle covered

\section{Personal hygleme around the chilld}

Hands washed before picking up child

\section{Domestic hygiene}

Table was cleaned within half hour after eating, cooking

Utensils cleaned within half hour after being used

Kitchen floor clean at onset of the observation

Living room floor clean at onset of the observation

Barrier against animals in the house

$45 \% \quad 40 \%$

Chase dogs out of the house when they enter

Chase pigs out of the house when they enter

Chase chickens out of the house when they enter

Garbage organized in little heaps or not present

Garbage (if present) $>2$ varagt from house

$67 \% \quad 17 \%$

\section{Water hygiene}

$>2$ water vessels in the house

$>25$ gallon water stored in the different vessels

All water vessels for drinking water covered

\begin{tabular}{rrrr}
170 & $35 \%$ & $35 \%$ & $24 \%$ \\
170 & $36 \%$ & $19 \%$ & $31 \%$ \\
162 & $38 \%$ & $29 \%$ & $30 \%$ \\
& & & \\
174 & $42 \%$ & $18 \%$ & $33 \%$ \\
157 & $37 \%$ & $25 \%$ & $29 \%$ \\
170 & $36 \%$ & $27 \%$ & $16 \%$ \\
22 & $31 \%$ & $20 \%$ & $0 \%$ \\
22 & $31 \%$ & $20 \%$ & $0 \%$ \\
\hline
\end{tabular}

\section{Safe faeces disposal}

No animal faeces in the patio

No faeces $<5$ varas from house

Child uses a diaper or underclothes

Child defaecated and bottom was cleaned

Faeces removed where deposited

as cleaned

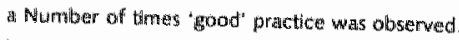

b क vartin 0.359 m.

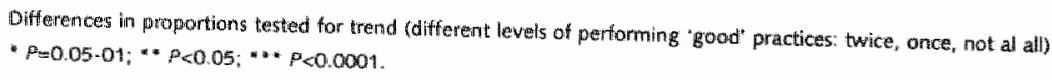


Table 3 presents the proportion of 'diarrhoea-free' families among those in whom 'good" practice was observed twice, once and not at all. Mothers of the three groups together form the effective sample size. In order to limit the amount of data, we only show those hygiene behaviours which were most closely related to diarrhoea in Table 2. In general, the children in families where the "good" practice was performed on both visits had lower rates of diarrhoea than those where it was observed on just one visit, and these had lower rates than children in families where the 'good' practice was not realized on either visit. Thus a clear trend is seen of decreasing number of 'diarrhoea free' families with increasing poor hygiene.

Table 4 gives the proportions of 'good' behaviour on both occasions compared to two levels of education: 'low' when schooling is $\leq 3$ years of primary school ( $54 \%$ ) and 'good' when $>3$ years $(46 \%)$. Of the 46 'good' practices studied, 32 were more often performed by mothers with 'good' schooling than by those with 'low' schooling, 13 less and for one the proportions were the same. Mothers with 'good' education covered their food, baby's bottle and water vessels and washed their hands before giving bottle or breast feeding significantly more often than those with lower schooling.

Table 4. The proportion in which "good" practice was observed on both wisits according to level of school ing.

\section{'Good' hygiene practices}

\section{Families}

Observed $2 \times$

\section{Food hygiene}

Hands washed before preparing food

Hands washed when contaminated during cooking

Fruit washed before eating

All food in covered pans or no food left

Utensils cowered

Hands of mother washed before eating

Hands of child washed before eating a meal

Hands of child washed before eating a snack

Child is assisted when eating.

113

87

41

171

171

50

47

53

39

\section{Baby's bottle hygiene}

Hands washed before preparing baby's bottle Hands washed before giving bottle or breast feeding 103

Hands of child washed before drinking bottle

Bottle given by adult (against child holds bottle)

Bottle used is clean

Bottle covered

Level of schooling

\begin{tabular}{rr}
\hline 'Good" & 'Low' \\
$+1+$ & $+1+$ \\
\hline
\end{tabular}

\section{Personal hygiene around the child}

Hands washed before picking up child

Child taken care by own mother not by caretaker

$42 \%$

$15 \%$

$9 \%$

$32 \%$

$94 \%$

$54 \%$

$69 \%$
$26 \%$
$10 \%$
$42 \%$
$7 \%$
$17 \%$
$4 \%$
$4 \%$
$52 \%$

$65 \%$

$25 \%$

$14 \%$

$23 \%$

$5 \%$

$11 \%$

$4 \%$

$8 \%$

$44 \%$
$35 \%$

$7 \%$

$6 \%$

$33 \%$

$89 \%$

$43 \%$ " *

$66 \%$

$\begin{array}{rrr}4 \% & 3 \% & 6 \% \\ 76 \% & 78 \% & 73 \% \\ 22 \% & 24 \% & 20 \% \\ 31 \% & 30 \% & 31 \%\end{array}$


Level of schooling

'Good' hygiene practices

Familles

Observed $2 x$

Domestlc hygiene

Table was cleaned within half hour

after eating, cooking

Utensils cleaned within half hour after being used

138

1.42

Kitchen floor clean at onset of the observation

Living room floor clean at onset of the observation

Barrier against animals in the house

Chase dogs out of the house when they enter

Chase pigs out of the house when they enter

Chase chickens out of the house when they enter

Garbage organized in little heaps or not present

Garbage (if present) $>2$ varas ${ }^{\text {a }}$ from house

\section{Water hygiene}

Cover on well is in use

Vessel to draw water is clean

Vessell to store water is cleaned

before filled with water

$>2$ water vessels in the house

$>25$ gallon water stored in the different vessels

All water vessels for drinking water covered

122

\section{Safe faeces disposal}

No dirty paper in and around latrine

No faeces on slab of latrine

No human faeces in the house

No human faeces on the patio

No animal faeces in the house

No animal faeces on the patio

No faeces $<5$ varas from house

Child uses a diaper or underclothes

Child defaecated and bottom was deaned

Faces removed from where deposited

Mother washes hands after visiting latrine

\section{Water and sanitation facilities}

Good water source (tap or protected well)

Distance water source 150 varas

Well has a cover on wellhead or cover is nearby

Existence of a latrine

$43 \%$
$27 \%$
$17 \%$
$17 \%$
$2 \%$
$3 \%$
$17 \%$
$5 \%$
$18 \%$
$38 \%$

$46 \%$

$34 \%$

$22 \%$

$22 \%$

$1 \%$

$6 \%$

$13 \%$

$2 \%$

$19 \%$

$41 \%$

$41 \%$

$21 \%$

$13 \%$

$14 \%$

$2 \%$

$2 \%$

$19 \%$

$7 \%$

$17 \%$

$36 \%$

$19 \%$

$86 \%$

$19 \%$

$18 \%$

$88 \%$

$17 \%$

$40 \%$

$38 \%$

$35 \%$ *

$47 \%$

$52 \%$

$92 \%$ * *

$96 \%$

$95 \%$

$89 \%$

$67 \%$

$89 \%$

$41 \%$

$65 \%$ *

$69 \%$

$92 \%$

$0 \%$

\section{a t varit $=0.9359 \mathrm{~m}$.}

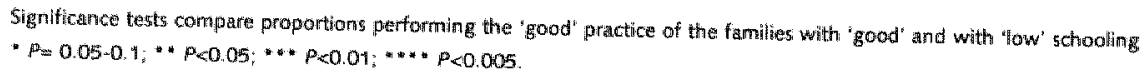


When analysing the association between education and the incidence of diarthoea we saw a borderline statistically significant relation: of the 12 mothers with $>6$ years of schooling $58 \%$ did not present diarrhoea during the entire study, meanwhile only $29 \%$ of those with $\leq 6$ years of education stayed 'diarthoea-free" $(P=0.06)$. Two socioeconomic indicators turned out to be important in this setting: type of floor and the presence of a radio. Of families with a 'good' floor plus a radio $48 \%$ stayed 'diarthoea free'; of families with a 'good' floor or a radio 35\%; and of those with an earthen floor and no radio only $16 \%$ ( $P$ for trend $<0.001$ ). Education was strongly related to these socioeconomic indicators: of families with a "good" floor plus a radio $68 \%$ had $>3$ years of schooling; of families with a 'good' floor or a radio $40 \%$; and of those with an earthen floor and no radio $35 \%(\mathbb{P}$ for trend $<0.01)$.

Table 5. The proportion of families in which 'good' practice was observed on both visits according to education and presence of a radio.

\section{No radio present Radio present}

'Good' hygiene practices

Families "Low'a "Good'b 'Low"a 'Good'b
observed $2 x$

\section{Food hygiene}

Hands washed before preparing food

$113 \quad 69 \% \quad 65 \% \quad 58 \% \quad 72 \%$

\section{Baby's bottle hyglene}

Hands washed before preparing baby's bottle

$85 \quad 28 \% \quad 41 \% \quad 43 \% \quad 59 \% *$

\section{Domestic hygiene}

Kitchen floor clean at onset of the observation

Living room floor clean at onset of the observation

Garbage organized in little heaps or not present

a. "Low' schooling is $\leq$ years of schooling.

b "Cood" schooling is $>3$ years of schooling.

Differences in proportions tested for trend ffor wiffenent llevelts of education and socloweconomic positioni

* $40.05 * 0.005$

In order to have an idea in how far economic position influences the effect of education on hygiene practices, we analysed those behaviours that were statistically significant related to diarhoea. All 'good' hygiene practices were most frequent in families where the mother had $>3$ years of schooling and where a radio was also present (Table 5).

\section{Discussion}

We investigated the influence of a large number of hygiene practices on the transmission of diarrhoea. This knowledge is necessary to develop successful hygiene education with 
appropriate messages. We also validated the technique of direct observation of hygiene behaviour. This information is needed to be able to evaluate the impact of hygiene campaigns on this behaviour.

Tables 2 and 3 give an impression of the effect of each hygiene practice separately. For some of the practices the effective sample size was very small and results should be interpreted with caution. Also, the large number of statistical tests performed means that one can expect several significant results to occur through chance alone. Almost all hygiene practices studied such as hand washing, food and water hygiene, cleaning food preparation area, general cleanliness and safe faeces disposal showed a clear relationship with diarrhoea. The families without diarrhoea were the ones who practiced 'good' behaviours more frequently and more consistently. Presumably because of the small sample sizes, only the more pronounced hygiene behaviours were statistically significant on their own. If one looks however at the overall picture, it is striking how consistent the trend is of increasing diarrhoea incidence with poorer hygiene behaviour.

We also found a trend that the proportion of 'diarrhoea-free' families increases with the number of times that a 'good' practice was observed (Table 3). This must be considered as a strong indicator of the importance of that specific hygiene practice in the transmission of diarrhoea. It was statistically significant for different types of hand washing, several practices within the category of domestic cleanliness and the use of a diaper or underclothes by the child. These practices might therefore be considered as targets for modification through health education campaigns. For each of these, earlier studies $5^{3-30,45,53}$ have also shown an effect on diarrhoea.

The facilities for water and sanitation have, of course, an excellent Kappa score; the few differences observed were caused by mothers who moved houses between the two observations. There was no less diarrhoea in families with piped-water or a protected hand-dug well than in those using untreated river water, so water quality does not seem to be a major risk factor in this setting. Distance to the water source and amount of water stored in the house (proxies for water consumption) seemed to have a weak association, as we had already found in the earlier study 3 .

As one can observe in Table 2, the existence of a latrine has a beneficial effect, but this has been noticed in many other studies. Mothers' behaviour with regard to disposal of children's stools is at least as important ${ }^{8,17,45}$. In rural Nicaragua children aged $<5$ years only infrequently use a latrine because they are afraid of the 'black hole' while mothers regard their faeces as benign. Consequently, cleaning occurs more for cosmetic/aesthetic reasons than because of mothers knowledge about transmission routes. This is also true for hand washing. As we discovered in the earlier study, knowledge about the importance of washing hands amongst the general population is quite prevalent, but limited to the hands of the mother when preparing food or baby's bottle; practices which also had a good Kappa score. Washing the child's hands before eating and the mother's before picking up the child are almost non-existent. This normative concept of mothers' behaviour performing the 'good' practice because it is socially acceptable behaviour, rather than effective in the prevention 
of diarrhoea has also been described elsewhere $28,42,48$ and fits well with Fishbein and Ajzen's Theory of Reasoned Action ${ }^{49}$.

A complicated relation has been described between socio-ecomomic status, education, cul tural factors and hygiene practices. Recent research has suggested that, in the US, afluence and education in the last decade of the nineteenth century made little difference to child mortality, until scientific knowledge showed households how to reduce dangers to their health. Since individuals with more education acquire and use new information more quickly, this emphasis on knowledge helps to explain the large differences in child mortality by mothers' education observed in developing countries today ${ }^{1,35}$. Most studies on hygiene show that practices improve as education (and affluence) increases, although in some studies only knowlledge, and not practices, increased 28. Several studies 28,50-54 found that the presence of certain material resources such as a latrine, water and soap should be considered as preconditions for a change in hygiene behaviour through health education. Without these preconditions, although knowledge exists, the "good' practice simply cannot be performed consistently; meanwhile social and cultural factors may have a reinforcing or restraining influence.

In our study no pronounced differences in hygiene behaviour were found for education, probably because this rural population is quite homogeneous for schooling; only 12 mothers had more than primary school education. Nevertheless differences were seen and in the expected direction -more schooling producing better hygiene behaviour, this being slightly stronger in the presence of a radio.

Several transmission routes of diarrhoea usually coexist ${ }^{55}$. Our results suggest that some routes, such as hand washing play a more important role than others. Of course the performance of one 'good' hygiene practice will have a strong correlation with the realization of other 'good' practices and although the practice itself may only be related weakly to diarrhoea transmission, it could be indicative for other behaviour which plays a more important role in the transmission.

What would be a good indicator for hygiene belhaviour in this setting? Indicators should at least be representative of general hygiene behaviour; easy to observe (no high education of field worker necessary); not costing much time (easy to observe during a certain time period); unambiguous (limited interobserver differences); almost all mothers can be observed for this particular practice (thus producing little missing data); not uniformly performed (e.g. $>10-20 \%$ or $<80-90 \%$ realizes the 'good' practice); accessible for the field worker (not necessary to enter bedrooms, etc). From the results of Tables 2 and 3 one can deduce that indeed hand washing has a relation with the transmission of diarrhoeal diseases, but only one of all types of hand washing had an effective sample size of more than 150 mothers and that one (before picking up the child) was performed by less than $10 \%$ of farmilies, leaving us with none of the different types of hand washing being an appropriate indicator for general hygiene behaviour.

In our case the cleanliness of the floor of kitchen and living room, the disposal of rubbish 
and whether the child uses a diaper or underwear seem to be good indicators for the measuring of hygiene behaviour. These practices fulfill almost all requirements: they have a clear effect on diarrhoea transmission; are easy to observe; do not cost much time; all mothers can be observed on this particular practice; $>15 \%$ and $<80 \%$ of mothers perform the 'good" behaviour and they are accessible for the field worker. Although cleanliness of the kitchen and living room floor are not completely unambiguous, training and especially frequent supervision of the field workers can limit the interobserver differences. Whether this finding can be generalized would require another study, preferably on another coninent, although results of all hygiene studies together on three different continents $3-30$-45-48,50-53.55 have given remarkably similar results (e.g. domestic cleanliness [kitchen, living room, yard] was often found to have an effect on diarrhoea incidence $5,8,11,12,17,18,45)$.

It was not feasible to combine hygiene practices in possible models and composite hygiene scores since almost none of the hygiene practices could be observed for all mothers during both observations. Excluding all missing data would leave us with a very small sample size and possibly a high selection.

The results of the Kappa score in our study present a low repeatability of observations of hygiene practices, less than half has a good repeatability and none an excellent score. This high variability at the individual level has been found in other studies 28,29 . Although individual practices are variable, the study in Burkina Faso 29 which observed 10 families on six separate occasions concluded that analysis of these six observations revealed a pattern of repeatability consistent with that suggested by a comparison of two observations. In Table 3 one can observe that apparently two observations were sufficient to group mothers in such a way that a trend in diarrhoeal incidence related to the level of hygiene could be uncovered. This trend would not have been detected if we had analysed both observations independently. As expected, the frequency with which the community as a whole performed the 'good' practice was about the same during the second observation as during the first.

\section{Conclusions}

This was the first investigation to study simultaneously a high number of hygiene practices hypothesized to relate to the transmission of diarnoeal diseases. A consistent effect of almost all hygiene practices on the diarrhoeal disease incidence was detected, even if this was statistically significant in relatively few cases. More schooling produced better hygiene behaviour, this being slightly stronger in the presence of a radio.

Relatively few practices were found to serve as an indicator for general hygiene behaviour related to the transmission of diarrhoea. These were cleanliness of the kitchen and living
room floor, disposal of rubbish and whether the child uses a diaper or underclothes.

The high variability of hygiene behaviour at the individual level requires repeated observations (at least two) -before and after the hygiene education in the event one wants to measure the impact of the campaign on the individual. The stable occurrence of practices in the 
community as a whole means that one observation before and one after the health education campaign should be sufficient to monitor its effect on the overall behaviour.

\section{Acknowledgements}

The authors ould like to thank The Leverhulme Trust, of Great Britain, which contributed to financing the investigation. We are grateful to Carmen Gonzalez, Joost. Hoppenbrouwer, Annemarie Sweep, Mayra Mejia, Gloria Garcia and Irza Picado for their participation in the field work. Our appreciation goes also to Prof. PG Kripschild for reviewing this paper.

\section{References}

1. Workd Bank. World Development Repont 1993, Investing it Health. Washington DC: World Bank, 1993.

2 Feachem RG. Preventing diarhores: what are the policy options? Health Poll Plann 1986; 1: $109-17$.

3 Bertrand WE, Walmus BF. Maternal knowledge, attitudes and practice as predictors of diarthoeai disease in young children. Int J Epidewiol 1983; 12: 205-10.

4 Clemens JD, Stanton BE An educational interyention for altering water-sanitation be haviours to reduce child hood diarthea in urban Bangladesh. I. Application of the case-control method for development of an intervention. Am J Epidemiol 1987; 125: 284-301.

5 Hunly SRA, Blum D, Kirkwood BR, Emeh RN, Feachem RG. The epidemiology of acute diarthoeit in a numi conmunity in Imo State, Nigeria. Trans R Soc Trop Med Hyg 1987; 81: 865-70.

6 Black RF, Lopez de Romana G, Brown KH, Brawo N, Bazalar OG, Ranashiro HC. Incidence and etiology of infatile diarthea and major routes of transmission in Husket, Beru. Am J Epidemiol 1989; 129: 785.99.

7 Alam N, Wojtyniak B, Henry FJ, Rahaman MM. Mothers' personal and domestic hygiene and diarhoea incidence in young children in rural Bangladesh. Int J Epidemiol 1989; 18: 242-47.

8 Han AM, Moe K. Household farecal contamination and diarrhoea risk, J Trop Med Hyg 1990; 93: 333-36.

9 Henry F. Rethim Z. Transmission of diarthoea in two crowded areas with different sanitary facilities in Dhaka, Banghadesh. $J$ Trop Med Hyg 1990; $93: 121-26$.

10 Konde-Luie JK, Elasu 5, Musonge DL. Knowledge, antikudes, and practices and their policy implications in childhood diar rhoea in Uganda. I Dir Dis Res 1992; 1: 25-30.

11 Baltazar IC, Tiglao TV, Tempongko SB. Hygiene behaviour and hospitalized severe childibod diarnoea: a casem control study. Bull World Health Ongan 1993; 71: 323-23.

12 Dikassa L, Mock N. Magnami. R, et al, Maternal behavioural risk factors for severe childhood diarrhowal disease un Kinsthasa, 2aire. In J Epidemial 1993;22: 327-33.

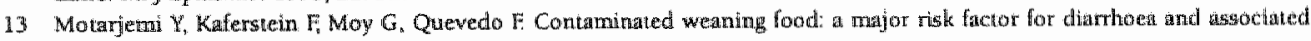
mallinutrition. Bull World Heath Orgam 1993; $71: 79-92$.

14 Feachem. RG. Interwentions for the control of dianthoeal diseases among young childrente promotion of personal and domes tic bygiene. Bull World Heallh Omgam 1984; 62 : $467-76$.

15 Stanton $B F$, Clemens JD. An educational interwention for altering water-santation behation to rethoe childhood diarthea in urban Bangladesh. II. A randomized trial to assess the impact of the intervention on hygienic behaviors and rates of diamen. Am J Epidemicl 1987; 125: 284-301.

16 Pinfold JV. Faecal contamimation of water and fingertip-rinses as method for evaluating the effect of low-cost water supply

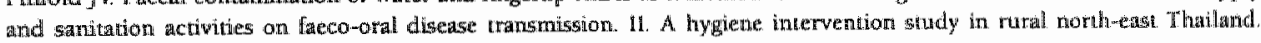
Eplidemiol infect 1990; 105: 377 89

17 Ahmed NU, Zeithin MF Beiser AS, Super CM. Gershoff SN. A longitudinal study of the impact of behavioural cham:ge futer.

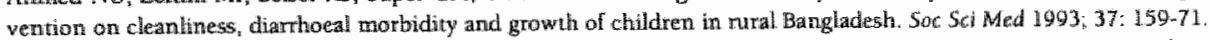

18 Haggerty PA, Muladi $K$, Kirkwood BR, Ashworth A, Manumebo M. Community based hygiene education to reduce darnthoeal disease in tural Zaire: impact of the intervention on diarrhoeal mortidity Int J Epidemiot 1994: 23: 1050-59.

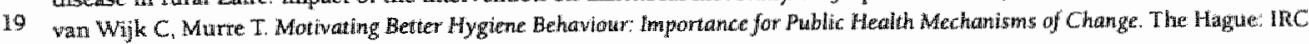
internationall Water and 5amitation Centre, 1994.

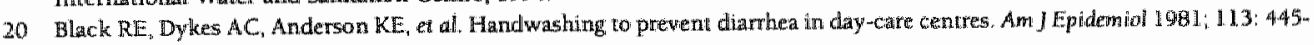
51 .

21 Khan MU. Internption of shigellosis by hand washing. Trows $R$ Soc Trop Med Hyg 1982; 76: 164-68.

22 Han AM, OO KN, Aye T, Hlang T. Personal toilet after defaecation and the degree of hand contaminatiwn according to difler- 
Eut methouls wged. I Trop Mited Myg $1986 ; 39: 237-41$.

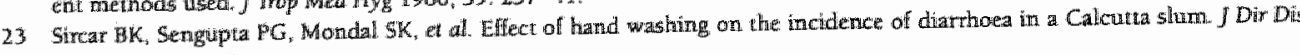
Thes $1.987: 5: 112-14$

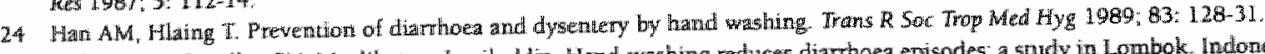

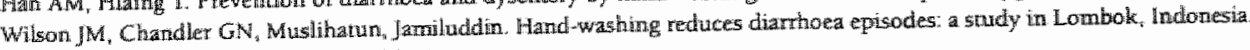
Jrans: R Soc Trop Med Hyg 199:; 85: 819-21.

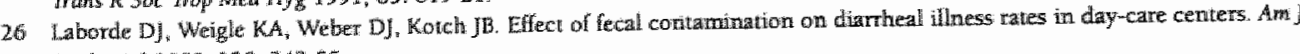
Eptidemial 1993; $138: 243-55$

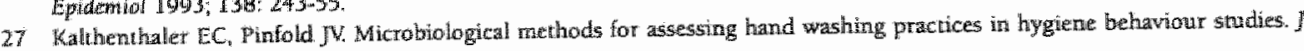
Irop Med Hyg 1995; 98: 101-06

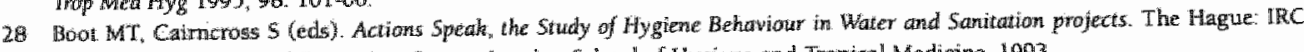
International Water and Sanitation Certure, London School of Hygiene and Iropical Medicine, 1903.

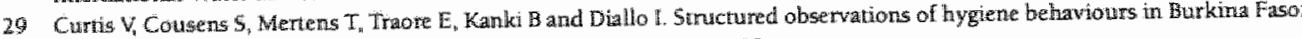
valdity, wariability, and utility, Bull World Health Orgat 1993:71: 23.32

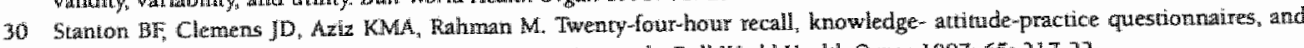
ditcel observations of sanitary practices: a comparative study. Bull World Health Organ 1987; 65: $217-22$.

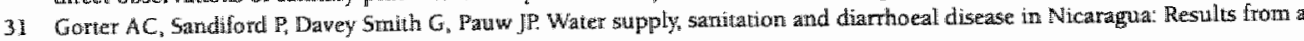
case-contról study Int J Epidemio! 1991; 20:527-33

32 Sandiford P Gorter AC, Davey Smith G, Pauw JPC. Determinans of drinking water qualiny in miral Nicaragua Epidemial Infect 19B9; 102: $429-38$.

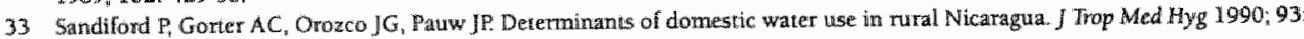
$383-89$.

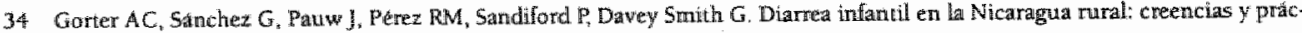
ticas de sahud tradicionales, Bol Offent Sanit Panam 1995, 119:377-90.

35 Sandiford $P$ Morales $P$ Gorter A, Coyle E, Davey Smith $G$. Why do child mortalty rates fall? An analysis of ahe Nicaraguan experience. An J Pallic Health 1991; 31: 30-37.

36 Sandiford $P$ Albers $H_{1}$ Otozo $f G$, Gotter A. The Nicaraguan rope pump. Waterhines 1993; 11:27-30.

37 Alberis $\mathrm{H}_{8}$ Meza $\mathrm{R}_{i}$ Solss $\mathrm{D}$, hodriguez $\mathrm{M}$. How the rope pump wom in Nicaragua. Waterlines $1993 ; 12: 3 i-5$.

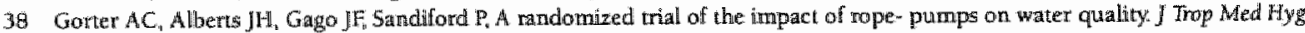
$1995 ; 98: 247-55$.

39. IRC International Water and Santation Centre. Evaluotion of the Nicoraguan Rope Pump. The Hague: 1RC, 1995.

40 Maciure $M_{3}$ Whllet WC. Misinterpretation and misuse of the Kappa statistic. Am J Epidemiol 1987; 126: 151-69.

41 Fleiss JI. Statistical Methods far Rates and Proportions, 2nd eda New Vork: John Wiley st Sons, 1981.

42 Feinstein AR, Cicchett. DV High agreement but low Kappa: I. The proble ans of two paradoxes. J.Clin. Epidemion 1990; 4.3: 543549 .

43 Cicchetri DV, Feinstein AR. High agreement but low Kappa: L. Resolwing the paradoxes. J.Clin. Epidemiol 1990, 43:551-558.

Af Sandiforc P. Pauw JP, Gonter AC, Davey Smith G, Morales P. Can Children with High Rates of Diarthoea be Identified from Recorts of Atrendancie at Health Serwices? International Ëpidemological Association (IEA), European Regional Meeting 1991, Basel 1991: 10

45 Bukenya GD. Nwolkolo N. Compound hygiene, presence of standpipe and the risk of childhond diarthoea in an urban settlement of Papua Mew Guitaen. Int J of Epidern iol 1991; 2: 534-39.

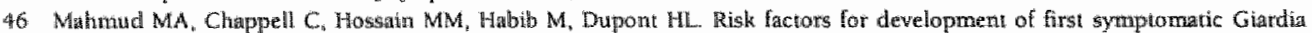

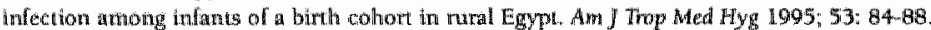

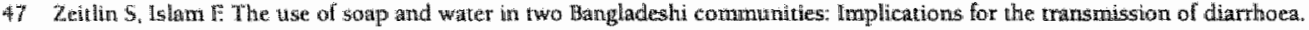
Rev Inflet Dis 1991; 13: $5259-64$.

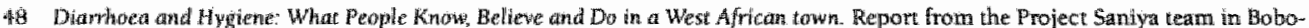
Dioulasso, Bu kina Faso. London Maternal and Child Epidemiology Unit, London School of Hyghene and Iropical Medicine, 1994.

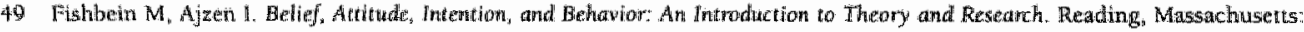
Addison-Wesle 1975.

50 Gilman RH, Marquis GS, Ventura $G$. Campas M, Spira W, Diaz E Water cost and awailabiliny: key detenminants of family hygien in a Peruvian Shantyown. Am J Public Health 1993 ; B3: 1554-58.

51 Koopran JS. Diarrhea and school tohle hygiene in Caili, Colombia. Am J Epidemiol 1978; 107: 412-20.

52 Morgan J. Loughborough Uniwersity of Technology, Whater, Engineering and Development Centre, Unban Hygiene Behaviour in Ethiopla, abstract in Highlights 1996; 7" 25-26.

53 Dargent-Molina P, James 5A, Strogatz DS, Savitz DA. Association between maternal equcation and infart diarrhea in different houselhold and community enwronments of Cebr, Philippines, Soc Sci Med 1994; $38: 343-350$

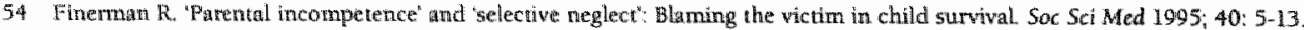

55 Blaser MJ, Smith PD, Ravdin JK, Greenberg HB, Guerrant R. (eds). Imfections of the Gastrointestinal Tract. New York: Rawen Press, 1995. 


\section{Section 4.5.}

\section{Childhood diarrhoea in rural Nicaragua: beliefs and traditional health practices}

Anna Cornelia Gorter, ${ }^{1}$ Germana Sanchez, Johanna Pauw, ${ }^{3}$ Rosa Maria Pérez, Peter Sandiford, ${ }^{4}$ and George Davey Smith ${ }^{5}$

Published in Boletin de la Oficina Sanitaria Panamericana (Bulletin of the Panamerican Health Organization), 1995; 119:377-390

Original title: Diarrea infantil en la Nicaragua rural: creencias y prácticas de salud tradicionales. Translated from Spanislx: Karen de Ayestas

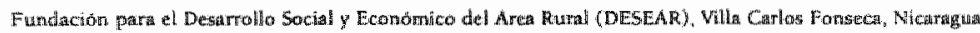

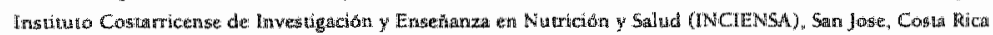

Asaciacion de Trabajadones en Salude Imiegración Social (TESTS), Mlaralagua, Nicaraguat

Departmens of International Community Health, Liverpool School of Tropical Medicine, Liwerpool, Uhe

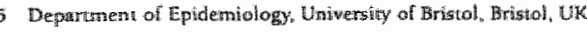




\section{Abstract}

In Nicaragua, the principal cause of infant mortality is diarrhoea, which is responsible of $40 \%$ of these deaths annually. This statistic reflects the low usage of health services and of oral rehydration therapy (ORT). Several studies were carried out in the Villa Carlos Fonseca municipality with the aim of creating programmes to improve this situation. This report describes two of those studies: one is ethnographic in character and was carried out in 1989, and the other epidemiological and was carried out in 1990. Both have as their aim, the gathering of information on traditional health beliefs and practices and their influence on the way in which mothers responded to their children's diarrhoeal illness. The ethnographic study involved interviewing 70 mothers with an average age of 28 years who had children under two years of age. The children represented two groups: one which was at a high risk of contracting diarrhoea and one which was at a low risk. The objectives included obtaining knowledge on the traditional taxonomy of diarrhoea, the perception of risk and the types of treatment being used. In the epidemiological study, 392 mothers of over 14 years of age participated, each with one or more children under the age of five, 216 of whom had diarrhoea in the two weeks preceding the survey. The objectives were to describe local health beliefs and practices and to determine the incidence of the types of diarrhoea according to the diagnoses made by the mothers.

At least 12 types of diarrhoea were identified, for which terms with names such as "empacho" and "sol de vista" were used. In the majority of cases, the mothers had more confidence in folkloric treatments that they themselves or the traditional midwifes or healers (curanderas) applied, than in the services provided by the health centres. This attitude limited their use of health services and of ORT, although it was observed that, in certain cases, mothers used traditional treatments in combination with those of western medicine. There was a direct correlation, though non-significant, between the level of formal education of the mothers and the frequency with which they visited the health center.

The authors suggest studying the effects of massage, herbal baths and other traditional treatments in order to evaluate their effectiveness and adapt them, to the extent possible, to "modern" medicine. Heal th services providers should become familiar with traditional nomenclature and beliefs in order to improve their communication with mothers, and reorient harmful practices to obtain better results in programmes for the prevention of infant diarrhoea. 


\section{Introduction}

Diarrhoea is one of the main causes of infant morbidity and mortality in developing countries ${ }^{1}$. In order to reduce this problem, the World Health Organization (WHO) has selected the following areas for special consideration: improvements in child nutrition, especially through the promotion of breast feeding and better weaning practices; improvements in potable water availability and sanitation; personal and domestic hygiene; immunization against measles in order to prevent diarrhoea associated with this disease and the improvement of the anti-rotavirus vaccine which is still in the experimental stage ${ }^{2}$.

Oral rehydration therapy (ORT), which consists of the administration of oral fluids - prepared with the appropriate homemade recipes; with commercially available oral rehydration salts; or those distributed by the WHO - can not be substituted in the treatment of diarrhoea. The systematic use of this therapy in health centres and in the home will undoubtedly contribute to the reduction of the rate of mortality caused by diarrhoea ${ }^{3}$. In rural zones, and more particularly in those that are isolated, the knowledge of preventive measures and of proper treatment of infant diarrhoea in the home, especially with ORT, can mean the difference between life and death.

During the last decades, several ethnographic studies on diarrhoeal disease in children of various socio-cultural environments have been carried out 4.15 . These studies have led to the analysis of the relationship between popular beliefs about diarrhoea and the behavior of mothers when faced with this illness in their children, including their inclination to use ORI. The results indicate that a modification of traditional practices in the home is necessary, but also note the importance of taking into consideration folkloric beliefs in planning campaigns to promote ORT and preventive measures directed at mothers of small children. Furthermore, in several epidemiological studies it was noted that some of these beliefs, attitudes and health practices may, in fact, increase the risk of diarrhoea. It is essential to have in-depth knowledge of these factors and seek ways for modifying them through health education programmes and other pertinent interventions $16-19$.

In Nicaragua, where ORT began to be promoted in the mid 1970's and where its use increased as of 197920 , a continuous decrease in the rate of infant mortality has been observed $^{21}$. Nonetheless, the present annual rate of 56 deaths per 1000 live births is unacceptably high ${ }^{1}$, mainly due to diarrhoea which causes $40 \%$ of these deaths ${ }^{22}$. Among the factors that could be related to this situation are: in case of diarrhoea not always the available health services are used; often these services are sought too late; and the use of ORT has not become generalized enough.

In societies with traditional cultures, mothers decisions on the treatment of their children suffering from diarrhoea are influenced by folkloric beliefs and customs. Taking this factor into consideration, in 1986, in the rural municipality of Villa Carlos Fonseca, a research programme was implemented as a basis for elaborating community projects for the prevention and treatment of childhood diarrhoea. This programme was financed by 
the WHO Work Group on Diarrhoea and by The Leverhulme Trust of Great Britain, and executed in collaboration with the Nicaraguan Ministry of Health, the Nicaraguan Institute for Water and Sewage, the Nicaraguan University of Engineering and the Foundation for Social and Economic Development of Rural Areas (DESEAR) in Villa Carlos Fonsecat $23-30$.

Through a first case-control study in 1986, in which 1402 families participated, risk factors directly related to the high incidence of childhood diarrhoea were identified. The most significant risk factors were low maternal education and low availability of water ${ }^{23}$. Based on this information, a project was elaborated in order to educate mothers in the principles of hygiene and to develop rope pumps in order to obtain water from hand-dug wells. Since then, the rope pump has become recognized as an appropriate technology and is presently being used in water and sanitation programmes in rural Nicaragua. This technology has been transferred to other developing countries such as Honduras and El Salwador ${ }^{24-26}$.

As a follow-up, in 1989, a prospective study was designed to clarify the relationship between mothers" hygiene practices and the incidence of diarrhoea in their children. A group of 172 mothers were selected randomly from the 1402 families who participated in the case-control study. The only criterion used in this selection was that mothers had children under the age of two years: half of the mothers with a history of frequent diarrhoea in their children and the other half with a history of low diarrhoea incidence in their children ${ }^{29}$. This study led to the identification of the most relevant of maternal practices related to diarrhoea and, based on these, permitted an improved design of the project for educating the population on hygiene principles. It was also decided to begin another project to introduce hand washing in schools.

This report presents the results of two other studies related to the previously mentioned investigations. The first, ethnographic in nature, was carried out in 1989 as part of the prospective investigation already described here, with the aim of obtaining information about traditional taxonomy, diagnoses and treatments for childhood diarrhoea used in the area. The second was a epidemiological survey carried out in 1990, with the aim of quantifying beliefs and treatment practices and determining the incidence of the types of diarrhoea, according to the traditional diagnosis made by mothers in the home.

\section{Materials and methods}

\section{Local context}

The municipality of Villa Carlos Fonseca, where the studies were carried out, is located 30 kilometers from Managua, on the pacific coastal plains of Nicaragua. Its population is approximately 30,000 , distributed among 38 communities. The local economy is dependent on agricultural production. Health resources available to the inhabitants of the municipality include one health center and six health posts, with six doctors, one den- 
tist, one pharmacist. two nurses, 12 nurse's aids and a health educator. There are also 80 midwives who also work as traditional healers.

\section{The ethnographic investigation}

Ethnographic research was carried out from March to June of 1989 , as part of the prospective investigation which complemented the case-control study of 1986 . Of the 172 mothers in the prospective study, 70 were randomly selected from a list of names to participate in the ethnographic research.

The participants had an average age of 28 years: $24 \%$ of them had never attended school, $67 \%$ had attended primary school from 1 to 6 years and only $9 \%$ had attended, though not completed, secondary school.

A semi-structured interview was used to gather information. A guide was designed, based on literature related to the topic and information provided by people who had thorough knowledge of the conditions of the community, such as traditional midwifes or healers, community leaders, and health and education personnel. A locally used taxonomy of the various types of diarrhoea was defined. In the semi-structured interviews, mothers were asked to verify the different types of diarrhoea as defined and it was sought to determine their knowledge and beliefs related to causes, symptoms and treatments depending on the types; their perception of risks; their use of health resources (official services or traditional midwife or healer); preventive practices and use of ORT.

The interviewers - a schoolteacher and a midwife, both mothers and residents of the municipality of Villa Carlos Fonseca - were fully trained by project personnel, emphasizing the need for objectivity toward folkloric beliefs. The two women had been interviewers in previous studies and had participated in the discussions related to the definition of the locally used taxonomy. Two students of Health Education from the University of Limburg (the Netherlands) observed the interviews as part of their study programme.

Data on age, education and socio-economic aspects of participants were taken from the prospective study, which has not yet been published completely 29 , and therefore are not included in this report.

\section{The epidemiological investigation}

The epidemiological study was included in the survey on morbidity and mortality, applied to 500 homes in the municipality of Villa Carlos Fonseca. These homes were randomly selected, by choosing every tenth house of the 5.000 located in the 38 communities. This survey was carried out from June to August of 1990 , which are the months of the highest incidence of diarrhoea during the year ${ }^{23-30}$.

Diarrhoea was defined as a period of one or more days, of three or more watery bowel movements. The interview for mothers with children under the age of five years included aspects related to the presence and type of diarrhoea, care of the child in the home, type of help sought and use of ORT. The interviews were carried out by four female res- 
idents of the municipality who had experience with previous studies and who were also trained by project personnel.

All women over the age of 14 years were interviewed and were asked the cause of death of any children who had died. If the death had been caused by diarnoea, they were asked to identify the type of diarrhoea.

\section{Results}

\section{The Ethnographic Study}

At least $90 \%$ of the mothers were familiar with all of the types of diarthoea according to the popular taxonomy, but only $77 \%$ knew about "bad stomach" and $74 \%$ about dysen" tery. In the following section an abstract is provided of the description made by the interviewed mothers with respect to each type of diarthoea and the use of ORT.

\section{Types of diarrhoea}

The statistics presented here are descriptive. The base for percentages is always given for the group of women who recognized and could comment on the type of diarrhoea in question.

Empacho. Empacho accurs when food or beverage sticks onto the wall of the stomach and rots. It can present a danger to the child's life. It causes a watery and foul-smelling, white or yellow diarrhoea, and is associated with swelling and pain in the stomach. It. may be accompanied by fever, vomiting and nausea, although some mothers explicitly mentioned absence of these symptoms.

According to $82 \%$ of the mothers, empacho should be treated with laxatives to clean the stomach and remove the material causing the diarthoea. Among treatments used are a laxative oil taken with or without lemon juice, and milk of magnesia. Other treatments include "sobada", a massage which is thought to umblock the stomach. A few mothers also mentioned ORT, antibiotics, herbs and antacids. Generally a mother or traditional midwife or healer was the appropriate person to treat empacho.

Infection. Infection is caused by a lack of hygiene. It is life-threatening and produces a watery, yellow or green diarrhoea, occasionally with mucous or blood. It is also accompanied by fever and vomiting.

In this case, $81 \%$ of the mothers mentioned treatment with antibiotics and $42 \%$ spoke of ORT, Almost all $(96 \%)$ said that infection should be treated by a doctor.

Sol de vista (mal de ojo). This is caused by the child having eye contact with people who are in what is considered to be a hot state. As examples of such people; $59 \%$ of the mothers mentioned workers who had worked all day in the fields; $54 \%$ mentioned pregnant women; $49 \%$ people with a penetrating gaze; $46 \%$ drunks and people with hangovers; 
$17 \%$ menstruating women; and $7 \%$ young women. Sol de vista can be life threatening.

This diarrhoea is green, with mucus, and defecation is painful. The child has a high fever and headache, cries and has sad or 'dirty" eyes.

Treatment requires the presence, symbolic or real, of the person who caused the condition. For example, $53 \%$ recommended that the child be wrapped in the sweaty shirt of the person who caused the diarthoea and $24 \%$ recommended that the child be held in the lap of this person. According to $39 \%$ of the mothers, this type of diarrhoea should be treated with alcohol or herb baths. Other suggestions included the application of father's urine on the child"s head; the application of a mixture of saliva and breast milk; stomach massage; and a hair being wrapped around one of the child's wrists. Only two women (3\%) mentioned ORT and one recommended taking the child to a doctor.

Sol de cielo (pujo de sol). This "diarrhoea of the sun" is attributed to several causes: heat and exposure to the sun $(92 \%)$, hot weather $(11 \%)$ and heat in the home $(11 \%)$. It is not considered dangerous. This diarrhoea is green and painful, with mucus and fever.

According to $72 \%$ of the mothers, treatment consists of baths with alcohol, herbs, wood and nut oils, or very cold water. Fruit drinks (frescos) were recommended by $17 \%$. In general, the mothers themselves treat children with sol de cielo, though $20 \%$ preferred to take them to a traditional midwife or healer. Only one suggested seeing a doctor.

Diarrea de movimiento. This diarrhoea is considered part of normal development. It occurs when the child is teething (92\%), starting to crawl (62\%) or walk $(89 \%)$. It is not considered dangerous and has no specific symptoms.

According to the majority (54\%) of the mothers, this diarrhoea does not require any specific treatment, but 16\% thought it was necessary to visit the health center. Some women mentioned antibiotics $(8 \%)$, fruit drinks $(5 \%)$, ORT (3\%) and rice water $(3 \%)$.

Worms and parasites. These cause two types of diarrhoea and can be life- threatening. They are considered to be almost identical, except that they can be distinguished by their size. Worms are easily detected in the child's stool, but parasites are invisible. Bad hygiene is associated with diarrhoea caused by parasites, but seldom with that caused by worms. Worms become dangerous only when they are activated by a full moon, foods such as milk and sugar, and fever (worm fever), which causes the worms to leave the stomach and circulate through the body.

The stool contains a gritty element (chingaste) in its generally liquid composition. Common symptoms are fever, vomiting, and a painful stomach which may be swollen. The child's eyes may remain open while sleeping. The worms can cause itching of the nose, face or stomach, and grinding of the teeth. Mothers give children medication for parasites each time they present these symptoms. 
The majority (92\%) of the mothers mentioned mebendazol, piperazine, or metronidazole, but also herbs such as "epazote' or wintergreen (20\%) and garlic (10\%), which cause worms that are circulating in the body to return to the stomach, where they can be expelled by medicines. Five women ( $8 \%$ ) mentioned the use of ORT when parasites are detected, but none mentioned it for worms. In the case of worms, $62 \%$ considered a visit to the doctor necessary, and $93 \%$ considered this necessary for parasites.

According to $39 \%$, self-treatment can also be used, especially for worms. The first step is to administer substances to calm or regroup the worms, then the patient is taken to the health center. Only two mothers (3\%) mentioned the traditional midwife or healer.

Bad stomach. The cause of bad stomach is bad or badly prepared foods $(51 \%)$, milk $(23 \%)$, food in general $(11 \%)$, or eating when angry (4\%). It is not a danger to the child's life. The diarrhoea is watery, with stomach pains and sometimes accompanied by vomiting. Ten mothers insisted that it did not cause a fever, while seven stated that it did.

Half of the mothers suggested milk of magnesia, with or without lemon, or a laxative oil to treat this diarrhoea, $34 \%$ recommended other antacids. In $60 \%$ of the cases, the mother administered the treatment, although $34 \%$ mentioned a visit to the health center and two $(4 \%)$ to the traditional midwife or healer.

Dysentery (desgaste). There was no consensus on the cause of this diarrhoea, but bad hygiene, factors related to food and beverage preparation and consumption were mentioned. Almost half of the mothers were unable to identify some cause. Dysentery is seen as an end-stage condition following a prolonged diarrhoea due to infection or sometimes empacho. It is seldom related to any other type of diarrhoea. It is the most dangerous type of diarrhoea and the less known. It is watery and bloody, and may be accompanied by mucus and sometimes by vomiting and fever.

Only 58\% of the women recommended any type of treatment, and ORT was the most frequently $(60 \%)$ mentioned. Some mentioned antibiotics, fruit drinks, and aluminum preparations, as well as baths. The great majority (90\%) stated that the person most appropriate for treating dysentery was the doctor.

Fallen fontanelle, $90 \%$ believed that this condition could be caused by falls, meanwhile $6 \%$ mentioned the child's head falling back suddenly and 1.5 to $3 \%$ suggested the rapid removal of the bottle; blows to the head; violent coughing; being held in the wrong way; having received a blow while eating; or drinking from a bottle with a nipple that was too hard. Almost half ( $45 \%$ ) thought that diarrhoea itself caused the fallen fontanelle and considered this condition to be fatal.

Treatments mentioned were pushing the roof of the mouth upwards with the thumb (79\%); applying massage (44\%); holding the baby upside down and hitting it on the bottom of its feet $(38 \%)$; a bath with oil $(5 \%)$; laxatives ( $2 \%)$; and giving herb infusions (2\%). The massage used in this case is different from that which is used for empacho. It 
begins with the hands and feet and moves to the center of the body. It is believed that this practice lifts the fallen fontanelle, as it "closes the body". Of the mothers $91 \%$ recommended a visit to the traditional midwife or healer; $11 \%$ a visit to the health center; and $5 \%$ the administration of home remedies.

\section{Attitudes towards oral rehydration therapy}

Of the mothers who were interviewed, $88 \%$ said they thought oral rehydration therapy was an appropriate treatment for diarrhoea. Some of their reasons included that it cleaned out or refreshed the stomach $(53 \%)$, that it eliminated dehydration (48\%), or that it sustained the child ( $15 \%)$. On the other hand, some mothers indicated that it was not efficient because it did not do any good (6\%), it did not stop the diarrhoea (5\%), that it produced swelling ( $2 \%)$, or that all it did was rehydrate the child $(2 \%)$.

When they did not have access to rehydration salts, $70 \%$ used substitutes. Of these, $81 \%$ used rice water (rice cooked in water, then strained and sweetened); $68 \%$ used lemon with sugar; $21 \%$ used home remedies (described by the mothers as a liter of water boiled together with sugar and salt) and $9 \%$ used fruit drinks.

As part of the analysis of the results, each mother was assigned a total of points rating them on a scale of "traditionalism" depending on their preference for "modern" treatments such as antibiotics, anti-parasite medication and ORT, or "traditional" treatments such as herbs, baths, fruit drinks and laxatives. They were also assigned a score according to the type of help they sought when their child became ill: "modern" when they mentioned the doctor and "traditional" when the treatment was applied by a traditional midwife or healer; by the mother herself; or by the person who had supposedly caused the condition. No correlation was found between the age and formal education, and the level of "traditionalism" of the women. Nevertheless, mothers with a higher level of schooling were those who had more favorable attitudes towards the use of ORT.

\section{The Epidemiological Study}

There were 3175 people living in the 500 homes that were interviewed (6.4 persons per family), of whom 799 were women over the age of 14 . Of these, 391 had one or more children under the age of five years. In total, 599 children under five years of age were recorded in the 500 houses, 216 of whom had diarrhoea during the two weeks prior to the survey.

Table 1 represents the number of cases of diarrhoea which occurred during those 14 days and the health resources and remedies sought by mothers. The cases of diarrhoea are distributed according to the ten types previously described, plus "pujo" and "hot stomach", which were identified on completion of the ethnographic study.

"Pujo" was described as watery, green diarrhoea, occasionally with mucus. The child suffering from pujo has to exert much pressure in order to defecate. "Their ribs become 


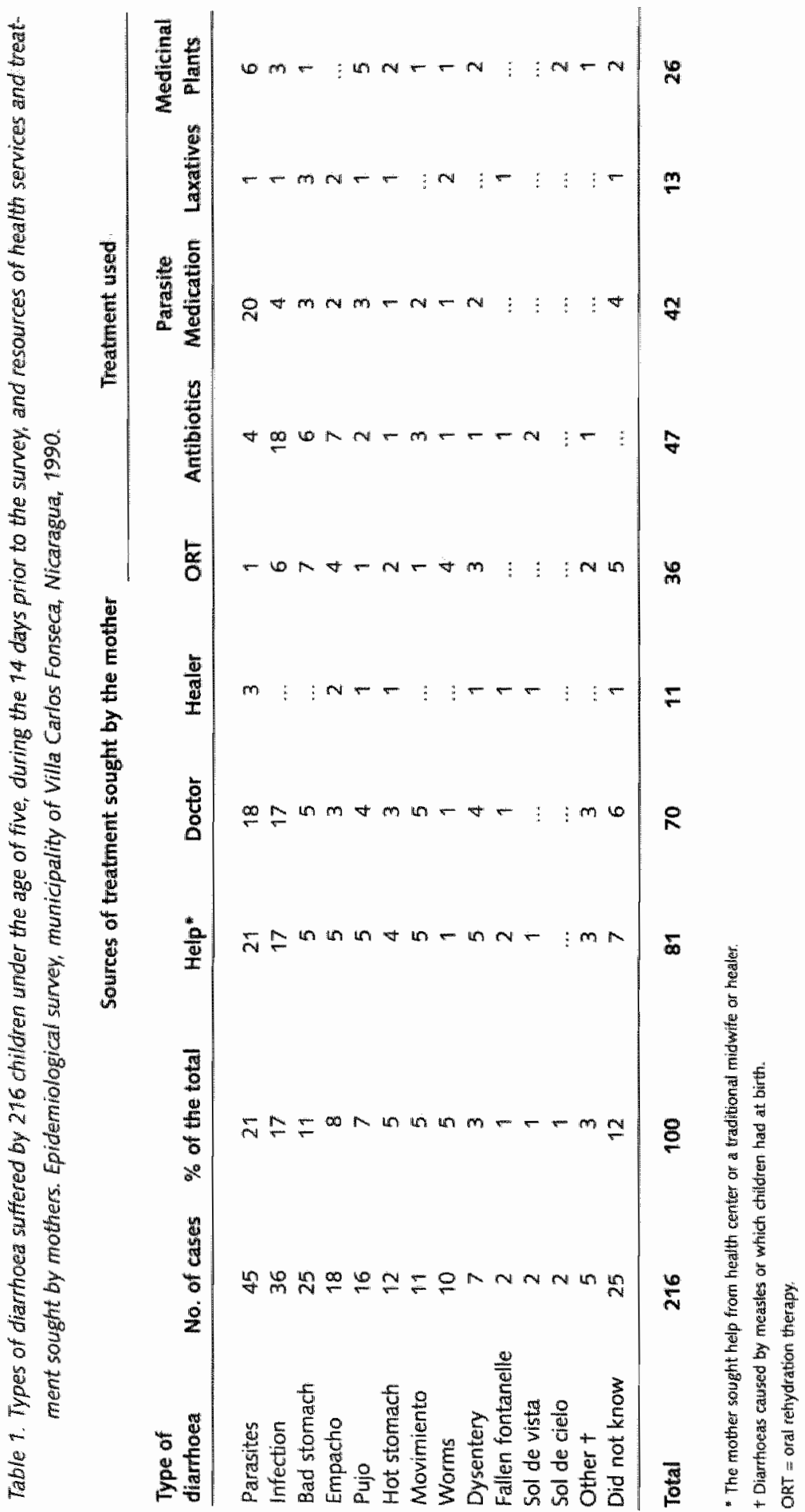


hot", but there is no fever. "Hot stomach", on the other hand, is a green or yellow diarrhoea, without mucus, and with only the stomach area becoming hot. It is believed that both diarrhoeas are caused by heat: high temperatures; "a strong gaze"; or lack of cooling drinks. They can be cured with cool drinks and baths.

As indicated in table 1 , in 81 cases $(37 \%)$ of the 216 children who had diarrhoea, mothers sought help; $70(32 \%)$ visited the health center and $11(5 \%)$ consulted the traditional midwife or healer. Only $36(17 \%)$ of mothers applied ORT. The use of ORT was directly related to the source of help sought by mothers. For example, $36 \%$ of mothers who visited the health center used ORT, while only $8 \%$ of those who did not seek help used it. None of the mothers who visited the traditional midwife or healer used ORT. With regard to other treatments, it must be mentioned that antibiotics and anti-parasite medication were used in a higher proportion than medicinal plants and laxatives.

The diarrhoeas considered by mothers to be potentially fatal in the ethnographic study were divided into two groups: one which included "traditional" diarrhoeas and the other "modern" diarrhoeas. "Traditional" diarrhoeas included empacho, sol de vista, fallen fontanelle whose causes according to the mothers were not similar to those of western medicine. Those that did have similarities to western medicine were classified as "modern", such as worms, parasites, infection and dysentery.

Table 2 shows the response of mothers to "modern" or "traditional" diarrhoeas, considered to be dangerous. It concerns a sample of 120 children from the total group of 216 children under the age of five. A relationship can be distinguished between the mother's diagnosis and her response to the diarrhoea. In the case of "traditional" diarrhoeas the administration of laxatives and visits to the traditional midwife or healer were more common. However, also in some cases, modern treatments were sought (doctor, ORT).

Table 3 records the responses of the mothers according to the diarrhoea most frequentlyt suffered by their children of different ages and to the question of whether or not their children under five years had ever had that type of diarrhoea. As can be observed, the epidemiology of the types of diarrhoea was different according to ages. During the first year of life, "traditional" diarrhoeas were the most important. It can also be noted that dysentery was the less frequent (13\%) type of diarrhoea while infection the most frequent $(67 \%)$. More than a quarter of the mothers indicated that one or more of their children had suffered from at least one of the "traditional diarrhoeas".

The 799 women over the age of 14 who were surveyed also informed the investigators of children who had died and the cause of death. In this group, 3516 children had been born and 451 had died, 143 from diarrhoea $(32 \%)$. Table 4 indicates the type of diarrhoea suffered by the child upon death, according to the mother's diagnosis. Three types of diarrhoea - empacho, sol de vista and fallen fontanelle - caused $26 \%$ of the deaths. As indicated in table 2 , only $18 \%$ of the mothers take their children in this state to the doctor. 
Table 2. Percentage of cases and types of diarrhoea according to heatth resources and treatments sought by mothers of 120 children under five and their perception of the diarhoea as "modern" or "traditional". Epidemiological survev, municipality of Villa Carlos Fonseca, Nicaragua, 1990.

\begin{tabular}{lccc} 
Health resource sought & $\begin{array}{c}\text { Parasites } \\
\text { Worms }\end{array}$ & $\begin{array}{c}\text { Modern } \\
\text { Infection } \\
\text { Dysentery }\end{array}$ & $\begin{array}{c}\text { Traditional } \\
\text { Empacho, Sol de Vista } \\
\text { Fallen Fontanelle }\end{array}$ \\
\hline Did not seek help & 60 & 49 & 64 \\
Visited a doctor & 35 & 49 & 18 \\
Visited a traditional midwife or healer & 5 & 2 & 18 \\
Used ORT (total) & 9 & 21 & 18 \\
Visited a doctor and used ORT & 5 & 14 & 50 \\
Did not visit a doctor, but used ORT & 11 & 44 & 11 \\
Used antibiotics & 9 & 14 & 46 \\
Used parasite medication & 38 & 2 & 9 \\
Used laxatives & 5 & 12 & 14 \\
Used medicinal plants & 13 & & 0 \\
\hline
\end{tabular}

ORT $=$ orall rehydration therapy

Table 3. Frequency percentage of different types of diarrhoeas according to the age of the child among children of the 391 mothers who were interviewed, according to the responses to questions indicated below. Epidemiological survey, municipality of Villa Carlos Fonseca, Nicaragua, 1990.

\begin{tabular}{|c|c|c|c|c|}
\hline \multirow[b]{2}{*}{ Type of diarrhoea } & \multicolumn{3}{|c|}{ Age } & \multirow[b]{2}{*}{ Sometimes: } \\
\hline & 0-12 months" & $1-5$ years $t$ & $0-5$ years & \\
\hline Parasites & 9 & 40 & 24 & 62 \\
\hline Infection & 26 & 11 & 19 & 67 \\
\hline Bad stomach & 4 & 12 & 8 & 47 \\
\hline Empacho & 13 & 2 & 8 & 38 \\
\hline Pujo & 9 & 4 & 6 & 52 \\
\hline Hot stomath & 10 & 6 & 8 & 51 \\
\hline Movimierito & 11 & 3 & 7 & 61 \\
\hline Worms & 4 & 21 & 13 & 59 \\
\hline Dysentery & 3 & 5 & 2 & 13 \\
\hline Fallen Fontanelle & 3 & 0.25 & 1 & 25 \\
\hline Sol de vista & 4 & 0.25 & 2 & 32 \\
\hline Sol de cielo & 3 & 0.25 & 2 & 30 \\
\hline
\end{tabular}

- What type of diarthoea was most frequent in your thilidren between the ages of 0 and 12 months?

t What type of eliarhoea was most frequent in your childanen between the afges of 1 and 5 years?

- Hact one on wore af your childiden under five years of age this type of diturhoed at any time?

A relationship, though not statistically significant, was discovered between age and schooling of the mothers and the type of help sought by them. Mothers who took their children to traditional midwifes or healers were older (on average 30.3 years) and had less formal schooling (2.8 years on average) than those who took their children to the 
health center (on average 27.4 years with 4.1 years of schooling). Mothers who did not seek help were on average 28.5 years of age with 3.3 years of schooling.

Table 4. Number and percentage of 143 children under the age of five who died from different types of diarrhoea, according to the mother's diagnosis and a comparison with its incidence. Epidemiological survey, municipality of Villa Carlos Fonseca, Nicaragua, 1990.

\section{Cause of death} No. of deaths Incidence:

\begin{tabular}{lrrr} 
Infection & 30 & 21 & 17 \\
Empacho & 27 & 19 & 8 \\
Dysentery & 16 & 11 & 3 \\
Worms & 9 & 6 & 5 \\
Sol de vista & 6 & 4 & 1 \\
Fallen fontanelle & 4 & 3 & 1 \\
Parasites & 3 & 2 & 21 \\
Pujo & 1 & 1 & 7 \\
Bad stomach & 1 & 1 & 11 \\
Did not know & 46 & 32 & - \\
\hline Total & 143 & 100 & -
\end{tabular}

- Based on Table $\|_{\text {. }}$

\section{Discussion}

The typology of diarrhoea that emerges from both studies is similar to those described in other research carried out in Nicaragua ${ }^{31-33}$ and to those that have been elaborated for other Central American countries $5,31,34$ and other Latin-American cultures outside the isthmus ${ }^{35.36}$. Empacho in Nicaragua is similar to what is also called empacho in Honduras, Guatemala, Mexico, Peru, Chile and among Puerto Ricans in the United States,15,31,35-38, and "pega" in Costa Rica ${ }^{39}$. It is also somewhat similar to what is called "infection" in Ecuador"t.

The classification of "cold" or "hot" is the central organizing principal underlying popular etiology of diseases within Latin American countries ${ }^{41,42}$. In Nicaragua, this classification explains the origins of diseases such as "sol de vista", and "hot stomach". Furthermore, it characterizes food and beverages, and indicates whether it is convenient or not to consume them. Nevertheless, it is a system that is not used in a generalized or coherent manner and can be compared to the case of Mexica, where the classification of "cold" and "hot" remains, but only in a very rudimentary way ${ }^{33,43 .}$

It is interesting to observe that the frequency with which the different diarrhoeas occurred in the 216 children, during the two weeks prior to the survey (see table 1), coincided considerably with those noticed by mothers in their children between the ages of 0 and 5 years of age (see table 3 ). This reveals a consistent popular nosology and a clear epidemiological pattern of the different types of diarrhoea. 
The epidemiology of the different types of diarrhoea appeared to be different depending on the age of the children. The "traditional" diarrhoeas played a significant role during the first year of life, when mortality resulting from diarrhoea is at its highest. Of infant deaths $26 \%$ were attributed to "empacho", "sol de vista" and fallen fontanelle, which is a very high number if the rate of frequency of occurrence is taken into consideration. This is especially true for "empacho" (see tables 1 and 4). Diarrhoeas identified with these names presented the following inconveniences: mothers were less likely to visit a doctor, and more likely to visit a "traditional midwife or healer", and more likely to use laxatives, increasing the risk of dehydration. This practice was motivated by the belief of many mothers that "doctors do not know about such diarrhoeas as 'empacho' and do not know how to cure them". Dysentery also claimed many victims if its low incidence is taken into consideration, although the majority of mothers did visit a doctor when they recognized it as such.

In both studies, the mother's diagnosis was very important in deciding what type of help to seek and what kind of treatment was required in each case of diarrhoea. This result has also been obtained in other studies carried out in other socio-cultural contexts, such as Zimbabwe $^{7}$, Pakistan 9.12 , Bangladesh ${ }^{10}$, South Africa ${ }^{11}$, Sri Lanka ${ }^{13}$, India ${ }^{14}$ and Guatemala'15. In many studies it has been proposed that the popular taxonomy of diarrhoeas, as well as mothers traditional responses to them, be taken into account when designing programmes to promote ORT ${ }^{7-14}$. Also in other studies it is suggested that "traditional midwifes or healers" be incorporated into these programmes ${ }^{11,12}$. Furthermore, it is recommended that health personnel's awareness of traditional beliefs be increased in order to improve communication with mothers. It is thought that if the personnel understood popular beliefs and used the popular taxonomy for diarrhoeas, it would facilitate access of members of traditional cultures to health services ${ }^{7,9}$.

In the ethnographic study, no relationship was established between the level of formal education and the age of mothers and their "traditionalism", but it was noted that mothers with more years of schooling had a more accepting attitude toward the use of ORT. In the second study, it was determined that the mothers who had received more schooling visited health centres more often.

As can be observed in table 2, mothers used "traditional" treatment (such as medicinal plants) for "modern" diarrhoeas, and also "modlern" treatments for "traditional" diarrhoeas. It can thus be inferred from this information that, although mothers will not change the traditional taxonomy for diarrhoea, their attitude towards treatment could change. This is why they were combining "traditional" and "modern" treatments, similar to what was described in an ethnographic study carried out in Papua New Guinea*. This is also the case in Hispanic communities of the United States where popular taxonomy, similar to that of Nicaragua ${ }^{38,44,45}$, is still used for diarrhoeas even though mothers take their children to doctors.

Health personnel often scorn many practices that are part of "traditional" treatment, considering them to be a danger to health. For example, it is believed that laxatives increase. 
dehydration, without taking into account the fact that usually only a very small doses is given to children. It is also thought that wrapping a child with fever in a sweaty cloth could provoke febrile convulsions, without considering the fact that this procedure is often combined with an alcohol or herb bath.

In 1990 the use of ORT was still infrequent and was not generalized in rural Nicaragua. Its use by $17 \%$ of the mothers in our study coincided exactly with the $17 \%$ registered in a study carried out in Honduras, where traditional medicine is similar to that of Nicaraguat6.

The ethnographic study showed that giving rice water to children with diarthoea a common practice was. It is worth mentioning that if part of the sugar were replaced by salt in the rice water, it would become an adequate means of oral rehydration.

\section{Conclusions}

The studies described here confirm that traditional beliefs and practices continue to exist in the rural areas of Nicaragua and have a direct influence on the manner in which mothers respond to diarrhoea in their children. Furthermore, they limit the use of health services and ORT.

On the other hand, although mothers maintain the traditional taxonomy for diarthoea, it is also true that their behavior can be changed regarding its treatment. It has been observed that "traditional" and "modern" treatments are, at times, combined.

It would be interesting to carry out research on traditional treatments and measure their effects. Empirical data should be obtained on practices such as the use of laxatives and massages applied when the case is believed to be "empacho" and the wrapping of children in a sweaty shirt when "sol de vista" is suspected, in order to evaluate the merits of each treatment and stimulate their adaptation or replacement. In this sense, promoting rice water with sall could be appropriate for replacing commercial oral rehydration salts.

The use of ORT was not very frequent in the population studies, but it was evident that its use increased when mothers visited the health center. In order for health services to receive all types of diarrhoea, including "traditional" diarrhoea, there must be better communication between mothers and health personnel. Therefore, it is essential that this personnel be trained in the knowledge of traditional medicine. This would permit understanding of traditional beliefs and practices and the use of popular names for the differw ent types of diarrhoea during medical visits. It would also lead to an increase in the understanding between mothers and health personnel, and, possibly the acceptance by mothers of the recommended "modern" treatment or adaptation of raditional medicine (such as rice water with salt), and of the fact that health services are valuable resources in the treatment of any type of diarrhoea. 
Traditional medicine can and should play an important role in designing programmes for the prevention of diarthoea. The results of the two studies described here can form a solid basis for planning and performing such programmes, as was done previously in the case of promoting hygiene in Villa Carlos Fonseca. A promotional programme must recognize the importance of popular knowledge, respect it and use it as a guide in the modification of potentially harmful practices. It is also important to recognize other difficulties, such as the lack of water, which at times creates an obstacle to these changes.

In Nicaragua, popular knowledge is a result of both traditional and modern medicine. A good programme must take into account this plurality and seek the means for explaining the causes of diarrhoea, combining traditional and modern concepts. Mothers will feel motivated to change their habits only if they understand the relationship between harmful hygienic practices and their children's diarrhoea. Infant mortality caused by diarrhoea could be reduced considerably in Nicaragua and other countries with similar societties and cultures if popular knowledge of diarrhoea were recognized, if communication between mothers and health personnel were improved and if programmes were desigmed to prevent diarrhoea and promote ORT in accordance with local cultures.

\section{Acknowledgements}

The authors would like to thank The Leverhulme Trust, of Great Britain, which contributed to financing the studies described in this article. They are also grateful to Carmen Gonzalez, Joost Hoppenbrouwer, Annemarie Sweep, Patricia Morales, Celia Moreira, Mayra Mejia, Gloria Garcia and Irza Picado for their participation in the fieldwork.

\section{References}

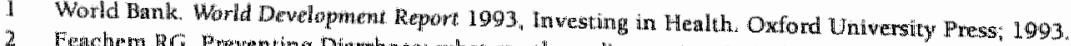

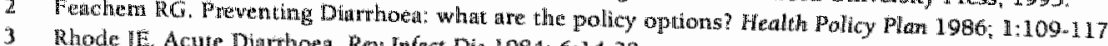

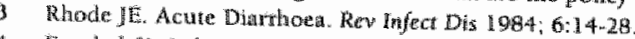

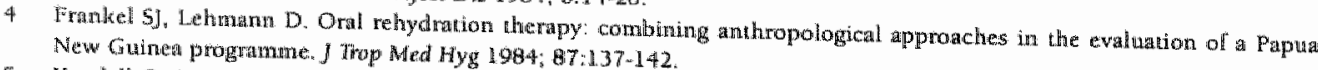

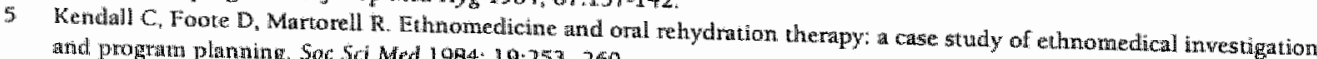

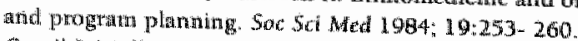

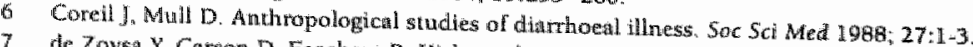

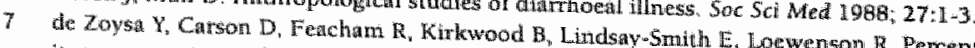
its treatume in rural Zumbabwe. Soc Sc Med 1 ,

(6) Kendall $C$ pulic

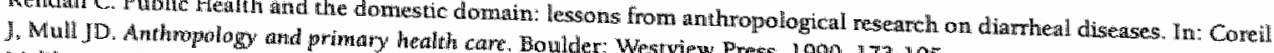

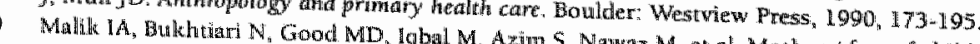

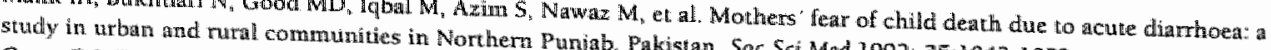

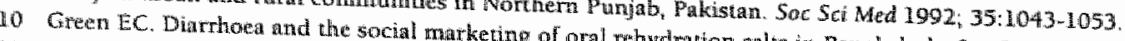

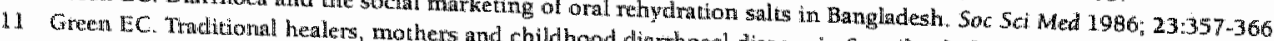

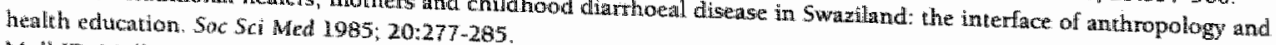

12 Mutl JD, Wall DS. Mother"s concepts of childhood Soc 5ci Med 1988; $27: 53$-67 


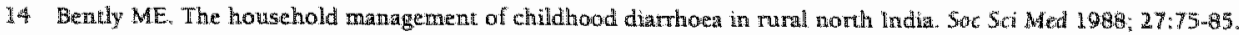

15 Weller SC, Ruebush. II TK, Klein RE. An epidemiological description of a rolk ininess: a calse study of empacho in Guatemala. Med Arthropol 1991; 13:19-31.

16 Mertand WE, Walmus. BF Materal knowledge, antudes and practice as predictors of diarrhoeal disease in young childrem. Int Eptidemiol 1983; 12:205-210.

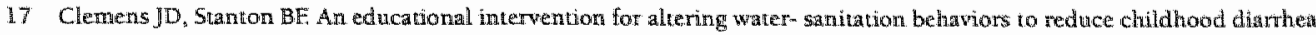
in wrban Bangladesh: 1 . Application of the case-control method for the development of an intervention. Am J Epidemiol $1987 ; 125: 284-301$

18 Stanton BF Clemens JD. An educarional intervention for altering water samitation behaviors to reduce childhood diarkea in arban Bangliadesh. 11. A randonized trial to assess the impact of the intervention on hygienic beliawion and rates of d.iarrhoea. Am / Epidemiol 1987; 125:284-301.

19 Konde-Luie JK, Elasu S, Musonge DL. Knowledge, anturues, and practices and their implications in childhood diarnoen in Uganda. J Diarthocal Dis Res 1992; 1:25-30.

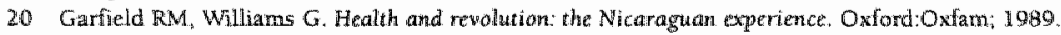

21. Sandiford P, Morales Pr Gorter A, Coyle E, Davey Smith $G$. Why do child montity nates fald: an analysis of the Nicanaguan. experience. Am I Public Health 1991; 81:30-37.

22 Republica de Nicazagua Ministerio de Salud. Plam Maestro de Salud 1991-1996. Managua: Impresiones EINM; 1991

23 Gorter AC, sandiford R, Davey Smith G. Pauw JP. Water supply, sanitation and diarthoeal disease in Nicaraguat results from a case-control sudy. Int $J$ of Epidemiol 1991; 20:527-533.

24. Sanditord P, Alberts H, Orozco JG, Gorter A. The Nicaraguan Rope Pump. Waterlines 1993, 11:27-30.

25 Alberts $H_{4}$ Meza $R_{*}$, solis $D$, Rodriguez M. How the rope pump won in Nicaragua, Whaterines 1993; 12:3-5.

26 Gorter AC, Alberts JH, Gago JF, Sandiford R. A randonaized trial of the impact of rope- pumps on water gualing. J Trop Wed Hyg $1995 ; 98: 247-255$.

27 Sandiford $P$ Gorter AC. Davey Smith G, Pauw JPC. Determinants of drinking walker quality in rural Nicaragua. Epidemiology and Infection. 1989; 102:429-438.

28 Sandiford P, Gorter AC, Orozco JG, Pauw JP. Determinants of domestic water use in rumal Nicaragua. 1 Trop Med Hyg 1990 ; $933.383-389$

29 Sandiford P. Pauw IP, Gorter AC, Davey Smith G, Morales D. Can childen with high rates of dianhota be identified from records of attendance at health services? In: International Epidemiological Association (1EA), European Reguonal Meeting 1991, Basilea, $1991 \div 10$.

30 Davey 5 mith $G$, Boersma A, Gorter AC, Sandiford P. What control group is appropriate for case-control studics of ehildhood diarrhoen? In: Intermational Epidemiological Association (IEA), European Regional Meeting 1991, Basilea, 1991:75.

31 Scrimshaw SCM, Hurtado E. Anthropological involvememt in the Central Amerncan diarthoeal disease control project. 506 Sci Med 1988; 27:97-105.

32. Hudelson PM. ORS and the treatment of chilidhood diarnoea in Managua, Nicaragua. Soc Sit Med 1993; 37:97-103.

33 Papart JP, Estrada 1, Guerra $\mathrm{R}$, Heggerick I. Pragrama de lucha cantra las enfermedodes dianreicas: investigacion operacional winculada a la accesibilidad de la terapia por rehidratacion oral. Managua: Centro de Investigaciones y Estudios de la Salud: 19818.

34. Weiss MG. Cultural models of dianthoeal illness: conceptual framework and rewtew. Soc Sd Met 1988; 27:5-16.

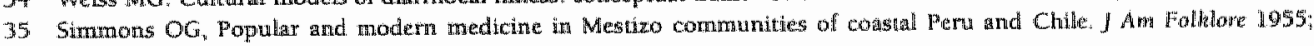
$68: 57-71$.

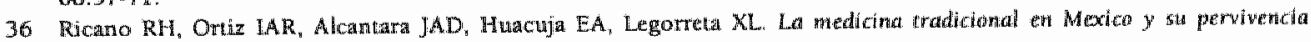
Mexico: Universidad Nacional Autonoma de Mexico; 1989.

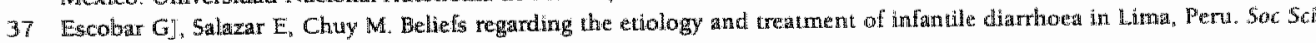
Med 1983; $17: 1257-1269$.

38: Lieberman 5. Medical-nutritional practices among Puerto Ricans in a small urban northerstern community in the United Stathes. Soc Sci Med 1979; 13:19:198.

39 Simpson SH. Some preirrinary considerations on the Sobada: a traditional treatment for gastrointestind fll thess in Costa Rica. Soc Sai Med 1988; $27,69 \% 73$.

40 Mckee L. Ethnomedical treatmen of chldren s stiartheal illnesses in the highlands of Ecuador. Soc 5oi Med 1987:25:11.471155,

41 Madsen W. The Wirgin 's chidrew. life in an Azter witlage today. Austin: University of Texais Press; 1960.

42 Foster GM. Disease etiologies in non western medical systerns. Am Anthropol $1976,78: 773-782$.

43 Messier E. Hot-cold dassificanor: theoretical and practical implications of a Mexican study. Sac $5 c i$ Med 1981; $1.50: 133$ 145 .

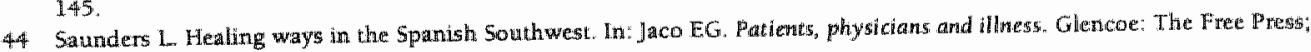
$1958: 189-206$.

45. Johnson CA. Infant diarthea and folk medicine in South Texas. Texas Med 1979; 75:69.77.

46 DeClerque J. Bailey P, Janowilts B, Dominik $R_{x}$ Fiallos C. Management and treatment of diarthea in Howduran children factors associated with mothers health care behaviors. Soe Sei Med 1992; 34:687-695: 


\section{Chapter 5}

\section{Well water study, part 2}

Anna Gorter, MD

Peter Sandiford, MD

A Consultancy Undertaken for COWATER International INC Liverpool Associates in Tropical Health 1992, updated in 1997 


\section{Summary}

While the theory of water contamination is well developed, there is a general lack of empirical support for the effectiveness of the numerous potential interventions to improve microbiological water quality. The few published studies which are available suggest that upgrading wells through improvements such as a windlass, bucket cage, drainage system, lining, head wall and cover are effective when they are provided as a combination. It is not known, however, how effective individual components of the upgrading are in reducing contamination nor whether their combined effect is greater or smaller than the sum of the separate effects. The provision of pumps seems to be useful in settings with gross contamination, and tube wells are consistently cleaner than handdug wells. There is also a need for a rigorous assessment of the potential impact of 'software' interventions, such as health education, on well water quality. 


\section{A literature review to identify which interventions are most likely to reduce faecal contamination of wells, waterholes and surface water}

\subsection{The Mechanism of Faecal Contamination of Water Sources}

Fresh water is essentially distributed between three different compartments - rain, surface water and groundwater. Rainwater is normally free from faecal contamination, at least until it is collected". Surface water on the other hand is typically highly contaminated in developing countries. The faecal contamination of surface water implies that at some stage in the water cycle faecal matter is mixed with rainwater. Groundwater, like rainwater, is also usually free from faecal contamination. The relative purity of groundwater compared with surface water is due to (a) the death of microbiological contaminants and (b) the filtering effect of soil 23 .

Coliform bacteria have a half life of about 17 hours ${ }^{4}$ and bacterial half-lives in wells and laboratory groundwater are mainly in the range of $8-24$ hours $^{3}$. This implies that without replenishment, FC contamination of water sources will decrease by a factor of 100 in less than 11 days. However, this process is highly dependent on temperature, and survival is therefore possibly lower in warm climates. On the other hand, as has already been pointed out, the survival of different pathogens varies greatly (table 1 of Well Water Study part 1).

Soil filters bacteria best when the particles are fine ( $<\mathbb{1} \mathrm{mm})$, when the unsaturated zone in the water table lies at more than $2 \mathrm{~m}$ below the surface, and when groundwater llow velocities are low. Faecal bacteria in soil are also eliminated by antagonistic aerobes and anaerobes ${ }^{3}$. The risk of groundwater contamination is therefore greatest where the water table is shallow and where fissured non-porous bedrock is overlaid by shallow soils. Lateral migration of faecal bacteria generally does not exceed the $10 \mathrm{~m}$. Older latrines polLute less, because of pore clogging of the walls. In general the distance between a water supply and an on-site sanitation unit for safe lateral separation should be $15 \mathrm{~m}$. It depends however, on the aforementioned factors and in some areas $5 \mathrm{~m}$ is probably sufficient.

From a public health point of view, groundwater contamination in developing countries is of much less significance than surface water contamination. The level of contamina tion of rivers, streams, canals, pond depends primarily on:

1. The degree of environmental surface contamination which itself is determined by a multitude of factors such as population density, the number of people using the source, the way people fetch the water, sources of pollution around water supply (eg animals), bathing and defecation practices, ambient temperature, humidity, rainfall and wind. 
2. The amount of water in which the pollution becomes diluted. This in turn will depend on the exact amount of water present at the moment of pollution and the turnover of the water. The more water is extracted or streaming away and the more water there is, the more dilution of contamination is taken place.

For scoop holes, waterholes and hand-dug wells the level of contamination is a function of groundwater quality, the rate of introduction of faecal contaminants, the rate of water extraction, the volume of water in the well, and the survival of the microorganisms.

\subsection{Determinants of the Level of Faecal Contamination}

\subsubsection{Water source}

There are many different studies which have documented water quali$1 y 5,6,7, \beta_{1}, 5,10,11,12,13,14,15,16,17,18,19,20,21,22,23,24$. The highest levels of faecal contamination of drinking water sources are usually found in rivers where they range from less than $10 \mathrm{FCs}$ per $100 \mathrm{ml}$ up to 2 million FCs per $100 \mathrm{ml}$. Ponds and canals can be equally contaminated while streams tend to be a little less contaminated.

Springs, waterholes and hand-dug wells have lower levels of faecal contamination with values typically ranging from 0 to $10,000 \mathrm{FC} / 100 \mathrm{ml}$. In some cases however, levels as high as one million FCs per $100 \mathrm{ml}$ can be found. The variation in contamination of these sources is enormous. Springs are usually less contaminated than waterholes and handdug wells. As stated earlier, rainwater is inherently clean but can readily be contaminated depending on the way it is collected 1,21 .

\subsubsection{Season}

The marked seasonal variation in water quality is well known 23.26 and is closely related to rainfall $16_{2,27}$. It tends to affect surface water and unprotected well water more than water from protected wells and boreholes ${ }^{24}$. There are two factors giving rise to the seasonal variation in water source contamination. One is the run-off effect whereby rain washes faecal matter into water sources. The other is the concentration/dilution effect in which dry weather reduces the volume of water and hence concentrates the existing level of contamination. Support for the importance of this effect was provided by Wright ${ }^{20}$, who in Sierra Leone noted increasing levels of faecal contamination during the dry season.

Blum 15 in Nigeria found that contamination peaked during transition from the dry to the wet season when the mean FC counts for all sources except rivers were 2.5 to 7.2 times greater than during the rest of the year. The lowest FC counts occurred at the height of the wet season. A similar pattern has been observed in Costa Rica ${ }^{28}$, Papua New Guinea ${ }^{29}$, the Gambia ${ }^{30}$ and Nicaragua ${ }^{31}$. Blurn's explanation takes both the run-off effect and concentration effect into account. The first rains wash the faecal matter into the water source, progressing the wet season there develops a rain induced dilution. At the onset of the dry season, bodies of water again begin to shrink and counts rise's. That there are still considerably higher levels of contamination during the wet season than during the 
dry season is because the water levels of the wells during rain rise, but not enough to counter the increased rate of pollution due to run-off 16 .

\subsubsection{Other factors}

Most of the microbiological pollution of water sources is due to the external introduction of contaminants through either poor design or unhygienic methods of water extraction. Interventions to reduce this cause of pollution are discussed below. There are several additional factors however, which relate to water contamination.

One of these is the number of households using the source. In a Kenyan study, $70 \%$ of the wells that were used by only one family, had FC counts below 100 per $100 \mathrm{ml}$, compared with $15 \%$ when one to five families used the well 23 . In the latter case, each family used its own bucket and rope which were frequently placed on the ground. In Nicaragua we found a relation between the quality of the water and the number of households using the well, the amount of water extracted daily and the distance of the well from the nearest kitchen ${ }^{31}$.

A marked variation between countries in the contamination levels of water sources car be observed from the literature. Low contamination was found in a study from Zambia 22

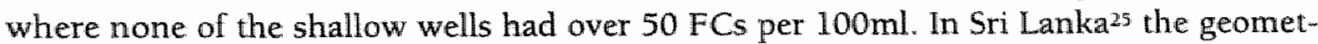
ric mean FC count for protected hand-dug wells was also low $(93 / 100 \mathrm{ml})$. Higher levels were seen in a study in Kenya where $68 \%$ of hand-dug wells and $19 \%$ of springs had more than $100 \mathrm{FCs}$ per $100 \mathrm{ml} 23$. In Gambia contamination of hand-dug wells was around $20,000 \mathrm{FCs}$ per $100 \mathrm{ml}$ during the dry season and up to $500,000 \mathrm{FCs}$ per $100 \mathrm{ml}$ during the wet season ${ }^{30}$. While there are many possible explanations for this variation, population density is one factor, which may be important. In Nicaragua, there was a significantly lower level of FC contamination in rivers, streams, unprotected wells, springs, and protected wells for small communities compared with large communities ${ }^{24}$. Also in between years differences in FC contamination can be found, probably due to variations in climate. In 1986 we found in protected hand-dug wells a geometric mean FC counts of over $1,000 \mathrm{FCs}$ per $100 \mathrm{ml}^{24}$, meanwhile in 1991 this was not more than $300 \mathrm{l} \mathrm{Cs}$ per $100 \mathrm{ml}^{31}$, although in both studies the sample sizes were small (15 wells).

\subsection{Interventions to Reduce or Prevent Faecal Contamination of Water Sources}

In our discussion of the various interventions, which can reduce or prevent faecal contamination of water sources, only those involving relatively simple and inexpensive constructions have been considered.

\subsubsection{Interventions to Reduce Surface Water Contamination}

Rivers, streams, canals and ponds are often heavily contaminated by run-off and defecation by animals and people in and around the water. Often people attempt to protect themselves from the effects of river and stream water contamination by taking their 
drinking water upstream of their village or by digging holes alongside the river, and sometimes even protected by a parapet. Water seeps into the hole and in doing so it is filtered by the soil. In Nicaragua it was observed that people completely empty the water from these little wells and allow them to refill each time they collect water ${ }^{24}$. interestingly, during dry periods the quality of water in these unprotected wells was significantly higher than in domestic wells protected with a lining and parapet and often less than $1 \%$ of the level in the adjacent river.

Another possibility is filtering the water within the source, for example Jempeng stone filter used in canals in Indonesia or sand-filtering wells developed in China ${ }^{32}$. Filtering the water in the home is also an option. For example, there is winnowing sieve, the cloth filter, clay vessels, plant material, and the farnily sand filter ${ }^{27,3}{ }^{2}$. It is claimed that these sorts of filters yield water of a very high microbiological quality (presumably $\mathbb{F C}$ counts of less than 50 per $100 \mathrm{ml}$ ) although no data have been found to verify this. Another option is solar disinfection as described in the earlier mentioned study in the Lancet ${ }^{33}$.

Spring water, which is often relatively clean anyway, can be improved by constructing a spring box consisting of a headwall, outlet pipe and backfill cover ${ }^{23.34}$. One study ${ }^{34}$ found that only $20 \%$ of protected springs tested positive for $E$. coli compared with $62 \%$ of unprotected springs. Rain jars with mosquito nets placed on the roofs of houses are a safe way of collecting rainwater with mean FC counts of less than 10 per $100 \mathrm{ml} .^{1}$

\subsubsection{Interventions to Reduce Well and Waterhole Contamination}

Four basic strategies can be used to reduce well and waterhole contamination. These are (a) diluting the pollutants, (b) preventing groundwater contamination, (c) preventing surface contamination and (d) treating the water ${ }^{35}$

\subsection{2. (a) Diluting the pollutants}

Blum ${ }^{15}$ in Nigeria found that contamination peaked during transition from the dry to the wet season. But the lowest FC counts occurred at the height of the wet season. This is presumably because of a dilution effect. One option for improving water quality would therefore be to increase the depth of water in the well or by widening the well.

However, another way to dilute the contaminants is to increase water turnover. Presumably this is why riverside waterholes may have better water quality than large, protected, hand-dug wells ${ }^{24}$. It may also partly explain why pumps on hand- dug wells are associated with better water quality ${ }^{24}$. Pumps generally increase the amount of water used and hence increase turnover. Morgan ${ }^{27}$ has demonstrated that this 'flushing effect' could be very significant in an experiment with a Bucket Pump installed on a tubewell. At normal rates of extraction, the total content of the tubewell is completely replaced within ten minutes. Since turnover is greater with smaller volumes of water in the well, this flushing effect will be less if the amount of water in the well is increased as suggested above. The impact of pumps on water quality in the Zimbabwe study is illustrated in table 1. In Nicaragua where electric or wind pumps are installed on traditional hand-dug wells, the geometric mean FC count was only 22 per $100 \mathrm{ml}$ compared with 1,410 for 
wells without purnps. Expressed in another way $90 \%$ of wells whithout pumps had over 50 FCs per $100 \mathrm{ml}$ compared with $33 \%$ of those with electric or wind driven pumps ${ }^{24}$, and $55 \%$ of traditional wells with hand pumps ${ }^{36}$. Another study in Nicaragua found that $26 \%$ and $23 \%$ of wells fitted with Dempster pumps and rope-pumps respectively had $F \mathrm{C}$ counts over $50 / 100 \mathrm{mll}^{37}$.

Table 1. Bacteriological quality of water that is taken from wells and hand pumps

Siource

Mean E. colii/100m

No. samples

Poorly protected well

Upgraded wells

266.42

65.94

233

Bucket Pump (overall)

33.72

Blair Pump (tubewells)

26.09

Bush Pump (tubewells)

6.27

234

338

248

$28 \%$

Sounce: Morgan, $1990^{27}$

\subsection{2. (b) Preventing groundwater contamination.}

Groundwater pollution is usually a minor source of contamination in most wells and therefore interventions to prevent it are unlikely to have a major impact on faecal coliform counts. A study in Nigeria for example ${ }^{18}$ in which 20 wells were studied, found no correlation between water quality and the distance between the well and the latrine, nor with the depth of the water table. This result is supported by another study in Sri Lanka's Kandy District where no relationship was found between the level of contamination and the distance of the latrine from the well. Tracer tests to investigate if surface water might enter the hand-dug wells were negative, perhaps due to the nearly ideal soil material in the unsaturated zone ${ }^{38}$. In Sri Lanka ${ }^{25} 95 \%$ of the protected open hand-dug wells were contaminated. Only $5 \%$ of deep tubewells with hand pumps were contaminated when the mouth of the tap was sterilised, in contrast to $52 \%$ when it was not. Mertens et al concluded that groundwater contamination was negligible, the contamination occurred at the periphery of the system. However, in cases where groundwater pollution is suspected to be significant, all nearby latrines and cesspits should be removed to a safe distance (15 to 30 metres) and the lining of the well upgraded, replaced or installed as necessary.

\subsection{2. (c) Preventing surface contamination.}

Several design features of the protected well are intended to reduce contaminants from the surface that enter the well. A head wall/parapet with a cover will prevent faecal material, dirt and debris from falling into the well and helps to keep animals and people away from the well water. A concrete apron around the base with a sanitary seal to the head wall and lining, a drainage channel and sump at some distance from the well will prevent spilt water and rainwater run-off seeping into the well. It also keeps the area dry, which reduces breeding of bacteria, which grow better in a moist environment. Improvements in the water-lifting device, such as a windlass or hand pump will decrease or eliminate contamination of the water via the bucket and rope. A study of the faecal contamination 
of upgraded wells compared with unimproved wells showed that the latter had over four times the concentration of faecal $E$. coll (Table 1), and over five times the concentration of faecal Streptococci. In this case the upgrading was extensive and consisted of installing a windlass, well cover, drainage apron and lining ${ }^{27}$. Another study in Zambia ${ }^{39}$ found significantly better water quality in upgraded wells, but drilling the wells produced even better results (figure 1). Hand-dug wells were upgraded with a lining, concrete cap, drainage channel and a windlass. A special cage around the bucket was developed to protect the bucket against stealing. Some wells were hand augured and a bucket pump was installed. Water quality was then compared between traditional wells, improved handdug wells some with a bucket cage and some without, improved hand-dug wells with a bucket cage and angered wells with a bucket purnp.

\section{Proportion of samples}

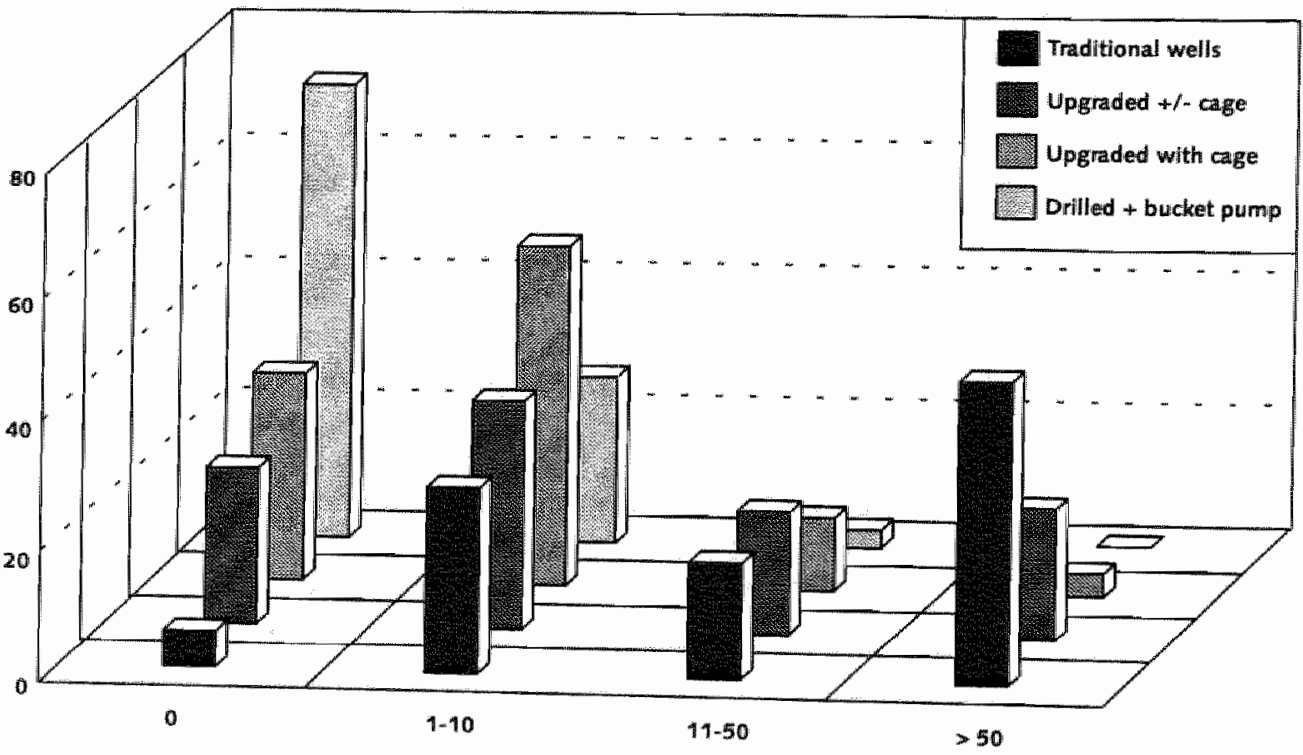

Faecal coliforms per $100 \mathrm{ml}$

Source: Lacey (1990)

Figure 1. Relationship between water quality and well type.

When a rope and bucket are used the cover should be designed in a way that prevents water from spilling back into the well. This means the cover should have a raised collar around the extraction port. However, a study in Kenya ${ }^{23}$ found that the presence of a cover and well lining had no effect on water quality. Similarly, the study in Nigeria ${ }^{18}$ did not detect any difference in water quality between the wells with a cover and those without. Likewise, a study in Indonesia found no improvement in faecal contamination when 
hand-dug wells were upgraded by fitting a hand pump and a sanitary cover. Among the improved wells with hand pumps, $20 \%$ had contamination levels over $100 \mathrm{FCs}$ per $100 \mathrm{ml}$ compared with $22 \%$ in the unimproved open dug wells ${ }^{21}$. Other studies however, have shown that a cover plate can make some difference. In a study from Cape Verde, $53 \%$ and $23 \%$ respectively of traditional hand-dug wells without and with cover plates contained E. coli. For coliforms the proportions were respectively $100 \%$ and $80 \%{ }^{34}$.

Our study31. of the impact of installing rope-pumps on hand-dug wells found a reduction of $62 \%$ of the geometric mean of FC compared to hand-dug wells equipped with a rope and a bucket, but no difference when compared with hand-dug wells equipped with a windlass. No difference was detected for the installation of a concrete cover plate.

Surface contamination is considerably reduced when wells are augured as the first few meters of the well are then protected by the casing which always goes with a drilled well. In addition, the opening of the well will be smaller and therefore easier to protect. The lifting device will also tend to be more hygienic. In the aforementioned Indonesian study, only $7 \%$ and $9 \%$ respectively of the shallow and deep drilled tubewells with hand pumps had more than 100 FCs per $100 \mathrm{ml}$ compared with $20 \%$ for among upgraded hand-dug wells and $22 \%$ among the unimproved hand-dug wells ${ }^{21}$.

\subsection{2. (d) Treating the water.}

Another way to reduce faecal contamination is by chlorination. This is normally done by periodic disinfection of the well but several methods of gradual chlorine infusion have also been experimented with. Table 2 illustrates the improvement in water quality of 4 different levels of chlorination of highly polluted open shallow wells and its effect on diarrhoeal disease. However, there are problems with chlorination such as the often unacceptable taste, the difficulty in determining and maintaining an appropriate dosage schedule, and the problems of guaranteeing a regular supply of chlorine.

Table 2. Influence of residual chlorine on water quality and on incidence rates of diarhocal discastes

\begin{tabular}{|c|c|c|c|c|c|c|}
\hline & & Control & 1 & 11 & III & IV \\
\hline Residual chlorine & & 0 & 0.5 & 0.4 & 0.3 & 0.2 \\
\hline Average & Before & 820 & 953 & 1089 & 1100 & 880 \\
\hline $\begin{array}{l}\text { MPN } \\
\text { count* }\end{array}$ & After & 727 & 17 & 41 & 49 & 82 \\
\hline $\begin{array}{l}\text { Diarrhoea } \\
\text { incidence }\end{array}$ & Before & 19.0 & 20.0 & 22.2 & 20.3 & 10.7 \\
\hline rate & After & 29.5 & 1.1 & 1.7 & 2.1 & 3.0 \\
\hline
\end{tabular}

- MPH =most probable rumber of Dacteria present per $100 \mathrm{ml}$

Source: Trivedi et al, 197140 


\subsection{3. "Software" Interventions to Reduce Faecal Contamination}

Certain behaviours may increase or decrease the level of contamination of a well. For example, placing the bucket and rope on the ground, defecating in the area near the well or allowing animals to do so, bathing or washing dishes/clothes close to the well may introduce surface contaminants. It is also conceivable that hand washing might prevent well water pollution by reducing the contact of bacteria with the rope or bucket. Hence, health education directed at modifying potentially harmful practices and promoting beneficial behaviours in addition to explaining how contaminants are introduced into wells, should in theory, give rise to water quality improvements. Health education may be particularly effective where there is private ownership of wells. However, no studies have been identified which demonstrate whether health education can lead to improved water quality and if it can, by how much.

\section{References}

1 pinfold $\mathrm{N}$, Horan $\mathrm{W}$ and Wirojantgud, The bacteriological quality of waner collected in rainjars in nural northeast Thalland with respect to drinking water quality guidelines, submitted to Water Research 15/3/1990.

2 Lewis WJ, Foster SSD and Drasar BS. The rish of groumatwater pollution by on-site samitation in developing countries, A literature review IRCWD-Report No.04/82, 1982.

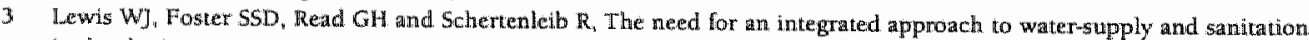
in. developirag countries, Science of the Tot al Enwironment 1981; 21:53-59.

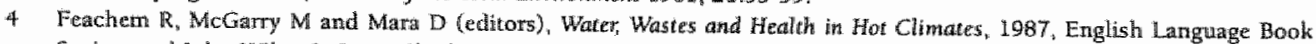
Society and John Wiley \& Sons, Chichesiler, UK.

5 White GF, Bradley DI, White AU, Drawers of Water Domestic water use in East Africa, University of Chicago Press, Chicago. 1972 .

6 Moe CL, Sobsey MD, Samsa GP and Mesolo Vacterial indicators of risk of dianhoeal disease from drinking-water in the Philippines, Bulletion of the World Health Organization 1991; 69:305-317

7 Feachen R, Bacterial standards for drinking water quality in developing countries, Lancet 1980; August. 2, $255-256$.

8 Molbak $K$, Mojlyng $N$ and Jepsen $\$$, Bacterial contamination of stored water tund stored food: a potential source of diarrhoeal disease in West Africia, Epidemtology and Infection 1989; 102:309-316.

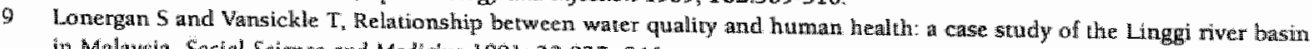
in Malaysia, soctal Science and Mediche 1991; 33:937-946.

10 Jiwa SFH, Mugula JK and Msangi, Backeriological quality of potable water sources supplying Morogoro municipality and

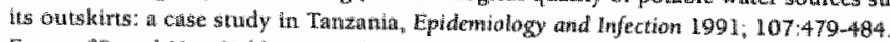

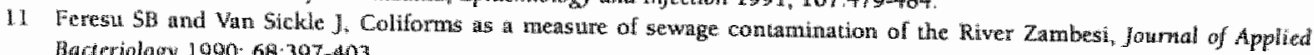
Batcriolagy $1990 ; 68: 397-403$.

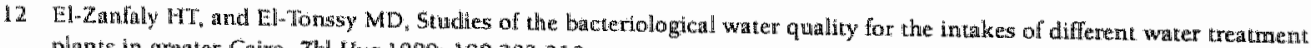
phants in greater Calliro, Zbl Hyg 1989; 188;303-310.

13 Marabas 5, Montoring natural waters for drinking-water quality, World Health Statistics Quanterly 1986; 39:32-45.

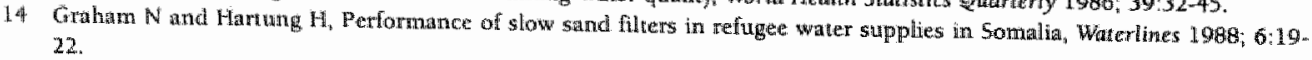

15 Blum D, Hutlly SRA, Okoro M, ell al. The bacteriologicit quality of traditional water sources in north-eastem Imo State, Miggeria, Epidemiology and Infection 1987; 99:429-437.

16 Lindskog RUM and Lindskog PA, Bacteriological contamination of water in rural aneas: an intervention study from Malnwi. Jounal Troptcal Medicine and Hygiene $1988 ; 91: 1-7$.

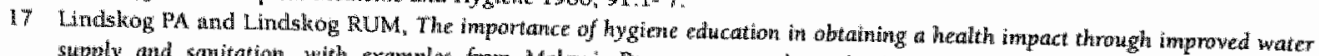
stapply and saxitarisw, with examples from Molawi. Maper presented at the Intmational Council Scientific Unions Commitec on Teactuing of Science Conference, 6-14 August 1985, Bangalore, lindia.

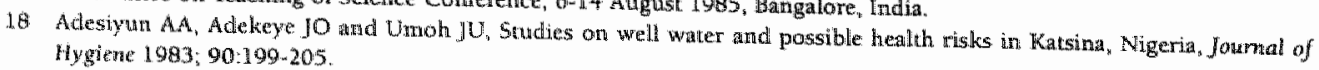

19 Thasay $\mathrm{ZW}$, Bacteriological quality of drinking water in Kaffa administratiwe region, south west Ethiopia, Jounal of

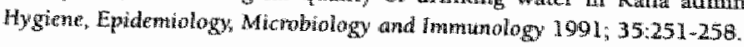




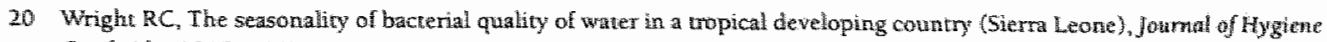
Cambridtge 1985; 96:75.

21 Loyd $B$ and Suyati S, A pilot rural water survellance project in Indonesia, Waterdimes 1989, 7:10-13.

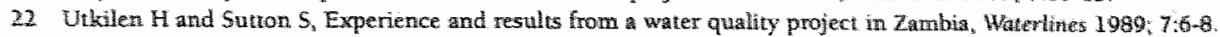

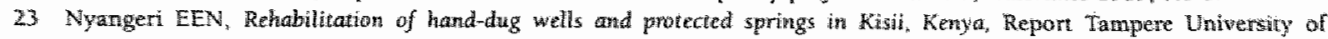
Technology in co-operation with Finnida 1986; No 29.

24 Sandiford $P$, Gorter AC, Davey Smith $G$ and Paw JPC. Determinants of drinking water quality in rural Nicaragum, Epidemiology and Infection 1989; 102:429-438.

25 Mertens TE, Fernando MA, Marshall TF de C, et al, Determinants of water qualiy awailability and the in Kurunegala, Sr Lanka, Tropical Medicine and Parasitology 1990; $41.89-97$.

26 Nichter M, From Aralu to ORS: Sinhalese perceptions of digestion, diarthea, and dehycration, Soctal Sctence wat Medicine $1988: 27: 39-52$.

27 Morgan P. Rural Water Sapplies and Sanitation: A Text from Zimbabmes Blair Resedrch Laboratory, 1990; London: Macmillan.

28 Moore HA, de la Cruz E and Vargas-Mendez O. Diarrheal disease sndies in Costa Rica: IV The influemce of saniution upon the prevalence of intestinal infection and diarrheal disease, American foumal of Epidemiology 1965; 82:162-1.84.

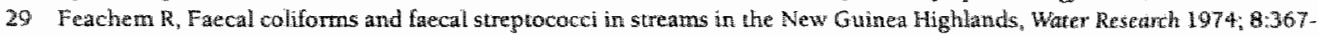
374

30 Barrell RAE and Rowland MGM. The relationship between rainfall and well water poliution in a West African (Gambian) village, joumal of Hygiene 1979; 83: $143-150$.

31 Gorter AC, Aberts JH, Gago JF and Sandiford P, A randonized trial of the impace of rope-pumps on water quality. Journal of Tropical Medicine and Hygiene 1995; 98:247-255.

32 Vigneswaran $S$, Tam DM, Visvanathan $C_{3}$ et al, Water Filtration Technologies for Developing Countries, Environmental Sanitation Reviews 1983; No12, Environmental Sanitation Information Center, Bangkok, Thalarid.

33 Conroy RM, Elmore-Meegan. M, Joyce T, McGügan KG and Barnes J. Lancet 1996; 348:1695-1697.

34 Bucthrieser $V$, Brosch $R$, Buchrieser $C_{2}$ et al, On the drinking water situation on the Cape Verde Islands (isiand of santiago), Joumal of Hygiene Epidemiology Microbiology and Immunology 1989; $33: 35443$.

35. Anomyrnous, A workshop design for well improwememt: protecting open wells. WASH Technical Report No. 34, Aglimgton, Virginia, May 1988 .

36 Wedgwood K, Nicaragua: rural water quality surveillance and improvenent, Waterlines 1989; 7:20-23.

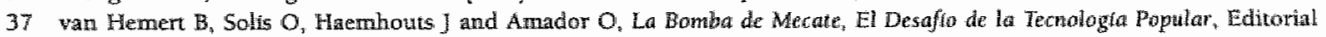
Enlace, 1991, Managua, Nicaragua.

38 Taka $\mathrm{M}$ and Aapoia $\mathrm{R}$, Study on bacteriological contanuination in hand pump wells, Kandy district water supply and sani tacion project, Soll and Water Lid, September 1988 .

39 Lacey E, Eng BEC and Eur Eng MIDI, Comparision between hand dug and hand angered wells. Report based on experiences in Zambia and Zimbabwe, 1990, IRC 212.5 .

40 Trivedi BK, Gandhi HS and Shukla NK, Bacteriological water quality and incidence of water borne diseases in a naral popwiation, Indian Journal of Medical Science 1971; 25:795-801. 


\title{
Chapter 6
}

\section{A randomized trial of the impact of rope pumps on water quality}

\author{
A.C.Gorter ${ }^{1}$ J.H.Alberts, ${ }^{1}$ J.FGago, ${ }^{1}$ \& PSandiford 2
}

Published in Journal of Tropical Medicine and Hygiene, 1995; 98:247-255 


\section{Abstract}

Rope-pumps are now widely promoted as a low cost, easily maintained means to improve water availability in developing countries. However, in some instances their acceptance has been limited by concerns over the microbiological quality of the water. This study looked at the well water quality under a variety of different conditions, comparing unimproved bucket and rope wells, with wells with a windlass and rope-pump wells with and without a concrete cover. Other factors influencing the water quality were also examined.

Results indicate a $62 \%$ reduction of the geometric mean of the faecal coliform contamination of the well water as a result of the installation of a rope-pump with or without a concrete cover on wells which were originally equipped with a rope and bucket. Other factors found to influence the level of contamination of water in hand-dug wells were rainfall, number of households using the well, amount of water extracted daily and the distance of the well to the nearest kitchen. The last three factors probably reflect domestic activities with poor hygiene around the well.

The installation of a simple rope-pump on family wells improves the water quality and availability at a favorable cost/benefit ratio. 


\section{Introduction}

The use of inadequate water supplies relates closely to the high incidence of childhood diarrhoea in most developing countries. Both quality and quantity of water used are believed to play a role. There is a reasonable consensus that interventions which increase water availability have a greater impact then those which improve the quality of water, but combined interventions have been associated with the greatest reduction in disease (Esrey et al. 1991).

From the small amount of relevant literature available, it would appear that reduction of faecal contamination from very high levels to moderate levels is more likely to have a positive health impact than reductions from moderate to low levels (Moe et al. 1991; Sutomo 1987; Trivedi et al. 1971). Reductions of faecal contamination from very high levels are likely to be more effective where many families share a water source, than where the water source is used by just one or two households.

In rural Nicaragua the preferred type of water supply is the family hand-dug well (Gorter et al. 1991). Sharing of a hand-dug well mostly occurs between farmilies who are relatives or in cases where the economical and/or geological factors have made it impossible to dig more wells. In the rural municipality of Villa Carlos Fonseca, more than half of the population is served by these private wells which are almost entirely equipped with a bucket and rope or a windlass. An earlier study (Sandiford et al. 1989) showed that these wells have high levels of contamination which rise after the rains, though not as much as other traditional water sources.

Improvements in water quality and availability for this type of rural populations can only be made at a favorable cost/benefit ratio only by upgrading the private wells and improving the method of water extraction. The few published studies of the effectiveness of the numerous potential interventions to improve microbiological water quality of hand-dug wells suggest that upgrading of wells through improvements such as a headwall, apron, drainage channel, lining, cover, handpump, windlass, or bucket cage are effective when provided as a combination (Buchrieser et al. 1989; Lacey et al. 1990; Morgan 1991). It is not known, however, how effective are the individual components of the upgrading in reducing contamination or whether their combined effect is greater or smaller than the sum of the separate effects. In order to design an effective cost/benefit intervention on hand-dug family wells the impact of the individual components of upgrading should be known.

In Nicaragua the rope-pump (Figure 1), based on the simple chain and washer pump (Lambert 1990), was introduced in 1983 (Sandiford et al. 1993). Extensive modifications have enabled rope-pumps to be produced which are easy to operate, have a high efficiency, low cost, and are easy to maintain (Alberts et al. 1993). More than 3,000 are installed in private and project sectors and recently the first 50 were introduced in Honduras. 


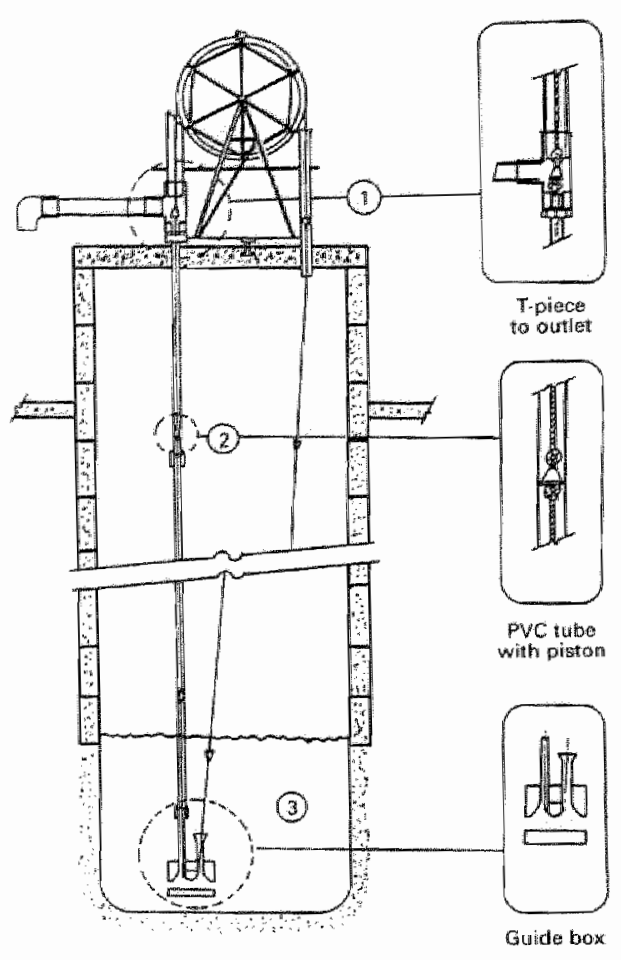

Figure 1. Cross-section of a rope-pump on a well.

\section{Material and methods}

The study was carried out in Villa Carlos Fonseca, a rural municipality on the Pacific coastal plains of Nicaragua with a population of approximately 30,000 . The area can be characterized as a tropical dry zone with small rivers which tend to dry up during the dry season. Thirty wells in 14 different communities were selected for the study and randomly assigned to three groups of 10 wells each: one group to be fitted with a rope-pump and concrete cover, a second group with only a rope-pump and the third group as a conurol group, not receiving a rope-pump until the end of the study.

To determine the baseline level of faecal contamination, two or three water samples were taken weekly from each well in the dry season and less than one month before the installation of rope-pumps and covers began. A baseline interview and observation were carried out to identify behavioral, structural and socio-economic factors which might influence faecal contamination. Days of rainfall were registered. Seven water samples were taken from each well every 3 weeks following installation for a total of 5 months.

The Oxfam Delagua portable water quality testing kit was used to measure faecal coliform counts by the membrane filtration method. The water quality laboratory of the 
water and sewage Ministry prepared the cultures and trained the research assistant to prepare the kit, take the samples and perform the water quality tests. At the study midpoint the kit was taken to the national laboratory after incubating and samples were counted independently by the research assistant and the head of the laboratory No differences in counts were found. The temperature reading of the incubator was also checked. Samples of $50 \mathrm{ml}$ were taken from the wells using the existing method of water extraction. The samples were incubated within 6 hours of sampling at $44^{\circ} \mathrm{C}$ for $16-18$ hours, on pads impregnaved with lauryl sulphate broth.

Data were entered in Epi-info and analyzed using Epi-info and SPSS programs. A water quality model was fitted by analysis of covariance with the natural logarithm of the faecal coliform counts as the dependent variable. The independent variables considered were; method of water extraction, design of the well, protection and distance from a source of contamination, amount of water extracted daily, amount of water in the well, and various socio-economic factors.

\section{Results}

\section{Description of wells and users}

Table 1 lists the characteristics of the 30 wells, and those of the well users. The latrine to well distance averaged 28 meters (range 8-67 meters), which means that, for the type of soil existing in the area (ocean sediments of clay and limestone, sometimes covered by volcanic sand), no lateral contamination of the water from latrine to well is likely (Lewis et al. 1981). The 61 families had a total of 396 members. Almost a quarter of the heads of families is illiterate. The vast majority are farmers though some work in the nearby capital.

Figure 2 shows that the more water is needed and the greater the well distance, the more people shift from the well to the river. For drinking, cooking and washing dishes, all fam-
ilies used only well water. In $25 \%$ of cases well water was also used. to irrigate their premises and in $26 \%$ to water the cattle.

\section{Water quality}

Table 2 shows the number and type of wells in each group. The Nicaraguan rope-pump company Bombas de Mecate SA installed 30 rope-pumps. Due to an initial misunderstanding between the research group and the company 3 wells in the intervention group with only a rope-pump received their rope-pump in error before the baseline measurements could be made and were therefore shifted to the control group. Of the rope-pump group with covers, 2 wells did not receive their rope-pump due the very low water levels in the wells after 3 years of severe drought in the study area and thus were also shifted to the control group. Eventually the controll group consisted of 15 wells, as did the intervention group. 
Table 1. Characteristics of the study wells and their users

Characteristics of the wells

Presence of a headwall

$100 \%$

Upper section lined with masonry

Equipped with a windlass

$100 \%$

$53 \%$

Some sort of cover on headwall

$43 \%$

$20 \%$

Cover is complete and in use

Apron around theadwall

$10 \%$

Drainage system

Protection against animals

$0 \%$

$0 \%$

Presence of a corral in the yard

$43 \%$

Cattle watered from the well

$37 \%$

Well has been cleaned

$93 \%$

Average time since well was cleaned(years)

0.5

Average age of the wells (years)

Average depth of the wells (m)

Average water depth in the well (m)

Average distance to kitchen (m)

Average distance to corral (m)

Average daily water extraction (gallons)

Average number of tamilies/well

Awerage number of persons/well

17

14

1.1

46

19

134

2.1

13.7

Characteristics of the users

Average schooling heads families (years)

Amount of family-heads illiterate

Average number of members/family

Average age children start drawing (years)

Average time to draw water (minutes)

Average distance family/well (m)

Average distance familly/river (m)

Average daily water use/family (gallons)

\section{Usual drawers of water}

Women

Men

Children

Children together with women or men

Men and women together
3.1

$21 \%$

6.5

10

40

40

650

67

$(0-11)$

(2-16)

(6-15)

(15-120)

$(0.7-170)$

$(17-2000)$

$(10-330)$

During a total of 283 visits 273 water samples were taken. Ten samples could not be taken because 4 wells were dry on $1-4$ occasions. Of these 273 samples 15 were discarded because of an error in the culture and 4 because of well construction or cleaning activities in the week before sampling, leaving a total of 254 samples for analysis. 


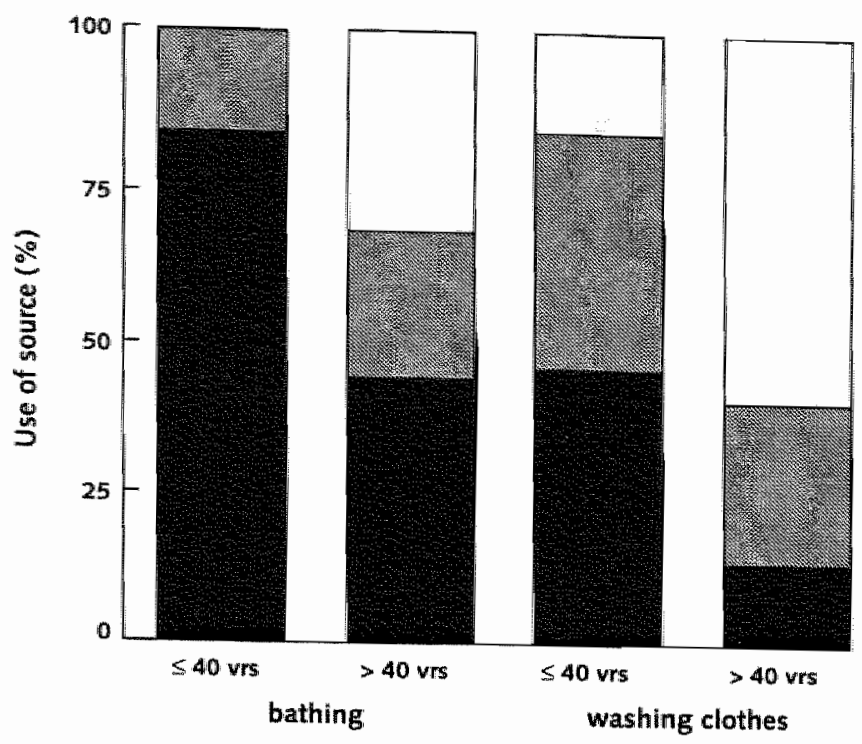

$\square$ Only river

Well and river

0 Only well

$\mathrm{vrs}=\mathrm{Varas}$

1 vara $=0.8539$ metres

Figure 2. Choice of water source for bathing or washing clothes in relation to the distance to the well.

Table 2. The number and type of well in each growp

\begin{tabular}{lcccc} 
Baseline & \multicolumn{3}{c}{ After modification } \\
\cline { 3 - 5 } Type & $\begin{array}{r}\text { Baseline } \\
\text { Wells }\end{array}$ & $\begin{array}{c}\text { Control } \\
\text { Wells }\end{array}$ & $\begin{array}{r}\text { Only pump } \\
\text { Wells }\end{array}$ & $\begin{array}{r}\text { Pump/cover } \\
\text { Wells }\end{array}$ \\
\hline Bucket & 14 & 4 & 5 & 5 \\
Windlass & 13 & 8 & 2 & 3 \\
Rope-pump & 3 & 3 & 7 & 8
\end{tabular}

Table 3. Effect of rain on the geometric mean of faecal coliform contamination of the 15 control wells

GM FC/ $100 \mathrm{ml}$

Dry season (February-mid May)

First rains (mid May-end July)

After first rains (end July-September)
N 
Rainfall commenced shortly after intervention and just one sample was taken in the dry period after intervention. Table 3 shows the effect of the rainfall on the level of contamination of the conrol group.

Table 4. Geometric means of faecal coliform contamination for different methods of extraction during the baseline measurements and the entire study

\begin{tabular}{|c|c|c|c|c|c|}
\hline \multirow[b]{2}{*}{ Method } & \multirow{2}{*}{\multicolumn{2}{|c|}{$\begin{array}{l}\text { Basellne study } \\
\text { Crude }\end{array}$}} & \multicolumn{2}{|c|}{ Entire study } & \multirow[b]{2}{*}{$n$} \\
\hline & & & $\begin{array}{c}\text { Crude } \\
\text { FC/100ml }\end{array}$ & $\begin{array}{l}\text { Adjusted } 1 \\
\text { FC/100ml }\end{array}$ & \\
\hline Bucket & 323 & 34 & 288 & 324 & 56 \\
\hline Windlass & 165 & 32 & 215 & 196 & 79 \\
\hline Only rope-pump & 81 & 7 & 174 & 169 & 72 \\
\hline Rope-pump/cover & - & & 131 & 136 & 47 \\
\hline Total & & 73 & & & 254 \\
\hline
\end{tabular}

Table 4 shows the geometric mean faecal coliform contamination of the different methods of extraction of the 30 wells during the baseline measurements and the entire study. The third column shows the results when adjusted for all the parameters included in the water quality model. Comparison of these values gave better results for the intervention with a rope-pump and concrete cover then for the rope-pump alone. Also it gives the impression that rope-pump wells are associated with better water quality then wells with a windlass.

However, the results of faecal contamination of the different subgroups before and after intervention as presented in Table 5 show no difference for rope-pumps with or without a concrete cover. A reduction of $62 \%$ in contamination was seen in the intervention group which was originally equipped with a rope and bucket; no reduction was seen in the group originally equipped with a windlass. Overall reduction of the faecal colliform counts of all the wells supplied with a rope-purnp was $47 \%$. 
Table 5. Geometric mean faecal collform counts before and after the intervention for the different types of baseline wells intervened and for the control group.

\begin{tabular}{|c|c|c|c|c|c|c|}
\hline \multirow[b]{2}{*}{$\begin{array}{l}\text { Type of } \\
\text { baseline well }\end{array}$} & \multicolumn{2}{|c|}{$\begin{array}{c}\text { Before } \\
\text { intervention }\end{array}$} & \multicolumn{4}{|c|}{$\begin{array}{c}\text { After } \\
\text { intervention }\end{array}$} \\
\hline & $\begin{array}{l}\text { Crude } \\
\text { FC/100ml }\end{array}$ & $n$ & $\begin{array}{c}\text { Crude } \\
\text { FC/400ml }\end{array}$ & $\begin{array}{l}\text { Corrected } \\
\text { for rain' } \\
\text { FCF } 100 \text { mil }\end{array}$ & $n$ & $\begin{array}{c}\text { Change } \\
(\%)(95 \% \mathrm{CD})\end{array}$ \\
\hline Control group & 189 & 35 & 238 & 189 & 87 & $0 \%(-28 / 40)$ \\
\hline Bucket modified with only rope-pump & 455 & 13 & 211 & 167 & 33 & $-63 \%(-78 /-39) *$ \\
\hline Bucket modified with rope-pump/cover & 196 & 12 & 99 & 79 & 30 & $-60 \%(-82 /-10)$ \\
\hline Windlass modified with only rope-pump & 108 & 5 & 147 & 116 & 14 & $+7 \%(-66 / 250)$ \\
\hline Windlass modified with rope-pump/cover & 171 & 8 & 213 & 169 & 17 & $=1 \%(-54 / 114)$ \\
\hline All modified bucket wells & 304 & 25 & 147 & 117 & 63 & $-62 \%(-77 /-37) *$ \\
\hline All modified windlasses & 143 & 13 & 180 & 143 & 31 & $0 \%(-48 / 91)$ \\
\hline All modified wells & 235 & 38 & 158 & 125 & 94 & $-47 \%(-65 /-20) *$ \\
\hline
\end{tabular}

- $P<0.05 ; * p<0.005 ; * * 0.0001$

11 lin onder to campiare the coumts before and after intervemtion, the effect of rainfall wras removed. Differences lbetween the means of the nattural logarithm of $F C$ counts in the dry period and the other two weather periods (see Table 3) were calculated and subtracted from the niatural logarithm of each FC count of the corresponding weather period.

Figure 3 shows the frequency distributions, before and after intervention, of the natural logarithm of faecal coliform counts of the group originally equipped with a rope and bucket.

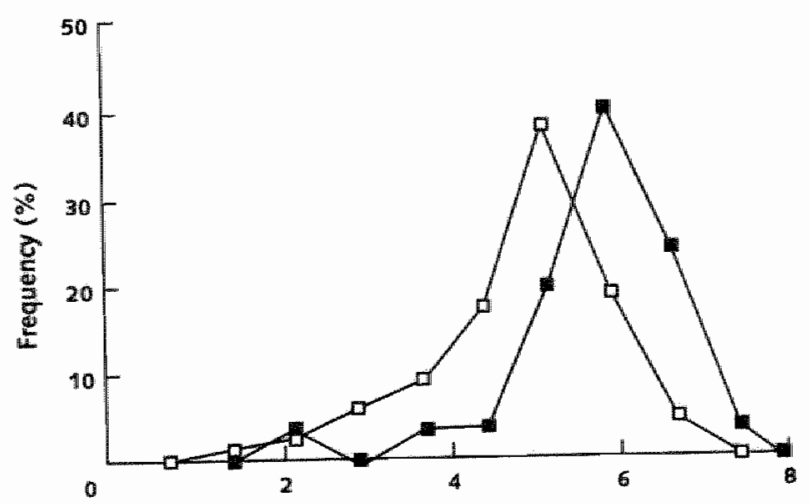

Natural logarithm faecal coliforms/100 $\mathrm{ml}$

- After intervention

Before intervention

Figure 3. Frequency distribution of the $\log _{\mathrm{e}}$ counts of the whole bucket group. (Atter intervention cor= rected for rain). 
When assigning the faecal contamination of the bucket wells to groups of very high, moderate, and low levels of contamination, all counts at the very high level are eliminated after intervention and part of the moderate counts is reduced to the low level (Table 6).

Table 6. Proportions of very high, moderate and low readings before and after intervention in the group origimally equipped with rope and bucket.

\begin{tabular}{lccc}
$\begin{array}{c}\text { Low level } \\
0-100 \mathrm{FC} / 100 \mathrm{ml} \\
(\%)\end{array}$ & $\begin{array}{c}\text { Moderate level } \\
101-1000 \mathrm{FC} / 100 \mathrm{ml} \\
(\%)\end{array}$ & $\begin{array}{c}\text { Very high level } \\
>1000 \mathrm{FC} / 100 \mathrm{ml} \\
(\%)\end{array}$ \\
\hline $\begin{array}{l}\text { Before } \\
\text { After }\end{array}$ & $\begin{array}{c}12 \\
31\end{array}$ & 80 & 8 \\
\hline
\end{tabular}

\section{Other factors influencing water quality}

The complete model, fitted on the water quality results of the entire study is shown in Table 7, together with the significance level for each variable. In fitting the water quality model, each measurement of a single well is considered as an independent sample as there was almost as much water quality variation for repeated samples from the same well as there was for different samples from different wells. No interactions were seen for the main effects. No difference in results of the fitted model was seen when the wells which mistakenly received their rope-pump too early and/or the wells which did not receive the planned intervention because of the drought, were excluded.

Table. 7 Parameters included in the water quality model

Variable name (and type)

Main effects

Method of extraction* *

(categorical)

Rainfall period*

(categorical)

Number of families/well*

(dummy)

\section{Covariates}

Distance well/kitchen * *

Amount of water extracted*
Range of values

1 rope-pumps

2 windlass

3 rope/bucket

I diy period (February-mid May)

2 first rains (mid May-end July)

3 after first rains (end July-September)

$1=1$

$2>1$

continuous

continuous

Pe0.05; * P<0.01; * P<0.004 
Contamination of the wells increases when more families are using the well and when more water is extracted daily, although these effects are less significant than the distance of the well from the nearest kitchen (Table 8). Structural factors such as a wooden cover and its use, the age or depth of well, the presence and distance from a latrine or corral, and socioeconomic factors such as schooling, type of waterdrawer and possessions of user families had no effect on water contamination. The effect of an apron, a good drainage system and protection against animals could not be assessed because none or almost none of the study wells possessed one. Neither could the effect of cleaning the well be determined, since the vast majority had cleaned their well within the last half year.

Table 8. Impact of the distance of the well to the nearest kitchen on the level of water contamination of the well

\begin{tabular}{lccc}
$\begin{array}{l}\text { Distance } \\
\text { well/kitchen } \\
\text { (varas) }\end{array}$ & $\begin{array}{c}\text { Crude } \\
\text { GM FC/100ml }\end{array}$ & Adjusted* & GM FC/100ml \\
\hline $1-9$ & 251 & 260 & 77 \\
$10-19$ & 201 & 200 & 87 \\
$20-29$ & 177 & 176 & 26 \\
$>30$ & 150 & 143 & 64 \\
\hline
\end{tabular}

Total

1 Wara 0.8359 meter

- Adjusted for the parianeters usied hin the water quality model method of extraction, ratufall, number of families/well and anount of water extracterd.

\section{Discussion}

Results of this study indicate that faecal coliform counts are reduced by an average of $62 \%$ when a rope-pump is installed in place of a bucket and rope. A concrete cover appeared to effect no additional improvement, but the concrete covers in this study were of a poor design and did not seal the headwall hermetically. A better design is needed and its impact should be investigated.

The effect of a simple windlass seemed almost as great as that of a rope pump, although pre and post-installation measurements were not made. The effect of a rope-pump or windlass must be ascribed to the elimination or reduction of contamination of the rope and bucket being dragged on the ground and touched by the hands. Improvement of water quality by installing a windlass and upgrading the well with a cover, drainage apron and lining has been reported in other studies (Morgan 1991; Lacey et al. 1990).

Other factors found to have an impact on contamination of the wells included rainfall, number of households using the well, amount of water extracted daily and the distance of the well from the nearest kitchen. The last three factors probably reflect domestic 
activities with poor hygiene around the well. The association with the number of households using the well has been described in Kenya (Nyangeri 1986). The amount of water within the well may have some influence; reflecting dilution of the faecal contamination introduced daily into the well and its subsequent die-off. The fact that contamination of wells peaks during the start of the rainy season and returns to normal levels after the first rains is consistent with studies in other regions (Barrell \& Rowland 1979; Blum et al. 1987; Feachem 1974; Mertens et al. 1990b; Moore et al. 1965; Wright 1985).

In developing countries, only around $40 \%$ of the rural population have access to good quality of water (Huttly 1990). The other $60 \%$ use traditional water sources of generally poor quality, among which the protected hand-dug well is one of the less contaminated; only springs are usually cleaner (Feachem 1980; Lindskog \& Lindskog 1988; Sandiford et al. 1989; Tensay 1991; Utkilen \& Sutton 1989; White et al. 1972; Wright 1985). Geological, socioeconomic and ethnographic factors determine the type of water supply and, in the case of hand-dug wells, the density of these wells. Where water depth makes it possible, people dig their own private or communal wells and this remains the most common method of groundwater exploitation, probably even more important than drilled wells (Clark 1988). To improve water and sanitation for this rural population, hundreds of programmes have been developed to drill, dig or upgrade communal wells and to equip them with a handpump. Many programmes failed due to abandoning of wells because of frequent breakdowns of the pumps and insufficient maintenance and hygiene education. Maintenance and hygiene education have now become a central feature of these programmes (Reynolds 1992; Kerr 1990). Besides, studies of water quality have shown that hand-pumps do not always yield the expected water quality improvement (Lloyd \& Suyati 1989; Mertens et al. 1989; Wedgwood 1989). Consequently a shift has taken place and programmes to upgrade the old-fashioned family well and equip them with an improved method of extraction have gained in popularity (McIntosh 1989; Morgan \& Chimbunde 1991; Utkilen \& Sutton 1989).

Such programmes could have an important impact on the incidence of diarrhoeal disease. In the first place, the amount of water used for hygiene purposes will increase as availability increases through a decrease in the distance to the water source, improvement of the method of extraction or a decrease in the number of users per water source (Cairncross $\&$ Cliff 1987; Frankel $\&$ Shouvanavirakul 1973; Hoque et al. 1989; Sandiford et al. 1990; White $e t$ al. 1972). Secondly, the level of contamination of the well will decrease from high to moderate and eliminate very high levels of water contamination. Finally, protected hand-dug wells are used by fewer families than most unimproved sources. Since disease transmits readily by person-to-person contact in such households, water quality is less important. Many studies of in-house contamination of stored drinking water found no relation with diarrhoeal disease (Han et al. 1991; Henry \& Rahim 1990, Mertens et al. 1990, Moore 1965). The same could account for the family well, in contrast to the community well where contaminating pathogens can come from all the families using the water source and where the source could be an important transmission route. Whether a persisting low level of faecal contamination of family well water still poses a serious risk for diarrhoeal diseases remains to be investigated. 
Simple cheap rope-pumps can yield a significant improvement in water quality while simultaneously increasing availability. Upgrading the well with a drainage system, a well designed cover or an extra large tube (to shift domestic activities around the wells to a point of some 10-20 meters from the well) and hygiene education programmes may further improve water quality. The low cost and easy maintenance of the rope-pump makes it appropriate for family wells.

\section{Conclusions}

Results indicate a $62 \%$ reduction in the geometric mean of the faecal coliform contamination of the well water due to the installation of a rope-pump with or without a concrete cover. Other factors found to influence the level of contamination of water in handdug wells were rainfall, number of households using the well, amount of water extracted daily and the distance of the well from the nearest kitchen. The last three factors probably reflect domestic activities with poor hygiene around the well.

The installation of a simple rope-pump on family wells improves the water quality and availability at a favorable cost/benefit ratio. They can be considered a viable option for rural water and sanitation programmes in developing countries and a good adjunct to the traditional family wells. Additional programmes of upgrading the wells and hygiene education may improve the water quality, but their impact remains to be investigated.

\section{Acknowledgements}

This study was funded by the British Embassy in Nicaragua. The authors would like to express their gratitude to Mario Gutierrez and Aura Perez of the Instituto Nicaraguense de Acueductos y Alcantarillados for their assistance during this investigation.

\section{References}

Allbers H., Meza R. Solis D. E Roditquez M. (1993) How the nope-pump conquered Nicaragua. Waterlines 12(2).

Barrell R.A.E. Rowhand MG.M. (1979) The relationship between rainfall and well water pollution in a West African (Gambian) village Joumal of Hygien (Cambridge) $83,143-150$.

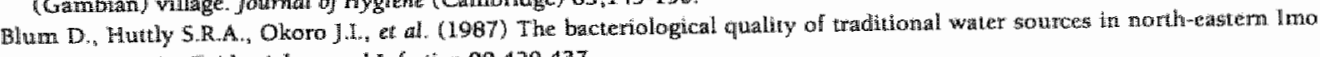
State, Nigerias. Epidemiology and Imfection $99,429-437$

Buchrieser $W$, Brosch $R_{+}$. Buchrieser $C$, et wil. (1989) On the drinking water situation on the Cape Verdige Islands (IIstand of

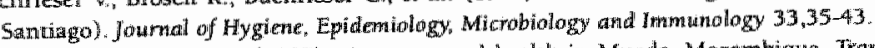

Cairncross 5. \& Cliff J.L. (1987) Watter use and healh in Mueda, Mozambique. Transactions of the Royal Society of Thopical Medicine and Hygierne $81,51-54$.

Clark L. (1988) The field guide to water wells and boreholes. Open University Press, New York- Toronto

Esrey S.A. Potash J.B., Robens L., G. Shiff C. (1.991) Effects of improved water supply and santation of ascariasis, diarrhoea,

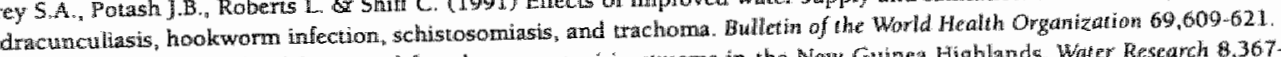

Feachem $\mathbb{R}$. (1974) Faecal colfforms and faecal streptococci in streams in the New Guinea Highlands. Water Research 9,367374.

Feachem R. (1960) Bacterial standartis for drinking water quality in developing countries. Lancut August 2,255-256

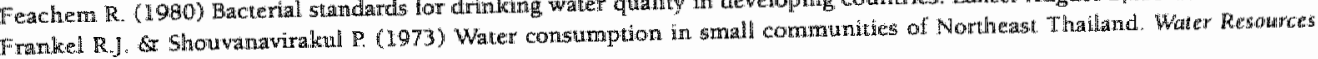


Research $9,1196-1207$.

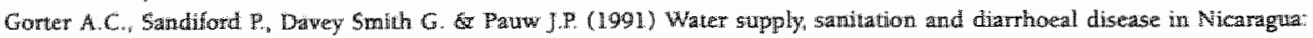
Resuls from a case-control study International jownal of Epidemiology $20,527-533$.

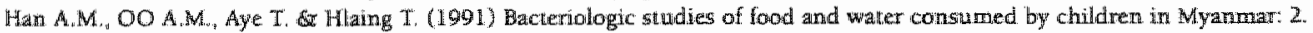
Lack of association between diarthona and contamination of Lood and water Joumal of Diomhozal Disease Research 2,91-93.

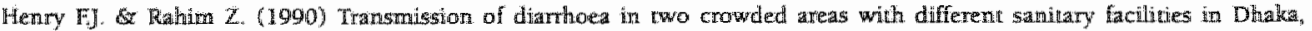

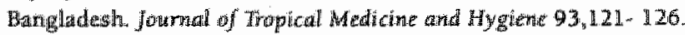

Hoque 3 A. Hutly SRA. Aziz KMA, al. (1989) Tubexell water consumption and its determinants in a rural area Bangladesh. Journal of Tropical Medicime and Hygieme $92,197-202$

Huthy S.R.A. (1990) The impact of inadequate sarizary conditions on health in developing countries. World Health Statistics Quarterly $43,118-126$.

Kern C. (Editor) (1990) Cammunty healh and sanitation. Intermediate Technology Publications. London.

Lacey E., Eng B.E.C. \&Y Eur Eng M.I.E.1. (1990) Comparison between hand dug and hand augered wells. Report based on experiences in Zambia and Zimbabwe, International Relerence Cencre for Community Water Supply and Saniation (IRC) 2125 the Hague.

Lambert R.A. (1990) How to make a repe-and-washer pump. Intennediate Technology Pablications. London.

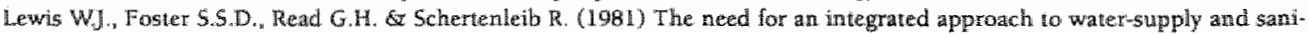
tation in developing countries. The Science of the Total Environment 21,53.59.

Lindskog R.U.M. \& Lindskog PA. (1988) Bacteriological contamination of water in mural areas: an intervention study from Malawi. Joumal of Tropical Medicine and Hygiene $91,1,-7$.

1.lloyd B. S Suyati S. (1989) A piot rural water swryejlance project in Indonesia. Waterlines 7(3),10 13.

Mclinosh A.C. (1989) Thume paper - The family handpump. In Women and water; Domestic shallow well water savplies, The family hand pump scenario. Asian Development Bank and United Nations Development Programme, Seminar. Manila.

Mertens T.E., Fernando M.A., Cousens S.N., et al. (1990) Childhood diarthoea in Sri Lankta a case-control study of the impact of improved water sources. Tropical Medicine and Parasitology 41,98-104.

Metens TE. Fernando M.A. Marshall TF de C, et al. (1990) Determinants of water quality, availability and use in Kururregala, Sri Lanka, Tropical Medicine and Parasitology 41,89-97.

Moe C.L. Sobsey M.D., Samsa G.P. Mesolo V. (1991) Bacterial indicators of risk of diarrhoeali disease from drinking-water in the Philippines. Bulletin of the World Health Orgunization 69,305-317.

Moore H.A., de fa Criz E. \& Vargas-Mendez O (1965) Diartheal disease studies in Costai Rica: W. The influence of sanitation upon the prevalence of intestinal infection and diarrheal disease. American Jourmal of Epidemiology 82,162-184.

Morgan P. (1991) Rural Water Supplies and Samitation. A Texi from Zimbabwet Blaim Resectreh Laboratory Ministry of Hiealih. Harare. MacMillan Education Ltd. London and Basingstoke. Morgan P. is Chimbunde E. (1991) Upgrading family wells ir Zimibabwe. Warerlines $9(3), 10-1,2$

Nyangeri E: E.N. (1986) Rehabilitation of hand-dug wells and protected springs in KKisit, Kenya. Report Tampere University of Technotogy in co-operation with Fimuish International Development Agency FINNIDA No 29.

Reynolds ). (1992) Hawdpumps: Toward a sustainable cechnology, research and development during the water supply and samitation decade. Water and Sanitation Report 5, United Nations Development Programme-Worldbank. Washingon.

Sandillord P. Alberts H. Orozco J.G. Gorer A. (1993) The Nicaraguan rope-pomip. Waterlines 11 (3), 27-30.

Sindiford P. Gorter A.C., Davey Smith G. \& Pauw J.PC. (1989) Determiname of drifiking water quality in rutal Nicatragu. Epplidtrmiology ard Irofection $102,429-438$

Stndiford P. Gorter A.C., Onozco J.G. \& Pau J.P. (1990) Determinants of domestic water use in rumal Nicaragua. Journal of Tropied Medicine and Hygiene $93303-389$.

Sutono S. (1987) Waker supply and dumtheal disease un rural areas of Indonesia. Bulletin Penelitian Kesehotan 15, 1-14.

Tiensay Z.W. (1991) Akcteriological quality of drinking water in Kafla administrative region, sowh west Ethopia. Joumal of Hygiene. Epudemiology. Microbiology and inmuthology 35,5251-258.

Trivedi B.K., Gandhi. H.S. Shukla N.K. (1971) Bacteriological water quality and incidence of water borne diseases in a rurall popultation. Indian Jourtal of Mcilical Sciences 25,$795 ; 801$

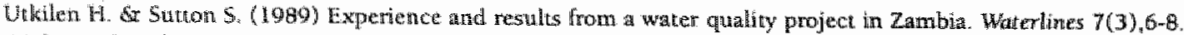

Wedgwood K. (1989) Nicaragua: rural water quality surveillance and improvement. Waterlines $7(3), 20-23$.

White G.E. Bradley DJ. \& White A U. (1972) Drawers of Water; Domestic water use in East Africa. University of Chicago Press. Chicingo.

Wright R.C. (1985) The seasonality of bacterial quality of water in a tropical developing councry (Sierra Leone). Journal of Hygiene. (Cambridge) $96,75-82$. 
Chapter 7

Discussion 


\section{Discussion}

Worldwide, death due to diarrhoea in children under-5-years has decreased from an estimated 4.6 million in $1982^{1}$ to 3 million in 19932, still it is the second most important cause of death in that age group. Of 11 million deaths among children under the age of 5 in the developing world, 4 million are attributable to acute lower respiratory infections, 3 million to diarrhoea and a further 1 million to measles ${ }^{3}$.

A review of the literature on diarrhoea provides no evidence of a decrease in its incidence in developing countries. The very rough estimates for the global incidence of diarrhoea have remained the same for the last 10 years: 1 billion episodes per year*. Diarrhoea remains a major cause of morbidity, with attack rates ranging from 5-12 per child under 5 per year to as many as 18 during the first year or two of life in the poorest areas of the developing world ${ }^{3}$. Each episode of diarrhoea, if it is not properly managed, contributes to malnutrition. When episodes are prolonged, their negative impact on growth is increased. In terms of incidence rates this condition dwarfs all others ${ }^{2}$. Many investigations have indicated that of all childhood illnesses, only diarrhoeal disease can have a significant negative effect on grow th ${ }^{6}$.

Prevention of the morbidity from diarrhoeal diseases will reduce malnutrition in infants, which in turn will result in a lower vulnerability to other diseases, such as respiratory infections and measles. This will not only result in fewer deaths due to diarrhoea but will also reduce deaths due to other infectious diseases. Diarrhoea contains $7 \%$ of the burden of disease in the world?, which makes major efforts to decrease its incidence justifiable.

In spite of many actions during the last decades, the incidence of diarrhoea in developing countries is still high. The attack rates in developed countries are currently estimated at only 1-5 per child under 5 per year, with the highest rates observed under special conditions such as in day care centres. The interruption of the transmission of diarrhoeal pathogens has proven to be much more difficult than originally expected ${ }^{\mathrm{a}}$.

In the developed world, with its relatively good infrastructure of water, sanitation and education, the transmission of diarrhoeal pathogens has become limited. When transmission occurs and the pathogens cause diarrhoea, the source of the pathogens and the transmission route are investigated and if necessary, measures are taken. (Examples: Cryptosporidiasis in water wells; E.Coli in the fast food chain; different types of pathogens in day care centres; Salmonella in the food chain)9.

Recent research has suggested that in the United States affluence and education in the last decade of the nineteenth century made little difference to child mortality, until scientific knowledge showed households how to reduce the dangers to their health 10 . Since individuals with more education acquire and use new information more quickly, this emphasis on knowledge helps to explain the large differences in child mortality by mothers" education observed in developing countries today. However, the presence of certain material resources such as water supplies, systems for the safe disposal of faeces, and 
soap in the case of prevention of diarrhoeal disease, should be considered preconditions for a change in behaviour through health education. Witlout these preconditions 'good' practices simply cannot be performed consistently, although knowledge exists. In this way poverty and ill-health are closely interrelated. "While poverty prevents a person from satisfying the most basic human needs (adequate food, safe and enough water and sanitation, and access to social services such as basic health and education), ill-health inhibits an individual's ability to work, reduces earning capacity and deepens poverty". 2

Table 1 gives an idea of the actual situation. In $199525 \%$ of the populations of developing countries still lacked safe water, $66 \%$ had no access to an adequate system for the disposing of faeces, and $38 \%$ of the women were illiterate ${ }^{3}$. Cleanliness of water is not the only issue; the importance of an adequate water supply for household hygiene cannot be over-emphasized. An unknown percentage of the population lacks an abundant water supply "on the premises". Unfortunately accurate data are not available. It can be assumed that an abundant water supply is available for fewer people than those who have access to clean water. Figures for households having safe water are the sums of combinations of households with different types of water sources, such as domiciliary connections and household wells, but also include communal hand-dug wells or communal perforated wells equipped with hand-pumps. Of these water sources an unknown, but probably much smaller number will be on the premises of these households.

Although Nicaragua belongs to the poorest 30 countries of the world ${ }^{11}$, it does not fall in the group of 47 Least Developed Countries (LDCs) as defined by the World Health Organization, which uses basic indicators such as life expectancy, under-5-mortality and infant mortality ${ }^{3}$. This is also reflected by the relatively good situation of Nicaragua's water supply, sanitation and female literacy in the urban areas (table 1). The data have been collected in a nationwide population survey in 199512. The table also shows data that we collected in 1990 during a population survey of morbidity and mortality of a random sample of $10 \%$ of the houses in Villa Carlos Fonseca.

Table 1. Unsafe water, inadequate disposal of faeces and Witerate women.

\begin{tabular}{lrrr} 
& $\begin{array}{c}\% \text { unsafe water } \\
\text { disposal of faeces }\end{array}$ & $\begin{array}{c}\% \text { illiterate } \\
\text { women }\end{array}$ \\
\hline Developing World & $25 \%$ & $66 \%$ & $38 \%$ \\
Range LDCs & $17-92 \%$ & $37-94 \%$ & $29-93 \%$ \\
Nicaragua all & $15 \%$ & $32 \%$ & $26 \%$ \\
Nicaragua urban & $1 \%$ & $5 \%$ & $15 \%$ \\
Nicaragua rural & $31 \%$ & $44 \%$ & $44 \%$ \\
Villa Carlos Fonseca & $24 \%$ & $38 \%$ & $32 \%$ \\
\hline
\end{tabular}

1 Least Developed Counthices 
An interesting aspect of the Villa Carlos Fonseca studies is that when our team started in 1986, we intended to perform only one study; one of the first case-control studies of diarrhoeal diseases in developing countries. At that time we had no idea how our research would develop over the next ten years. It became an integral programme of diarthoeal disease research with the utilization of the results in health promotion programmes. Later components were shaped by the earlier work - e.g., the evaluation of the installation of rope-pumps was inspired by the evidence from the case-control study that lack of water availability caused more diarrhoea.

When our first water and sanitation study started, the importance of the role of the water quantity versus the water quality in the transmission of diarrhoeal diseases was still unknown. Over the course of time the evidence from our and other studies showed that the amount of water that was available to households, was more important than its quality. The role of sanitation is still discussed, but it is now generally accepted that not only the sanitary equipment but also the hygienic behaviour around the disposal of faeces is important.

Our Villa Carlos Fonseca studies showed that the quality of the drinking water was less important than the distance from the house to the water source. In spite of marked differences in water quality between the different types of water supply, no effect of water quality on diarrhoea morbidity was found. In contrast, there was a clear association between the water availability and diarrhoea morbidity. Children from homes with water supplies over 500 metres from the house had much higher rates of diarrhoea compared to children from houses with their own water supply. The presence of a latrine made no difference. A mother's level of schooling was inversely correlated with the frequency of diarrhoea in her children. A significant effect on the incidence of diarrhoea was also found for the number of children under the age of five living in the house.

In the hygiene study we detected a consistent effect of almost all hygiene practices on diarthoea. More schooling produced a better hygiene behaviour, this being slightly stronger in the presence of a radio. Our study was one of the first to observe simultaneously these many hygiene practices, to perform the observation on more than one occasion and to relate the findings to the incidence of diarthoea. In our hygiene study the existence of a latrine had a beneficial effect, but mothers' behaviour with regard to the disposal of children's stools was at least as important. In rural Nicaragua chilciren under' the age of 5 use a latrine infrequently because they are afraid of the "black hole", while mothers regard their faeces as benign. Consequently, cleaning occurs more for cosmetic/aesthetic reasons than because of the mothers' knowledge of transmission routes. This normative concept of the mothers' behaviour performing 'good' practices because they are socially acceptable rather than effective in the prevention of diarchoea, has also been described elsewhere and fits well with Fishbein and Ajzen's Theory of Reasoned Action ${ }^{13}$.

The ethnographic work shows the importance of local health beliefs. The studies confirm that traditional beliefls and practices continue to be important in rural areas of Nicaragua and have a direct influence on the manner in which mothers respond to diarrhoea in 
their children. Traditional medicine must still play an important role in the design of programs for the prevention of diarrhoea. A promotional program should recognize the importance of popular knowledge, respect it and use it as a guide in the modification of potentially harmful practices. In Nicaragua, popular knowledge is a result of both traditional and modern medicine. A good program must take into account this plurality and seek the means for explaining the causes of diarrhoea, combining traditional and modern concepts. Mothers will feel motivated to change their habits only if they understand the influence of harmful hygienic practices on their children. Infant mortality caused by diarrhoea could be reduced considerably if popular knowledge of diarrhoea were recognized, and if programs were more designed in accordance with local cultures and health beliefs.

A complicated relationship exists between socio-economic status, education, cultural factors and hygiene practices. Most studies on hygiene show that hygiene practices improve as education (and affluence) increases, although in some studies only knowledge, and not also practice, increases 28. People's behaviour is not only determined by their level of knowledge of disease prevention, but also by the local culture and the available preconditions, such as water, soap and time. Even if enough knowledge exists, without these preconditions, 'good' practices simply cannot be performed consistently, while social and cultural factors may have a reinforcing or restraining influence. Personal, domestic and community/public hygiene are now considered to play a far more important role than was foreseen years ago. Recently dozens of hygiene studies have been performed, and many are still underway.

To reduce the transmission of diarrhoea, several important transmission routes must be blocked. As Briscoe argues, for diseases such as diarrhoea, where there are multiple transmission routes, reducing transmission by the dominant route will not necessarily produce a corresponding reduction in the incidence rate of that disease ${ }^{14}$. In highly contaminated environments, where multiple transmission routes are acting together, the health impact of improved water supplies or sanitation may be limited. Shuval et al. even claim that there is a socioeconomic threshold below which investments in water supplies and sanitation facilities alone will result in little or no health improvementis. Cairncross et al. reason that the control of the disease transmission not only depends on safe and sufficient water, proper sanitation and good hygiene at the household level, but must also include hygiene in the public domain such as public places of work, schools, commerce and recreation as well as the streets and playing fields. They state that the overall levels of hygiene in villages may play an even more important role than in the householdi6. Children spend a lot of their time in other households, at school and on the streets, and households can share meals or buy water and food from street vendors. In several studies crowding was reported a risk factor for diarrhoea as well as the number of children per household. Koopman stresses that in schools, in addition to toilets, there are other factors such as person-to-person contact, that are responsible for the transmission of diarrhoea. He argues that interventions in schools are probably more effective than household-basedl ones; schools having a central role in the diarrhoea transmission of a village because they disseminate the transmission ${ }^{17}$. 
There are interactions among interventions, and therefore the effect of a particular intervention will not only depend on its own merit, but also on those of the other interventions with which it interacts. Theoretical models suggest that such interactions exist between water supply, sanitation and hygiene interventions. The impact of improvements in water supply, sanitation and hygiene together are greater than the sum of the effects of the interventions alone. Furthermore, if the interactions are strong, the health impact from an improved water supply may depend critically on whether sanitation and hygiene conditions are good or poor ${ }^{18,19}$. The Villa Carlos Fonseca studies have made it clear that supplying only hardware is not sufficient to reduce the incidence of diarrhoea. Personal, domestic and especially community hygiene plays a crucial role in the transmission of diarrhoeal pathogens. If e.g. a latrine is not used by all members of a family, its impact on the incidence of diarrhoea will significantly be reduced.

A final practical consequence of our studies was the development of the rope-pump technology. It was an unexpected, although logical outcome of our research, based on the results obtained in the water, sanitation and hygiene studies. The hand dug well is the traditional type of water source, that is mostly used in the rural areas of the developing world. The majority of these wells have been dug near the house or in the middle of a group of houses. One can consider these sources as "on the premises". However, drawing water from these sources with a rope and a bucket is an arduous and time-consuming task. Facilitating this task by a rope-pump makes it possible not only for women (who are traditionally the ones who fetch most of the water), but also for children, to draw the water. The time that is needed to get water will be reduced and the total amount of water that is used, will increase. When water becomes easily available, hygienic behaviour can improve. Another positive effect of the rope-pump is that, since the water is so easily drawn, bathing and washing of clothes in the river will diminish considerable. Rivers are highly polluted sources, with pathogens not only from members of the household, but also from animals and other families of the village and villages upstream. Mothers often take the smallest infants with them to the river, where they come into close contact with unfamiliar pathogens. Reducing the amount of time spent in rivers reduces the contact of the child with these potential pathogens. Providing households with their own water source will eliminate the drinking of water that is polluted by other people. Equipping these water sources with rope-pumps will also result in less contaminated water.

The rope-pump can have a real impact on the water and sanitation programmes throughout the developing world. Moreover it is a low cost technology that can easily be maintained and repaired. The technical and cultural aspects have recently been evaluated by the International Water and Sanitation Centre, a WHO Collaborating Centre in the Hague. This evaluation together with our study of the improvement of the water quality has led to a wider recognition of the potential of rope-pump technology. Over 12,000 rope-pumps, which serve at least $10 \%$ of the rural population, have already been installed in Nicaragua during the last decade. The National Water Institute of Nicaragua considers it now as the most appropriate pump for the rural areas and a means to improve its 
water supplies, as do the regional offices of several multilateral organizations such as UNICEF WHO, Red Cross and Foster Parents. The rope-pump is also being used in the neighbouring countries Honduras and El Salvador. Other countries of the developing world, such as Ecuador, Sri Lanka and Zimbabwe are setting up production units. A special unit for the transfer of the rope-pump technology to other countries has been set up in Nicaragua. Though the interest from water and sanitation organizations in other poor countries has been large, thus far the transfer of the rope-pump technology has been slow due to limited funds. However it is expected that on short term more funds will become available to support the south-south transfer of this rope-pump technology.

\section{What should we have done differently?}

In the Villa Carlos Fonseca studies we have tried to identify risk factors that play a major role in this setting. With hindsight, the case-control study could have been better designed. Some interview questions could have been better adapted to the local situation. Besides diarrhoea as a health parameter, we could also have looked at the nutritional status of the child. A larger sample size would have obtained clearer results. The choice of a community based or a clinic based study might have been discussed more in depth.

We compared the results of the clinic based case-control study with those of the morbidity and mortality survey that we carried out in Villa Carlos Fonseca during the rainy season when diarrhoea incidence is at its highest. In the case-control study children with diarrhoea who presented themselves at one of the health facilities were compared with children who were presented at the same health facilities with other conditions. The distance from the water source and maternal literacy, but not the type of water source or latrine ownership, were identified as risk factors for diarrhoea. In the community study, families with a child under 5 years who had diarrhoea in the two week period before the survey, were compared with families with one or more children under 5 years who had no diarrhoea. In this survey the distance from the water source, and also the type of water source were identified as risk factors for diarrhoea. The type of water source played a more important role when the distance to the water source was shorter, especially when the distance was less than 10 metres. There was a small effect of maternal schooling and no evidence that latrine ownership was associated with diarrhoea.

In our survey we also asked mothers of children with diarrhoea whether they had visited a health centre. Mothers with a domiciliary connection visited a health centre more often than mothers from the group with a hand-dug or unprotected well. This different behaviour could have been the reason that we did not find any relation between the type of water source and the incidence of diarrhoea in the clinic based study. It is, of course, possible that mothers from the domiciliary connection group also brought their children more frequently to a health centre when they had a different problem. The mothers behaviour of bringing a child to a health centre depends on many factors, such as the distance to the facility, education, the type of illness and the socio-economic situation. Not all illnesses will be treated the same by the mothers, and behaviour may differ between cultural and socio-economic groups. As an example: more educated mothers may bring a child with diarrhoea to a health centre sooner than when the child has a respiratory 
infection, and mothers who are less educated may do the opposite. This kind of behaviour may result in selection bias. A community-based case-control study would not suffer from this bias.

The type of water source can be considered a proxy for the quality of the water, domiciliary connections having the best water quality, followed by protected wells, whereas unprotected wells and rivers are most contaminated. The time required to draw water from a domiciliary connection is also much shorter than from a hand dug well with a rope and a bucket, which in turn requires less time than fetching water from the river. The type of water source, being a risk factor in the community survey, should not be interpreted as evidence that this is entirely due to the quality of water.

The first water quality study, the inventory of the types of traditional water sources in Villa Carlos. Fonseca, and the study of the determinants of the water quantity that was used by the households are examples of appropriate investigations. They were among the first of a still very limited number of studies that look at traditional water supplies and facilities for the disposal of faeces. Many water supply interventions may have had no impact because the people simply continued to use the traditional sources and were not prepared to use and maintain the new water supply. For an intervention to be effective the minimal condition must be that the design takes into account how people actually live and what they consider as appropriate.

The health beliefs study provides evidence of the importance of the local culture. Any health education campaign may be technically impressive, but if it does not have much meaning for the local population, its effect will be limited. Health education, as well as water supply and sanitation interventions, must be culturally appropriate.

In the water quality study of the rope-pumps several things went wrong. Rope-pumps were already installed before we could take baseline data and the rains of that year were almost non-existent. Nevertheless, the results were quite clear. It is a pity that we did not obtain funds for the randomized trial we designed to investigate the effect of the installation of rope pumps and hygiene education on the incidence of diarrhoea. Although we approached several donors, none was prepared to finance such a study. Around that time,

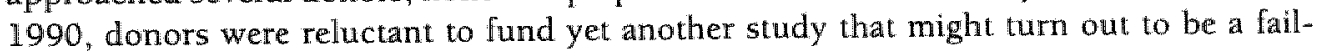
ure.

It might have been better to start with an exhaustive literature review of the actual. situation of the water supply, sanitation and hygiene in the poorest countries beforehand. Data that are made avalable through the World Bank and WHO publications are based on national statistics which have limited usefulness without disaggregation. Descriptions and figures of the traditional situation are rare, but can be found in the "grey" literature of the huge amount of reports written for donors, however many of these reports do not describe in detail the situation belore the intervention started. Secondly, a literature review of all potential interventions, estimates of their costs and indicators to measure their impact would have been useful. If an appropriate intervern- 
tion (feasible, and with low costs and high impact) had been identified, such an intervention could have been piloted. To demonstrate its effectiveness on a larger scale an appropriate investigation could have been performed.

\section{References:}

1 Snyder JD and werson MH, The magnitude of the global problem of acute diarthoeal disease: a review af active surveit-

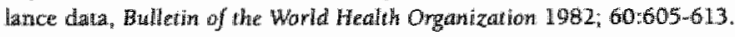

2 World Health Organization, The World Health Repont 1995, Bridging the gaps, Geneva, World Health Orgamization, 1995.

3 World Heallh Orginzation, The World Health Report 1996, Fighting discase, Fostering development, Genewa, Worlct Health Ongizizization, 1996 .

4 Bem C, Martines J, de Zoysa I and Glass RI, The magnicude of the global problem of diarrhoeal disease a tern-year update, Bulletim of the World Health Organizat lon 1992; 70 : 705 714.

5 Guerrant RL, Hughes JM, Lima NL and Crane J, Diarthea in deweloped and developing cowntries: magnitude, special settings, and etiologies, Rewiews of Infectious Diseases, 1990; 12(51) :541-550,

6. Motarjeni $\gamma$, Kaferstein F, Moy $G$ and Quevedo $F_{4}$ Review/Andyses. Contaminated weaning food: a major risk factor for diarthoea ard associtted. malnutrition, Bullevin of the World Hedilth Organization 1993; $71.79-92$.

7 Dloom BR. Infectieziektern, de rijhe landen en de Derde Wereld, wat ows nog te doen staat, De Anatomische Les $1996^{\prime \prime}$ de Volkskram, Amsterdam, 1996.

7 World Health Organization, Declaration of Alma Alat report on the Intermational Conference on Primary Health Care, Genewa. World Health Organization, 1979.

9 Diser MJ, Smith PD, Ravdin J1, Gremberg HB and Guertan Rl, (eds), Infections of the gastroimtestinal tract, Raven Press, New York, 1995

10 World Barke. World Dewelopment Repon 1993, inwesting in health. Washington DC: World Bank, 1993.

11 World Bank, World Dewelopment Report 1997, the state in a changing world, Washington DC: World Hank 1997.

12 Instituto Nacional de Esiadisticas y Censos, INEC, Resumen censal, VI censo macianal de poblacion y III de vivienda, 1995 Managua, Nicaragua, 1996.

13. Fishbein M, Ajzen I. Belief, attitude, intention, and behawior, An introduction to theory and research. Reading, Massachusietts: Addison-Wesle, 1975 .

1.4. Briscoe J, Intervention studies and the definition of dominant transmission noutes, Americapl Joumal of Eptdemiology 1984 120:449-455i.

15 Shuval HI, Tilden RL, Perry BH and Grosse RN, Effect of investments in water supply and samitation on health statuis. a threshold-saturation theory, Bulletin of the Worta Health Organization 1981; 59:243-248.

16 Catrncross $S$, Blumenthal U, Kolsky P. Moraes $L$ and Tayeh $A$. The public and domestic domains in the transmission of disease, Tropicat Aedicane and Intemational Health 1996; 1:27-34.

17 Koopman 15, Diamea and school toile hygiene in Cali, Colombia, Americatu Joumal of Epidemiology 1978; 107:412-420.

1 Vamberslice J and Briscoe J, Environmental interventions in developing countries: interactions and their implications, American Joumal of Epidemiology $1905 ; 141: 135$; 14

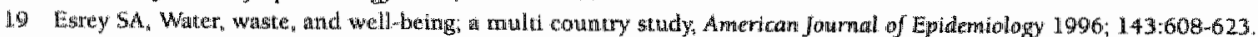




\section{Summary}




\section{Summary}

In Villa Carlos Fonseca, west of Managua in a rural area of Nicaragua, an integrated programme of diarrhoeal disease research was performed.

The first investigation was a case-control study to examine the relative importance of water-borne versus water-washed transmission, mechanisms in childhood diarrhoeal disease. As part of this study the microbiological quality and the amount of water consumed was investigated. Traditional water sources were grossly contaminated whereas piped water sources were much cleaner. A close association between rainfall and faecal contamination was demonstrated. The water of traditional sources was more contaminated in large communities compared to small communities. Factors found to affect domestic water use were household size, site of clothes washing, the type of water source, mother*s level of schooling, distance to the water source, wealth, and the ownership of cattle. A decrease in the distance to the water source from 1000 to 10 meters was associated with a clear increase in per capita water consumption. Families where the mother had at least 6 years of schooling used more water than families where the mother had no formal education.

In our case-control study 1229 children under the age of 5 were matched to an equal number of children of the same age presenting with other illnesses unrelated to water and sanitation. In spite of marked differences in water quality between the different types of water supply, no effect was found of the water quality on the diarthoea morbidity. In contrast, there was a clear association between water availability and diarrhoea morbidity. Children from homes with water supplies over 500 metres from the house had much higher incidence rates of diarrhoea than children from houses with their water supply "on the premises". The ownership of a latrine was not found to be significantly related to diarrhoea morbidity. A mother's level of schooling was inversely correlated with the frequency of diarthoea in her children.

Next we conducted a prospective follow-up study on the hygiene practices. From the database of the case control study 172 families with a child under the age of 2 years were recruited. Hygiene behaviour was observed and diarthoea incidence was recorded for 5 months. Of 46 "good" practices studied, 39 were associated with a lower risk of diarrhoea, 5 were unrelated and only for 2 a higher risk was observed. Washing of hands, domestic cleanliness (kitchen, living room, yard) and the use of diapers/underclothes by the child had the strongest protective effect. Schooling and better economic position had a positive influence on general hygiene behaviour. Individual hygiene behaviour appeared to be highly variable.

In order to gather information on raditional health beliefs and practices we performed two studies: one ethnographic and the other epidemiological. In the ethnographic study, 70 mothers with children under 2 years were interviewed. In the epidemiological study, 392 mothers with a child under the age of 5 participated, 216 of whom had had diarrhea in the previous two weeks. The studies confirmed that traditional beliefs and practices 
continue to be important and have a direct influence on the manner in which mothers respond to diarrhoea in their children. Popular health beliefs are a mixture of ideas drawn from traditional and modern notions of disease aetiology, prevention and treatment. A good program combines traditional and modern concepts. Mothers will feel motivated to change their habits only if they understand the effect of harmful hygienic practices on their children.

We also performed a literature review of the health impact of water supplies, sanitation and hygiene on the incidence of diarrhoeal disease. There is a reasonable consensus that water quality improvements do not generally have as great an impact on health as interventions which increase the availability of water or provide human faeces disposal facilities. Those interwentions that improve hygienic behaviour at the household level and/or the community level, seem to have the greatest impact. Programmes to improve the level of hygiene practices may be highly effective, but depend on the available preconditions such as the mother's level of education, easy access to a reliable water supply and facilities for faeces disposal. Social and cultural factors may also have a reinforcing or a restraining influence.

A further literature review was carried out to identify which interventions are most likely to reduce faecal contamination of wells, waterholes and surface water. The few published studies suggest that upgrading wells is effective through improvements such as a windlass, bucket cage, drainage system, lining, head wall and cover when these are applied together. It is not known, however, how effective individual components of the upgrading are in reducing contamination. The provision of pumps seems to be useful in settings with gross contamination, and tube wells are consistently cleaner than hand dug wells.

A final practical result from our studies was the development of the rope pump technology. Rope pumps are now widely promoted as a low cost, easily maintained means to improve water availability in many developing countries. The hand-dug well is the traditional type of water source that is mostly used in rural areas. Facilitating the task of drawing water through the installation of a rope pump will reduce the time that is needed to get water. The total amount of used water will increase. Our study looked at the well water quality under a variety of different conditions, comparing bucket and rope wells, with wells with a windlass and rope pump wells. Results indicated a strong reduction of the faecal coliform contamination of the well water due to the installation of a rope pump, compared to bucket and rope wells. Other factors found to influence the level of contamination of water in hand-dug wells were rainfall, the number of households using the well, the amount of water extracted daily and the distance of the well to the nearest kitchen. The last three factors probably reflect domestic activities around the well.

On the basis of our empirical studies we conclude that increasing the quantity of water available to people in developing countries can reduce the transmission of diarrhoeal pathogens considerably. Together with other preconditions, such as education, mothers 
will be able to develop good hygiene at the personal, domestic and community level. Diarrhoea is a major health problem and affects all infants in the developing world. None of the developing countries has full coverage of adequate water supplies and sanitation facilities, and in general they have poor hygiene at the household as well as at the public level. Improvements of one or more of these factors should increase the health and survival of many infants in these countries. 
Samenvatting 


\section{Samenvatting}

Een integraal diarree-onderzoeksprogramma werd uitgevoerd in Villa Carlos Fonseca, een landelijk gebied ten westen van Managua.

Het eerste onderzoek betrof een case-control studie waarin het relatieve belang van 'water-borne' versus 'water-washed' transmissie-routes van diarree bij kinderen werd onderzocht. Als onderdeel van deze studie werd de microbiologische kwaliteit en de hoeveelheid water gebruikt in het huishouden bestudeerd. Traditionele waterbronnen waren ernstig vervuild, terwijl kraan-aansluitingen veel schoner waren. Er werd een nauwe samenhang tussen regenval en faecale contaminatie aangetoond. Het water van de traditionele bronnen was in de grote dorpen meer vervuild dan in de kleinere. Factoren die de hoeveelheid water, welke in de huishoudens wordt gebruikt, beinvloedden waren; grootte van het gezin, plaats waar kleren worden gewassen, type waterbron, scholingsniveau moeder, afstand tot de waterbron, inkomen en eigendom van vee. Een afname van de afstand tot de waterbron van 1000 tot 10 meter werd gerelateerd aan een duidelijke toename in de hoeveelheid water gebruikt per hoofd van het gezin. Families waar de moeder minstens 6 jaar lager onderwijs had ontvangen, gebruikten meer water dan families waar de moeder geen opleiding had.

In onze case-control studie werden 1229 kinderen onder de 5 jaar gekoppeld aan een gelijk aantal van dezelfde leefrijd die zich bij dezelfde gezondheidspost met een andere ziekte, welke niet gerelateerd was aan water en sanitatie, hadden gepresenteerd. Ondanks grote verschillen in de kwaliteit van het water van de diverse soorten waterbronnen werd er geen effect van deze waterkwaliteit op de diarree-morbiditeit geconstateerd. In tegenstelling hiermee werd een duidelijke samenhang gevonden tussen de bereikbaarheid van het water en de diarree-morbiditeit. Kinderen van gezinnen waar de waterbron op meer dan 500 meter van het huis ligt, hadden veel hogere diarree-incidenties dan zij waar zich de waterbron in of naast het huis bevindt. Het beschikken over een latrine was niet significant gerelateerd aan diarree morbiditeit. De frequentie van diarree bij kinderen was invers gerelateerd aan het niveau van de opleiding wan de moeder.

Vervolgens werd een prospectieve follow-up studie betreffende hygiene gebruiken uitgevoerd. Er werden 172 families met een kind onder de 2 jaar geselecteerd van de dataset van de case-control studie. De hygiene gebruiken werden geobserveerd en de diarreeincidentie werd gedurende 5 maanden gemeten. Van de 46 bestudeerde 'goede' gebruiken, waren er 39 gerelateerd aan een lager diarree-risico, 5 waren niet gerelateerd en alleen bij 2 werd een hoger risico geobserveerd. Handen wassen, huishoudelijke hygiëne (keuken, woonkamer en erf) en het gebruik van luiers/ondergoed door het kind had het sterkste beschermende effect. Opleiding en een betere economische positie hadden een positieve invloed op het algemene hygiëne gedrag. Het hygiëne gedrag bleek per individu hogelijk variabel.

Om informatie te verzamelen over de traditionele ziekte concepten werden twee studies uitgevoerd: een etnografische en een epidemiologische studie. In de etnografische studie 
werden 70 moeders met kinderen onder de 2 jaar geinterviewd. Aan de epidemiologische studie namen 392 moeders deel met een kind onder de 5 jaar waarvan er 216 diarree hadden gehad in de twee voorafgaande weken. De studies bevestigden dat traditionele ziekte concepten en gebruiken nog steeds belangrijk zijn en een direkte invloed hebben op de manier waarop moeders reageren op diarree van hun kinderen. De locale ziekte concepten zijn een mengsel van ideeên afkomstig van de traditionele en de moderne denkbeelden betreffende ziekte-oorsprong, -preventie en -behandeling. Een goed programma combineert de traditionele en moderne concepten. Moeders zullen alleen dan zich gemotiveerd voelen hun gebruiken te veranderen, wanneer ze begrijpen wat het schadelijke effect van bepaalde hygiẻne gewoontes op hun kinderen kan zijn.

Wij voerden ook een literatuur-onderzoek uit betreffende het gezondheidseffect van water, sanitaire voorzieningen en hygiěne op het voorkomen van diarree. Er bestaat een redelijke consensus dat de toename van de kwaliteit van water over het algemeen niet zo'n grool effect heeft als interventies die de bereikbaarheid van water verbeteren of sanitaire voorzieningen leveren ter hygiënische verwijdering van humane faeces. Die interventies die het hygiene gedrag zowel in het huishouden, als op het openbare niveau verbeteren schijnen de grootste invloed te hebben. Programma's ter verbetering van de hygiêne gebruiken zouden wel eens hooglijk effectief kunnen zijn, maar dit zal ook afhangen van de bestaande omstandigheden zoals het opleidingsniveau van de moeder, toegang tot een betrouwbare waterbron en sanitaire voorzieningen. Sociale en culturele factoren kunnen een versterkende of een remmende invloed hebben.

Ook werd er een literatuur-onderzoek uitgevoerd ter identificatie van die interventies die mogelijk tot vermindering van de faecale contaminatie van putten, watergaten en oppervlaktewater kunnen leiden. De weinige gepubliceerde studies suggereren dat verbetering van putten effectief is indien tegelijkertijd een windas, een kooi om de emmer, een drainage systeem, wandbekleding in de put, putranden en een deksel worden aangebracht. Het is echter niet bekend hoe sterk iedere individuele component op zich de vervuiling vermindert. Het plaatsen van pompen schijnt nuttig te zijn in die omstandigheden waar er ernstige vervuiling is en daarnaast zijn geboorde putten gemiddeld veel schoner dan hand-gegraven putten.

Een uiteindelijk praktisch resultaat van onze studies was de ontwikkeling van de touwpomp-technologie. Er wordt nu uitgebreid bekendheid gemaakt voor de touwpomp als een goeckkope en gemakkelijk te onderhouden techniek om water in veel ontwikkelingslanden beter bereikbaar te maken. De hand-gegraven put is de traditionele waterbron die in de rurale streken het meest wordt gebruikt. Het vergemakkelijken van de taak om water te putten door middel van de installatie van een touwpomp vermindert de tijd die nodig is om water te halen. De totale hoeveelheid water die wordt gebruikt zal hierdoor toenemen. Onze studie onderzocht de kwaliteit van het water onder verschillende omstandigheden; waarbij de kwaliteit van water opgehaald met een touw en emmer, met een windas en met een touwpomp werd vergeleken. De resultaten tonen een sterke afname van de vervuiling van het water met faecale coliformen ten gevolge van de installatie van een touwpomp, vergeleken met het water dat geput werd met een touw en 
emmer. Andere factoren die de mate van vervuiling in hand-gegraven putten beinvloeden zijn regenval, het aantal huishoudens dat de put gebruikt, de dagelijkse hoeveelheid water onttrokken uit de put en de afstand tot de dichtsbijzijnde keuken. Deze laatste drie factoren geven waarschijnlijk de huishoudelijke activiteiten rondom de put weer.

Op basis van onze empirische studies kunnen we concluderen dat een toename in de hoeveelheid water beschikbaar, de overdracht van diarree-pathogenen onder de bevolking in ontwikkelingslanden aanzienlijk doet verminderen. Tezamen met andere positieve omstandigheden zoals opleiding, zal dit moeders in staat stellen een goed hygiënisch gedrag te ontwikkelen, zowel persoonlijk, in het huishouden als in haar woonomgeving. Diarree is een groot gezondheidsprobleem en betreft alle kinderen in ontwikkelingslanden. In geen enkel ontwikkelingsland zijn de voorzieningen voor water- en sanitatie volledig en over het algemeen is er een beperkte hygiène, zowell in het huishouden als op het openbare niveau. Verbeteringen van een of meer van deze factoren zal de gezondheid en overlevingsmogelijkheden van vele kinderen in deze landen verhogen. 
Resumen 


\section{Resumen}

En la Villa Carlos Fonseca, ubicada en la zona rural de Nicaragua, al oeste de Managua, fue llevado a cabo un programa integral de investigación en diarrea.

La primera investigación era un estudio de casos y controles para examinar la importancia relativa del modo de transmisión de la diarrea en los niños; directa a través de agua bebida o a través de la contaminación indirecta (falta de higiene). La calidad microbiológica y la cantidad de agua usada fueron investigadas como parte de este estudio. Fuentes de agua tradicionales estaban fuertemente contaminadas, mientras conexiones domiciliares estaban mucho más limpias. Se demostró una fuerte relación entre la lluvia y la contaminación. El agua de las fuentes tradicionales estaba más contaminada en las comunidades grandes que en las comunidades pequeñas. Factores que afectan la cantidad de agua usada en la casa eran: número de miembros de la familia, lugar de lavar ropa, tipo de fuente de agua, nivel de escolaridad de la madre, distancia a la fuente de agua, posición económica y tenencia de ganado. Una diminución en la distancia a la fuente de agua de 1000 a 10 metros era asociada con un claro aumento en la cantidad de agua usada per cápita. Familias en donde la madre tenía por lo menos 6 años de escolaridad usaban más agua que familias en donde la madre no tenia ninguna educación.

En nuestro estudio de casos y controles 1229 niños menores de 5 años eran apareados con una misma cantidad de niños de la misma edad que se habian presentado con otra enfermedad que no era relacionada con agua y saneamiento. A pesar de las grandes diferencias en la calidad del agua entre los diferentes tipos de fuentes de agua, no se detectó ningún efecto en la incidencia de la diarrea debido a la calidad del agua. Al contrario de ésto, se encontró una clara asociación entre la disponibilidad del agua y la incidencia de diarrea. Niños de familias con una fuente de agua a más de 500 metros de la casa tenían incidencias de diarrea más altas que niños de las familias con una fuente de agua dentro de su casa o en el patio de la misma. La existencia de una letrina en la casa no era relacionada significativamente con la morbilidad de diarrea. El nivel de escolaridad de la madre tenía una correlación invertida con la frecuencia de la diarrea en sus niños.

Posteriormente realizamos un estudio prospectivo en prácticas higiénicas. De la base de datos del estudio de casos y controles se escogió 172 familias con un niño menor de 2 años. Se observó el comportamiento higiénico y se anotó la incidencia de la diarrea durante 5 meses. De las 46 prácticas higiénicas estudiadas, 39 eran asociadas a una incidencia de diarrea más bajo, 5 no tenían relación y solamente con 2 se observó una incidencia de diarrea mås alta. El lavado de manos, higiene doméstica (cocina, sala y patio) y el uso de pañales/calzoncillos por el niño tenian el efecto más grande para proteger contra la diarrea. La educación y una mejor posición económica tenían una influencia positiva en el comportamiento higiénico en general. El comportamiento higiénico en la misma persona era altamente variable.

Realizamos dos estudios para recoger información sobre creencias y prácticas de salud tradicionales: un estudio era etnográfico y el otro epidemiológico. En el estudio etnográ- 
fíco se entrevistỏ a 70 madres con niños menores de 2 años. En el estudio epidemiológico participaban 392 madres con un niño menor de 5 años, de los cuales 216 tuvieron diarrea en las dos semanas anteriores. Los estudios confirman que creencias y prácticas tradicionales siguen siendo importante y tienen una influencia directa sobre la manera en que las madres responden a la diarrea en sus niños. Creencias de salud populares son una mezcla de ideas que vienen de conocimientos tradicionales y modernos sobre la causa, prevención y tratamiento de una enfermedad. Un bien programa combina estos conceptos tradicionales y modernos. Así las madires podrian sentirse motivadas a cambiar sus costumbres si ellas entienden el efecto que pueden tener las malas prácticas higienicas en sus niños.

También hicimos una revisión de literatura sobre el impacto en salud de agua, saneamiento e higiene sobre la incidencia en diarrea. Hay bastante consenso que el mejoramiento en la calidad del agua no causa generalmente un impacto tan grande como las intervenciones que aumentan la disponibilidad del agua o proveen facilidades para la eliminación de las heces humanas. Las intervenciones que mejoran el comportamiento higiénico a nivel doméstico y/o a nivel de la comunidad parecen tener el impacto más grande. Un programa para mejorar las prácticas higiénicas puede ser altamente efectivo, pero depende de las condiciones existentes, como el nivel de la escolaridad de la madre, el fácil acceso a una buena fuente de agua y facilidades para la eliminación de las heces. Factores sociales y culturales pueden también tener una influencia que refuerce o disminuya el efecto.

Se realizó otra revisión de literatura para identificar cuales intervenciones podrían reducir la contaminación fecal de los pozos, charcos y agua superficial. Los pocos estudios publicados sugieren que mejorar los pozos es efectivo cuando se combinan mejoramientos como un malacate, una jaula de hierro alrededor del balde, un sistema de drenaje, revestimiento del pozo, un brocal y una tapa. Pero no se sabe el efecto por aparte de cada componente en reducir la contaminación. La instalación de bombas de agua parece ser útil en los pozos con bastante contaminación. Los pozos perforados son casi siempre más limpio que los pozos excavados a mano.

Un resultado final y práctico de nuestros estudios era el desarrollo de la tecnologia de la bomba de mecate. Ahora las bombas de mecate son promocionadas ampliamente como un medio de bajo costo y de fácil mantenimiento para mejorar la disponibilidad del agua en muchos países en vías de desarrollo. Los pozos excavados a mano son el tipo de fuente de agua más común en las áreas rurales. Facilitar la tarea de halar agua por medio de la instalación de una bomba de mecate reducirá el tiempo que se necesita para obtener el agua, lo cual aumentará la cantidad total de agua usada. Nuestro estudio investigó la calidad del agua de los pozos bajo diferentes condiciones, comparando la calidad del agua de los pozos con mecate y balde, con los pozos con malacate y con los pozos con una bomba de mecate. Los resultados indican una fuerte reducción de la contaminación por coliformes fecales del agua en los pozos, debido a la instalación de una bomba de mecate, comparado con el agua de los pozos con mecate y balde. Otros factores que influenciaban el nivel de la contaminación del agua en los pozos eran la lluvia, el múmero de 
casas que utilizaban el pozo, la cantidad de agua extraida cada día y la distancia del pozo a la cocina más cercana. Los últimos tres factores reflejan probablemente las actividades domésticas alrededor del pozo.

En base a nuestros estudios empíricos podemos concluir que aumentar la cantidad de agua disponible a la gente de los países en vias de desarrollo reducirá la transmisión de patógenos diarreicos considerablemente. En conjunto con otras condiciones, como la educación, las madres serán capaces de desarrollar buenos comportamientos higiénicos personales, domésticos y a nivel comunitario. La diarrea es un problema de salud mayor y afecta a todos los niños de los paises en vías de desarrollo. Ninguno de los países en vías de desarrollo tiene una completa cobertura de facilidades de agua y saneamiento, y por lo general la higiene es pobre a nivel doméstico y a nivel comunitario. Mejorar uno o más de estos factores puede mejorar la salud y la sobrevivencia de muchos niños en estos paises. 
Summary of references in alphabetic order 


\title{
Summary of references in alphabetic order
}

\author{
After each reference the number of the chapter and that of the reference are given; \\ where the references were ordered alphabetic the number of the chapter and "alph" are \\ indicated.
}

\section{References}

\author{
Chapter + [Ref $]$
}

1 Adak GK, Cowden JM, Nicholas $S$ and Evans HS, The public health hbotatory service national case-conuol sudy of pritmary indigenous sporadic cases of campylobacter infections, Epidemiology and Infection 1995; 115:15-22.

3[19]

2 Adesiyun AA, Adekeye 10 and Umoh JU, Studies on well water and possible health risks in Katsina, Nigeria, Joumal of Hygiene 1983; 90:199-205.

$5[18]$

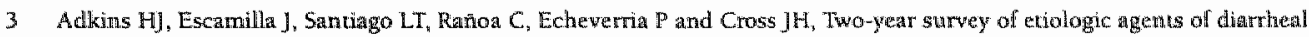
distease at Sam Lazaro Hospical, Manila, Republic of the Philippines, Journal of Clinical Microbiology 1987; 25:1143-1147. $2[28]$

4 Ahmed F. Clemens JD, Rao MR and Banik AK, Family latrines and paediatric Shigellosis in rutal Bangladesh benefit or risk? International Journal of Epidemiology 1994; $23,856-862$

$3[67]$,

5 Ahmed NU, Zeitin ME Beiser AS, Super CM and Gershoff SN, A longitudinal study of the impact of behavioural chuange intervention on cleanliness, diarrhoeal morbidity and growth of children in rural Banghdesh, Social science and Medicine $1993 ; 37: 159-171$.

3[96], 4.4[17]

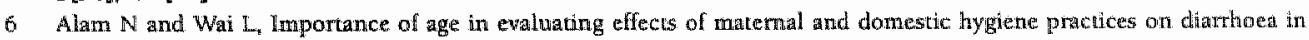
rural Bangladeshi children, Joumal of Diarhoeal Disease Research 1991 ; $9(2): 104-110$.

3:[기미

7 Alam $N$, Predictors of dharrhoea in young Bangladeshi children, Joumal of Tropical Pediatrics 1995; 41:278-280. 3[B3]

8 Alam $N_{*}$ Wojtymiak $\mathbb{B}_{n}$ Henry Fl, Rahaman MM. Mothers = personal and domestic hygiene and diarthoea incidence in yourag children in maral Bangladesh. Irit J Epidemiol 1989; $18: 242.47$.

$4.4[7]$

9 Aberts $H_{i}$ Meze $R$, Solis $D$, Rodriguez $M$. How the rope pump won in Nicaragua Waterines $1993,12: 3-5$.

$4.4[37]^{4}, 45[25]_{1} 6[a l p h]$

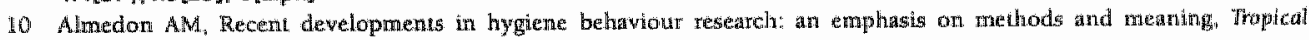
Medicine and Uniemational Heallh 1996: 1:171-182.

$3[60]$

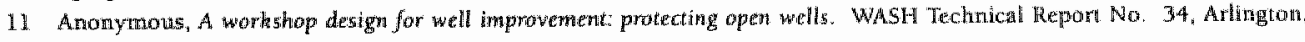
Virginia, May 1988.

$5[35]$

12 APHA (1981). Standand Mathods for the Examination of Water and Waste-water: Whatington: American Public Health Association, American Water Works Association and Water Pollution Control Federation.

4.1 1 [alph]

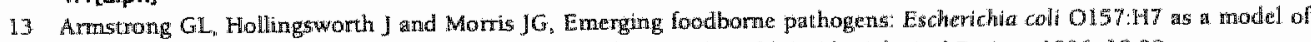
eniry of a rew pathogen into the food supply of the developed world, Epidemiological keviews 1996; 16:29-.

$2[21]$

14 Atherton FE: Newnan CPS and Casemore DP, An outbreak of waterborne cryptosporidiosis associatied with a publie water supply in the UK, Epidemiology and Infection 1995; 115:123-131.

$3[20]$

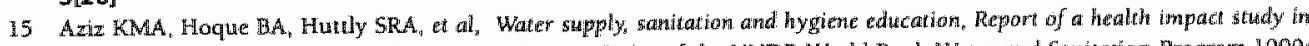
Mirapur, Bangladesh, Water and Sanitation theport Series of the UNDP-World Bank Water and Sanilation Proggram 1990; I.

$3[39]$ 


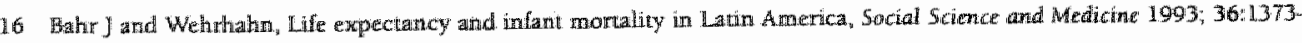
1382.

$2[3]$

17 Baltazar J. Wriscoe j, Mesola $V$ al. Can the case-control mathod be usied to assiess the impact of water supply and saniwation on diarthe $A$ sudy in the Philippines. Bull WHO 1986; 66; 627-635. 4.3[12], 3131]

1.6 Ballazar $J C$ and Solon FS, Dispossal of faces of chidren under the two years old and diarthoea incidence: A case-comirol study, Intertiational Joumal of Epidemiology 1999; 18(SL2):516-519.

$3[73$

19 Waltazar JC. Tigha TV and Tempongko SW, Hygiene behawour and hospizalized severe childhood diarthoea: a case-comtrol study, Bullew of the World Heath Organization $1993 ; 71: 323-328$.

3[32]

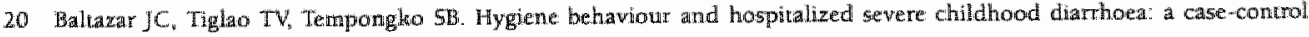
3turly. Bull World Health Organ 1993; 71: 323-28.

$4,4[11]$

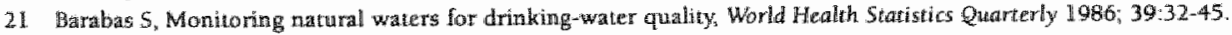
$5113 !$

22 Banell R.A.E Rowland R.G.M. (1979) The relationship between rabiall and well water pollution in a West Arican (Gambian) village. Journd of Hygienc (Cambridge) $83,143-150$.

4. 1[alph]. $5[30], 6$ talph]

23. Behm H, Primante DA La moralidad en lor primeros años de vida en paises de la America Laina: Nüaragua 1966-67. San Jose: Centro Latimomericano de Demografia, 1977; Series A; no 1036

4.3[4B]

24. Dently ME. The housiehold management of childhood diatrhoea in rural north India. Sor Sct Med 1988; $27: 75-85$. 4.5[14]

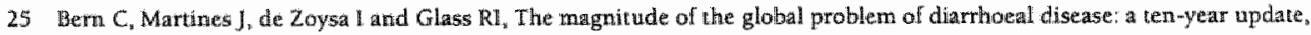
Bulletin of the Wold Heallh Organization $1992 ; 70: 705 \times 714$.

$1[1], 2[9], 7[4]$

26 Bertrand WT, Walmus BF Matemal hnowledge, atucudes and practice as predictors of diarrhocal disease in young chil dren. Int J Epidemio! 1903; 12:205-10.

$4.4[3], 4.5[16]$

27 Birmingham ME, Lee LA, Nakibirora M, Bizimana F and Deming M. A household survey of dyserntery in Burundi: impli cations for the current pandernic in \$ub-Saharan Africa, Bulletin of the World Health Onganization 1997; 75:45-53. $3[186]$

29. Black RE, Brown KH, Becker $S_{3}$ et all, Longindinal studies of infectious diseases and physical growth of children ita rural Bangladesth. II. Incidence of diarrhea and association with known pathogens, American Jounal of Epidemiolow 1982 115:3.15 32.4.

2[25]

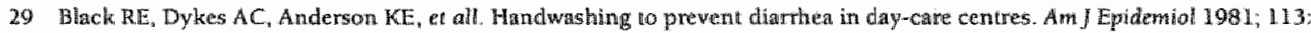
$44,3=51$.

\section{4[20]}

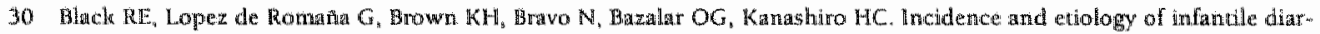

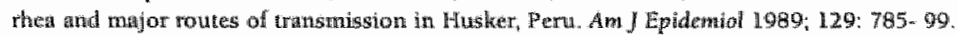

\section{4[6]: $2[27]$}

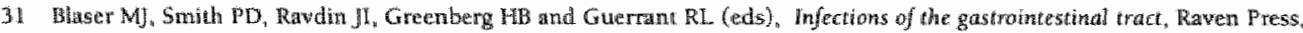
New York, 1995.

$4[2], 2[2], 4,4[55], 7[9]$

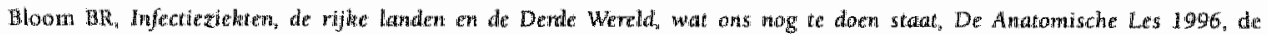
Wolksktrant; Amsterdam, 1996.

$7[1]$

32 Mhu $D$ and teachem R. Measuring the impact of water supply and sanitation inwestments on diarrhoeal diseases: prob lems of methotology International Journal of Epidemiology $1963,12.357-365$.

\section{2[15]: 4.3]6]}

33 Dhu D, Emeh RN, Huttly SRA, et al, The Imo State (Nigeria) drinking water supply and sanitation project, 1. Description of the project, evaluation methods, and impact on intervening variables, Transactions of the Royal Society of Tropical Medicine and Hygene 1990; 8 4 309. 315.

3,00

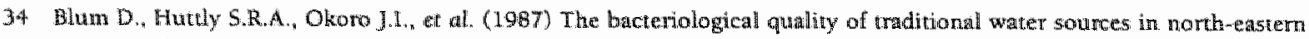
inno Statc. Nigeria. Epudewiology and Infection 99,429-437.

$5[15], 6[a] p h]$ 


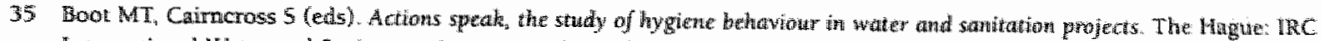
International. Water and Santation Centre, London School of Hygiene and Tropical Medicine, 1993 $3[77], 4.4[28]$

36 Bridgman SA, Robertson RMP Syed Q, Speed N, Andrewa N and Hnarer PR, Outbreak of oryptospontidusim associated with a disinfected groundwater supply: Epidemiology and Infection 1995:115:555:566.

322].

37 Briscoe J. Akin $]$ and Guilkey D, People are not passive acceptors of threats to health: Lendogientity and its consequences, Intermationat Jounal of Epidemiology $1990: 19: 1474153$.

$3[35]$

38 Briscoe J. Baltazar J and Houng $B_{i}$ Case-control studies of the effect of eriwirommental sanitation on dianthoes monbidity.

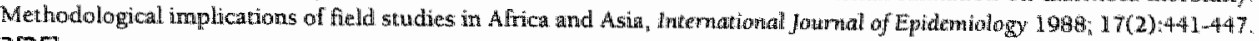
3 [25]

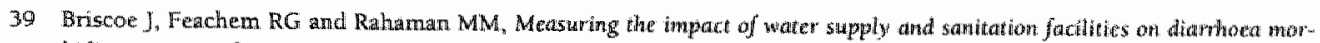
bidity: prospects for case wontrol methods. Who/CWS/85.3. World Health Organization, Geneva, Switzerland, 1985.

15], 3[17], 4.3[8]

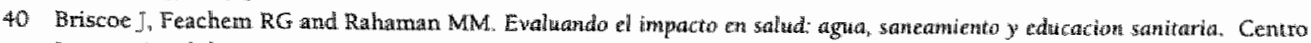
Internacional de Investigaciones para del Desarrollo, Ottawa, Canada, 1987.

$3[18]$

41 Briscoe J, Feachem RG, Rahaman MM. Evahating healih impacts: water sanitation and samitary educution. Ottawa: International Development Research Centre, 1987 ; publication no IDRC-248.

$4.3[7]$

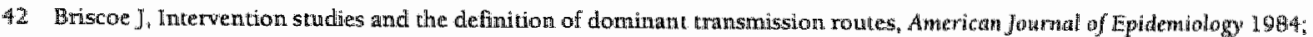
$120: 449-455$.

$3[2], 7[14]$

43 Briscoe, J. (1978). Role of water supply in improwing health in poor countries (with special reference to Bangladesh). American Journal of Cliriucal Nutrition $31,2100-2113$.

4.1[:alph]

44. Eruch HA, Ascoli W, Scrimshaw $\mathrm{NS}$ and Gordon JE, Studies of dianheal disease in Central America. V. Environumental Iactors in the origin and ransmission of acute diarrheal disease in four Guatemalam villages, Americam Jowrnat of Tropical Medicine and Hygiene 1963; 12:567-579.

$3[103]$

45 Buchrieser $\mathrm{V}$, Brosich $\mathrm{R}$, Buchrieser $\mathrm{C}_{\mathrm{i}}$ et al, On the drinking water situation on the Cape Verde Islands (Island of Santiago), Jounal of Hygiene Epidemiology Microbiology and Immunology 1989; 33:35-43.

$5[34]$

46 Buchnieser W, Brosch R., Dwchrieser C., et al. (1989) On the drinking water situation on the Cape Verde Islands (Isiand of Santiago). Journal of Hygicne, Epidemiology, Microbiology and Immunology 33,35-43.

6[alph]

47 Bukenya GB and Nwokolo $N$, Compound hygiene, presence of standpipe and the risk of childhood dianthoea in an wrban secteratent of Papua New Guinea, Interyational journal of Eptodemiology 1991; 20:534-539.

$3[72]_{*} 4.4[45]$

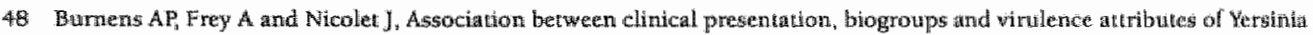
enterocolitica strains in human dianthoeal disease, Epidewtology and Infection 1996; $116: 27-34$.

$2[17]$

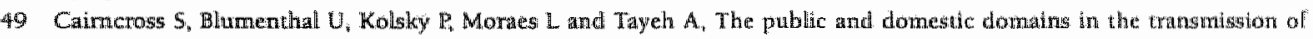
disease, Tropical Medicime and Intemational Healch 1996; 1:27-34.

$3[76], 7[16]$

50 Caimcross 5 , Developing evaluation guidelines for studying hygiene pratuces, Waterlines $1991 ; 10(1): 2,5$.

$3[78]$

51 Caimcross: 5 , Ingested dose and diarrhea transmission routes, Lance 1984; 125:921-922. $3[3]$

52. Caimeross 5. Cliff J.L. (1987) Water wse and healih in Mueda, Mozambique. Transactions of the Royal Society of Troplcal Medicine and Hygilene 81, 51 .

4.2[alph],6[alph]

53. Carncross 5. (1987) The benufits of water supply. In Developing World Water II, (edd. J. Piclsford), Groswertor, London. 4.2[alph]

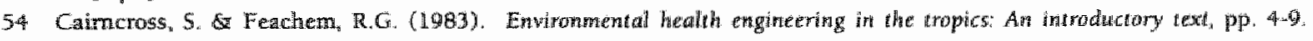
Chichester: Wiley sons.

4.1 [alph] 


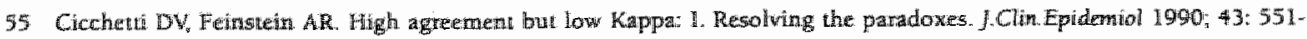
558.

4.44:43]

56 Claeson Mand Merson MH, Global progress in the control of diatrheal diseases, Pediatric infectous Disiease journall 1900 ; $9(5): 345-355$

204

57 Clark L. (1988) The feld gudd to wate wells and borcholes. Open Universily Press, New Vork- Toronto.

G[alphit

S6 Clemens JD and Stanton BF Ap edueational imtervention for altering water-sanitation behaviors to reduce childhood diar whea in urban Bangladesh. 1. Application of the case-control methad for development of an intervention, American Joumal of Epidemiology 1987; 125(2):284-301.

$3[24]]_{3} 4.4[4], 4.5[17]$

59 Conroy RM, ELmore-Meegan M, Joyce T, MeGuigan KG and Harnesi J. Lancer 1996; 348:1695-1697. $3[46]]_{8} 5[33]$

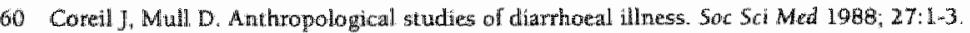
$45[6]$

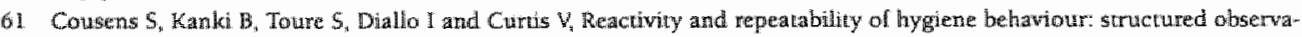
thons from Burkina Faso, Sochal Science and Medicine 1996, 43:1299*1308,

3[79]

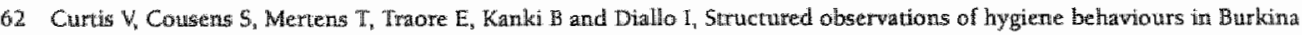
Fasso: validity wariability, and atility, Bulletin of the World Heallh Organization 1993; 71:23-32.

3[95], 4.4[29]

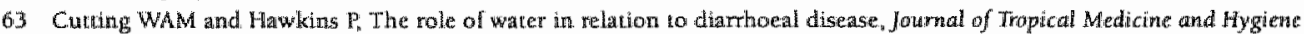
$1982 ; 85: 31-39$

$2[32]$

64. Daniels DL, Cousens $\$ N$, Malkoue LN and Feachem RG, A case-control study of the impact of improwed samitation on diarrhoea motbidity in Lesotho, Bulletion of the Worlit Health Organization, 1990; 68:455-463.

$3[29]_{r} 4.3[14]$

65 Darnent-Molina $P_{3}$ James $\$ A_{n}$ strogatz DS, savilz DA. Association between maternal education and infant diarrithea in difrerent household and community environments of Ceba. Philippines, Soc Sci Med 1994; 38: 343-350.

\subsubsection{3]}

66. Darr ". Feldman S.L. Kamen C. S. (1975) Socio-economic factors affecting domestic water demand in lstael. Water Resources Research 11,805 .

\section{2[alph]}

67 Davey Smith $G_{0}$ Boersma $A$, Gorter $\mathrm{AC}_{\mathrm{a}}$ Sandiford P. What control grwup is appropriate for cast-control studies of childhood diarthed? In: International Epidemiological Association (IEA), European Regional Meeting 1991, Biasil La, 1991:75. $4.5[30]$

68 de Zoysa $Y$, Carson $\mathrm{D}$, Feacham $\mathrm{R}$, Kirkwood $\mathbb{B}$, Lindsay-Sminh E, Loewenson R. Perceptions of childhood diarrhoea and its treament in ruwal Zimbabwe. Soc So Med 1984; 19:727-734.

$4.5[7]$

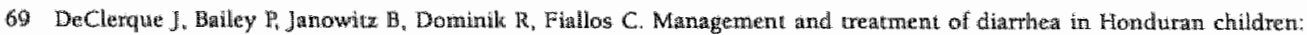
factor associaced with mothers heralth care behviors. Soc sci Med 1992; 34:687-695.

\section{$4.5[46]$}

70 Dtarrhota awd Hygien: What people know beliewe and do in a West African town. Report from the Project Saniya leam in Bobo-Dioulasso; Burkina Faso. London: Maternal and Child Epidemiology Unit, London School of Fygiene and Tropical Medictine: 1994.

\subsection{1}

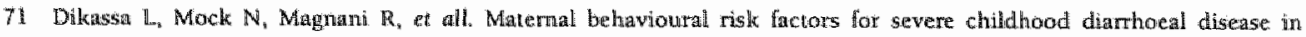
Kinsthasa, Zaire. Ihe If Epidemiol 1993; 22: 327-313.

$4.4[12]$

72 Dikassa $L$, Mock N, Magnini $R$, Rice J, Abdoh A, Mercer $D$ and Bertrand W, Matemal behavioural risk factors for severe childhood diarrhoeal disease in Kinshasa, 2aire, Intemational Jourial of Epidemiology 1993;22:327-333.

3[97]

73. Dworkin MS, Goldrun DP, Welils TG, Kobayashi JM and Herwaldt BL, Cryptosporidiosis in Washington State: an oubrealik associated with well water, Joumal for Infections Discases 1996; 174,6, 1372-1376.

358]

74 Einot, 1. G Gabriel, KR, (1975). A study of the powers of seweral methods of tnultiple comparisons. Jeurnal of the American Statistical Association 70,57 .

$4.1[\mathrm{~m} / \mathrm{m}]$ 


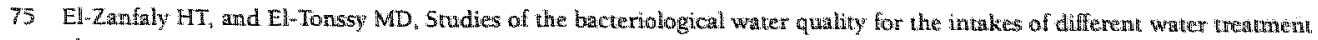
plans in greater Cairo, Zbl Hyg 1989; $188: 303-310$.

$5[12]$

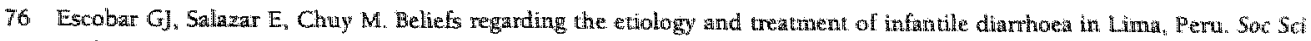
Med 1983; 17:1257-1269

$4.5[37]$

77 Estey S.A. Feachem R.G. G Hughes J.M. (1985) Interwentions for the control of diarhoeal diseases among young chan

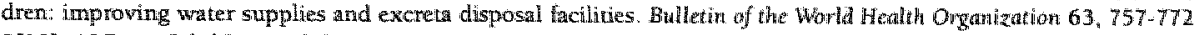

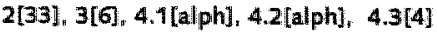

78 Estey S.A., Potash. JB., Roberts L. Shiff C. (1991) Effects of improved water supply and samitation on aseariasis, diarm rhoea, dracunculiasis, hookworm infection, schistiosomiasis, and trachoma. Bulletin of the World Health Orgatization 69,609-621.

$3[381,6[\mathrm{al} / \mathrm{ph}]$

79 Esrey SA and Habich JP, Epidemiologic evidence for health benefits from improved water amd sanination in developing Countries, Epidemiologic Reviews 1986; 8:117-128.

4.2[alph , 3[37], 4.1[alph! 4.315]

80. Esrey SA, Water, waste, and well-behng; trulli conntry study, Anuerican journal of Ephdemiology 1996; 143:608-623.

$3[41], 7[19]$

81 Ewald PW, Waterborne transmission and the ewolution of wirulence among gastrointestinal bacteria, Epwdemiolagy and Infection 1991; 106:83-119.

3[9]

82. Fayer DJ. Encuesta demogndfica nacional de Nicaragua Andisis de las preguntas retrospectivas. Sam Josê Centro Latinoamericano de Demografta, 1982.

$4.3[17]$

83. Feachem R, Bacterial standards for drinking water quality in developing countries, Lancet 1980; August 2, 255.256. 5[7], 6[a!ph]

84 Feachem $R$, Faecal coliforms and frecal streptococci in streams in the New Guinea Hightands, Water Research 1974; 8:367374

5[29], 6[alph]

85 Feachem R, McGary M and Mara D (editors), Water Wastes and Health in Hot Climates, 1987 . English Language Book Society and John Wiley \& Sons, Chichester, UK.

$3[5], 5[4]$

86 Feachem RG and Jamison Dil (eds), Disease and mortality in Sub. Sotharan Africa, Oxford Uni wersity Press, Oxford 1991 . $2[4$

87 Feachem RG, Hogan RC, Merson MH. Diarnoeal diseases controli reviews; of potential intenventions. Bull WHO 1983; 61: $637-640$

4.3[2]

38 Feachern RG. Imterventions for the control of diarrhoeal diseases among young children: promotion of personal and domestic hygiene. Bull World Health Organ 1984; 62: 467-76.

4.4[1:4]

Q9 Feachem RG. Preventing diarthoea: what are the policy options? Heall Policy wind Plamnimg 1986; 1: 109-147.

$4,3[3], 4.4[2], 4.5[2]$

90 Feachem, R.G., Burns, E., Caimcross, A.M, Cronit, A, Cross, P, Curtis, D., Khalid Khan, M., Lamb, D. Ex Southall, H. (1978). Water" health and dewelopment: An interdisciplinary exaluation Trimed Books, London 1978.

$3[13], 4.1$ [alph], 4.2[alph]

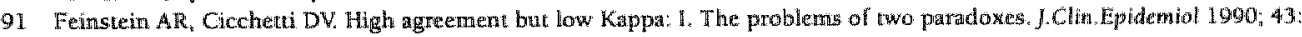
543.549 .

4.4[4.22]

92 Feresu SB and Van Sickle J, Coliforms as a measune of sewage conkamination of the River Zainbesi, Joumal of Applied Bacteriology $1990 ; 68: 397-403$.

$5[11]$

93 Finerman R. >Parental incompetence: ard >selective neglecte: BLming the victim in child survival. Soc 56i Med 1995; 40 :

5. 13.

$4.4[541]$

94. Fishbeim M, Ajzen I. Belich, attitude, intention, and behawior: An introduction to theory dand research. Readling, Massuchusetts: Addison:-Wesiey, 1975 .

4.4[49], 7[[13]

95 Fleiss $\mathrm{JL}$. Statistical methods for rotes and proportions. New York: John Wiley 5ons, 1981, 2nd edilion. 4.2[alph], 4.4[41] 


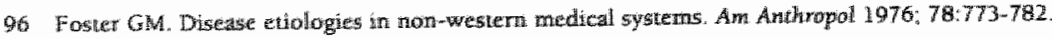
4.5[42]

97 Frakel If. Ex Shouvanavatul P. (1973) Water consumption it small communities of Northeast Thationd. Waier Resources Reseank $9,119 \%-1207$

\section{4 , 2[alph, 6[alph]}

98 Funkel SI. Lehmann D. Oral rehydration therapy: combining anthropological approaches in the ewaluation of a Papua Wew Guinea programme. J Trop Med Hyg $1984 ; 87: 137-142$.

4.5[4]

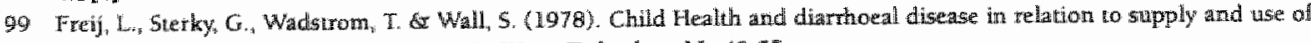
water in Antican Contrmunities. Progress in Water Technology 11, 49-55.

4.1[alph]

100 García Canales E, Evaluan granes daños ocasionados par AE Niño. La Prensa, 16 de Ocrubre de $199 \%$ $1[10]$

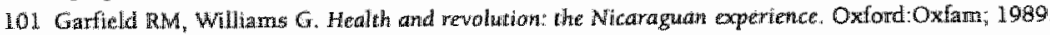
4.5[20]

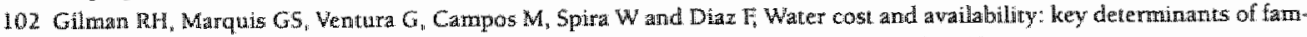
ily hygieme in a Perwian Shantytown, American Joumal of Public Health 1993; 83:1554-1558.

$3[99] .4 .4[50]$

103 Gortar $A$, Sandiford $P$, Davey Smith $G$ and Pauw J. Wher supply sanitation and diarthoeal disease in Nicaragua: Results from a case-control study International Joumal of Epidemiology 199: 20:527-533.

$2[15], 3[33], 4,4[31], 4.5[23], 6[a l p h]$.

104 Gorter AC, Alberc JH, Gage JF and Sandiford P. A randonized trial of the impact of rope-pumps on water quality. Journal of Troplat Madicine and Hygiane 1995; $98: 247-255$.

$4.4[38]_{1} 4.5[26], 5[31]$

105 Corter $A C_{\text {, }}$, sanchez $G_{n}$ Pauw J, Perez RM, sandiford $P$ and Dawey Smith G, Diarrea infantil em Nicaragua naral: imaportancia de comprender las creencias y practicas medicas tradicionales. Boletin de la Oficina Samitaria Panamericana, 1995 ; 1.19:377-390.

$3[93], 4.4[34]$

106 Goner AC, Sandiford P, Pauw J, Morales T, Pérez RM and Alberss H, Hygiene behaviour in rural Nicaragua in melation to diarkhoca, accepted Ior publication in the hutrmational foundal of Eprideniology.

$3[74]$

107 Graham $N$ and Hartung $H$, Peformance of slow sand filters in refugee water supplies in Somalia, Waterines $1988 ; 6: 19-$ 22. 5[14]

108 Green EC. Diarthoea and the social marketing of oral rehydration salis in Bangladesh. Soc Sci Med 1986; $23.357-366$. 4.5[110]

109 Green EC. Tradivional healers, mothers and childhood diarthoeal disease in Swaziand: the interiace of anthropology and health educrion. Sor Sci Med 1985; 20:277-285.

4.5[11]

110 Grosse RR, A wffey C. Literacy and health status in developing countries. Ann Rev Public Health 1989; 10:281-297. $4.319]$

11 Guerrant RL, Hughes, M, Lina NL and Cranc, J, Diarrhea in developed and develloping countries: magnitude, special settings, and etologios, Rewiews of Infectious Diseases, 1990; 12(51):541-550.

2[[리, 7 [5]

I12 Hagerty PA. Muladi K, Kirkwood BR, Ashworth A and Manunebo M, Commenity-based liygiene education to reduce

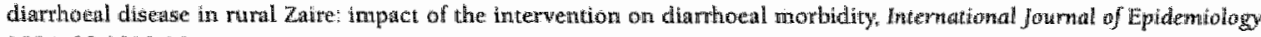
1994: 23:1050-1059.

$3[98], 4: 4[18]$

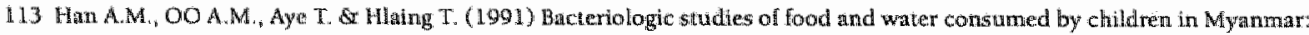
2. Lack of association between diarhoea and contamination of food and water. Joumal of Diarthoeal Disease Research 2,91 93. G[alph]

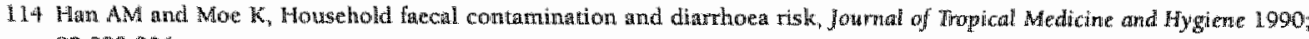
$93: 333.336$.

$3[69]_{1}, 4.4[22]$

115 Han AM, Haing T. Ptevention of diarrhoea and dysentery by hand washing. Trans R Sor Trop Med Hyg 1989; $83: 128$ 31. 4.4[24]

116 Han AN, OO KN, Aye T, Hhing T. Personal toilet after defaecation and the degree of hand contamination according to different mothods ased. I Trop Med Hyg 1986:39: 237,41 .

4.4[22] 


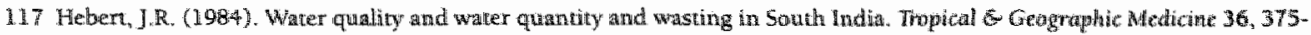
381.

4. 9 [alph]

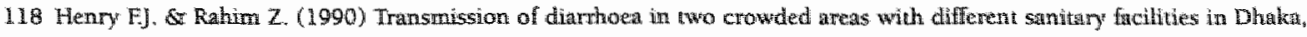
Bargladesh. Jowrnal of Tropical Midicine and Hygierit 93,121-126.

\section{4[9],6[alph]}

119 Hertz E, Hebert JR and Landon J, Social and emvironmental factors and Hife expectancy infant thortality, and antemal mor-

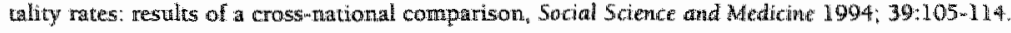

$3[75]$

120 Holmes 5. Morrow AL and Pickering LK, Child-care practices. elfects of sacial change on the epidemiology of infectious diseases and ancibiotic resistance, Epidemiologic Rewiews 1996; 18:10-28.

$3[107]$

121 Hoque B.A., Huttly S.R.A., Aziz K.M.A. et al. (1989) Tubewrell water consumption and ins determinanus in a raal area of Banglatesh. Jowrual of Tropical Medicine and Hygiene 92, 19\%-202.

Glalph:

122 Hoque BA, Juncker $T$, Sack RB, Ali M and Aziz KM. Sustanabilicy off a water, sant tation and hygiene educution project in rural Bangladesh: a 5 -year follow-up, Bulletin of the World Health Organization $1996 ; 74: 431-437$.

$3[40]$

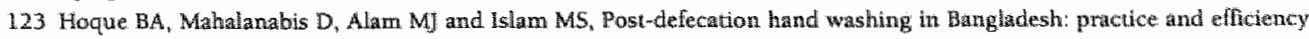
perspectives, Public Health 1995; 109:15-244.

$3[84]$

124 Hossmin MDA. Alber MJ and Hasan KHZ, Epicleniology of shigellosis in Tekmaf, a coastal area of Banghdesh: a 10 -year survey, Epidemiology and linfection 1990; 105:41-49.

$2[34]$

125 Hudelson PM. ORS and the treatment of childhood diarthoer in Managua, Nicaragua. Sac Sci Med 1993; 37:97-103. 4.5[32]

126 Hutty S.R.A. (1990) The impace of inadequate sanitary conditions on health in deweloping countries. World Health Statistics Quarterly $43,118-126$

2[7], 6[aiph]

127 Hutcly SRA,Blum D, Kirkwood BR, et al, The epidemology of acutie dianhoea in a rural community an Imo State, Nigeria. Transaction of the Royal Society of Tropical Meditine and Hygiene, 1987; 81:865-870.

$3[48], 4.4[5]$

120 Huttly SRA, Bhm D, Kirkwood BR, et al, The Ino State (Nigeria) drinking water supply and sanniation project, 2. Impact on dracunculiasis, diamhoea and nutritional stams, Transactions of the Royal Soctety of Tropical Medicine and Hygiene 1990 84:316-321.

$3[51]$

129 Huttly SRA, Hoque BA, Aziz KMA, et al, Persistemt diarthoea in a rural area of Bangladesh: A community-bossed longitudinal study, Internaciantul Journal of eppidemiology $1989 ; 18: 964$.

$2[31]$

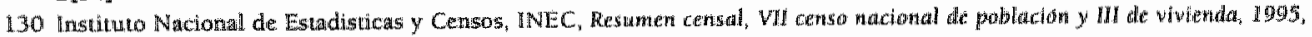
Mariagua, Niciaragua, 1996 .

177. $7[12]$

131. International Bamk for Reconstruction and Development. Measurement of the health bentefits of investmunts in water supply. Repart of ar Expert Pand, Public Utilies Deparment Report No. PUN 20, World Bardic Wasingingon DC. 1976. $3[16]$

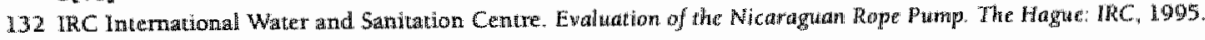
$4.4[9]$

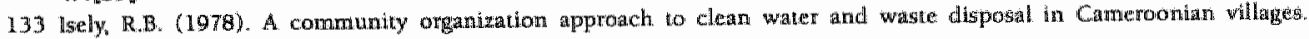
Progress in Water Technology $11,109-116$.

4.1 [alph]

134 Isiam SS and Khan MU, Risk factors for diarhoeal deaths: A case-control study an a disurrocial disease hospital in Bangladesh, Intermational Joumal of Epidemiology 1986; $15(1): 116-12 \mathrm{l}$.

323]

135 Jinadu MK, Olusi SO, Agwn Jl and Fabiyi AK, Childhood diarrhoea in rutal Nigeria. L. Studies on prevelence, mortallity and sociomenvirommental factors, Joumal of Dianhoent Disease Research 1991; $9: 323-327$.

$3[711$

136 Jiwa SFH, Mugula JK and Msangi, Bacteriological quality af potable water sounces supplyung Morogono mumichpality and

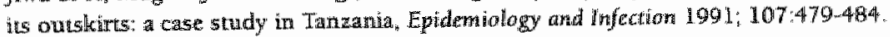

$5[10]$ 


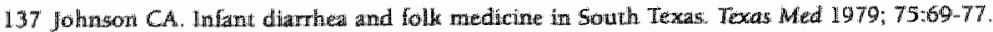
$4.5[4.5]$

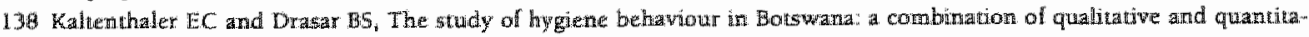

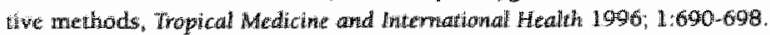
$3[94]$

139 Kaherthaller EC and Phiold JV, Microbiological nethods lor ssessing hand washing practices in hygene behaviour stud-

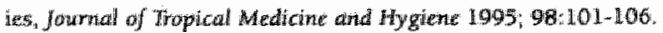
$3[899,4.4[27]$

140 Kal tenthaler EC, Elsworth AM, Schweiger MS, Mara DD and Braunholcz DA, Faecal contamination on chidren's hands and whinonmental sortaces in primary schools in Leeds. Eppdemiology and Infection 1995; 115:527-534.

$390]$

141. Kawati K. (1979) Water and other environmenual interkentions - the minimuna invesmeral concept. American Joumal of Clinical Nutrition 31,2114 .

4.2 [alph]

142 Kendall $C$, Foote D, Martorell R. Euhomedicine and aral rehydration therapy: a case study of ethomedical investigation and program planning. Soc Sci Med 1984; 19:253-260.

4.5[5]

143 Kendall C. Public Health and the domestic domain: lessons from anthropological research an diarmeal diseases. In: Coreil I. Mull ID. Anthropology and primary health care. Boulder: Westwiew Press, 1990, $173-195$.

$4.5[8]$

144 Ken C. (Exitor) (1990) Community health and sanitation. Intermediate Technology Publications. Iondor. 6[alph]

145 Khan MU. I atemption of shigellosis by hand washing. Trams R Soc Trop Med Hyg 1982: 76: 164-68. 4.4[21]

1146. Knighte SM, Toodayan W, Caique WC, et al, Risk factors for the Eransmission of diarthoea in childreth: A case-control study in tural Malaysia, Intermational Journal of Epidemialogy $1992 ; 21: 812-816$. $3[28]$

147 Konde-Luie JK, Elasu 5 , Wusonge DL. Knowledge, atumudes, and practices and their policy implications in child hood ditarphoea in Uganda. J Dir Dis Res 1992;1:25-30.

$4.4[10], 4.5[19]$

148 Koopman J5, Diarthea and school toilet hygiene in Cali, Colombia, American Journal of Epidemiology 1978, 107:412 420. $3[106], 4,4[51], 7[17]$

1.49 Kourany $M_{1}$ Vasquez MA and Mata LJ. Prewalence of pathogemic enteric bacteria in children in 31 Panamanian communihes. Anerican Jowmal of Tropical Medicine and Hygiente $1971 ; 20: 608 m 615$. 3[41]

150 I aborde DJ. Weigle KA, Weber DJ and KotchjB, Eflect of fecal contamination on diarrheal ilness tates in day-care centers, American Joumall of Epidemiology $1993 ; 138: 243-255$

3[88: 4 4[26]

151 Lacey E., Eng B.E.C. Eur Eng M.1.E. (1990) Comparison between hand dug and hand augered wells. Report. based on experiences in Znmbia and Zumbabwe. International Reference Centre for Community Water Supply and Samilation (IRC) 212.5 The Hargue.

$5[39], 6[a t p h]$

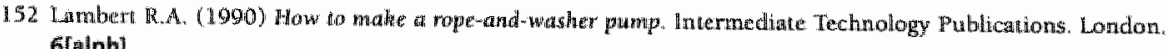
$6[a \mid p h]$

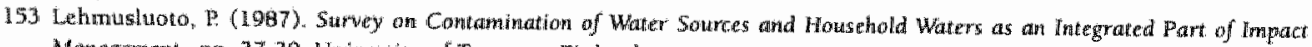
Managemewt, pp. 37-39. Uniwersity of Tampere Finland.

4.7 [alph]

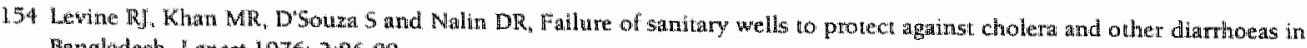
Bangladiash, Lancet $1976 ; 2: 86-89$.

आ[12)

155 Lewis W]. Foster SSD and Drasar BS. The rish of groundwater polinution by on-site sanitation in developing coumtries, A literatherentew, IRCWD Report No,01/82, 1982.

$5[2]$

150 Lewis WJ, Foster SSD, Read GH and Schervenleib $\mathrm{k}$, The need for an invegrated approach to water-supply and sanitation in developing countries, Sriewee of the Total Frivingment 1981, 21:53-59.

5[3] 6[alph]

157 Lebeman 5 ; Medical anutritional practices among Puerto Ricans in a small wrban northeastem commumity in the Lnted States. Sac Sci Med 1979: 13B:191-198.

$4.5[38]$ 


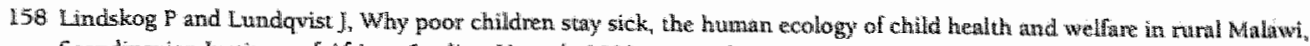
Scandinavian Mastitate of African Smdies, Uppsala 1989; Research keport No 85 $3[92]$

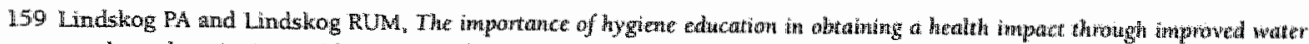
supply and samitation, wh examples from Malawi. Paper presented an the International Council Scitunite Unions Commitue on Teaching of Science Conference, 6-14 Augus! 1985, Bangallone, India.

$5[17]$

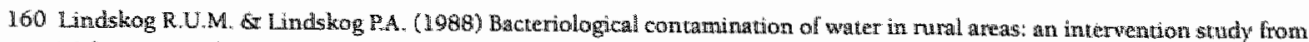
Malawi. Jounal of Tropical Medicine and Hygiene $91,1 \times \bar{l}$.

$5[16]_{1} 6[\mathrm{alph}]$

161 Lindskog U, Lindskog $P$ and Wall $S$, Water supply, sanitation and hesth education programmes in developinge countries: Problems of Evaluation, Scandinamian Joumal of Soctal Medicithe $1987: 15: 123-130$.

3[64]

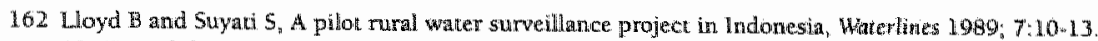
5[21], 6 [alph]

163 Lomergan 5 and Vansickle $T_{4}$ Relationship beween water quality and human health: a case study of the Lmgei niver basin in Malaysia, Social Science and Medicine $1991 ; 33: 937-946$.

$5[9]$

164 MacDongld LAR, Gould IM and Cumow J. Epidemiology of infecton due to Escherichin woli O157: a 3 -year prospective study, Epidemiology and Infection 1996; 116:279-284.

2[23]

165 Mackenzie, Kazmierczak J] and Dawis JP, An outbreak of cyptosporidiosis associated with a resiont swamming pool Epidemiolagy and Infection 1995; 115:545-553.

$3[21]$

166 Maclure M. and Willett. W.C. (1987) Misinterpretation and misuse of the Konpa statistic. American Joumal of Epidewiology $126,161$.

4.2[alph], 4.4[40]

167 Madsen W. The Virgin s children: life in an Aztec willage today. Austim. Universily of Texas Press; 1960. $4.5[41]$

168 Mahfouz AAR, Abdel-Moneim M, Al-Erian RAG and A1-Amari OM, Impact of chlorination of water in domestic storage tanks on childhood diarthoea a communicy rial in the rural areas of Saludi Arabia, Joumal of Tropical Medlicine and Hy giene $1995 ; 98: 126-130$.

$3[44]$

169 Mahmud MA, Chappell C. Hossain MM Habib M, Dupone HL. Risik factors for development af arsit symiptomatic Giardia infection among inflants of a birth cohort in rural Egypt. Am J Trop Med Hyg 1995; 53: 84 88.

$4.4[46]$

170 Malik IA, Bukhtiar N, Good MD, Iqbali M, Azim S, Nawaz M, en al. Mothers" fear of clild death due no acute diarrhoea: a study in urban and rural communities in Northern Punjab, Pakistan. Soc Sci Med 1992; 35: 1.043-1053.

4.5[9]

171. Manun webo MN, Haggerty PA, Kalengaie M, Ashworth A and Hirkwood BR, Intluence of demographic, socioeconomic und

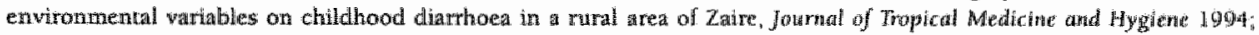
$97: 31-38$.

3[56]

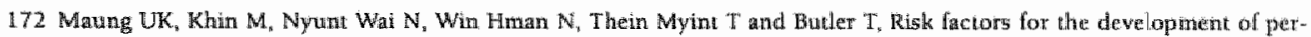

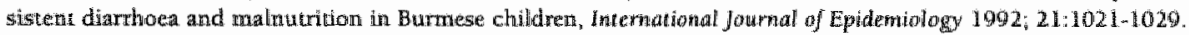
$3[68]$

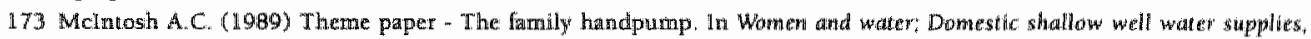
The family hand pump scenario. Asian Development Bank and United Natons Development Programue, Seminar. Manila. G[alph]

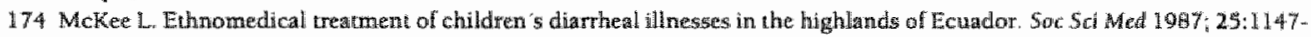
1155

$4.5[40]$

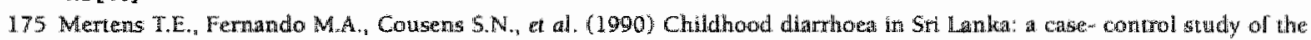
impact of improved water sources. Tropical Medicite and Parasitollagy $41,98-104$.

$2[14], 3[26], 4.3[15], 6[a / p h]$

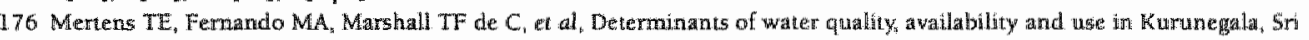
Lanka, Tropical Medicine and Parasitology 1990; 41:39-97.

5[25], 6[alph] 


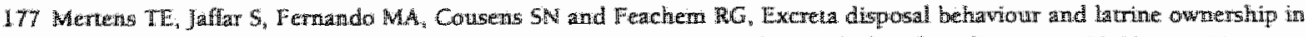

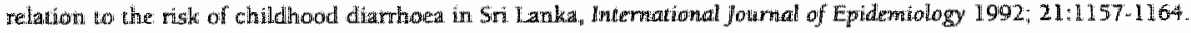

$3[27$

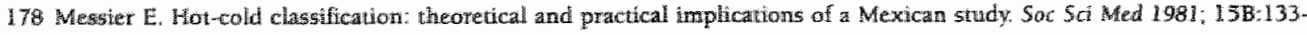
145 ,

$4.5[43]$

179. Miller CI, Feachern RG and Drasiar BS, Cholerif epidemology in developed and deweloping countries: new thoughts on mantsmission, seasonality, and cortitol, Lanct 1985, Feb 2,261-263.

$3[4]$

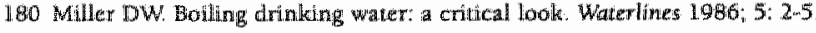

4.3[16]

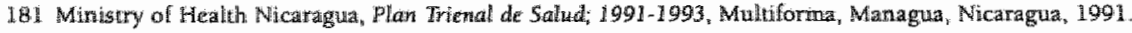
[4], 2[10]

192 Mo CL, Sobsey MD, Samsa GP and Mesolo V, Dacterial indicators of risk of diarthoeral disease from drinking-water in the Phalippines, Bulletin of the World Feallh Onganization 199: 69:305-317

$3[53], 5[6], 6[a l p h]$

193 Molbak $R_{,}$Hojlyng N and Jepsen $S$, Bacterial contamination of stored water and stored food: a potential source of diarthoeal disease in West Alitica Epidemiology and Imfecion $1989 ; 102309-316$.

$5[8]$

lat Moore HA, de lla Cruz and Vargas-Mendez O, Diartheal disease studies in Costa Mica: IV. The influence of sanitation upon the prevalence of intestiral infection and diartheal disease, Americam Journal of Epidemiology 1965; 82:162-184.

4.1 [alph], 5[2], 6[alph]

1.85 Morgan J. Loughborough University of Technology. Water, Engineering and Dewelopment Centre, Urban Hygiene Behaviour in Exhopia, abstract in Hightights: 1996: $7: 25-26$.

$4.4[52]$

186 Morgari P. Rural Water Supplies and Sanitatiom: A Tox from Zimbabwe's Blair Researdh Laboratory, 1990; London: Miacmillan.

$5[27]$

187 Morgan P. (1991) Rural Whater Supplies and Samidarion: A Text from Zimbabwes Blair Research Laboratory. Ministry of Health. Harare. Mackillan Education Ltol. London and Basingstoke. Morgan P. Chimbunde E. (1991) Upgrading fanily wells in Zimbabwe. Waterlines $9(3), 10-12$.

Gialph]

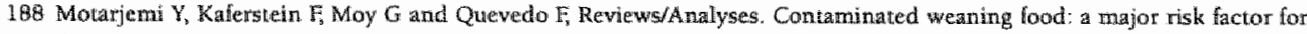
diarrhoea and associated malnutrtion, Bulletin of the World Health Organization 1993; 71:79-92.

3[61], 4.4[13], 7[6]

189 Muliammed, S.I. Morrison, S.M. (1975). Water quality in Kiambu District, Kenya. Ease African Medical Joumal $52,269$. 276.

4.1 [alph]

190 Mull JD, Mull DS. Mother s concepus of childhood diarthoea in rumal. Pakistan: what ORT program planners should known Sow Sol Mad $1988 ; 27: 53-67$.

4. 4 [. $[12]$

191 Nulker $\mathbb{M}$, Machin Sanchez $R$ and Suswillo Rh, Evaluation of a sanitation programme using eggs of Ascaris lumbricoides in household ynd soils as indicatars, Journal of thopical Medicine Hygiche 1989; 92:10-16. $3[66]$

102 Murphy $\mathrm{H}$, Stanton and Galbraith J, Prevention. Envirommental Health Interventions to Sustain Child Surviwal, Applied study No.3, Environmental Health Project, prepared for the Office of Health and Nintrition, US Agency for International Development (EHP activity $127-\mathrm{CC}$, June 1996.

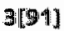

193 Nichter M, From Aralu to ORS: Siruhallese perceptions of digestion, diarthea, and dehycl ration, Social Science wnd Medicine $1989 ; 27: 39-52$

4.5[13], 5[26]

194 Nyangeri ENEN. (1986) Dehabilitation of hand-dug wells and protected sprimgs in Kisi. Kenya. Report Tampere University of Techrology in co-operation with Finuish International Development Agency, FINNDA Wo 29. 5[23], 6[alph]

195 Omotade 00 , Kayode CM, Adeyemo AA and Oladepo O, Observations on thand washing practices of mothers and environmental conditions in Ona-Aral Local Government Area of Oyo State, Nigeria, Journal of Diamhoual Disease Research $1995 ; 3: 224-228$

$3[87]$ 
196 Orndorf GR, Sadjum $\mathbb{I}_{1}$ simanjuntak $\mathrm{CH}, \mathrm{O}=$ Hanley P, Punjabi NH, Tjokrosonto S, Corwin A, Dibley M, Letoron CI and

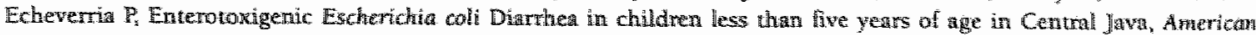
Joumial of Tropical Medicint and Hygiene 1996, 55:449-451 2[20]

197 Pacey A. Hygiene and hteracy. Whaterlines 1982; 1: 26-29. $4.3[20]$

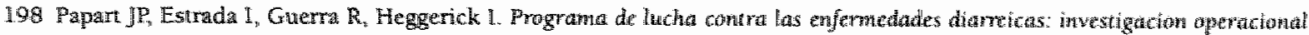

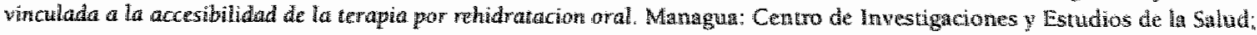
1988 .

\section{$4.5[33]$}

199 Persistent diatriboen Bulletin of the Programme for Control of Diarrinotal Disierses, WHO, 1989: 4:1-4. 2[12]

200 Pickering H, Hayes RI, Tomkins AM, at, Alemative nuesusures of dianhoeal morbidity and their association: with social and enwronmental faetors in urban children in The Gambia, Transactions of the Rayal Saciety of Toppical Medicine and Hygiene 1987; 81:853-859.

$3[102]$

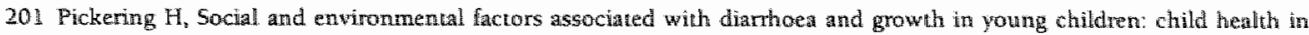
urbarn Africa, Social science and Medicine 1985; 21:121-127. $3[101]$

202 Pinfold JV, Faecal contamination of water and fingertp-tinses as a method for ewaluating the effect of low-cost watter sipply and sanitation activities on faeco-oral disease transmission. If. A hygiene intervention study in rural north-east Thailand, Epidemiology and Infection 1990; 105:363-389. $3[104], 4.4[16]$

203 Pinfold JV, Horan W] and Mara DD, Seasonal effects on the reported incidence of acute diarmoeal diserase in Northeast. Thailand, Intemational Joumal of Epidemiology $1991 ; 20: 777-786$.

$2[26,3[7]$

204 Pinfold $\mathrm{JV}_{\mathrm{N}}$ Horan $\mathrm{N}$ and Whrojanagud The bacteriological quality of water colfected in nainjars in rural northeast Thailland with respect to drinking water quality guidelimes; submitted to Worker Reseurch 15/3/1990. $5[1]$

205 Rahman M, Rahaman MM, Wojtyniak B and Axiz KMS, Impact of environmental sanitation and crowding on infarzt noriality in rural Bangladesh, The Lancet 1985; July 6.

$3[105]$

206 Republica de Nicaragua, Ministerio de Salud. Plan Matstron de Salud 1991-1996. Managua: Impresiortes EINM; 1901. $4.5[22]$

207 Reynolds 1. (1992) Handpumps: Toward a sustainable technology, research and developwent daring the water supply and sanitation decade. Water ard Sanitation Report 5, United Nations Development Programme-Worldtiank. Washington. 6[alph]

208 Rhode IE. Acute Diarthoea. Rev Infect Dis 1984; 6:14-28 $4.5[3]$

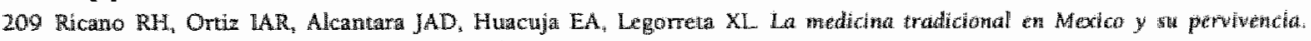
Mexico: Universidad Nacional Antonoma de Mexico; 1989.

4.5(36)

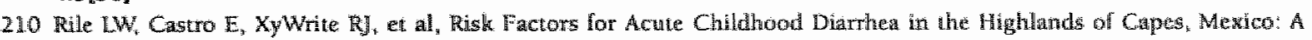
Strategy for Intervention, Bulletin of the Panamerican healih arganization 1990; 24:210-216 $3+80]$

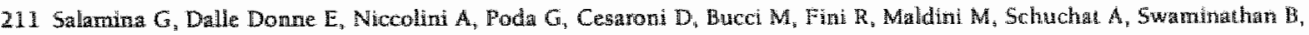

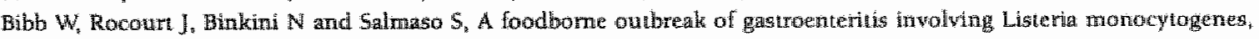
Epidemiologi and linfection $1996 ; 117: 429-436$.

2[18]

212 Sandifond P. Alberte H, Omozco JG, Gorter A. The Nicaraguan rope pump. Waterlines 1993; 11:27-30. $4.4[36], 4.5[24], 6[\mathrm{alph}]$

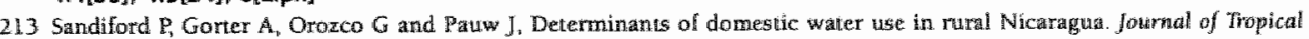
Medicinte and Hygieme $1990 ; 93: 383-389$.

$3[59], 4.3[40], 4.4[33], 4.5[28], 6[\mathrm{alph}]$

21.4 Sandiford P, Gorter AC, Davey Smith $G$ and Pauw JPC, Determinants of drinking water quality in ruatl Nicatagua. Epidemiology and Infection $1989 ; 102: 429-438$.

$4.2[\mathrm{alph}], 4.3[9], 4.4[32], 4.5[27], 5[24], 6[a l p h]$

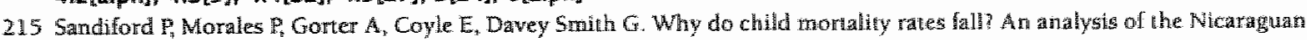
experience. Am J Ptablic Health 1991; B1: 30-37.

4.4[351.4.5[2 1] 


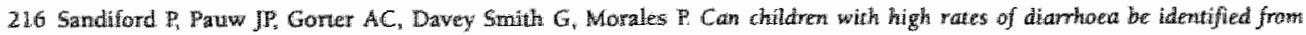

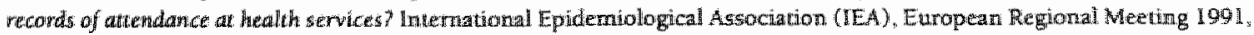
Based 199: 10 .

\section{$4.4[4.44,4.5 \llbracket 29]$}

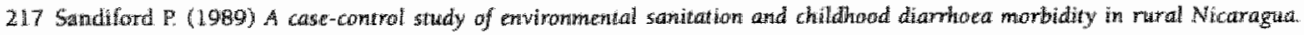

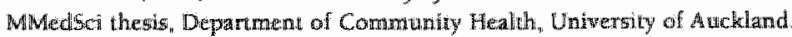

\section{2 [atiph]}

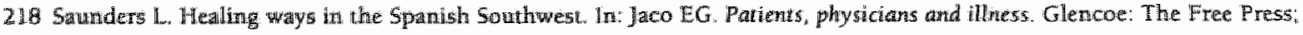
1958:189-206.

\section{5[4.4.]}

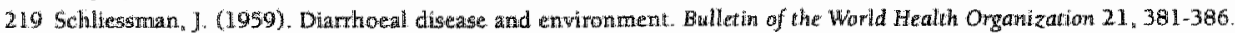
4. 1[ailph, 4.2[alpti]

2.20 Schneider, RE, Shiffnan, M.A. Ex Figeriblnm, IM. (1978). The potental effect of water on gastrointestinal infections prevallentin developing countries. American Joumal of Clinical Nutrition 31, 2089-2099.

\section{1 [alph]}

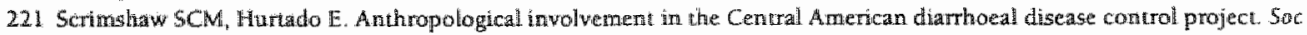
Sci Med 1989; $27: 97-105$

\section{5[31]}

222 Shahd WS, Greenough WD, Samadi AR Huq Mil and Rahman M, Hand washing with soap meduces dianhoea arid spread. of bacterial pathogens in Bargladesh willage. Joumal of Diamheal Disease Rescarch 1996: 1.4:85-189. $3[85]$

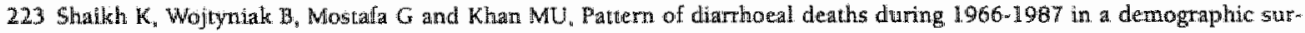

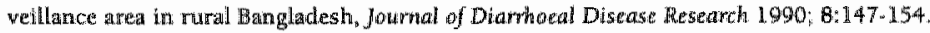

$2[301$

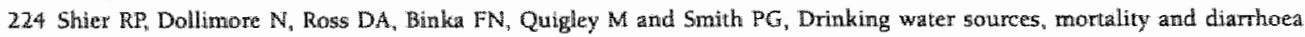
morbidity among young, children in Northern Ghana, Tropical Medicine and Imernational Health 1996; $1.334-341$. 3[52]

225 Shifmain, M.A., Schnetder, R.E, Faigenblum, J.M. Helms, R. B Tumer, A. (1978). Field studies on water satitation and heath education in relation to health status in Central America. Progress in Water Technology 11, 143.150.

$3[44]_{*} 4.1$ [alph]

Shuwal M, Tilden RL, Perry BH and Grosse RN, Effect of investments in water supply and sanitation on health stabus: a threshold-5aturation theary, Bullet of the World Kealth Organization $1981 ; 59: 243-248$.

$7[15]$

226 Simmons $O G_{7}$ Popular and modern medicine in Mestizo communities of cosalal Pern and Chile. J Am Folkiore 1955; $68: 57-71$

\section{5[35]}

227 Simpson SH. Some preliminary considentions on the Sobada: a traditional treatment for gastrointestinal ilness in Costa Rica, Soc Sici Med 1988; 27:69-73.

4.5[39]

226 Sitcat BK, Sengupta PG, Mondal SK, Gupta DN, Saha NC, Ghosh 5, Deb BC and Pal SC, E Effect of hamd washing on the

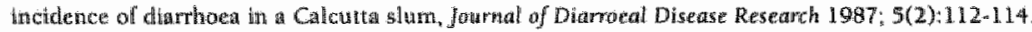
$\left.\left.3\left[\mathbb{E}_{1}\right]\right]_{1}, 4.423\right]$

229 Snyder J1, Merson Mlt. The nugwitude of the global problem of acute diarthoeal disease: a review of active surveillance duta Hull whO $1982 ; 60: 605-613$

4.3[1], $7[1]$

230 Sorvillo 10 . Lieb LE, Kerad PR and Ash LR, Epidemiology of Cryptosporidiosis among persons with acçured immunodefiency syndrome in Los Angeles county, Anterican Jowrnal of Tropical Medicine and Hygiene 1994; $51: 326-331$. $2[19]$

231 Stanton BE Clemens JD, Azi. KMA, Rahman M. Twenty-four-hout rectll, knowledge-attitude-practice questionnaines, and direct obserwations of sanitiry practices: a comparative swdy: Bull World Healih Organ 1987; 65: $217-22$.

4.4[30]

232 Stanton $1 \mathrm{~F}$ Clemens JD. An educatomal interventon for altering water-sanication behavions to reduce childhood diarthea in arban Bangladesh. II. A randonized trial to assess the impact of the intervention on laygienic behaviors and rates of diarhea. Am J Epidemiol 1987; 125:264-301

$4.4[15], 4.5[18]$

233. Sulliwan PS, DuPont ML, Arafat RR, et al, Mhess and reservoirs associated with Giardia Lamblia infection in rural Egypt: The case against treatment in developing world environments of high endemicity, American Joumal of Epidemiology $190 \mathrm{a}$; 127:1272-1281. 
234. Sutomo $S$ and Tilden $\mathbb{R}_{,}$Water supply and samiation are good predictors of disthea. Water supply and distrheal disease in rural areas of Indonesia, Bull Peneltit Resehat 1987; 15:1-14.

$3[55]$

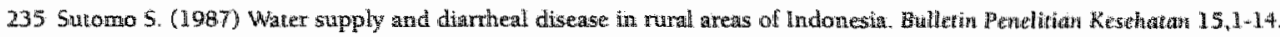
6 [alph]

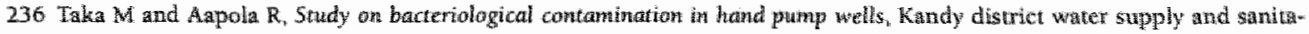
tion project, Soll and Water Ltd, September 1988.

5[38]

237 Taylor MB, Parker 5, Grabow WOK and Cubitt WD, An epidemiological investigation of Norwalk virus infection in south Africa, Epidemiology and infection 1996; 116:203-206. $2[16]$

238 Temsay $\mathrm{ZW}$ "Bacteriological quality of drinking water in Kaffa administrative region, south west Emiopia. Joumal of Hy giene, Epridemiology. Microbiology and Immanology $1994 ; 35 ; 251-258$. 5[119]. 6[alph]

239 The Cebu Study Team, Underlyng and proximate determinans of child health: The Cebu, Longitudinal health and nutrithon study. American Joumal of Epideminotogy 1991; $133: 185-201$.

$3[36]$

240 The Imo State Evaluation Team, Evaluating water and sanitarion projects: lessons from Imo State, Nigeria, Hedih Policy and Planning $1989 ; 4: 40-49$.

3[49]

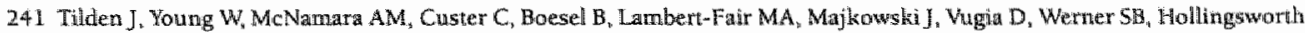
and J, Morris $1 G$, A new route of transmission for Escherichia coli: infection from dry fermented salami, Amentcan Jeumal of Public Health $1996 ; 86: 1242-1145$.

2[22]

242 Tomkírs, A.M. Drasar, B.S., Bradley, A.K. W Williamson . WA (1978). Water supply and mutritional status in mural Northern Nigeria. Tramsactions of the Royal Soctety of Tropical Medicine and Hygiene $72,239-243$.

4. 1 [alph]

243 Torres Escobar ID, Determimantes de la morbi-montalidad por enfennedad diarreica de los menores de binco anos que acuden a los hospitales anfantiles en Managua/Nicaragua, Tesis de grado para optar al titulo en Epidemiologia en el Crits, 1906. $1[6]$

244 Torum, B. (1982). Environmental and educational interventions againsi diarthea in Guatemala. In: Diarthea apd maluatrition: interactions management and interventions (ed. L.C. Chen and N.S. Scrimghaw). pp. 235-266. New York: Platrum Press 3[65], 4.1[alph]

245. Trivedi B.K., Gandhi H.S. Shukla N.K. (1971) Bacteriological water quality and incidence of water borne diseases in at rural popuiation. Indian Journal of Medical Sciences 25,795-801.

3[54], 5[40], G[alptit]

246 Utkilen $H$ and Sution $\$_{x}$ Experience and resuls from water quality project in Zambia, Waterlines 1989; 7:6-8. 5[22], 6[alph]

247 Uting P. Treess Peoplo and Power, Earthsican, 1993.

19]

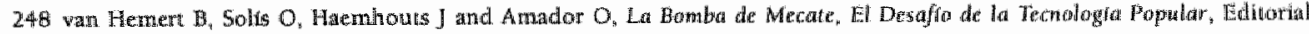
Enlace, 1991, Managua "Nicaragua.

$5[37]$

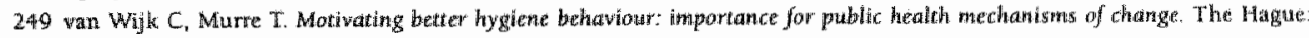
IRC International Water and Sanitation Centite, 1904.

$4.419]$

250 VariDersilice J and Briscoe J, All coliforms are not created equali. A comparison of the effects of water source and iti house water contamination on infantile diarheal disease, Water Resources Research 1993; 29:1983-1995.

$318 \|$

251 WanDerslice J and Briscoe J. Environmental interventions in developing conmtries: interactons and their inplicstions, American jounul of Epidemiology $1995 ; 141: 135-144$.

$3[42], 7[18]$

252 VanDerslice J, Popkin B and Ariscos J, Drinking-pwater quality santation, and breast-feeding: their interactive effects on infant the alth, Wulletin of the Wortd Health Organization: 1994; 72:589-601.

$3[57]$

253 Vizquez ML and Mosquera M (eds), Diarrea y enfermedades tespiratorias agudas em Nicaragua, un desudio dhe intervencion educativa, 1989-1992, lnoprenta UCA, Managua, Nicaragua, 1994.

2[11] 


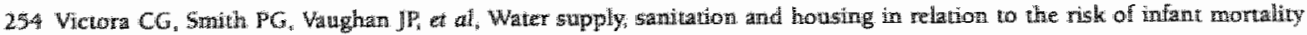

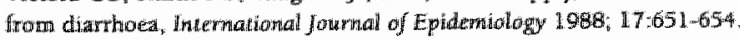

$3[3,4], 4,2[a \mid p h], 4.3[43]$

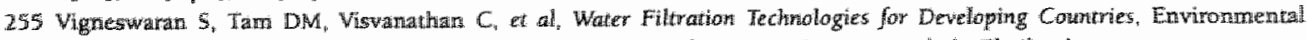

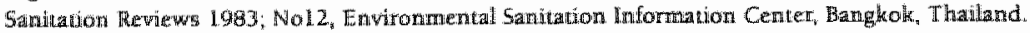

5[32]

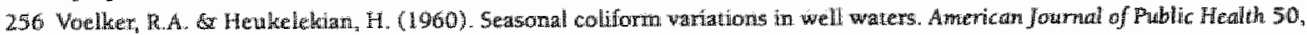
$1973-1881$

\section{1[alph]}

257 Walsh. J.A. \& Watren KS. (1979). Seliective primary healch care. An interim strategy for disease control in developing countries. Wew England Journal of Medicine $301,967-974$

\section{4 [alphi?}

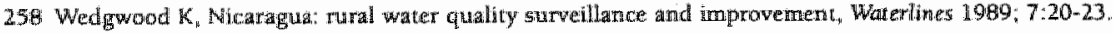
5[36]. 6[alphi

259 Wean JM. An evaluation of health and samitation in Egyptian villages. Jow $1952 ; 27: 55-114$. $3[10]$

260 Weiss MG, Culwral models of diarmoeal illiness: conceptual framework and review. Soc Sci Med 1988; 27:5-16. 4.5[34]

261. Weller SC, Ruebush II TK, Klein RE. An epidemiological description of a folk illness: a case study of ernpacho in Guatemala. Med Anthropol 1991; 13:19-31.

4.5[1]5]

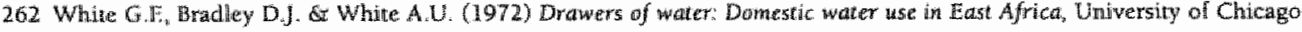
Press, Chicango.

\section{$3[1], 4.2[a i p h], 5[5], 6[a l p h]$}

263 Wibowo $D$ and Tisdell $C$, Health, safe water and sanitation; a cross-sectional health production function for Central Java, Indonesta, Bulletin of the World Health Orgawization 1993; $71: 237-245$

$3[45]$

264 Whison JM, Chandler. GN, Mustihatum and Jamiladdin, Handwashing reduces diarrhoes episodes: a study in Lombok, Indonesia, Transactions of the Royal Sodiety of Trapical Medicine and Hygiene $1991 ;$ 85:819-821. $3[82], 44[25]$

265 Wong S.T. (1987) Thai rural domestic water consumption: A case study of a willage conmuniry with no organized water supply system. Water International 12,60 .

4.2[alph]

266 World Bank, World Developmett Report 1993, Inwesting in Healih, Washington DC: World Bank, 1993. $1[3], 2[1], 4.4[1] 4.5[1], 7[10]$

267 World Bank, World Development Report. 1997, The state in a changing world. Washington DC: World Bank, 1997. $1[8], 2[5], 7[11]$

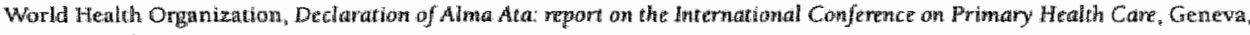
World Heath Orgarization, 1979.

7 (a)

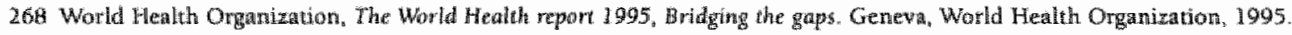
$2[0] 7[2]$

269 World Health Onganization, The World Health Report 1996, Fighing disedse, Fostering developmen, Grenewa, World Healuh Ongunizatiour, 1996 .

$2[6] \div ; 3]$

270 Wrigh GE, El Alimy M, DuPont HL, at, The role of home enwirontent in infant diarthea in rusal Egpt, Americam Journal of Epidemiology $1091 ; 134: 867-894$. $3[47]$

271 Wright R.C. (1985) The seasonality of backerial qualicy of water in a ropical deweloping country (Sierra Leome) Journal of Hygient (Cambritge) $96,75-82$. 5 [201, 6[a

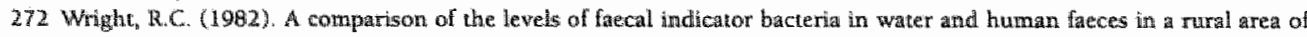
a tropical developing country (Sieria Leone), Jow of Hygtene 89, 69-78.

$4.1[\mathrm{lph}$

273 Young B and Briscoe I, A case-control study of the effect of environmental santation on diarrhoea morbidiry in Malawi, Joumall of Epidemiology and Community Heal th 1988 ; $42.83-88$.

$3[30]_{1} 4.1[\mathrm{alph}], 4.3[11]$ 


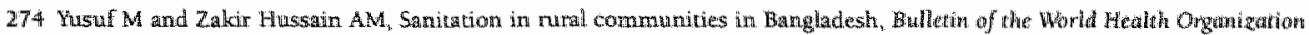
1990; $68: 6519 \cdot 624$.

$3[63]$

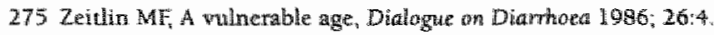
3[62]

276 Zeitlin Ma, Ahmed NU, Beiser AS, Zeitlin IA, Super CM and GLdan GS, Developmental, behavioural, and ervirommenta

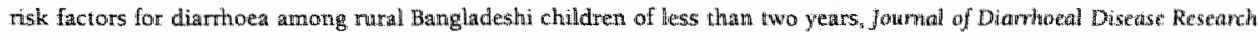
$1995 ; 13: 99 m 105$. $3[100]$

277 Zeitlin 5 , Islam F The use of soap and water in wo Bangladeshi communities: Implucations for the urarusmission of diatthoed. Rew Inject Dis $1991 ; 13: 5259-64$.

$4.4[47]$

278 Zeng-sui $W_{*}$ Shepard DS, Yun-cheng $Z$, et al, Reduction of enceric infectious disease in rural China by providing deep-well tap water. Bulletin of the World Health Onganization $1989 ; 67: 171-180$.

3[43] 
Curriculum Vitae 


\section{Curriculum Vitae}

Anna Cornelia Gorter was born August 20, 1953 in Roosendaal, Netherlands. She grew up in Roosendaal and finished there her secondary school at the Gertrudis College (HBSB) in 1971. She studied medicine at the University of Amsterdam where she obtained her medical degree in 1980 . In order to qualify to be posted abroad as a medical doctor by the Department of International Development of the Dutch Government she specialized during a period of one year in general surgery and obstetrics in the Willem-Alexander hospital in "s Hertogenbosch, Netherlands. Then she worked a year at the municipal methadone program for drug-addicts in Amsterdam. The Certificate of Tropical Medicine was obtained in 1982 at the Royal Institute of the Tropics in Amsterdam. In 1983 she left for Nicaragua to work as a medical officer at the rural health area Villa Carlos Fonseca. In 1986 she started her diarrhoeal disease research. Since 1989 she has also been involved in the development of programmes for the prevention of AIDS and Sexually Transmitted Diseases. She is still living in Nicaragua with her husband. They have two children.

\section{Qualifications:}

B.A. Medicine, University of Amsterdam 1974

M.A. Medicine, University of Amsterdam 1977

M.D. Medicine, University of Amsterdam 1980

Certificate of Tropical Medicine, Royal Institute of the Tropics, Amsterdam 1982

M.Sc in Epidemiology, Council of the Netherlands Epidemiological Society 1996

\section{Professional experience:}

1995-pres Field manager/consultant epidemiologist for IHSD (Institute for Health Sector Development, London) and Liverpool School of Tropical Medicine for the Nicaraguan project: "Voucher systems to improve sexual health services and control sexually transmitted diseases". ICAS (Instituto Centroamericano de la Salud). British Government (Seedcorn Fund).

1992-pres Consultant epidemiologist on STDs/AIDS and drug addiction for the Nicaraguan NGO TESIS, a foundation working with street kids, glue-sniffers and female sex workers in Managua.

1989-pres Consultant epidemiologist on water/sanitation and hygiene for the Nicaraguan NGO DESEAR, a rural development organization.

1988-1993 Supervisor of Health Education students from Maastricht, performing research in Nicaragua as part of their training.

1992 Consultant Liverpool School of Tropical Medicine, Well pollution study commissioned by Cowater International, Sri Lanka, for World Bank.

1989-1992 Field manager/consultant epidemiologist for the University College London of a major EC funded AIDS project in Nicaragua. AIDS Task Force, European Community. 
1988-1990 Consultant epidemiologist of a Nicaraguan water and sanitation project, organized by the Technical University of Managua. UNICEF.

Consultant epidemiologist of the Nicaraguan research project for Health System Development, funded by Leverhulme Trust (UK).

Principal investigator of a diarrhoeal disease and hygiene study in rural Nicaragua. Funded by UNICEF and Leverhulme. Trust.

1986 1988 Coprincipal investigator of diarrhoeal disease and water/sanitation study in rural Nicaragua. Funded by the WHO.

1983-1986 Medical Officer rural health area in Nicaragua. Dutch Government.

1981-1982 General practitioner of the Methadone Program for drug-addicts, Amsterdam.

1980-1981 Registrar in general surgery, obstetrics and gynaecology, Den Bosch, Netherlands.

\section{Publications}

* Gorter AC, Sandiford P, Pauw J, Morales P, Pérez RM and Alberts H, Hygiene behaviour in rural Nicaragua in relation to diarrhoea. Accepted by International Joumal of Epidemiology.

* Sandiford P, Coldham $C$ and Gorter A, Should publicly-funded health services be distributed by vouchers?: A review of experience in other sectors. Submitted to Health Policy and Planning.

* Standing H, Gorter A, Sandiford P, Monge R, Palmen M, Tellez A and Pauw J, The management of health related occupational risks among FSWs in Managua. Submitted to Social Science and Medicine.

* Pauw J, Ferrie J, Rivera R, Medrano J, Gorter A and Egger M, A controlled HIV/AIDSrelated health education prograrnme in Managua, Nicaragua. AlDS 1996; 10:537-544.

* Sandiford P, Gorter A and Torres MdC, Sexually transmitted diseases in developing countries [letter]. Transactions of the Royal Society of Tropical Medicine and Hygiene $1996 ; 90$.

* Gorter AC, Alberts JH, Gago JF and Sandiford P, A randomized trial of the impact of rope pumps on water quality. Journal of Tropical Medicine and Hygiene 1995; $98: 247$. 255.

* Gorter AC, Sanchez G, Pauw J, Pérez RM, Sandiford P and Davey Smith G, Diarrea inlantil en la Nicaragua rural: creencias y prácticas de salud tradicionales. Boletin de la Oficina Sanitaria Pananericana, 1.995; 119.377-390.

* Medrano D, Pauw J and Gorter A. "Estamos en la calle....." Un estudio sobre niños, niñas y adolescentes en situación de riesgo de Managua: su modo de vida, su sexualidad, ETS y SIDA. In collaboration with UNFPA, Imprimatur 1995, Managua.

* Egger M, Ferrie J, Gorter A, González S, Gutiérrez R, Pauw J and Davey Smith G, Conocimientos, actitudes y practicas acerca del SIDA entre estudiantes de escuelas secundarias de Managua. Boletin de la Oficina Sanitaria Panamericana 1994; $117: 12$ 21.

* Davey Smith, Gorter A, Hoppenbrouwer J, Sweep A, Perez R, González C, Morales $\mathbb{P}_{*}$ 
Pauw J and Sandiford P, The cultural construction of childhood diarrhoea in rural Nicaragua: Relevance for epidemiology and health promotion. Social Science and Medicine 1993; 36:1613-1624.

* Sandiford P, Alberts $H$, Orozco JG and Gorter A, The Nicaraguan Rope Pump. Waterlines $1993 ; 11: 27-30$.

* Gorter A, Miranda E, Ortells P, Davey Smith G and Low N, How many people actually use condoms, an investigation of motel clients in Managua. Social Science and Medicine $1993 ; 36: 1645-1647$.

* Egger M, Ferrie J, Gorter A, González S, Gutierrez R, Pauw J and Davey Smith $G$. Knowledge, attitudes and behaviours regarding HIV/AIDS among Managuan secondary school students. Bulletin of the Panamerican Health Organization 1993; 27:360-369.

* Low N, Egger M, Gorter A, Sandiford P, Gonzalez A, Pauw J. Ferrie J and Davey Smith $G$, Aids in Nicaragua: Epidemiological, political and sociocultural perspectives. International Joumal of Health Services 1993; 23:685-702.

* Low N, Arauz R, Gorter A, Guevara M, Gonzallez A, Sequeira G, Morgan M, Rocha R, Serna $R$, González Al and Davey Smith $G$, Conocimientos acerca del SIDA de la población adulta de Managua. Boletin de la Oficina Sanitaria Panamericana 1992; 112: 319-326.

* Gorter A, Sandiford P, Davey Smith G and Pauw J, Water supply sanitation and diarrhoeal disease in Nicaragua: Results from a case-control study. Intemational Joumal of Epidemiology 1991; 20:527-533.

* Sandiford P, Morales P, Gorter A, Coyle E and Davey Smith G, Why do child mortality rates fall? An analysis of the Nicaraguan Experience. American Journal of Public Health $1991 ; 81: 30-37$

* Sandiford P, Gorter A, Orozco G and Pauw J, Determinants of domestic water use in rural Nicaragua. Joumal of Tropical Medicine and Hygiene 1990; 93:383-389.

* Low N, Davey Smith G, Gorter A and Aráuz R. AIDS and migrant populations in Nicaragua [letter]. Lancet 1990; 336:1593-1594.

* Sandiford P, Gorter A, Dayey Smith G and Pauw J, Determinants of drinking water quality in rural Nicaragua. Epidemiology and Infection 1989; 102:429-438.

\section{Abstracts}

* Gorter AC, Sandiford P and Villabella C, A voucher scheme to improve access to health services for female sex workers reduces sexually transmitted diseases, abstract 12 th World Aids Conference, Geneva, June 28-July 31998.

* Villabella $C$, Gorter $A$, Sandiford $P$ and Monge $\mathbb{R}$, Ensayo de un sistema de bonos para mejorar la calidad, eficiencia y equidad de los servicios de salud y el control de las enfermedades de transmisión sexual en trabajadoras sexuales. Paper at $v$ Conference Latinoamericano de SIDA, Lima, Peru, Dec. 3-6, 1.997.

* Villabella C, Gorter A and Sandiford P, Programa de Bonos para control de Enfermedades de Transmision Sexual en Trabajadoras Sexuale. Paper at XXI Congreso Centroamericano de Ginecologia, Managua, Nicaragua, Nov.17-21 1997.

* Gorter A, Sandiford P, Villabella C. Monge R, and Standing H, Female sex workers: more 
than a core. Paper at Pre-conference workshop on health needs for FSWs, International STD congress, Sevilla, Spain, 19-22 October 1997.

* Sandiford P and Gorter A, Enfermedades de Transmision Sexual/SIDA. Prevención y Consecuencias en la Salud de Hombres y Mujeres. Paper at II Curso International "Salud Reproductiva y Sociedad", Lima, Peru, 3-7 March 1997.

* Sandiford P, Gorter AC and Braddock M, Are voucher systems the way to arganize health care in the 21st century? Paper at Sixth International Conference on System Science in Health Care, Barcelona, Spain, September 16-20, 1996.

* Espinoza F, Egger $M_{i}$ Gorter A, Herrmann $B_{\text {; }}$ Rivera $R$ and Davey Smith $G$, Low incidence of AIDS in Nicaragua: why and for how much longer? Poster at the IXth International Conference on AlDS, Berlin, June 7-11, 1993.

* Sandiford P, Pauw J, Gorter A, Davey Smith G and Morales P, Can children with high rates of diarrhoea be identified from records of attendance at health services? Paper presented at European Regional Meeting of the International Epidemiological Association (IEA), Basel, Switzerland, Aug. 29-31, 1991.

* Davey Smith G, Boersma A, Pauw J, Gorter A and Sandiford P, What control group is appropriate for case-control studies of childhood diarrhoea?. Paper presented European Regional Meeting of the IEA, Basel, Aug.29-31, 1991.

* Davey Smith G, Low N, Gorter A, Miranda E and Aráuz R, Condom use in motels in Managua: an opportunity for Aids prevention. Paper presented at the 35th annual meeting of the British Society for Social Medicine 1991.

* Gorter A, Davey Smith G, Aráuz R and Low N, Aids prevention in motels in Managua. Paper presented at the International Conference Assessing AIDS Prevention, Montreux, Switzerland October 29-November 2, 1990.

* Arăuz R, Low N, Gorter A, González A, Homosexuals and AIDS prevention in Nicaragua. Paper presented at the International Conference Assessing AIDS Prevention, Montreux, Switzerland October 29-November 2, 1990.

* Low N, Aráuz R, Ortells P and Gorter A, Preventing AIDS in Nicaragua: Health education with the 'contra'. Paper presented at the International Conference Assessing AIDS Prevention, Montreux, Switzerland Oct. 29-Nov. 2, 1990.

* Sandiford P, Gorter A, Pauw J and Davey Smith G, A case-control study of water accessibility and water quality as risk factors for diarrhoea. Congress 50 th Anniversary Pedro Kouri Institute Tropical medicine, Havana, Cuba, 1988. 
Appendix:

1. The Nicaraguan rope pump

2. Why do child mortality rates fall? An analysis of the Nicaraguan experience 


\section{The Nicaraguan rope pump by Peter Sandiford, Henk Alberts, Juan Guillermo Orozco, and Anna Gorter}

\section{Despitte numerous setbacks, the rope pump's development in Nicaragua has finally fulfilled its promoters' expectations. Even pumps installed during an emergency in an area without access to spare parts are still working.}

\author{
ALTHOUGH THE FIRST rope-and \\ washer pumps appear to hase been \\ introduced inco Nicaragua aboul 20 \\ years ago. it was not until 1983 that a \\ Belgian dechnician named Jen \\ Haemhous seriously began to develop \\ the rope punp in Nicaragus. He had \\ been involved with a peasiant self. \\ development proged in Hati jo which \\ the rope pump was one component. \\ but the political sibuation there find ly \\ made funher work imposible and be \\ left the country. He betieved that the \\ rope pump, at lechnology thin coulyl bo \\ produced by peatsants themselves \\ contl serve als at catalys around which \\ the people could orytnize thensedwe \\ to resolve their problems alit dimprone \\ thetr lives. His experience in Hatil \\ however, hat convinced bin thatl suld \\ a process could only be successful \\ when set within a sipportive political \\ enviromment.
}

He tumed insectut to revolutionary

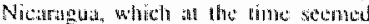
to be the idestl setting to try oull the ideas. He filt that before the rope pump could gain acceplance in needed to be developed to a stage where il could the presented as a highty relitible yet incrpensive water supply - in onter wards. as an appropnate technology. The devetopezent of the rope putikp

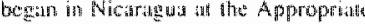
Tecthnology Restarch Centre of the Aurntian Relom Imsirutio

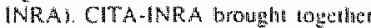
profensionals who wera entllusiast cully promoting a whole has an icchollogies inchuting biogats, wirnd mills for both electricity generatom and woter pumping. and hydratio rams, and pent them so work on the rope pump. Nicaraguan wersions of the rope pumps evolved and at major cflort was

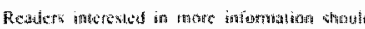

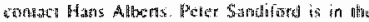

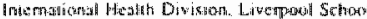
of Thomical Mediche Pembrotse Plase.

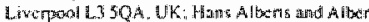

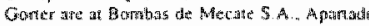

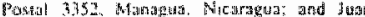
Guallemo Oroze is a UNep" Managua Nicaragus.

mantio to demonghan thes peasants

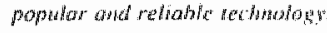

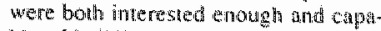

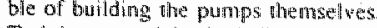

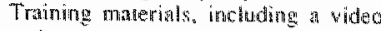
and a cartoonl book lat, were prodiated at thas thine

Despire some notable suchesses CITA-INRA wris allisbunded in 1985.

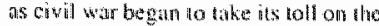
country"s ragide economy. By that stage serious fimiations hat beome arident. Too math eftory had been pu into the scientific ofurolophent of techolonges, while insubloien allem

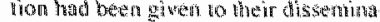
thon within the nimistres and the ithstivitions responsible for llaeir appla cation on a targe swate. Neverthelesw the anperionce un CITA-INRA hod demonstrated whe scceptiabiting of the rope pump withing the Niskaguan

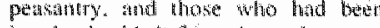
introlved with bi from the enty stages conthued to seet opportunities for lu

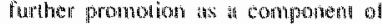
the rum demelopment projects being anderation an thath time.

The fect thes rope pumps are shill being mate by locill catrontes in the

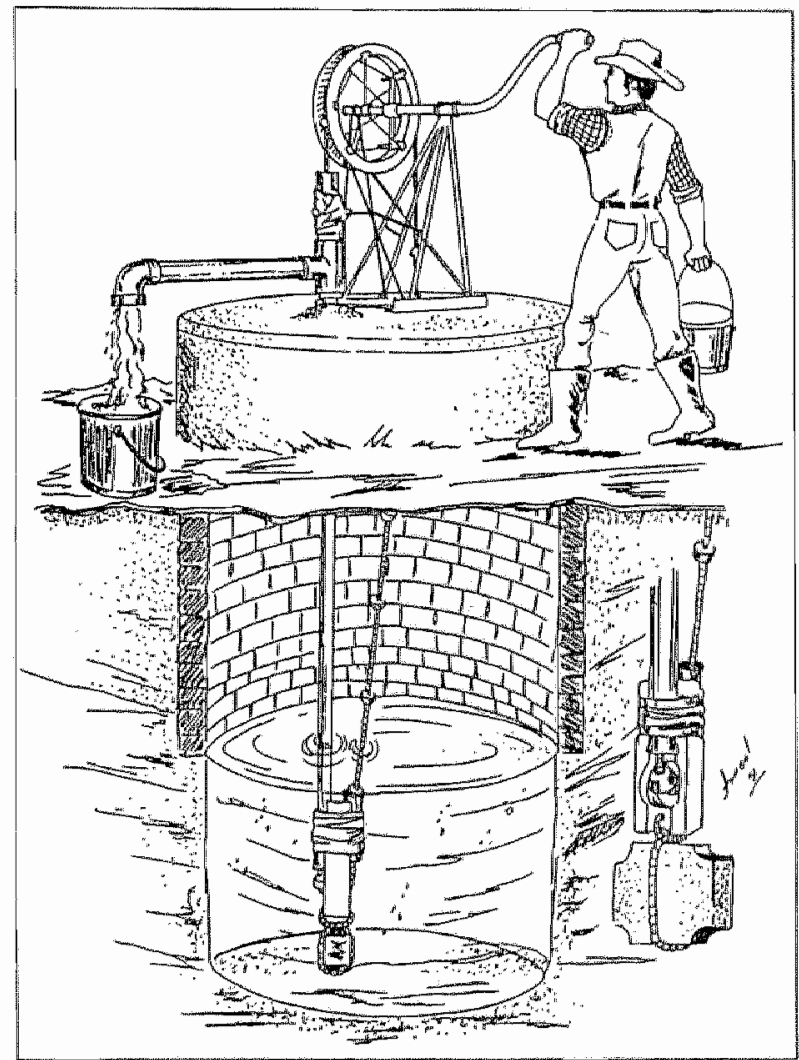

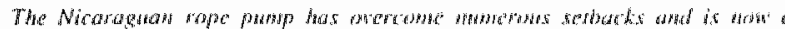




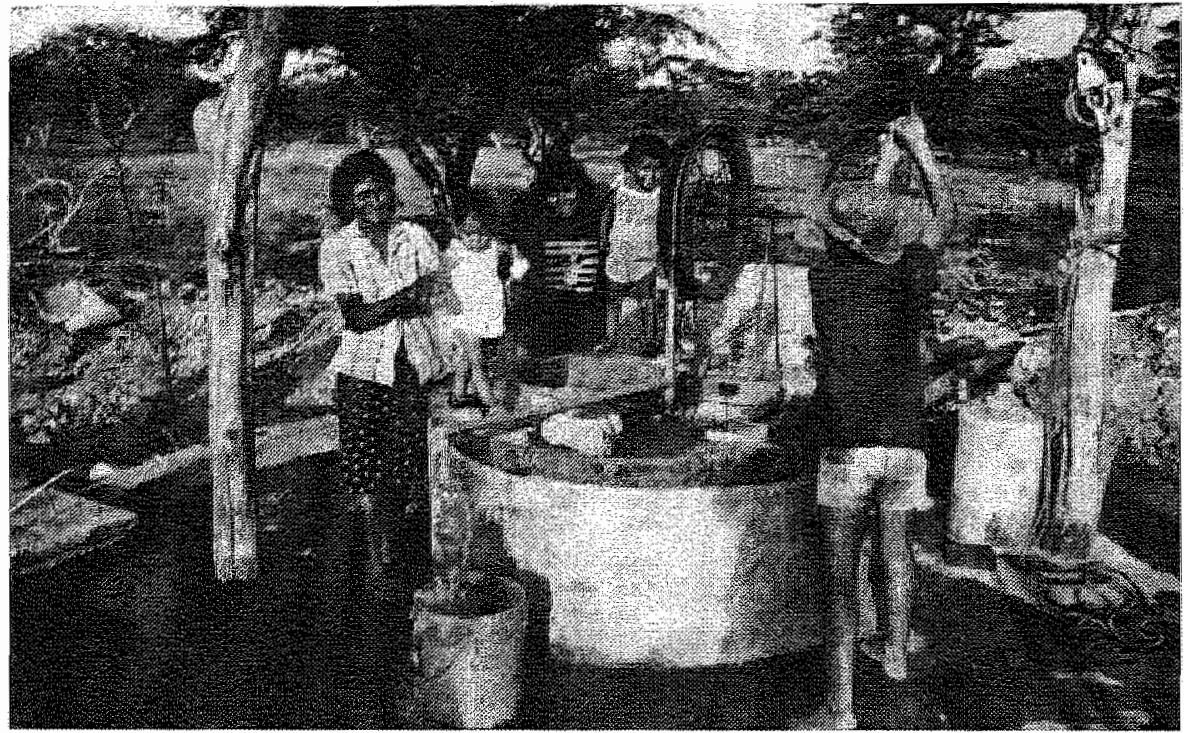

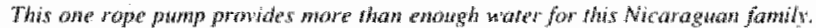

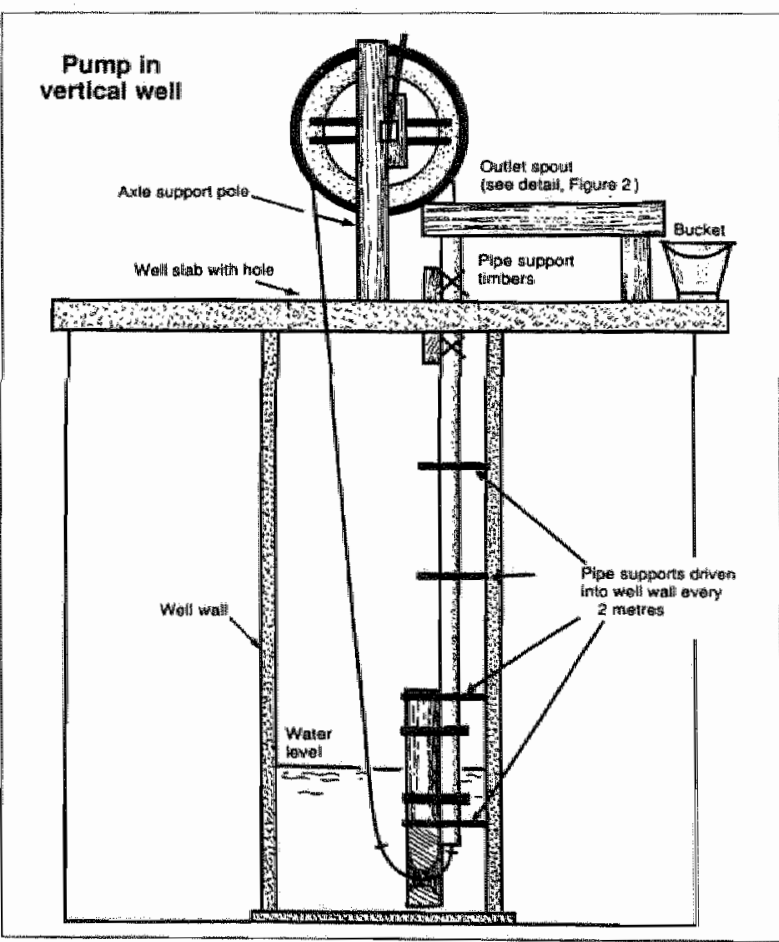

Figure 1. A rypical desigu for o rope pump for tase in a veraical well. (Figures

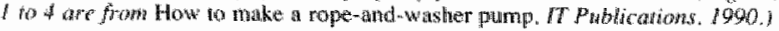

area surrownding the CITA-centre. without any institutional promotion since 1985, demonstrates the impact of those activities during that period. An accurate estimate is impossible to obtain because the pumps were installied all: over Nicaragua and mate by differem people. but well ower a hundred pumps must have heen prodiuced by these artisans.

\section{Try again}

A significant turning poing in the fortunes of the rope pump took place in 1987. Jus Cruillermo Orozes, at Colombian sanilatry engineer working as a consubant in the recently establisthed Enviromental Engineering Frograment UNGAM of the Nalunal Eirginescing University, wogether with Haenhous, was looking for opporthnintics to continue to promote the rope pamp in a setting withou the problems of war and institutional politics which hath plagued the project in CITAINRA. They storted work atganin with a small fornaly-based co-operandive in Moute Fresco, willage some $30 \mathrm{~km}$ from the capital, Marnggua. The setting appeared to be prerlect - the San Jose co-operative had been foinded by peasants who did mot have sufficien! land to work on, and who had therefore raken to prodiucing brooms, brushes, and other domestic articles. The cooperative had sonte equipment and staff and in seemed that, with a little training and investment, it could produce rope pumps and perhags evern 
realize Hatmhours vision of peasmi self-advancement. The idea was thas the rope parno would be jus one. though the firsis of several tech nologies which would bi developed alad then produced on a larger scalle in the comperative.

Seeding finance of about $\$ 10$ 000 was obtanned from the govermments of New Zealand and Holland. The interyfion was to use this money lo develon. produce, and install one thousand pumps in the thand-dug wells in the surnounding area. Once buillt. if wotlld be possible to study and perfect the pump.

The project quickly made sone significant adwances. Lin the inisial stage an number of technical improvements were maxie to the protoryphe puntrs, effectively ansfoming then from a 'Heanh Rolbinson' endeawour into a truly appropriate technology. ahthough still lacking in impontant respects. The project was starting to stagnate in much the same way that it had in CITA-INRA, howewer - over 50 prosotypes had been made withou anyone daring 10 take the plunge and star productioni on a commercial scale.

At was an illl wind. however, theat blew good fortune to the project. In September 1988 humicane Jumana struck Nicaragua, devastating mucth of the Allantic coast of the country. A llowal of about 200 rope pumps were sold to the interuational organizations which were providing energency aid to the victims of the disaster on the eastern aperative was forced to enter into production of the rope pump on a signiffcant scale.

\section{Work under pressure}

It did so with considenable sucoess. Interestingly, at least 75 per cent of seabourd. For the first lime, the co-

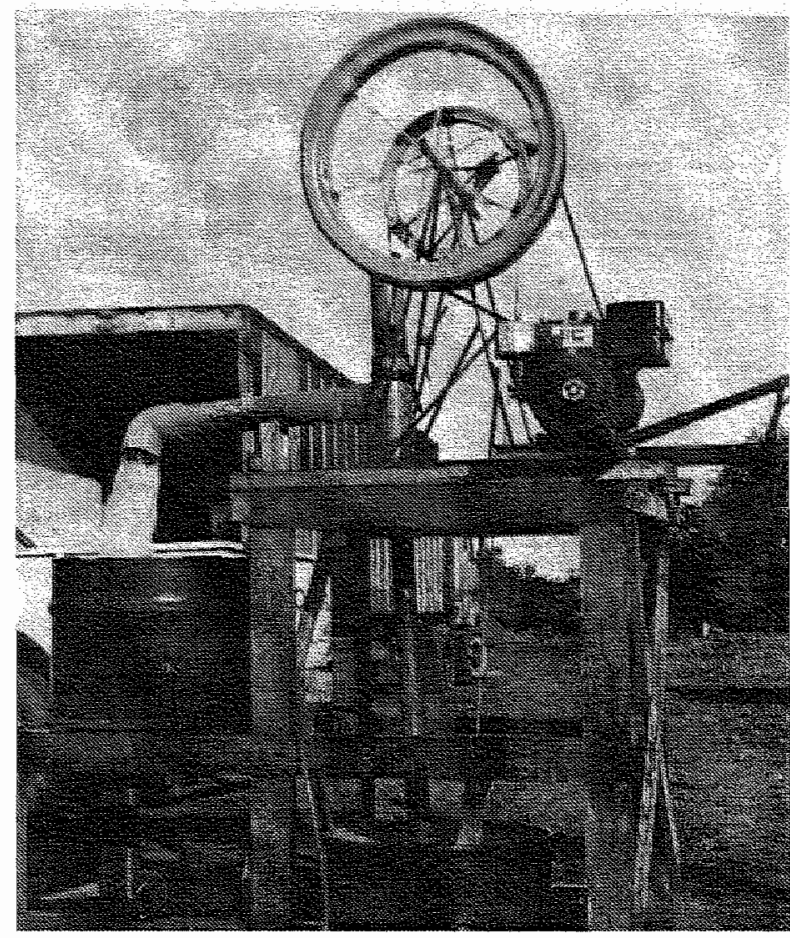

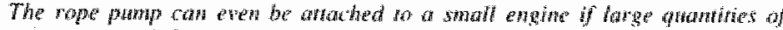
wrater are needed.

those: pumps were still functioning perfectly two years after their inst bllathota despite the fact that no backup laad bees prowided and that ihe supply of replacement parts no the isolated Atlantic const is motoriously difficult The eauses of failure fon these that did brank down have now baten iddentified and have been resolved in the more

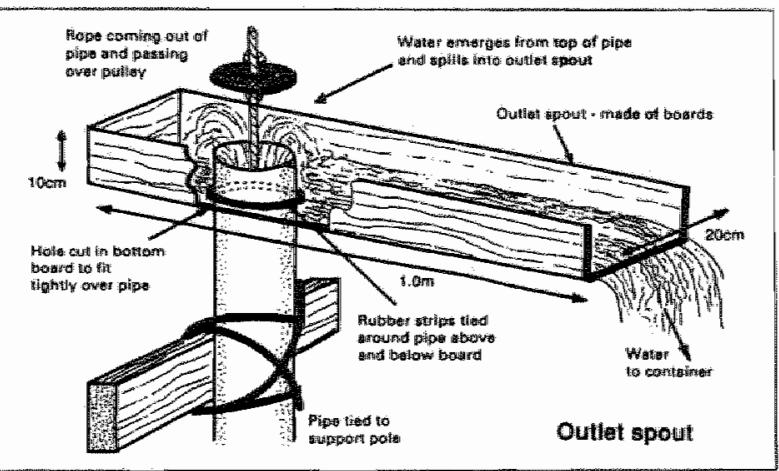

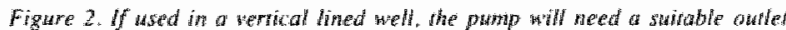
spout. Jf a pre-formed spour is nor avallable, whs destign can be used. recent improvements to the design.

Unfortumately success does not al ways breed success. At this poinl, there emerged a serious rift between the phillosophies of the two key protagonists of the rope purneprogect: one sex a role for the university in providing technical assistaco and an opportureby for the envirommentall enguneering subdens to learn from the practical application of apporoprate techmoloEues, while the other fict that tecturiot

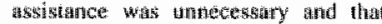
the pearants the thiselves had sufficient innovative ability to develop the partin

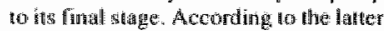
view. the involventumat of the studtents would only detract from potenta innovation. While one felt that the future for the project lay in elling pumps on a conmencial busis, the other thought that this would destroy the potential of the rope pump to gurve ats a cratyst for peassint self-advance ment. In the end these philosophicat differances led to the complate col lapse of the relationship between the San Jowe Co-operulive and the Enw ronmental Enginesting Posgrambute 


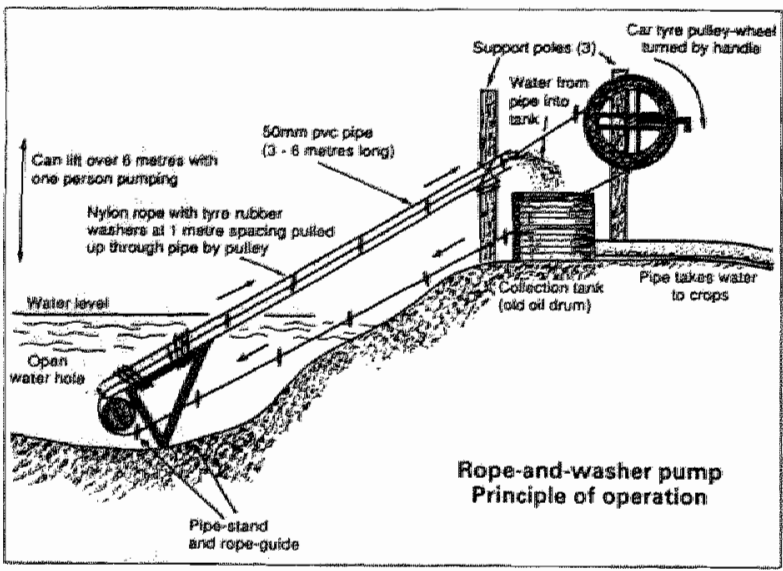

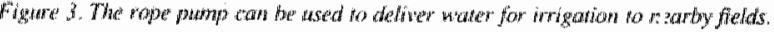

\section{New supporters}

Belore thall took place, fhowever, both UNICEF and a Dutch wolaneer organization had seen the potential suc. cess of the rope purmp project. The Duch group, who weye underaking a water and isant tation development project in one of the regions of Nicaragua, opted to tse whe tope pumps rather than the imported handpumps that they had originally intended to use. In this project the pumps were to be installed on communal wels, and the organiza tion fett is urtuportant to ensure hla microbiological qualiry wits adeąudate. They therefore focused on ways to prevent the introduction of external contaminans through, for exumple, the use of well-thead covers.

Meanwhile. UNACEF pitanned a new project which was to the exectild by the Environmental Engineering Pro

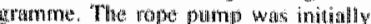
a key compantent of this project, bu

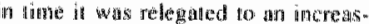
ingly periphtioral role as it was consid-

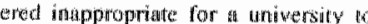
be involved in induserat production. The university role was restriched to one of detarmining guidelines and prodtucing poworypes. no longer producing rope pumps - in had never developed the skitls to market the pump - and the wniversity had effectively lost interest in working with the comoperative. Formal agreements between the coloperativa and the uniwersify had failed to prowide an adequate foundation for fintritur work Meither the co-operative nor the universily hat the skills tequired to market the pump affectiwelly, 10 prom wide the back up services, or to manage the resotures involved in prodthetion.

Unabie to rely an the continued supply of the rope purmps, the INGAMI UNICEF project decided in early 1990 to discontinue promoting the pumpand to concentrate on their new role in developing policy guidelines. This left t"to rope pump prometers without job. and a number of disgratated familie in the area who lat been promised rope pumps by the UNICEFAMGAM project.

In Felphary 1900 an historic met ing rook place letween the rwo pump promoters, the UNICEFANGAM projec administrutor two that alsi been laid off, and a Duch physixis who had previously worked in Nicara pua producing wint-driven water
By this stage the comoperative was pumps, The fenting which pervaded this meeting wats "let "s do it ourswestes - independently of ary bureaucracy".

Here statied whal became, in August 1992. Bambas de Mecalle S.A. (Rope Pumps Lid \%. a smalll contage industry producing tope punnow for whe Nicara guan populauon. Beginning on a smat scale it placed a heary emphasis in the minizl sitage on promoung the pump. tating advanke of the variong farrs and exhibitions about the coumtry to demonstrate its worth and thereby obtain sales. Advernisements in rews papers and on the radio were also wsect. Now it emplows a dozem workers and installs on average 60 rope pumps each month. As the putro becturne better known. the need for aclive masketing diminished and mos sales ane cur rently derived from the recomintendaions of other puntep ownters. Sales lave increvsed stefidily and Bornbas de Mecale is now operating commercially without any extemal subsidles. There ase plans to establisin branches in different parts of the country and perhaps even ourside of Nicaragua The Dutch group has also had some success. Following the example of Bombas de Mecate, they have started to sell the purmps on a commercial busis. Some of the componemts of their rope pumps are sold to them by Bombas de Mecale.

So what are the lessons from this story? Why his the rope pump proved such a successful technology while other hand partrups hase been such dismal failures? Why thas the rope purng so stubbonly aternerged from whe institutional mires which have threatened to sink in? Surely this is the rest of a truly appropriate rechnollogy - one which overcontes the inevitable obstacles which are phaced in its path. The ease of operation. low cost. simpicily of maibtenance, ready avallability of spares, and high efftciency are undoubtedly important factors. They have perhaps ensured that the rope pump did not fade into abscurity in Nicaragua.

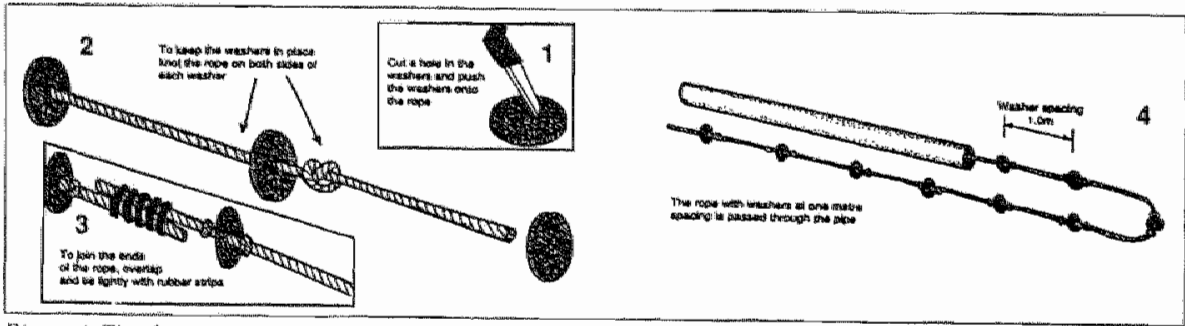

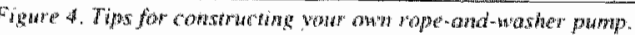


Why Do Child Mortality Rates Fall? An Analysis of the Nicaraguan Experience

\section{A B S T R A C T}

A comprehensive review of availabte sources of mortality data wasi undertaken to doeument the changes that have occurred in infont. mortality in Nicaragua over the last: three decadies. It was found that a rapid fall in infant mortallity consmenced in the early 1970 and has continued steadily since. Trends in seweral different factors which might have led to this breakthrough were examined including: inoome, wutrition, bre:astfeeding practices, maternal education, immunizations, acoess to health services, provision of water suspplies and sanitation, and anti-malarial programs. Of these, improwed. access to healt th services appears to have been the most important factor. Al a time when the number of hos. pital beds per capita was dropping, increasing numbers of health care professionals, particularly nurses, were becoming awaitable to staff prim mary thealth care facilinies buill in the 1960 . These were prowided at least partly in response to the growing political turmoil erveloping the nation at that time Certain Nicuragruan cul. wral attributes may have added to the impact of the reforms. Efforns in the field of public health made silutec the 1979 insurrection appear to have matintained the decline in child mortally. UAm I Public Heallh 1991; $81: 30 \cdots-37)$

Peter Samdiford, MBChB, MMedSC, Panicia Morales, BA, Anwa Gorre; MD, Edwand Conte, MBChB, and Geonge Dawey Smith, MB BChi; MLA, MS

\section{Introduction}

Poor child health in developing countries continutes 10 be a source of concerin. it In recent years it thas become apparent what while poverty is probably the mingor facior affecting survival in the early years of life, there are undoubuedly other influences playing an important role. Some countries, in spite of a low per capita gross mationall product, have succeeded in achieving mortaling tevels close or equall to those of the industrialized world. In contrask, there are others with poor levels of child health despite enjoying relatively high per capila incomes. ${ }^{2}$ Efforts have recently been made so identify the factors besidie sociosconomic status: which are determinants of infant mortality. In 1985, the Rockefellex Foundation sponsored a conference which studied the striking monality neductions: in Kenla State (Indis., Sri llanka, Costa Rica, and Chine, In each case, morlallity has fallen shamply over a delatively shor period leading to thigh life expectancy relative to national uncome. Seven wond thons werc purported to be essentala no the observed improvements: female atuonomy, aduction (ers. pecially femate), the provision of accessibe heall lis serwices, a mechanism to gutarantec the efficien operation of healah services, sin adequatce ninimal standard of mutrition, universal immunization, and a commintment to the establishment of offec tiwe antenalal and obstetric services.

Nicartagu is another conmry which has experienced a recent breaklihough in child monallity. This anticle describes that breakthrough wind looks at ins relationship with some of the factors atleged o be in. portann dewerminams of child mortality. It is hoped this work serve as a model for the type of intersectoral data analysis advocated recently by de Kadd ${ }^{2}$

\section{Methads}

Seven different sources of data were identified. which could provide time-located estimaies of infarth morthatity in $\mathrm{Nic}$ aragua from 1960 to 1986 s-11 A thrief de. suription of each sounce of diats is giwen in the Appendix. Except for data obusined from the Civil Register, the Imfant montal. iny est imates were derived using the Brass technique based on the ratio of sturwiving to ever born olvildren of mothers olussiffed by five-year age group. The rationate behind this method is thent the proportions dead of ever born children for womnen of a certain age correspond to discreet child swrvival probabilities. These surwival probabilities can be used to calculate in. fant montality fates (MNRs) if onc assumes

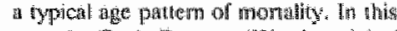
casce the Coatle-Demery "West" modtel of mortality was used. is

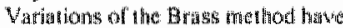

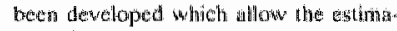
tion of trends in mornalizy ahange, recoge nixing that the deaths in childircin bon to

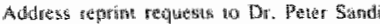

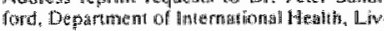

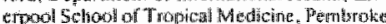

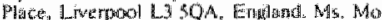

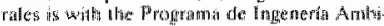

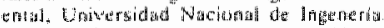

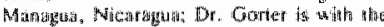

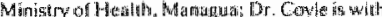

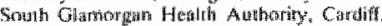

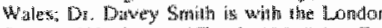

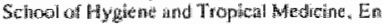

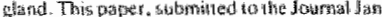

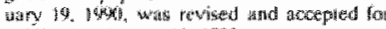

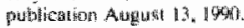

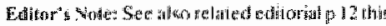
iscinses. 
women ages 15 m 19 years hate occurred more tecervly thath the deaths in children of womar ages 45-49. The Trussell method, sithich was tomployned in this analysis is one

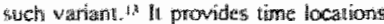
for the infan morality sumates obnained from each fve-year age group of mothers.

Estimates of infant morality fromithe desth register were catculated by dividing the number of deaths negistered in each year by the prejected population under the age of ame. Detath segistration is sell hown to be variable and incomplete so the se hindres were not used in further calculations. However, the relatively low raste of omission for birth regisitrition al lows a more cocetrate estimation of the IMR by asking atbout the surwinal of preceding births at the lime of registration. The data for 1966 (STEVM-86) were analyzed in this way by the Centro LatinoArneric ano de Demografia (CELADE)."

There atse a number of factors which fre believed to be important determinants of etrild mortality. These include: income, nutrition, maternal education, breastfeeding, inmunization croverage, the provision of thealut services, acoes to water supplies and sernitation, malaria contiol, ins well as ee rtain ctifural antibutes of the population. Tricndis in the se factors were exemined and related to the observed changes in infant mortility in Nicaragua from: 1960 to 1989 . Wherewer possible, datia were obtatned from the originat sonrces in Nicaragua by wisiting libraries and flocumentation centars in government mimistries and institutions.

Data on per capita Gross National Product (GNP) were obnained from an analysis pertorned by the National Av-

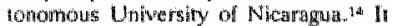
wes not powsthile to ancurately quantify changes int income distribution.

An asisessnent of arends in chilld intetrithonal siatus was based on three starveys of hationayde ssisaples of chiddren in 1966 , $197 \%$, and 1986, 15m" Height for ange wh visted as the indicator of nutritional status Ins in was the only one measured in all three surveys. In cwion of the sumeys, 14,46 the children measured were under the age of 5 , in the third they were school chitdren wiges $6-9$ years. Figures for food productow and calone intake were derived from World Bank sand Uniled Mations food and Agricultural Organization's staristics. respectively. The frequency of breast-

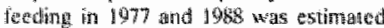
from two ad hoc stureys perfomed in

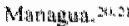

Levels of ititeracy in Nicaragua were gatsined form the censuses of 1950,22

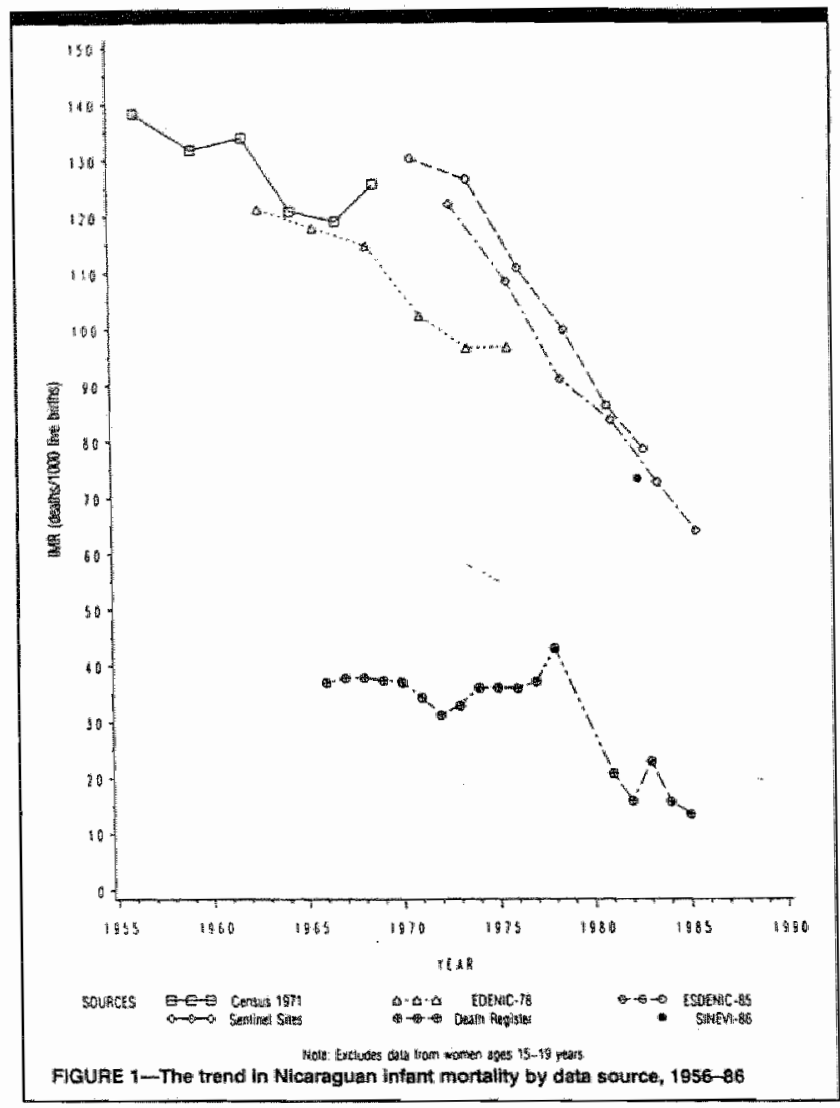

$1963 .{ }^{33}$ and $1971^{\text {s }}$ and from the EDENIC-79 and ESDENIC.85 sur. weys. Wh population ages 10 years and ower, for the urban and rural populations, and for women ages $1.5-44$ yents.

An anditysis of Minisiny of Health cause of death statistics by CELADE documenis changes in death rates in children due 10 inm mo-preventable diseases. 13 These were compared with an indicator of vaccinat ion coverage, estimated by divitiing the Mintisty of Health figures for the atime al number of inoctalations by ihe pop ulation of children under the age of five for that year.

There have been several artalysich of Nicaragua's health system, mosty comparing the situatton before and after the

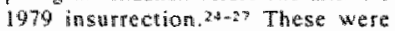
revicured and combined with shatistics from the health sectorsesesos (public and private) to obuan an overvicw of the trends in the provision of health servicesboth as infrastructure and as human resources-um fom 1960 to 1985

National statistics wierie nged to déremine whal changes had taken place in dorntestic water supply and sanitation facilities. ${ }^{\text {th }} .30$ Figures for latrine construetion were iaken from Minisury of Wealith reconds. ${ }^{28}$ An andilysis by Garfield and Verromind" and national records of lationratory wests for malatia we re used to look at trends in the incidence of malaris.

\section{Resulles}

\section{Infom Morfality Errimates}

Figure I shows the thitant monality estimates from each of athe aforement- 


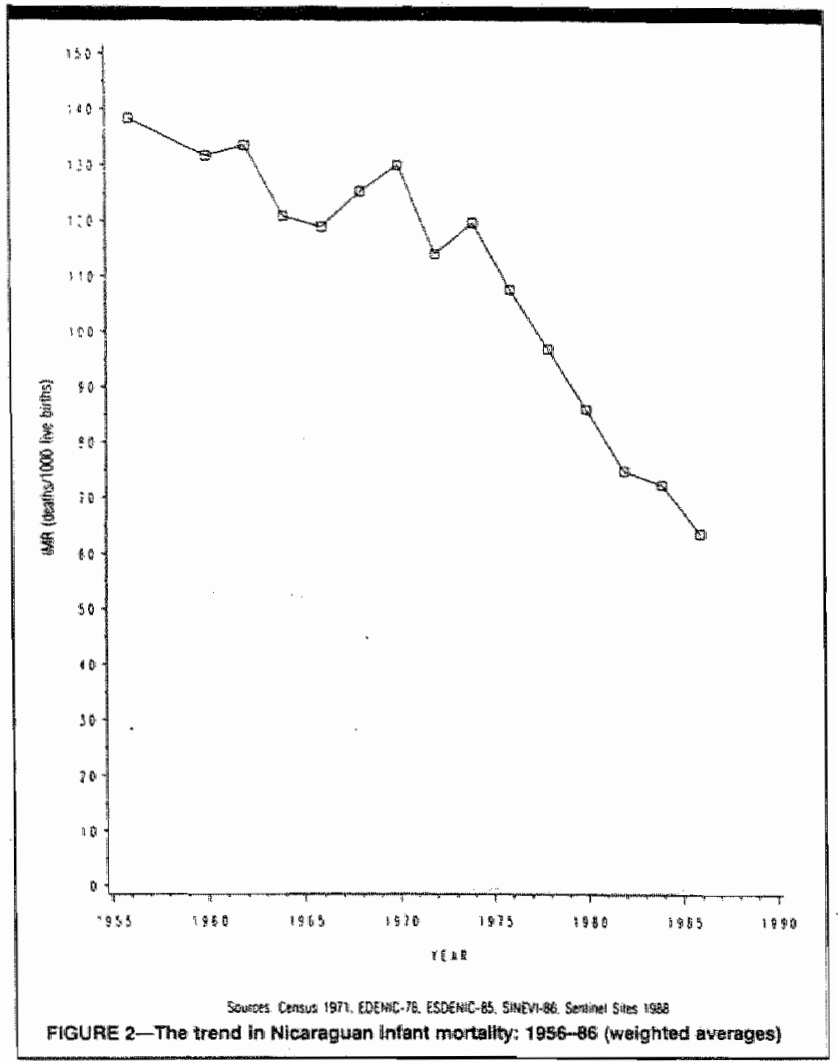

vioned soumces ploned aggairst time. Esti. nhates from ESDENIC.85, SINEV]-86 and the 1971 Census, the three targest dat tabases. give a consigsen profile of the rend in morality. Moreover, the IMKs from the sentinet sites study agree remark. ably well with those of ESDENNC.85. There is some divergence in the monality escimales from EDEVIC-78, particularly for the early $1970 \mathrm{~s}$ but hhese are based on data from a stothl] number of women and hence this may be diste to sampling crror The rates colculiated from death registrat tion are incompattibto with the other estimatates. a reftection of gross inadecquacies in coverage of this system. They are not used in ruither andyses.

A. weighted average of infant mont. inty wa imialles from the 1971 censuss, the CDENIC.78 and ESDENIC-BS SUREys, the SINEV1-86 anditysis of birtly registrat fion and the sentincl sites srudy wats made: for esch pwoycar inueval, Lates obtatumed from wormen ages $15-19$ years nere not included as these are well krown wo be unelinble. "The pesuls are ploted in Fig. ure 2. Figure 3 prosents the same dala plotted on a logarithmic scale which more approprately portrays the change in the rate of dedine, Tuken as a whok, the studfes indicate that the rale of fall in indani montality, which we sis slow in the 1960 oss, oncreased sharply in the exrly 1970s, and that ans rapid decline was sill continuing in 1986. The infant moradiry rate drops on

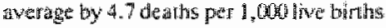
for each year from 1974 io 1986 . Assuming a "West" montality schedule, this is equiv. atent 10 an anroual increase in life expectancy of 0.75 years each year over this 12 year periou.

Figure a presems urban and rural IMRs from the 1971 Census and ES. DENIC-85. Changes int the definitions of "urtbart" and 'rural" and internal maigranion make interpretation difficult but there is no clear evidence that in Nicaragum the breakt hrough was more pronounced in nurat areas than in wrbary areas.

Differential infant montaliny rates ac conding to levels of raternal educh ton are provided by the CELADE and alysis. In the three time periodis examined-1965-67. 1973-74, and 1982-38-infan mortallity rates for mothers with secondary or higher education were considerably lower than for mothers with primary or no formal edverition. The results suggested that this differential namowed over the period in question (diata rot showm).

\section{Explanations for the Decline in Child Mortatity}

How ean this sharp drop in child nwortality be explained? In the first place, in should be reoognized that more than one factor may be involved. The resson that mortality started to fall may be different from the reason that it continues to folli. Since this is act a controlled experiment. canses can easily be conntused willo effects, and one is always left in doubt as to what would have happened in a different set of circunstances. Nevertheless, the Nicaraguan case has some very interesting teta tures which niake it worth examaining in greater detail.

Income- The observed infant mortality dectine in Nicaragua does not cor respond 10 a rise in general liwing $5 \mathrm{atan}$ dards. Per capita GNP rose rapidly in the carly 1960 s bur flattened off in the 1970 s before falling sharply in the 1980s. This fall may have been ofiset somewhat by a mone equat distribution of wenth followith the insumecion las a fresult of the warges pol. iny. food substdies and rationing, price controts, and ren controly, but inere are insufficient data to guandy changes in the come distribution ower this period.

Nutrition-in 1966, 36 percent of children under the age of 5 were found to be below two standard devistions ins the reference range for height for age. In the survey perforned from 1977 to $197 \%, 26$ percent of children under the atge of 5 weres below two standardi deviatons for height for age and in 108 s the correspontling prevalence of stumting inf first grade sehnool childien (ages b-9 years) was 22 perceryt. Although Nicaraguas hata high pates of primary school atuendance, poor children tend 10 starn later" than the rest. This produced an age bias in the resuls of the 1 gor survery such that in 6-year-old first gratide cinidren the prewalence of low hethen tho 


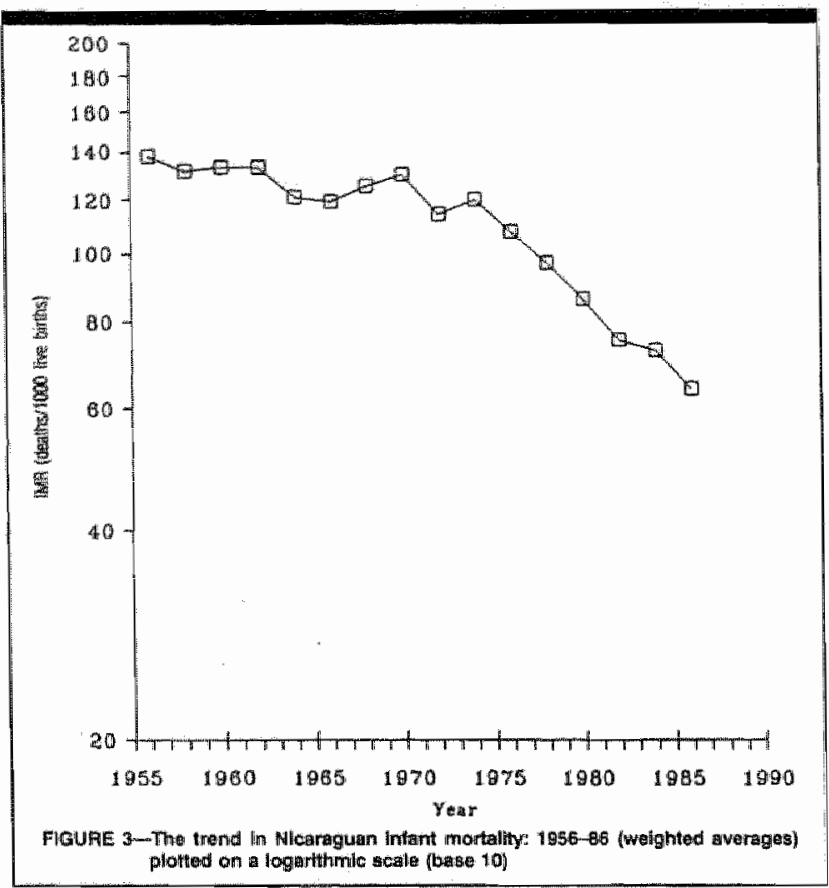

age was only 1 t. 5 percent compared with 32.7 percem! for 9 year-old first grade pupils.

Despite the deficiencies in the available data, it would semil reasomable to concivde that nutritional status in Nicaragustn chidden improved steadily from 1966 to 1986 , but the factars leading to this improwementare sneerlath. Food produc: tion in 1986 was only 70 perent of what it wets an 106 having falles strangly from its peak in 1928 . The number of food calories per head of poptation dropped from 2,410 in 1070 to 2,344 in 1975 and then 102,258 in 1484, recovering slightly by 1983 to

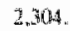

On the other lyand, at saliety of programs and activities ammed at irmoroving child nutrition atheady existed in 1970 , 2 Therex ware expounded in 1973 in response to the threat posed by the 1971 drought and the 1972 earathquake. A milk distritu tion program of the Minisnsy of Puitic Hexluth was in operation since the 1960

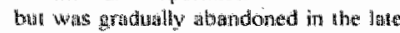
19\%0, It was recommonded for several ycats following the 1979 insurrection alonge whith other policies amed an astab.
Misthing an adequale nutritional standard. These included food subsidies, rationing, and supplementary feeding programs for pregnant wornen and mainourished chil dren.

Breasufectivg - The limited data available suggest that there las been no increase, and perthaps a decrease occurred Ix the averagage duration of breasnfeedting in Nicaragua over the period of rapidly de. clining child mortalisy. In 1977, 58 percen of mothers in Manaigsa were theastficed. ing theif children for an least six months. In 1958, only $33^{3}$ percent of children tretween three and five nonths of age were still pecenting breas? nillk.

Material Education-The changes in the rate of illteracy in Nicaragua are summariaed it Table 1 . The tendency has: been for illiteracy to tecrese t biroughou: the period fom 1950 io 1985 . The overall drop in illiteracy is greater that the andi. vidual falls in urbain, and fural oreas becanse of migration to fhe town and cilies. The stowest rate of change in the oweroll prevalence of illicracy wis observed between 1941 and 1978 . Between 1978 and 1955 there was a marked drop in $n$ the prev- a lence of iltiteracy。 mainly as a consequence of the 1980 National Lineray Cn sade and the exnensive adulu foducation program withich followed.

Mmmitomizanions-Mortatity due 10 diseases prewentable by immulnizanion in the ages 1 - 4 dropped from 21 per 10,000 in 1975 to 3 per 10,000 in 1986 for from 17 percent to a percent as a proportion of total montality in this age groupi. Uniforunately, the poor quality of the statistics did nol permil a similar and yysis for childrent under onte year of age

Table 2 shows the change in rates of immunizeation ower the perrod from. 1970 ro 1985. Prion 101979 rates of vaccination coverage varied widely ats periodic campaiggns were launched in response to cyclic epidemiles of immuno-prewentable dis. ease. Since 1979 coverage has been higher and strown less variation. The participation in massive nationwide waccination campaigns of large numbers of voluniary health workers in the years immediately following the insurrection was probably the main factor in this improvement.

Heath Senices-lin comparison with other developing countries, Nicaragua's thealth system suffered more from maidistribution of resoures than from a lack of irvestment. Heallh serwice infia structure and personmel were concertrated in the cities and particularly in the capita!. In the 1960 s and 1970 s, efforts were made to tedress this imbalance and improve access to thealth care. A USAID loan of SUS 2.2 million was received in 1965 to set up 55 health centers and provide outreach programs in rural areas. By 1974 there were 33 hosipindsis, 93 health centers and 38 healin posts spread throughout the country, and the Rural Mobile Healih Program provided care to remote areas. More primang health care facilives were bualt in the first years following the insurrection.

Although considerable infrastructure was atready installed by 1973 , an evaluat tion of the 55 heath centers built Irom USAID loan found low witilization rates owing to the latill of personnel, supplies, and management support. Two further USAID grants were made in the mid. 1970 so correct these deficiencies.

in contrasi 10 the grow ho in prinary health care facilities, there was a general deterioration in hospital care since the early 1970s. The number of hospinal beds per capis peaked at $2.6 \mathrm{in} 1971$ and has graduatly dropped since. The National Social Security Institute (INSS), a health care provider, grew slowly but steadily from 1940101980 . In $196 \%$, only 4.1 per. 


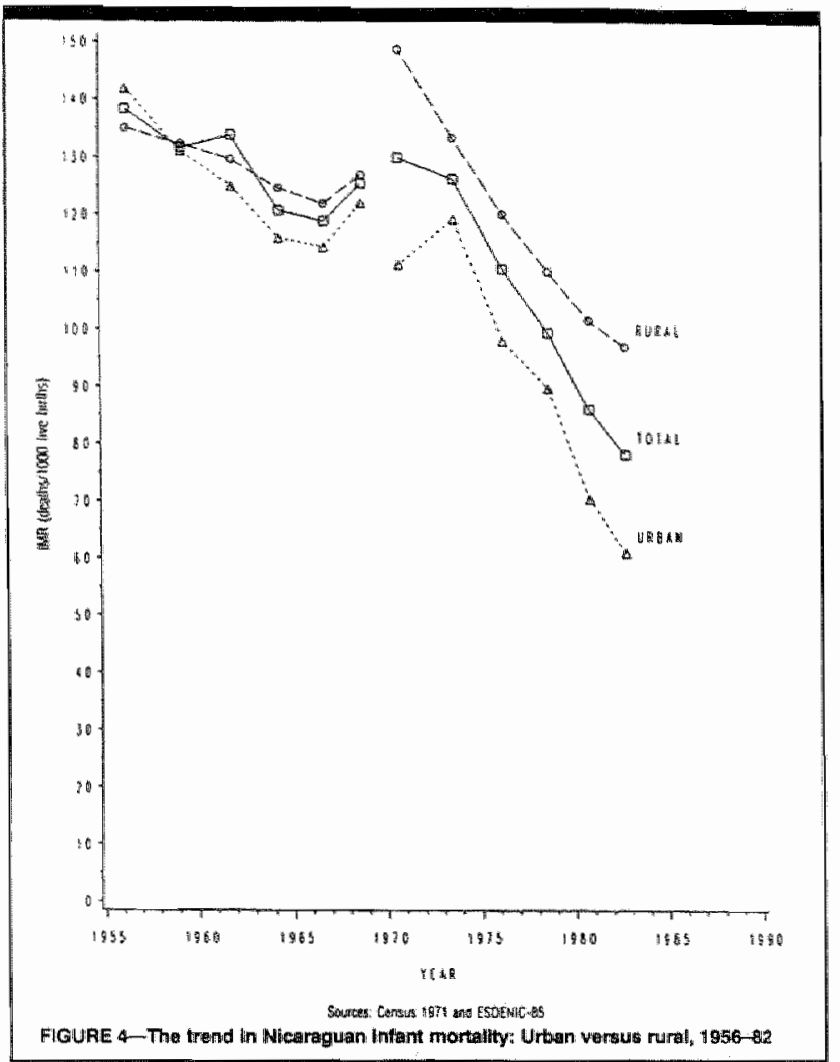

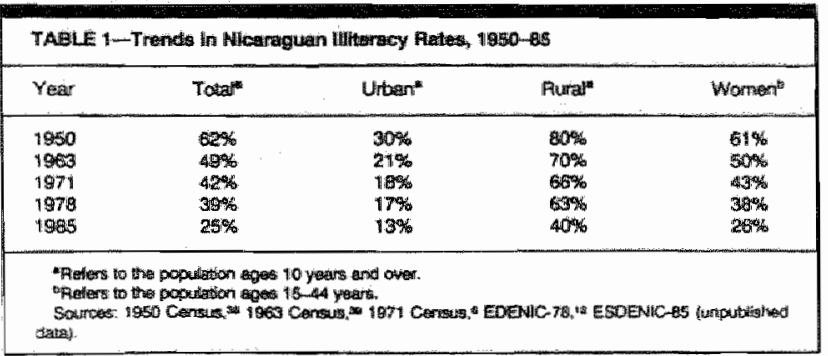

cent of the population were insured. By 197 cowerate of the population had in coessed to 7.5 percent and by 1978 to 18.4 pertent. In 1960 under the Governsnent of National Feconstruction, coverage: reached 10.1 percent of the population.

The rumber of doclors and especially nurses per head of population incretused between 197.4 to 1985. From 1970-74. there were 5.4 doctors and 2.3 nurses per $10_{2} 000$ inhabitants. For the period 1975 -79 there were 5.8 doctors and 2.6 numses per 10,000 population and in the five years from 1980-64 there an average of 6.0 . doctors and 3.3 nurses per 10,000 popula

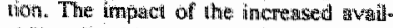
ahility of health care profersionals (togethef th thopping numbers of hospital beds per heat of population was reffected in rising per capita rates of hospinal discharge and rapidtly increasing numbers of outpathent consultations (especially emergency constultations).

Onter Public Heably MeasuresNicaragua undoubtedly had low rates of access to plentiful clean water wipplies and sanitation procio 10 1974, but the situation has changed littlie since thent. In 1981. the number of urban domiciliary connections was allmost iderricical to that prior to the earthquathe in 1972 . Lairine construe. tion by the Muturstry of Heilth, which av. eraged 4,590 per year from $1974-78$, was barely sufficient to keep up with the increase in the rural population.

The use of residu insecticictes for the conttol of malaria decreased steaclity in the ta 197ds as the World Health Organization camprign for the elimination of malaria loge ats monientum. The number of notified cases vartied widely from one year to the next but showed no secular dowimard trend from $1972 \mathrm{~m} 82$. The aver age annual reported number of laboratory confirmed cases was 15,386 from 1972-76 and 18,738 from 1977 - 1 . A renewed of fort was made to control malaria in 1984 by the administration of mass chemoprom phylaxis but the impract was transient.

\section{Discussion}

From a variety of saurees of infant monality estimates, this paper hes dowimented a rapidd decline in infant nortallity in Nicaragua which commenced in bout 1974 and was stlll in progress in 1986. Tho rate of decline since 197 it is impressive. particularly condidering that t toceurred iat at the when the mond bity decline in most countries in Asia, Africa, and Lutin America was sllowing down ${ }^{33}$ The rate of in provement in life expectancy is similar to that expenenced by wither Costa $\mathrm{Kica}$ ( $\mathrm{a}$

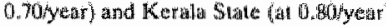
during their respecestue periods of rapid morteblity decline, but is not as high as $\mathrm{Sr}$

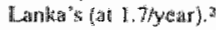

Mucki work on the deteminimis of reductions in child mortality has locused supon econionic factors. It has ofnen been difficull to separate the role of heralth and other social interventions from generd economic proger sosis since chatingers have occured in paratiell. In Nicaraguatis this was not the case as the shatp drop in child monality rook place at at lime wisen the 


\begin{tabular}{|c|c|c|c|}
\hline Years & DFT & Porlitio & 800 \\
\hline $\begin{array}{l}1970-75 \\
197 t-80\end{array}$ & $\begin{array}{l}0,50 \\
0.49\end{array}$ & $\begin{array}{l}100 \\
124\end{array}$ & $\begin{array}{l}0.211 \\
0.17\end{array}$ \\
\hline 1069 & 0.90 & 266 & 0.30 \\
\hline
\end{tabular}

gentral living standards of the population, measuded in ternas of per capita nattonal income, acturally decreased.

Althougti there was some improwement in the niututiontional states of Nicaraguan children between 1966 and 1988 , this was probutly more dive to a reduced bur.

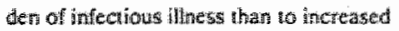
food intake. The laclors which led lo a drop in the incidence, severity or duration of infection may be the siame as thase which brought about lower child montatity. It is diffeult to follow breastieceding pracuice owe the last 20 years bu if does seem that exclusive oreastifeding s still lar from the norm for a tariefy of nea

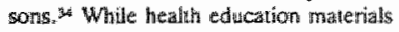
were concerned with pronotirg breast feeding the fire milk provided by Ministry of Health programs betiore and after the insurrection may have encouraged mothers lo abamdon the practice.

The 1974 turning point in child mortaliny does; not appear to have been brought about by a sudden increase in leve els of fennale literacy, although this factor

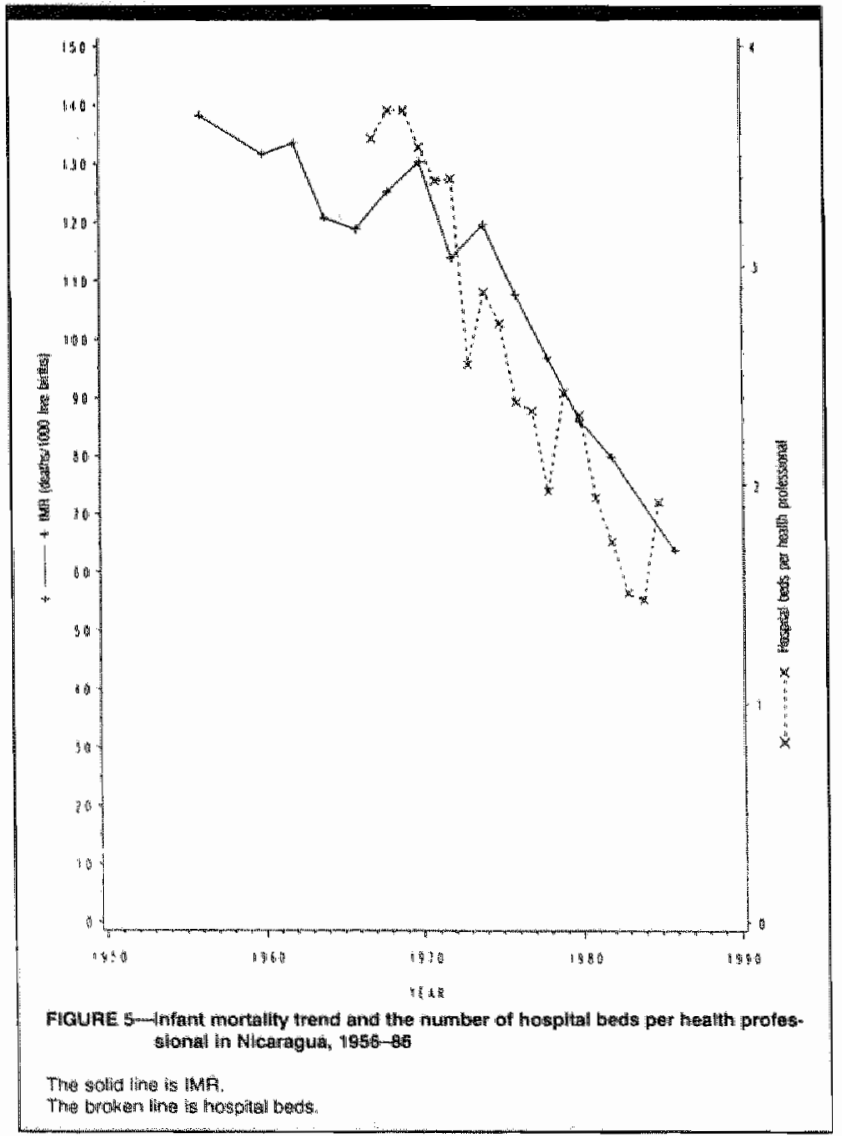

may tarve contributed to more recent falls in child mortality. Sirmilarly, most of the reduclion in monatiry due lo diseases pre. ventable by vaccination probably occurred some rime in the exarly 1980 s and does not coincide with the onser of the decline in child mortality.

The introduction of oral rehydration therapy (ORT) for the management of $d$ arthea did not occur until the mixidle of the period of rapidly decliming mortalify. The Ministry of Heath's plan for $1976-80 \times 3$ does not even mertion ORT, and in was not until 1980 that wal dehydration unies were established in health centers and health posts.

The resulus of this investigation sug gest that the awailability of water supply and sanitation did not improve signiffcantly trom 1974-86. Any improvement in malaria control is unlikely to have been sufficiently great to account for the declime in infant mortality given that malaria is not a major cause of death in this age group in Nicaragua ${ }^{36}$

The most plausibte explanation for the onset in 1974 of Nicaragua's rapid decline in infatit mortality can be found in the charnges in health services which stanted to tukte place at that tine. The combined im. pact of declining per capita numbers of hospitals beds wh increasing numbers of health care professionals meant giteater avalsability of persomel to work in the urderstaffed clinics which had been buitt in lise 1960s. In other worts, there was in effeet a sharp shift in resources away from hospitals and towards primery and second. ary health care. Figure 5 shows how the number of hospilat bedis per health profes. sional dropped sharply in 1972 and showed a rendency to decrease until itt leagit 1984 . paralle to the anfant monality declinge.

The reason for this sudden shiff in the rature of health care in Nicatragua is connplex. The dectersing avaitability of hospital bedus was due combination of the devastalios resulting from the earthquatike, the war, rapid popalation growah, and economic constraings to public spending. Training of health can professionals. on the other hand, sterpassed the increase in propulation.

Peititical influercas wave no doybt also played an part in this situration. The decline and fall of Somozs has bech dated from the 1972 earthquake ${ }^{2,57}$ and politicall turmoil has theen the nom ever since. A trass popwar movemen grew up in the late 1900 culmuinating in the 1979 insurrection. Per. hatps sensing that the grourd was slipping out from benealh him, Somoza with United States id began vo make significant invest- 
thin in secial programs. In these programs the guowntent tried to target areas with axtijor guerilla acrivity."

In post-revolutionary Nicaragua, polical factors have been equally intportarnt. The Sandinista Nationel Liberation Front took power on a program in which thesalth and education were key components in President Onega's specech on the lon anniversary of the Nicaugauan pevolution, reductions in rates of illiter acy and infant montality were the first irems theld up as gans of the revolution. ${ }^{39}$

Cuhnol factors may also hawe been inportant. Alshough tradition changes too slowly to explain a sudden reduction in mortality of the sort experienced by Niearagua, certain cultural atributes facilitate rapid reductions in monality. Primary thealth care prograns can have little impact without appropriate patterns of healthseeking behavior. In Nicaragua, there exists what has been described as a pill cutwre. * People regard orthodiox medticine and its providers (i.e. doctors and nurses) with high esteem. Manufactured pharmaceuticals, particularly when given by injection, are generally preferred to traditional herbal remedies al thought of ten both will be employed. Nicaraguans readily change treatments when a rapid improvement is mot seen and are highly sensitve to the progress of illness in their childrem. As a resulk, when heath services became more generally avaitable in the $1970 \mathrm{~s}$ and $1980 \mathrm{~s}$, the population quickly made use of them.

If is inveresting to compare Nicaragud's period of rapid mortality decline with that of neightoring Costa Rica which calso occurred during the early $1970 \mathrm{~s}, 41,32$. Both countries had experienced a slow ratc ofl improwement during the 1960 - - a pownomenon common to many developing countries ${ }^{33}$ In Costa Rics, the drop in infane mortality was greater hn rural aress.

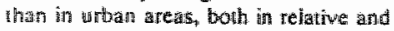
absolute terms. An analysis of Costa Rica"s recent dectine in infant mortality dso shows up the singular imporiance of primany health care 4 ?

Hawing rewiewed the available data, in is possible to postulate the following scefourio. In the late 1960 s. United Staies aid was used to pay for the construction of primary hes all h care facinties throughou! Nicaragu. In the 1970 s, earthouake." war. rapid populat ion growth and leconomic re. cossion reduced the number of hospirat bods per capouta. At the same tirne there was an inclease in the supply of nurses and dichors per head of population which made it porsible to slaff the recently built primuty hath care facilitics. The net ef- fect was an increas in the rellative imparfunce of phinary and secondary thealth care vis a vis tertiary heallth tare. The heall hare facilities prowided gained rapid acceptance from the population which at. ready had some culnural affreity for Westam medieine.

The social reforms con tributing to de. clining child montally wer made by an isolated and threatened dictatorsthip in response to the mobilization of impover- ished sectors of society. They ware continured and extended following the insur. rection, as part of the political progran of the Sandinista Governmen which re. placed the dicterowship. In early 1900, a new gowernment was elected which is commint ted to contration of public expen. difure. Morntoring the effects of any change in polloy on child heralith and sur. trival will growide an oppoitunty to $e x$.

\section{APPENDIX-Souros of Infmit Montalliy Statistics in Nllearagua}

\section{A review wes performed to identify the}

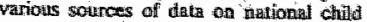
montality rates in Niosnagua from 1960 to 190\% Thes are dhown in Table A A mote of explantion is neossiany, about ench of the data bases:

\section{The 1971 const}

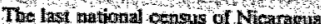
took pltwoe on Apint 201901 sinos then,

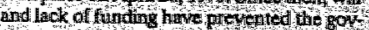

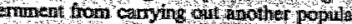

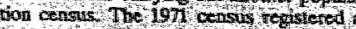

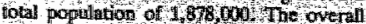

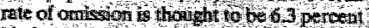

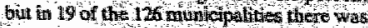
an average orrisssogal no of 32 peroen and in

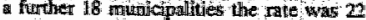

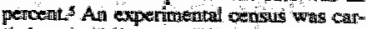
thed out in 1969 as a probide to the 1971 cen. sus buil its sample was smaill whol unepre. sents tive of the entine population so the:

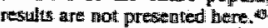

\section{The National Dhemographic: Sitwey of Alicaragina (EDENTC 78 )}

This was a survey carried ost from 1977 to 1978 which indudied relirospective ques-

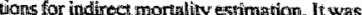

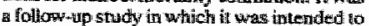

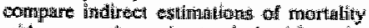
shith prospective estumitides derived fiture the

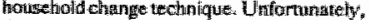
dorting the 1079 inisurnection all of the prom spective datid fromid this survey wente lost.

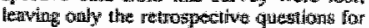

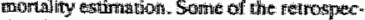

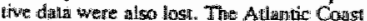
Deparinientic of Zelaya and Rio San Munn were excluded form the sumpliag frame. Av.

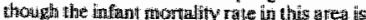

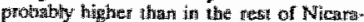

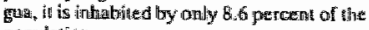
popilatitifort.

\section{The Socidodemographic Sturvey of Micomagua (ESDENTC-GS)}

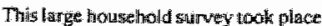
ifit ]

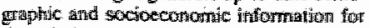

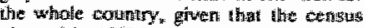

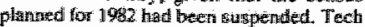

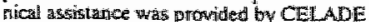
and the Unitud Nations Demantmenti of Technicul Cooperation for Devitopizent.

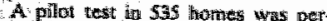

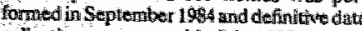

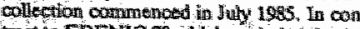

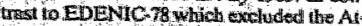

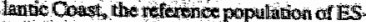
DENICLS cowened the entime oowntry. A

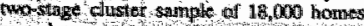
wo hosetio

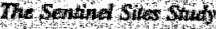

I in the

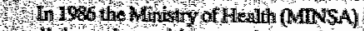

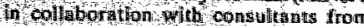

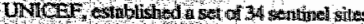

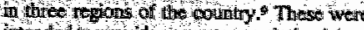

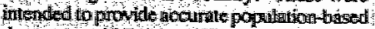

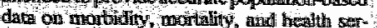

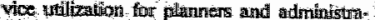

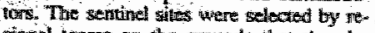
gional teams an the garounds that they be

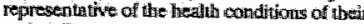

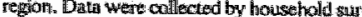
wey with indinest questions on chuld mortiality.

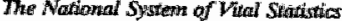
(SNEVT)

In the 1960ts, the civil regiter was ad ministented by the Directorate General of St tisties and Censuses which was park of the Mirnistry of Economy. In 1970 the DOEC

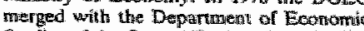

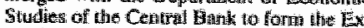

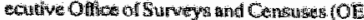

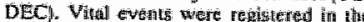

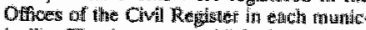

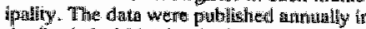

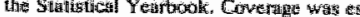

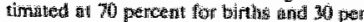

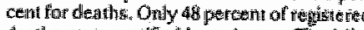
denths were certified by a doctor. The Min

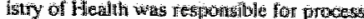

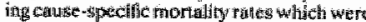

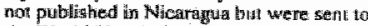

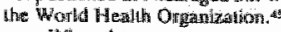

When athe niew girwernment took pors er in 1 thos, sewerall chandyes were introcluced

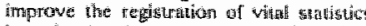

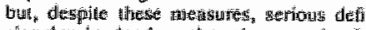
*iencies in death registration remain. in

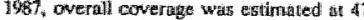
percem, 36 but onbly atout 34 percent of inflam

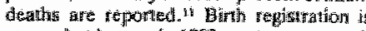

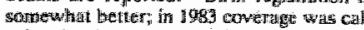

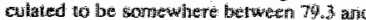

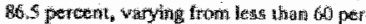

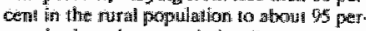
erent in the urbatin population. 


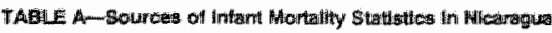

\begin{tabular}{|c|c|c|c|c|}
\hline 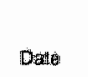 & Data soun & Tupe of Datus & 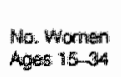 & $\begin{array}{l}\text { Auegiona } \\
\text { Converage } \\
\text { \% }\end{array}$ \\
\hline 1971 & 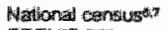 & Fopulation congus & 256007 & 100 \\
\hline 1978 & EDERAC-7 & Sarnote survay & 6237 & 9 \\
\hline 1905 & ESDENULBS & Sumplosing & 22,000 & 100 \\
\hline 190068 & 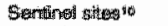 & 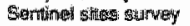 & 10,615 & 54 \\
\hline $1050-40$ & Sill & 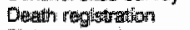 & - & 100 \\
\hline 1908 & 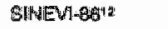 & Buth rogistuation & $112,200^{\circ}$ & 100 \\
\hline
\end{tabular}

plore the validisy of the explanations aitvaguced in this paper.

\section{Acknowledgriments:}

This work formis part of a study of healtin in forriation systems funded by the Leverthitime Trust. The a d thon wrond like to express thei reratitude to the extremcly thelpfut personnel of the ingtiftetions whichl provided ine doctuments and doata on which this work ss basted.

\section{Quferences}

1. UNICEF; The stale of the world" ${ }^{4}$ chituren-1989. Oxford: Oxford Universiny fress, 1980

2. Cilchwesl IC: Routes to loow mortalify in poor congtries. Popul Dev Rev 1986 $12: 171-220$

3. Halshead $\mathrm{SB}_{4}$ Whalsh JA, Warten $\mathrm{kS}$ (cods) Gond Health at how Cost: Proceedings of a Conference held at the Bsellagio Confer.

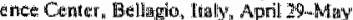
2. Nows. New York: Rockefeller Founda tion, 1085

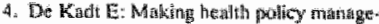
frient diterseciloral: Is

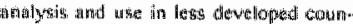

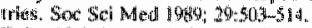

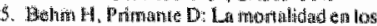

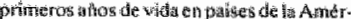

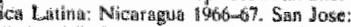

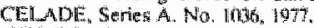

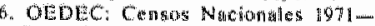

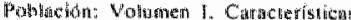

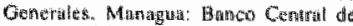

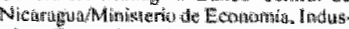

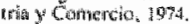

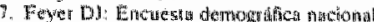

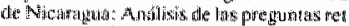

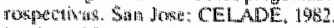

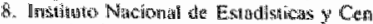

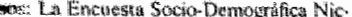
aragiense: Wolumen 1H. Cufacneristicias

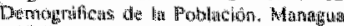
INEC. 1989

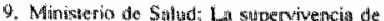

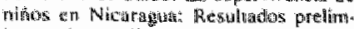

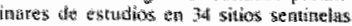

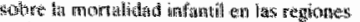

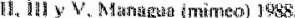

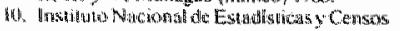

(DEDEC prior to 1979): Anumio EstAdis tico Man

11. Centro Lailincamericano dis Denoografia

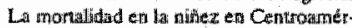

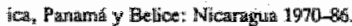
San Jase: CELADE 1908

12. Cowle AJ, Denneny P. The gional Model Life Tiables and Stable Populwrions. Princeton,

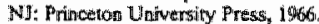

13. Unitsed Nitions: lndire thechniques for denongraphic extintation. Papulition Studies No. 81, Manual X. Defpartment of Internathionat Economis and Sacial Affairs, ST/ ESIE/Senies ANB. New York UN, 19:3.

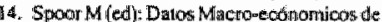
Nilcaragua (1960-86). Managua: Deparia-

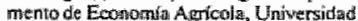
Navional Austonoma de Nicaragat, 1987.

15. Instituto de N whición de Centro America $y$ 耳anaró (INGAP)Oficira de Investiga" ciones Internacionates de los Inshitutos Nay cionales de Sidud (EEUU)Manisterio de Salubriadad Publica: Enaluacion Nurictomal de la Pablación flie Centro Américal y

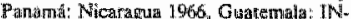
CA. 1969.

66. Walle BL, Behman. JR: Detentifnants of child moratiry, healts, and mutring in a

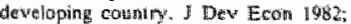
I1: $161-194$

12. Navas GE Cuedra $C$ Aburto A: Primer

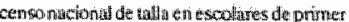

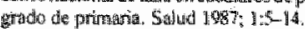

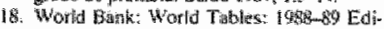

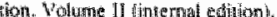

19. Ehandryic and Socizal Departanent. Lisuiled

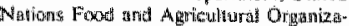

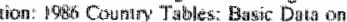

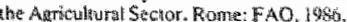

20. Whidat de Autetisis dol Seclor be Satud: Equaluation del cornponente nutriciosal

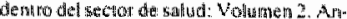

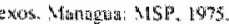

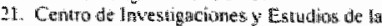

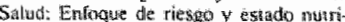

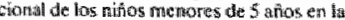
Region I0: juario 1985. Managra: Ministe-

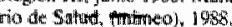

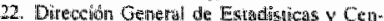
sos: Consen machorates 1950. Managat DCER, no diste.

23. Direceion Geriegal de Esladisticas

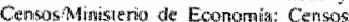

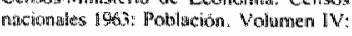

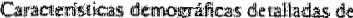

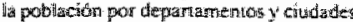

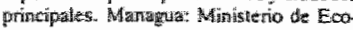
tomía:

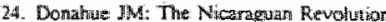

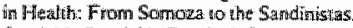

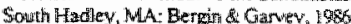

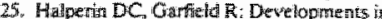

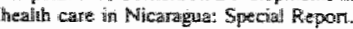

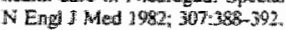

26. United Staties A quency for linternationall De

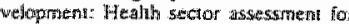

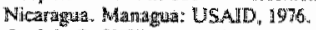

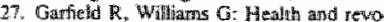
lletion: The Nicaraman experience. Oxford: OXFAM, 1989

28. Ministerio de Sallid: Serites Historicas 1974-73: foblacion: recumos, actuidindes. Boten Estadistico Mo, 3. Matagula: OFTNEMTMSA4 1981 .

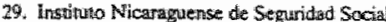
(Instintio Nicanaguense de Segunidat Socjal y Bienesiar after :979): Anuario Estodistieo

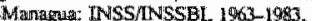

30. NEC: Nicaragutan. 10 años en cifrabi ManHgua: I] VEC 1989

31. Garfield RM, Viemund SH: Cosanges an ma-

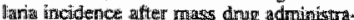

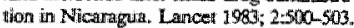

32. Minitrerio de Salud Públicau Infonme de la Bituacion de la sallat durante el periodo

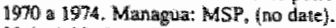

33. Unitued Nations: Departruent of Bnterma tiont Economits and Soc all Affairs: Mor Walty and Heallin Policy, Procesdings of the Experi Group on Morlatify and Heallo Pol lisy. Rome, $30 \mathrm{May}$ tho 3 June 190\%. New York.: Unitied Nations, 1964 .

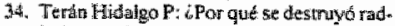

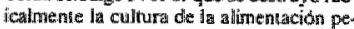
cho? El Nuewo Diario 29 Jully 1289.

35 Ministeriode Salud: Plan de Salud: Periodo 1976-1980. Mangour: MINSA, 1975.

36. Minjsterto de Salud: Plan de Salwd 3988 90: Managar: MINSA, 198 ?

37. Close D: Nicaragha: Pofitics, eoonomics: and sacjery. London: Pinter. 1908 .

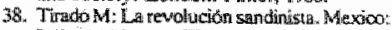

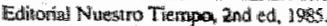

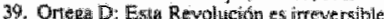

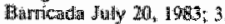

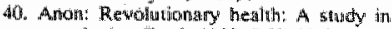

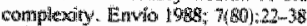

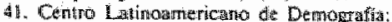

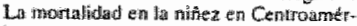

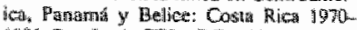

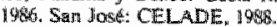

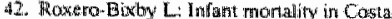
Ricar: Explainging the recent decline. Sumd

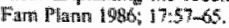

43. Direcrion Guenteral de Estadtstiens y Cen-

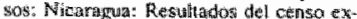
perintental de potulacion. Serte AS $\mathrm{No}$. 17. SAn Josie CELADE. $19 \% 9$.

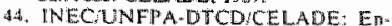

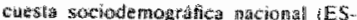
DENIC BS: Mall wal del entmetrator. Sant Jose: CELADE=, 1485.

45. Hastinge Nacional de Estiadisnicas y Cen

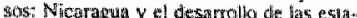

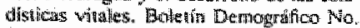
6. Mianagua: IMEC, 1983.

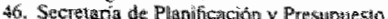
Deprarame nto de Población: Comsid. eracomes sobre ell stictemin macional de es.

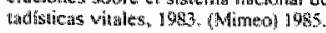




\section{Dankwoord}

Gaarne wil ik hierbij alle mensen bedanken die aan deze onderzoeken hebben deelgenomen of bijgedragen. In de eerste plaats de bevolking van Villa Carlos Fonseca die door haar positieve houding het mogelijk maakte alle studies tot een goed einde te brengen. De medewerkers in Nicaragua van de stichting DESEAR, het instituut ICAS, het Ministerie van Volksgezondheid, het Ministerie van Water, de Technische Universiteit, het onderzoeksinstituut CIES en alle veldwerkers: Leonel Argüello, Julio Delgadillo, Juan Gago, Gloria Garcia, Iris Gutierrez, Carmen Gonzalez, Mario Gutiérrez, Mayra Mejía, Patricia Morales, Celia Moreira, Aura Pérez, Rosa Maria Pérez, Irza Picado en Sergio Tercero. Verder alle internationale medewerkers: Edward Coyle, George Davey Smith, Joost Hoppenbrouwers, Guillermo Orozco, Jose Pauw, Germana Sánchez, Peter Sandiford en Annemarie Sweep. Mijn dank gaat ook uit naar de medewerking van de London School of Hygiene and Tropical Medicine, de Liverpool School of Tropical Medicine en de financierende organisaties WHO, UNICEF, de Leverhulme Trust en de Engelse Ambassade in Nicaragua.

Mijn bijzondere dank gaat uit naar mijn man Henk Alberts die een stimulerende rol speelde gedurende de hele onderzoeksfase en actief deelnam aan de onderzoeken in zake hygiëne gewoontes en de touwpomp. Ook gaat mijn speciale dank uit naar mijn ouders die al die jaren van ons verblijf in het buitenland ons van support en leesvoer hebben voorzien. Mijn promotor Paul Knipschild moet ik niet vergeten, zonder hem had ik het nooit afgemaakt.

Zonder al deze mensen waren de onderzoeken niet mogelijk geweest en ik ben met name dankbaar voor de prettige en ontspannen wijze waarin al dit werk heeft plaats kunnen vinden.

\section{Anneke Gorter \\ Los Cedros, augustus 1998}

